\title{
Androgenic-anabolic steroid use in strength athletes; effects on body composition and cardiovascular system
}

Citation for published version (APA):

Hartgens, F. (2001). Androgenic-anabolic steroid use in strength athletes; effects on body composition and cardiovascular system. [Doctoral Thesis, Maastricht University]. Universiteit Maastricht. https://doi.org/10.26481/dis.20010620fh

Document status and date:

Published: 01/01/2001

DOI:

10.26481/dis.20010620fh

Document Version:

Publisher's PDF, also known as Version of record

Please check the document version of this publication:

- A submitted manuscript is the version of the article upon submission and before peer-review. There can be important differences between the submitted version and the official published version of record.

People interested in the research are advised to contact the author for the final version of the publication, or visit the DOI to the publisher's website.

- The final author version and the galley proof are versions of the publication after peer review.

- The final published version features the final layout of the paper including the volume, issue and page numbers.

Link to publication

\footnotetext{
General rights rights.

- You may freely distribute the URL identifying the publication in the public portal. please follow below link for the End User Agreement:

www.umlib.nl/taverne-license

Take down policy

If you believe that this document breaches copyright please contact us at:

repository@maastrichtuniversity.nl

providing details and we will investigate your claim.
}

Copyright and moral rights for the publications made accessible in the public portal are retained by the authors and/or other copyright owners and it is a condition of accessing publications that users recognise and abide by the legal requirements associated with these

- Users may download and print one copy of any publication from the public portal for the purpose of private study or research.

- You may not further distribute the material or use it for any profit-making activity or commercial gain

If the publication is distributed under the terms of Article $25 \mathrm{fa}$ of the Dutch Copyright Act, indicated by the "Taverne" license above, 
Androgenic-anabolic steroid use in strength athletes 
(c) Fred Hartgens, Eijsden 2001

ISBN $909014885 \mathrm{x}$ 


\section{Androgenic-anabolic steroid use in strength athletes; effects on body composition and cardiovascular system}

\section{Proefschrift}

ter verkrijging van de graad van doctor aan de Universiteit Maastricht op gezag van de Rector Magnificus, Prof dr AC Nieuwenhuijzen Kruseman, volgens het besluit van het College van Decanen, in het openbaar te verdedigen op woensdag 20 juni 2001 om 14.00 uur

door

\section{Fred Hartgens}

geboren te Roermond op 22 oktober 1959 
Promotor

Prof dr H Kuipers

Co-promotor

Dr HA Keizer

Beoordelingscommissie

Prof dr WHM Saris (voorzitter)

Prof dr WL Mosterd (em. Universiteit Utrecht)

Prof dr G van der Vusse

Prof dr KR Westerterp

Prof dr Tj B van Wimersma Greidanus (Universiteit Utrecht) 


\section{CONTENT}

CHAPTER 1

Introduction 7

CHAPTER 2

Effects of androgenic-anabolic steroids in athletes: a review

CHAPTER 3

Androgenic-anabolic steroid-induced body changes in strength athletes 57

CHAPTER 4

Body composition and anthropometry in bodybuilders: regional changes

due to nandrolone decanoate administration $\quad 73$

CHAPTER 5

Androgenic-anabolic steroids and human deltoid muscle fibers:

difference between polydrug regimens and single drug

administration $\quad 89$

CHAPTER 6

Prospective echocardiographic assessment of androgenic-anabolic steroids administration on cardiac structure and function in strength

athletes 103

\section{CHAPTER 7}

Effects of androgenic-anabolic steroids on apolipoproteins and lipoprotein(a) 121

CHAPTER 8

General discussion 133

Summary 143

Samenvatting 147

Nawoord 151

Curriculum vitae 152

Publications 153 


\section{CHAPTER 1}

\section{Introduction}

\section{THE NETHERLANDS CENTRE FOR DOPING AFFAIRS AND SCIENTIFIC RESEARCH UPON DOPING SUBSTANCES}

In 1989 by collective effort of the Dutch government, the Dutch sports organizations and the Dutch Association of Sports Medicine the Netherlands Centre for Doping affairs (NeCeDo) was founded. Primarily, the main goals of $\mathrm{NeCeDo}$ were to provide information about doping and to coordinate various doping issues in the Netherlands. In the early years NeCeDo mainly provided information to the organized sports (especially to national sports federations and elite athletes) and advised the Dutch government upon doping affairs. However, another important group of athletes that had to handle with doping issues was recognized soon: the unorganized strength athletes who trained in gymnasiums.

From foreign research as well as from lore in our own country it was apparent that strength athletes in gyms and fitness centers were engaged in the abuse of doping substances. To obtain insight in the extent of the proposed (ab)use of doping substances among these athletes an investigation was started. Based on that study it was concluded that at least 35.000 athletes in fitness centers and gyms had administered doping substances during their life. The substances most often abused appeared to be the androgenic-anabolic steroids (AAS) (Vogels, 1994). The data from the latter study were of great concern and were the base for NeCeDo to install an independent scientific department to investigate issues of doping abuse in athletes. Since many questions about the effects of AAS in athletes were unanswered the first task was to design a research program focussed on the effects of AAS. It was proposed that the research data would provide a better foundation for the educational and training programs of $\mathrm{NeCeDo}$ to athletes, trainers and sports federations.

To enhance the quality of the research work NeCeDo was convinced that a scientific environment was indispensable. At that moment Maastricht University (Department of Movement Sciences) was the only university in the Netherlands that had already experience in investigating the (patho-)physiological effects of anabolic substances in athletes. This department was well-known and had an outstanding international reputation in scientific research upon exercise physiology and sports-related issues. Since the 
head of the Department of Movement Sciences (Professor Harm Kuipers) was very interested in the proposed research he offered to be host of the scientific department of $\mathrm{NeCeDo}$. In close cooperation the research project studying the effects of AAS was designed. The main purpose of the research was to investigate the desired and untoward effects of AAS in strength athletes. Based on the scientific knowledge at that moment the main target issues for investigation were the effects of AAS on body composition including muscle tissue and the untoward effects on the cardiovascular system.

\section{THE AAS PROJECT}

\section{Introduction and main objectives}

In close cooperation with the head of the Department of Movement Sciences an extensive research proposal was designed. The investigation was entitled "The effects of strength training and nutrition with or without the use of androgenic-anabolic steroids on body composition and health status", later abbreviated to "The AAS project".

From the literature it was obvious that the knowledge about the effects of AAS on body composition and health was incomplete and equivocal. With respect to body composition and anthropometry it was still undetermined whether AAS induced an increase in muscle mass, blood volume and / or water retention. Additionally, research data did not provide information about the effects of current AAS administration regimens, the use of different doses AAS abuse nor about differences in duration of AAS administration as is commonly practiced in gymnasiums nowadays. To meet scientific standards we also intended to obtain data with newer and more appropriate methods for determination of, for example, body composition and cardiovascular function, and to re-establish the value of older assumptions (e.g. metabolism, liver function).

Therefore, in general, we wanted to investigate the effects of different AAS administration regimens and dosages of AAS on body composition and health status. Additionally, the difference between short-term and long-term administration of these anabolic substances on the same parameters was subject of our research. Finally, we also investigated the effects on these parameters after drug withdrawal.

Our main objectives were tot elucidate possible AAS induced changes in body composition, anthropometry and the cardiovascular system. Moreover, in the AAS project we additionally studied the effects of AAS on the haemostatic system, vessel wall properties, psyche and behavior, liver function, hematological system and several metabolic parameters. 


\section{General study approach}

Study designs. To meet the study objectives it was decided to conduct two prospective studies that were supposed to be complimentary: a double blind placebo controlled study and a study in which the participants administered a self composed course of AAS. The rationale for this choice was that a randomized, double blind, placebo controlled study would provide data that could stand scientific criteria completely, but would be not suitable for investigating the effects of high doses of AAS from an ethical perspective. Therefore, we opted for a study in which strength athletes self-administered AAS that would provide the information about the effects of high doses and long courses of AAS abuse as is generally practiced in gyms.

To obtain complementary data from different investigations the approach in both studies was comparable, except for the blinding aspect. Our general approach was that in all participants of the different studies measurements were performed at baseline, after 8 weeks AAS administration as well as 6 weeks after drug withdrawal.

In the self-administration study we investigated also the impact of duration of an AAS course. Approximately half of the participants had decided to self-administer AAS for 8 weeks, whereas the remaining subjects intended to use these drugs for 12-16 weeks. In these subjects we performed additional measurements at the end of the self-administration period after 12-16 weeks. This provided the opportunity to compare short-term (8 weeks) AAS abuse with long-term administration (12-16 weeks).

Subjects. Strength athletes were recruited by flyers in local gymnasiums and fitness centers. A total number of approximately 90 male strength athletes volunteered in one or more studies. However, in the studies described in this thesis a total number of 56 subjects participated. Subjects who applied to participate underwent a full medical examination for evaluation of their health status.

Volunteers had to meet the inclusion criteria set by the investigators, which included male, strength training experience of at least 3 years and age between 20 and 45 years. The following exclusion criteria were set: hypertension, diabetes mellitus, liver disease or abnormal liver enzyme serum levels, hereditary hypercholesterolaemia, elevated serum cholesterol $(>6,5$ $\mathrm{mmol} / \mathrm{l})$, infertility and smoking. Volunteers who appeared to be healthy and who met all criteria set by the investigators were admitted to the study. Before entering the study all subjects were informed extensively about the study and undersigned a written informed consent.

Drop-outs. In the double blind, placebo controlled study only one subject had to stop shortly after the randomization procedure due to a change in his employment that could not be combined with participation in the study. Four out of the 39 participants of the non-blinded study did not complete 
the study because of various reasons. One subject changed his job and moved to another region in our country. One strength athlete opted out owing to lack of time. One withdraw due to an injury and one participant stopped without giving any reason.

Monitoring and compliance. Since the training load and nutritional intake are important for optimizing the effects of a strength training program with or without AAS, it is important to monitor these factors. Additionally, objective insight into the actual drug use is important. Therefore, in all participants training and nutritional habits were monitored by collecting dietary and training data and drug use was monitored by urine analyses.

Data of training load were collected by means of a one week log book. For evaluation of nutritional intake a three day diary was used. Nutritional intake was assessed using a computer software package (Becel, version 4.0). To obtain insight into the compliance of the subjects with respect to drug administration or abstinence the urine samples were analyzed for metabolites of doping substances by the Netherlands Institute for Drug and Doping Research, Utrecht, The Netherlands. At random approximately one third of all collected urine samples were analyzed.

At baseline, after 4 and 8 weeks study period as well as 6 weeks after cessation the training and nutritional data were collected and urine samples were taken from all participants in the double blind study.

In the non-blinded study from all subjects dietary and training data were collected before the start of the study and in week 8 . In addition, in strength athletes who had decided to administer AAS for 12 to 16 weeks nutritional and training data were also obtained at the end of the AAS administration period. Finally, in all AAS users these data were monitored six weeks after drug cessation. Urine samples were obtained at the same times as the nutritional and training data.

Assessment of side effects. The entire study was conducted to investigate the effects of androgenic-anabolic steroids (AAS) on body composition as well as on health status in strength athletes. Several experiments focused on the effects on body composition, whereas the majority of experiments was designed to investigate the detrimental effects of these anabolic agents. The effects of AAS on the cardiovascular system were assessed by means of echocardiography to detect alterations of cardiac structure and function and to assess large vessel wall alterations. Moreover, several cardiovascular risk factors, including serum lipids and lipoproteins, blood pressure, and the coagulation and fibrinolytic system were evaluated. Blood was also drawn for evaluation of liver function enzymes and glucose metabolism. The effects of AAS on psyche and behavior were assessed with questionnaires, e.g. Profile of Mood State (POMS). 


\section{THE THESIS}

\section{Main objectives}

The main objective of this thesis was to investigate the effects of AAS on body composition and cardiovascular system in strength athletes. In all investigations we intended to study whether the effects were influenced by the doses of AAS administered and / or by the duration of misuse of these substances. The next questions were formulated to address these issues:

- What are the effects of the administration of AAS on body composition and anthropometry in experienced strength athletes?

- What are the effects of AAS on the cardiovascular system with special reference to cardiac size and function and to serum lipids and lipoproteins?

- Is there a relationship between the observed (side-)effects and the dose of AAS used?

- Is there a relationship between the observed (side-)effects and duration of AAS administration?

\section{Outline of this thesis}

In Chapter 1 an introduction of the Netherlands Centre for Doping Affairs ( $\mathrm{NeCeDo}$ ) and its scientific research upon doping substances is provided from a historical perspective. Furthermore, a detailed description of the androgenic-anabolic steroids project (AAS Project) is given. The background for AAS research is described, and the objectives, the study design as well as recruitment of volunteers is delineated. This chapter ends with a brief overview of the main objectives of the studies presented in this thesis.

Chapter 2 reviews the current knowledge about the effects of AAS abuse in athletes by reviewing the scientific literature. It starts with an introduction about AAS, the therapeutic indications and the general effects of these substances. Then an in-depth review of the studies that investigated the desired and untoward effects of AAS in athletes is provided. After an overview of the mechanism of action of these substances this chapter finishes with conclusions and future directions.

In Chapters 3, 4 and 5 the experiments investigating the effects of AAS on body composition and anthropometry in strength athletes are presented. Chapter 3 describes the effects of self-administration of high doses androgenic-anabolic steroids, as well as the impact of duration of AAS use on body composition and anthropometry in strength athletes. The intention of this study was to obtain complementary information to the use of one single anabolic steroid (as described in chapter 3 ) since it is common practice among strength athletes to self-administer several AAS simultaneously in suprapharmacological doses. However, there is no scientific evidence that 
such regimens may lead to better results than the use of a single anabolic steroid. In a non-blinded study we investigated the effects of eight weeks self-administration of AAS on body weight, bone-free lean mass, fat mass, and percentage fat using DEXA measurements. These parameters were determined for total body composition and for regional body parts. Additionally, we studied the effects of long-term AAS self-administration (12 to 16 weeks) and drug withdrawal on anthropometric parameters.

Investigating the effects of administration of nandrolone decanoate (Deca-Durabolin ${ }^{\circledR}$ ), a commonly used and very popular anabolic steroid among strength athletes, is subject of Chapter 4. In a randomized, double blind, and placebo controlled study design nandrolone decanoate $(200 \mathrm{mg}$ per week) or placebo was administered intramuscularly to the participating bodybuilders for eight weeks. We investigated the effects on total body composition and anthropometry, but studied also alterations on regional level. Alterations at the regional level are of special interest in bodybuilders since muscle dimensions and symmetry are important targets for these athletes. The parameters studied on whole body level were body weight, bone-free lean body mass, fat mass, percentage fat by using dual-energy $x$-ray absorptiometry (DEXA). Additionally, we investigated the changes of bone-free lean body mass, fat mass, percentage fat in three regional body parts, i.e. arms, trunk and legs. To study the effects on body composition and anthropometry after withdrawal the same measurements were performed again six weeks after drug cessation.

Chapter 5 deals with the impact of AAS on muscle ultrastructural characteristics since muscle tissue is the most important target organ for strength athletes. From the strength athletes in study 1 and 2 a muscle biopsy from the deltoid muscle was obtained at baseline and after eight weeks AAS administration. The effects of training in combination with AAS administration on muscle fiber size and fiber type distribution using the ATP-ase staining method were investigated.

In Chapters 6 and 7 the untoward effects of AAS on the cardiovascular system are subject of the investigations. From clinical studies as well as from reports in athletic populations it was not clear which effects AAS exert on cardiovascular risk factors and cardiac structure and function, although AAS abuse is associated with the occurrence of serious cardiovascular events in healthy, young athletes. Therefore, Chapter 6 describes the effects of AAS on heart morphology and function, as determined by echocardiography, in well trained strength athletes. The investigations of these issues, again, were performed in two studies, a double-blind and a non-blinded, in order to obtain insight into the effects of relatively low and high doses AAS as well as the impact of duration of AAS administration. In Chapter 7 we investigated the effects of AAS administration on cardiovascular risk factors, in particular 
serum lipids and lipoproteins with special reference to apolipoproteins and lipoprotein(a).

The general discussion in Chapter 8 provides a summary of the most important findings of the investigations and an attempt is made to synthesize the impact of the observations in the different studies. Finally, some ethical considerations regarding scientific research upon the effects of doping substances in healthy athletes are described. 
[14] 


\section{CHAPTER 2}

\section{Effects of androgenic-anabolic steroids in athletes: a review}

Fred Hartgens
Harm Kuipers

Netherlands Centre for Doping Affairs, Capelle aan den IJssel

Dept of Movement Sciences, Maastricht University, Maastricht

Submitted for publication 


\section{ABSTRACT}

Androgenic-anabolic steroids (AAS) are synthetic derivates of the male hormone testosterone. They can exert strong effects on the human body that may be beneficial in athletic performance. In athletes short term administration of these drugs can increase strength and body weight. Strength increments of about $5-20 \%$ of the initial strength may be expected. Increments of $2-5 \mathrm{~kg}$ body weight, that may be attributed to an increase of the lean body mass, are likely to be observed. A reduction of the fat mass does not seem to occur. Although AAS administration may affect erythropoiesis and blood haemoglobin concentrations, no effect on endurance performance has been found. Little data about the effects of AAS on metabolic responses during exercise training and recovery are available that do not allow definite conclusions.

The main untoward effects that male athletes self-report most often are an increase of the sexual drive, occurrence of acne vulgaris, increase of body hair, and increment of aggressive behaviour. AAS administration will disturb the regular endogenous production of testosterone and gonadotrophins that may persist for months after drug withdrawal. Cardiovascular risk factors may undergo deleterious alterations, including elevation of blood pressure and depression of serum HDL-, HDL2-and HDL3-cholesterol levels. In echocardiographic human studies AAS did not affect cardiac structure and function, although in animal studies these drugs have been observed to exert hazardous effects on heart structure and function. In athletes studies AAS were not found to damage the liver. Psyche and behaviour seem to be strongly affected by AAS. Generally, AAS seem to induce increments of aggression and hostility. Mood disturbances (e.g. depression, (hypo-)mania, psychotic features) are likely to be dose and drug dependent. AAS dependence or withdrawal effects (like depression) seem to occur only in a small number of AAS users. Dissatisfaction with the body and low self-esteem may lead to the so called "reverse anorexia syndrome" that predisposes to start AAS use. Many other side-effects have been associated with AAS misuse, including disturbance of endocrine and immune function, alterations of sebaceous system and skin, changes of haemostatic system and urogenital tract.

The mechanism of action of AAS may differ between compounds due to variations in the steroid molecule. The affinity of different AAS to androgen receptors is another key factor. Several pathways mediated by enzymes have been recognised. The enzymes 5 -alpha-reductase converts AAS into dihydrotestosterone that acts in the cell nucleus of target organs, like male accessory glands, skin, prostate. The enzyme aromatase is located inside the cell and converts AAS in female sex hormones (estradiol and oestron). This enzyme becomes probably important when the androgen receptors satured by AAS. In addition, AAS may act antagonistic to estrogens when supraphysiological serum levels are present. Another competitive antagonism has been described for the glucocorticoid receptors. Furthermore, AAS stimulate bone formation and counteract bone breakdown. Finally, AAS may stimulate the erythropoietin synthesis and red cell production. 


\section{INTRODUCTION}

Since many years androgenic-anabolic steroids (AAS) have been very popular among athletes both for performance improvement and for esthetical reasons. The first documented reports about misuse of AAS by athletes stem from the 1950's. At the world championship weightlifting in Vienna (Austria) it was rumoured that the Russian team physician would have told to the US team doctor that some Russian athletes used androgens to enhance their performance. Back in the United States the team physician introduced the administration of these drugs in athletes. Since the first results were less motivating he concluded that androgens might exert particularly psychological effects. However, since several AAS using athletes won competitions and championships in that period the abuse of these agents in sport began to spread $(217,222,237)$.

The International Olympic Committee (IOC) started the fight against doping in the sixties. The first doping control procedures were performed at the Mexico Olympic Games in 1968. The AAS were placed on the list of banned substances in 1976. A decade later the IOC decided to introduce the so-called out-of-competition doping controls. The reason for starting these controls was that many athletes used doping substances (especially AAS) in their training period rather than during competition. Since many years the anabolic agents are by far the most detected doping substances in IOC accredited laboratories (104).

Abuse of AAS is not limited to elite athletes, but is also common practice among many amateur and recreational athletes. It has been established that the use among athletes in gyms is very extensive. Although the sports organisations and media pay less attention to the abuse of AAS by these athletes it is of great medical concern. In recent years many reports about the side-effects of these substances in athletes have been published $(5,24$, $81,102,106,148,167,181,229$ ).

In this article we will review the effects of AAS administration on body composition and performance as well as the untoward effects on health status in athletes. Furthermore, we will describe what AAS are and discuss the mechanism of action of these steroids.

\section{WHAT ARE ANDROGENIC-ANABOLIC STEROIDS?}

AAS are synthetic derivatives of the male hormone testosterone. In humans testosterone is produced in the Leydig cells in the testes. For many years it was well known that castration resulted in the loss of certain secondary male sex characteristics. Therefore, since the beginning of the previous century several attempts were made to obtain a substance with the same potential as testosterone. At the end of the 1920's an active extract came 
available and the production of synthetic androgens was possible in 1935 (117-119). Although the separation of androgenic and anabolic properties was pursued, until now complete separation was not successful. However, nowadays there are products with more androgenic and substances with more anabolic properties. The androgenic actions include primarily the development of the male characteristics, i.e. increase of strength, voice deepening, and the typical male hair growth. The anabolic action affects protein metabolism by stimulation of protein synthesis and inhibition of protein breakdown $(118,228)$.

Both oral and parenteral administration of the hormone testosterone do not exert significant effects in the human body because they are rapidly metabolised. To circumvent this problem several chemical modifications of testosterone have been developed. The variety of these modifications have lead to substances with different action modes. Three major modifications can be distinguished that have therapeutical potential. First, alkylation at the 17-alfa-position with methyl or ethyl group. Alkylation was important to create orally active compounds since this implies slower degradation of the drug by the liver. Second, by esterification of testosterone and nortestosterone at the 17-beta-position it was possible to administer these substances parenterally and the duration of effectiveness could be prolonged. Agents soluble in oily vehicles used for injections may be present in the body for several months. Finally, alterations of the ring structure of testosterone were applied for both oral and parenteral agents and increased the activity of these substances $(27,228)$.

Nowadays the therapeutic use of AAS is limited and may vary between steroids. The most important indications are endocrine dysfunction of the testes and of the hypothalamus-pituitary-gonadal axis (i.e. male hypogonadism and growth retardation). Furthermore, AAS are used to treat disturbances of nitrogen balance and muscular development and several other non-endocrine diseases, including several forms of anaemia, hereditary angioneurotic edema, breast carcinoma and osteoporosis.

Besides the established indications several attempts have been made to develop adequate treatment of male infertility with testosterone administration. On the other hand, testosterone is also subject to extensive clinical trials in the development of a male contraceptive. Until now these efforts were not satisfactory $(11,156,234,235)$.

Recently the value of AAS treatment in several acute and chronic diseases has been investigated (59). From clinical trials it seems likely that small amounts of AAS may exert a positive effect on nitrogen balance in polytrauma patients, after abdominal surgery and after burn injury (59). Additionally, in chronic obstructive pulmonary disease $(74,189)$ and HIV patients $(30,86,204-206)$ AAS have been shown to increase lean body mass, although this effect seems to be related to nutritional status and intake (59). 
Furthermore, clinical data indicate that these drugs may exert beneficial effects in muscular dystrophy (226) and several dermatological diseases (77, 96). However, because of the small number of investigations the actual value of AAS treatment in these conditions has to be established.

\section{EFFECTS OF AAS IN ATHLETES}

\section{Body composition}

Since many years the effects of AAS on body composition in athletes were of interest for many scientists. By investigating the effects on body composition most researchers used the two compartment model, dividing the body in lean and fat mass. The method most frequently applied was measurement of four skinfolds from which the percentage fat was derived $(2,4$, $18-21,38,43,61,70,76,78-80,82,87,97,98,108-110,112,125,135$, $157-159,187,198,200,207,225,230)$. In a minority of studies the underwater weighing method was used to determine percentage fat $(48,70,88$, 223). From body weight and percentage fat the fat mass and lean mass can easily be determined.

Although many strength athletes frequently report increments of about 10-15 kg of body weight due to AAS administration, such alterations have not been documented in well designed prospective studies. Most studies show that body weight may increase by 2 to $5 \mathrm{~kg}$ due to short term (less than 10 weeks) AAS use $(97,98,108,109,125,159,230)$. The most pronounced average gain of body weight after 6 months self-administration of several AAS in high doses was reported by Alen and co-workers (4) (Table 1).

The alteration of body weight was mainly caused by an increase of lean mass. Apart from a single exception (2) no study was able to elucidate significant fat mass decrements $(2,3,33,75,97,98,125,223)$. The precise composition of the increased lean mass has not been established yet. Although AAS have been demonstrated to stimulate protein synthesis (91), only little evidence for an increase of muscle mass due to AAS use in athletes is available yet $(98,124)$. On the other hand, there are indications that in normal men an increase of blood volume $(101)$ and / or water retention $(97,98)$ may be responsible for the weight gain.

After drug withdrawal the alterations of body composition fade away slowly in several weeks or months. One study reported that three months after AAS cessation body weight and lean body mass were still increased compared to baseline values in bodybuilders $(75,125)$. However, the final net result of AAS administration on body composition seems to be rather small. From our own observations this seems especially the case in recreational athletes since they do not seem to be capable to maintain nutritional intake and training work load on the required level (95). On the other hand, in these athletes short term AAS self-administration results in fast gains and is, therefore, very attractive. 

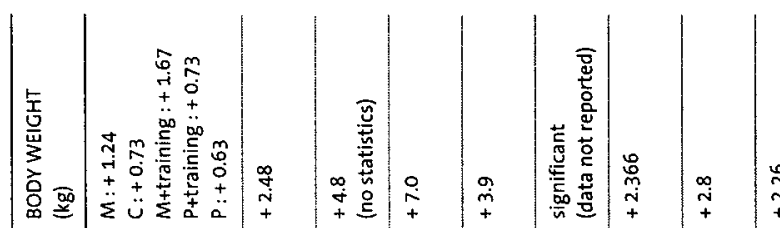

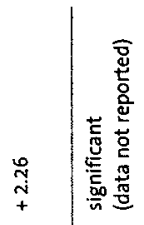

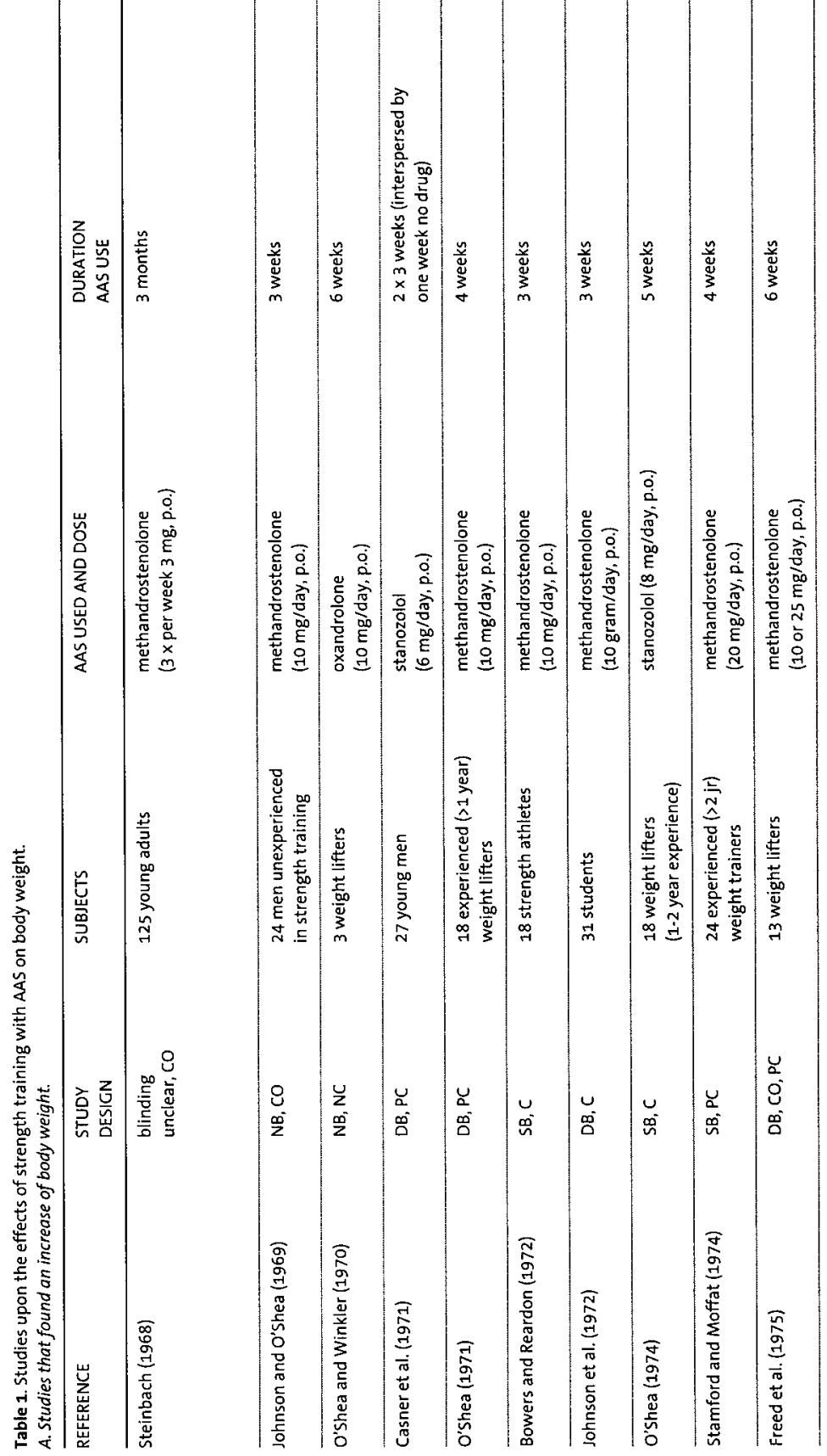




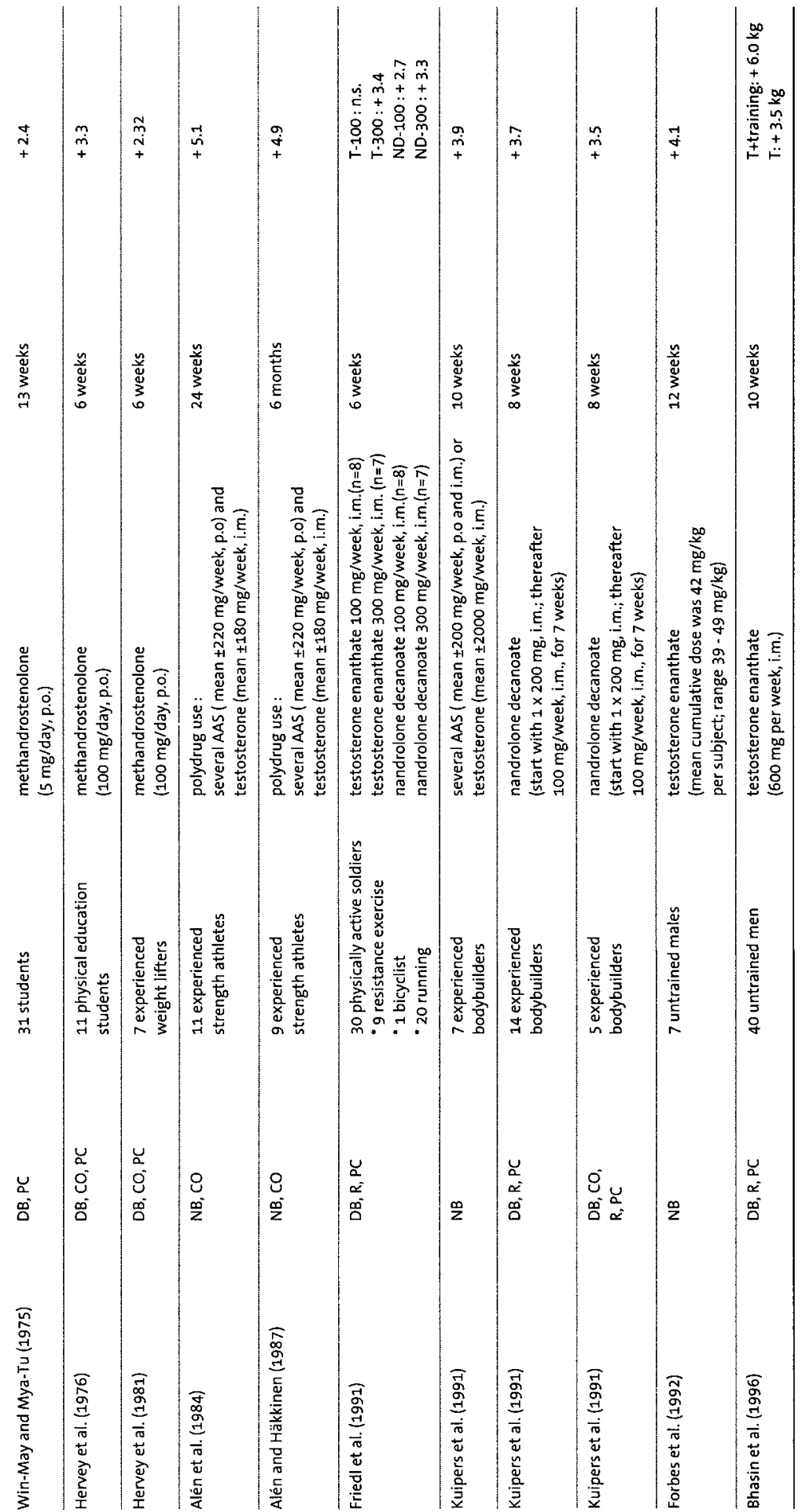




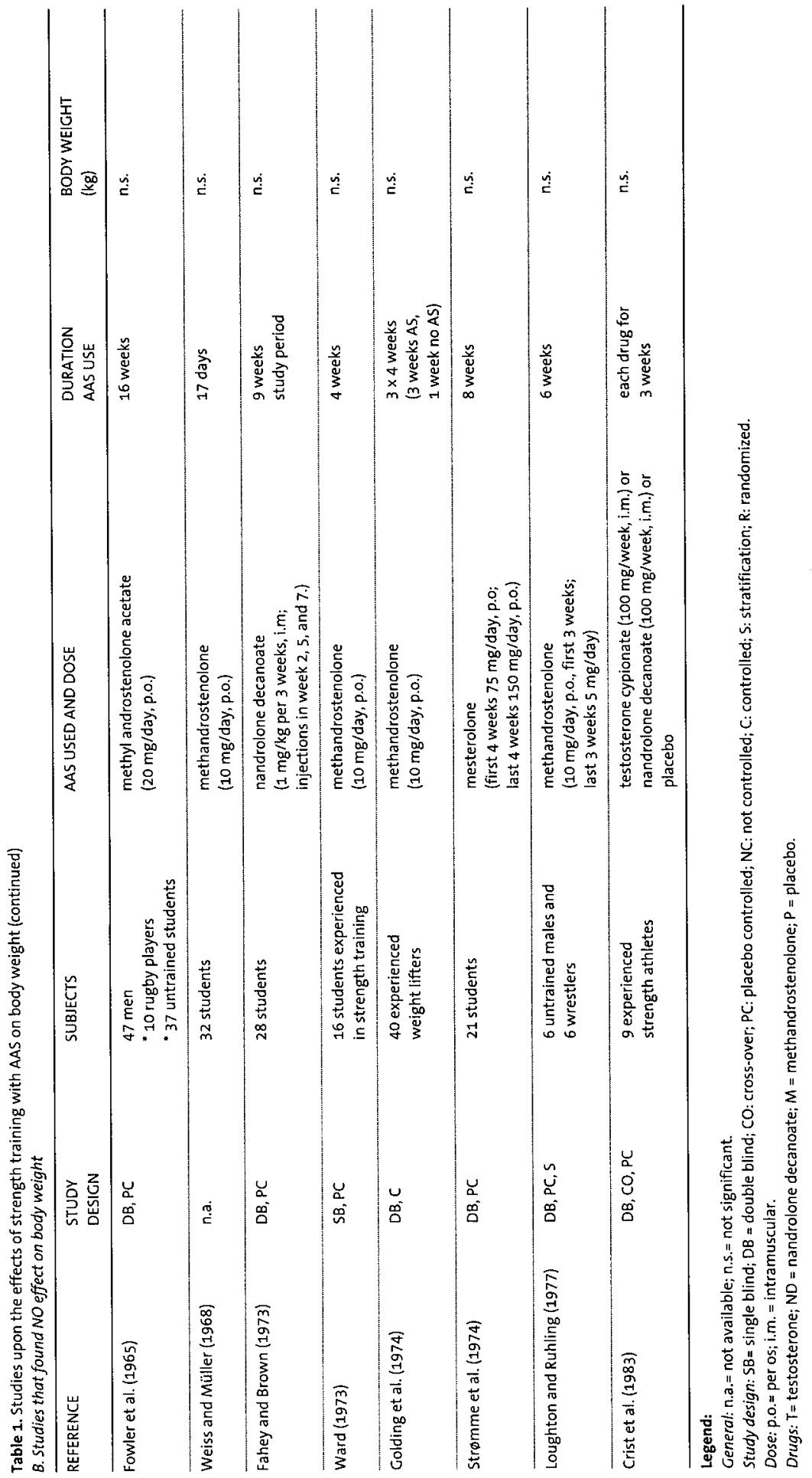




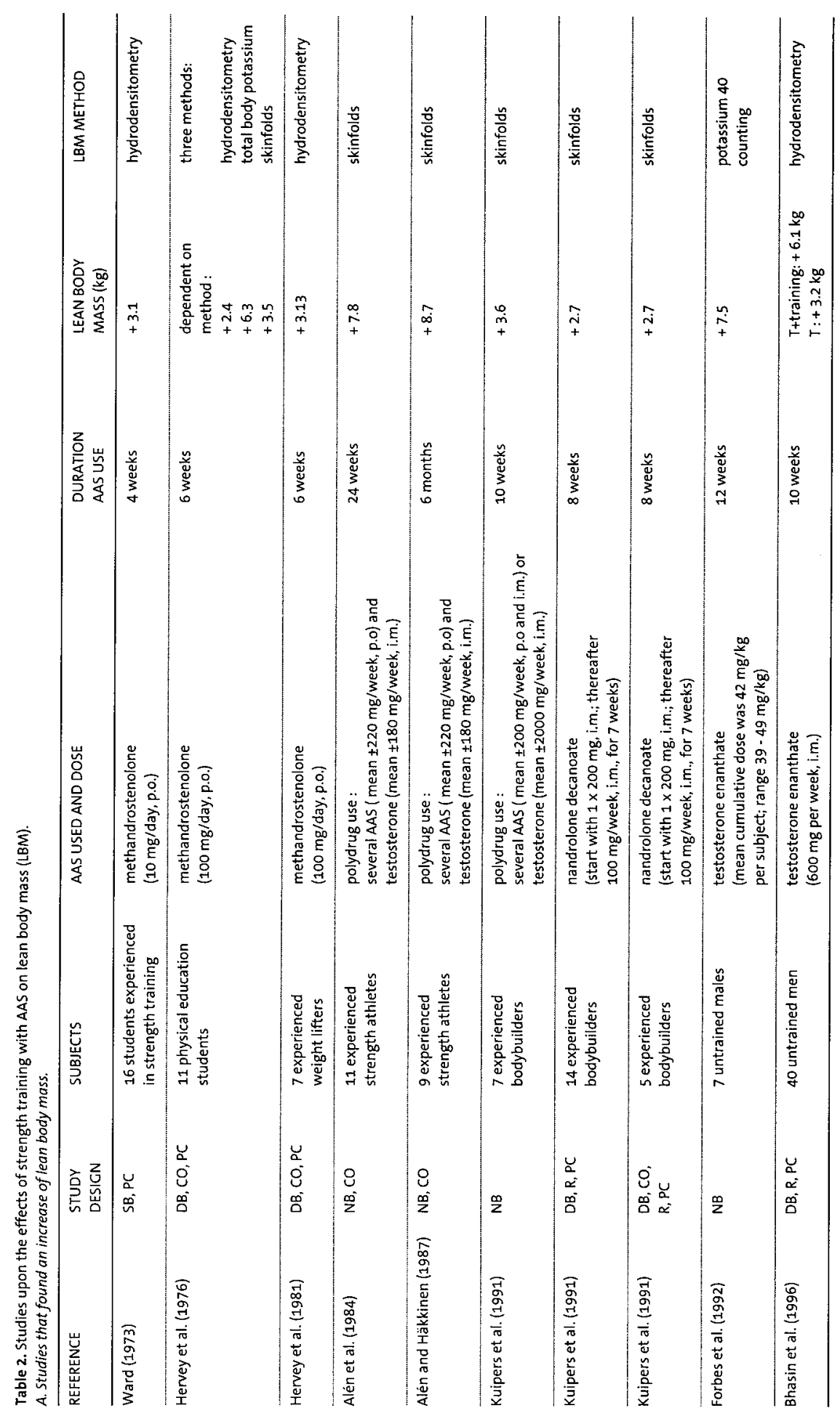




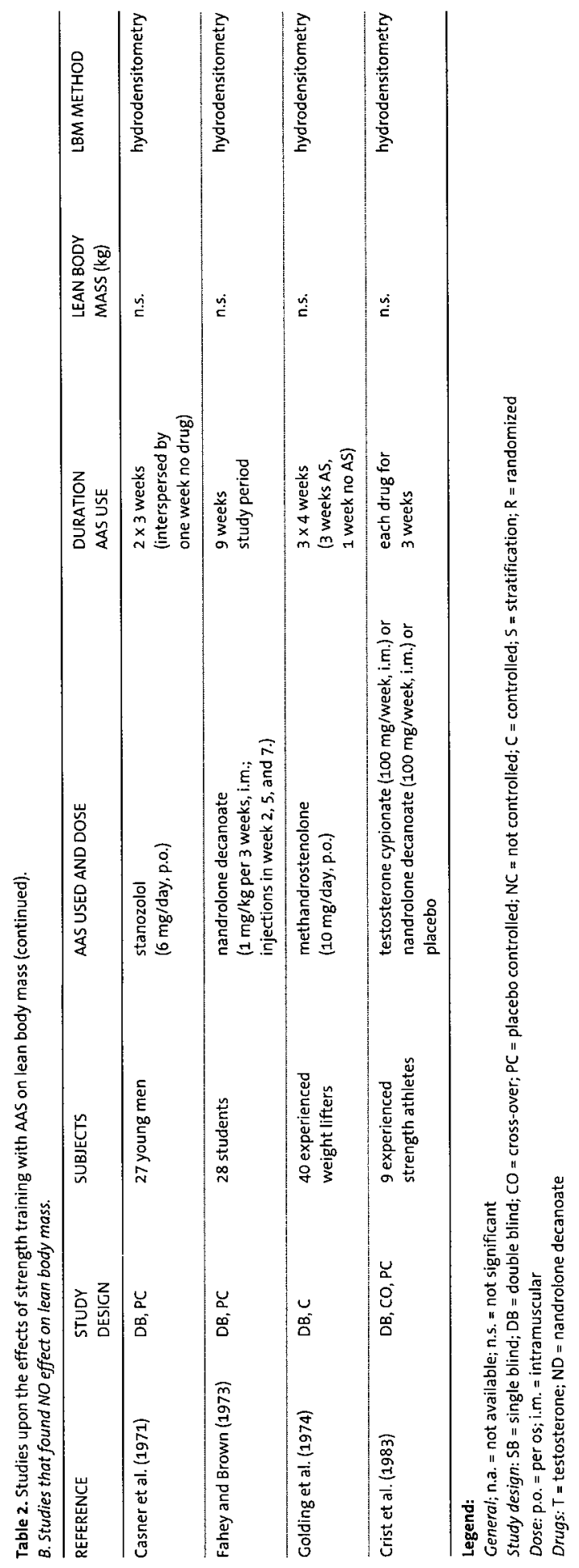




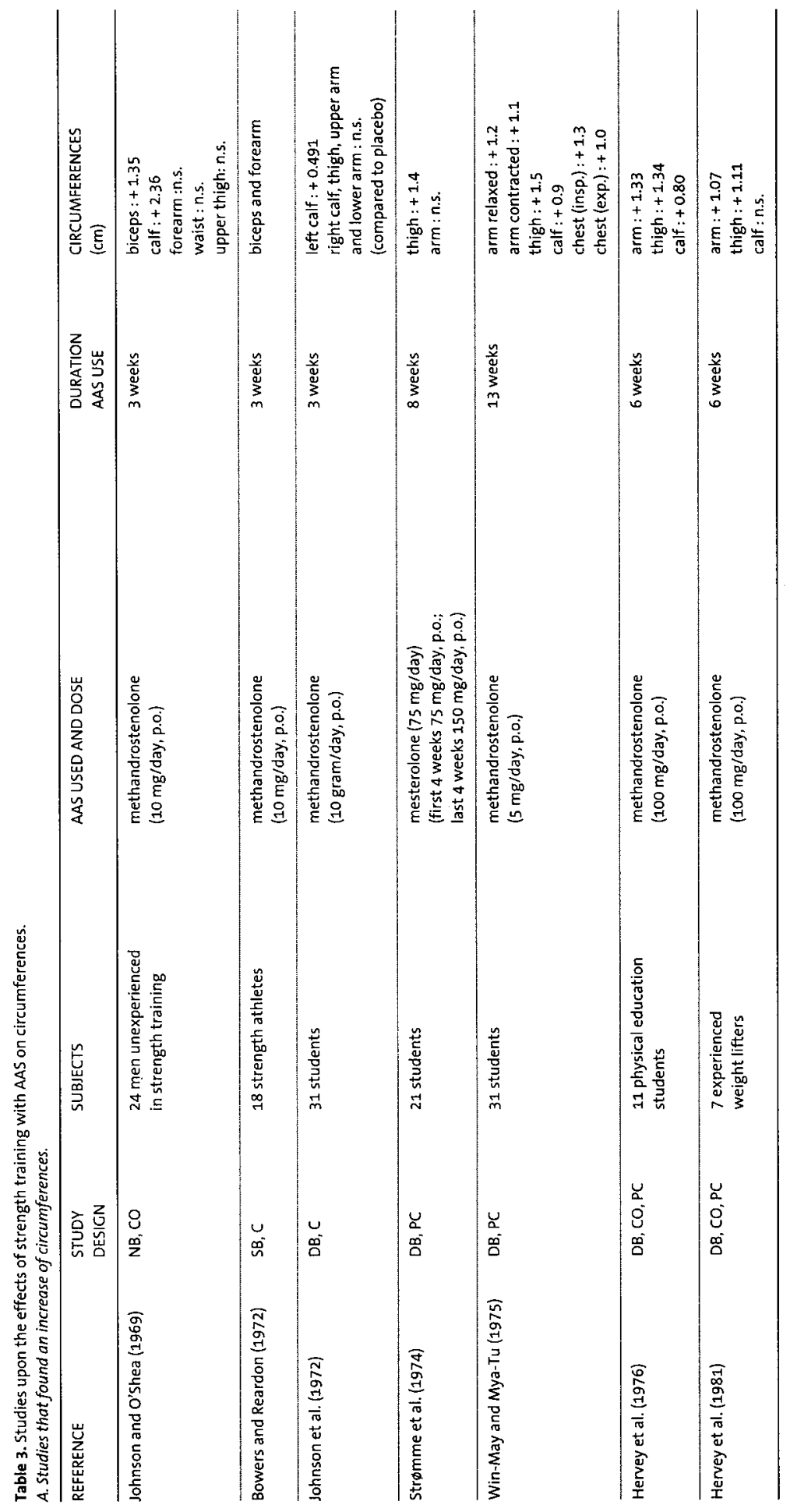




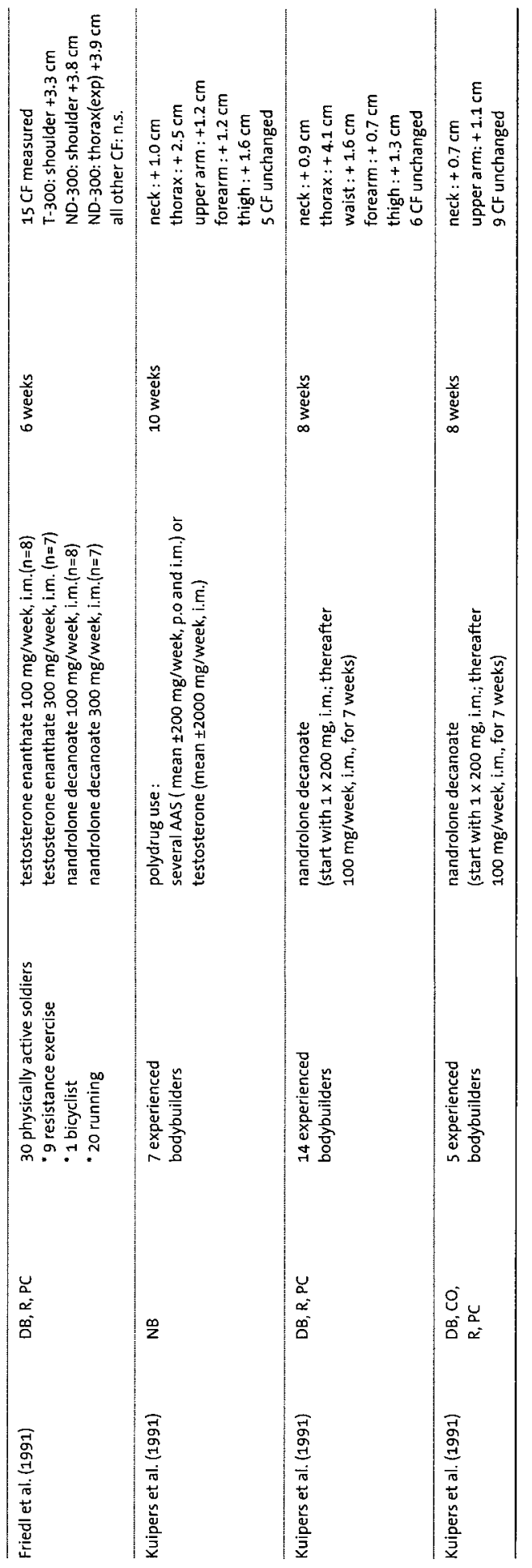




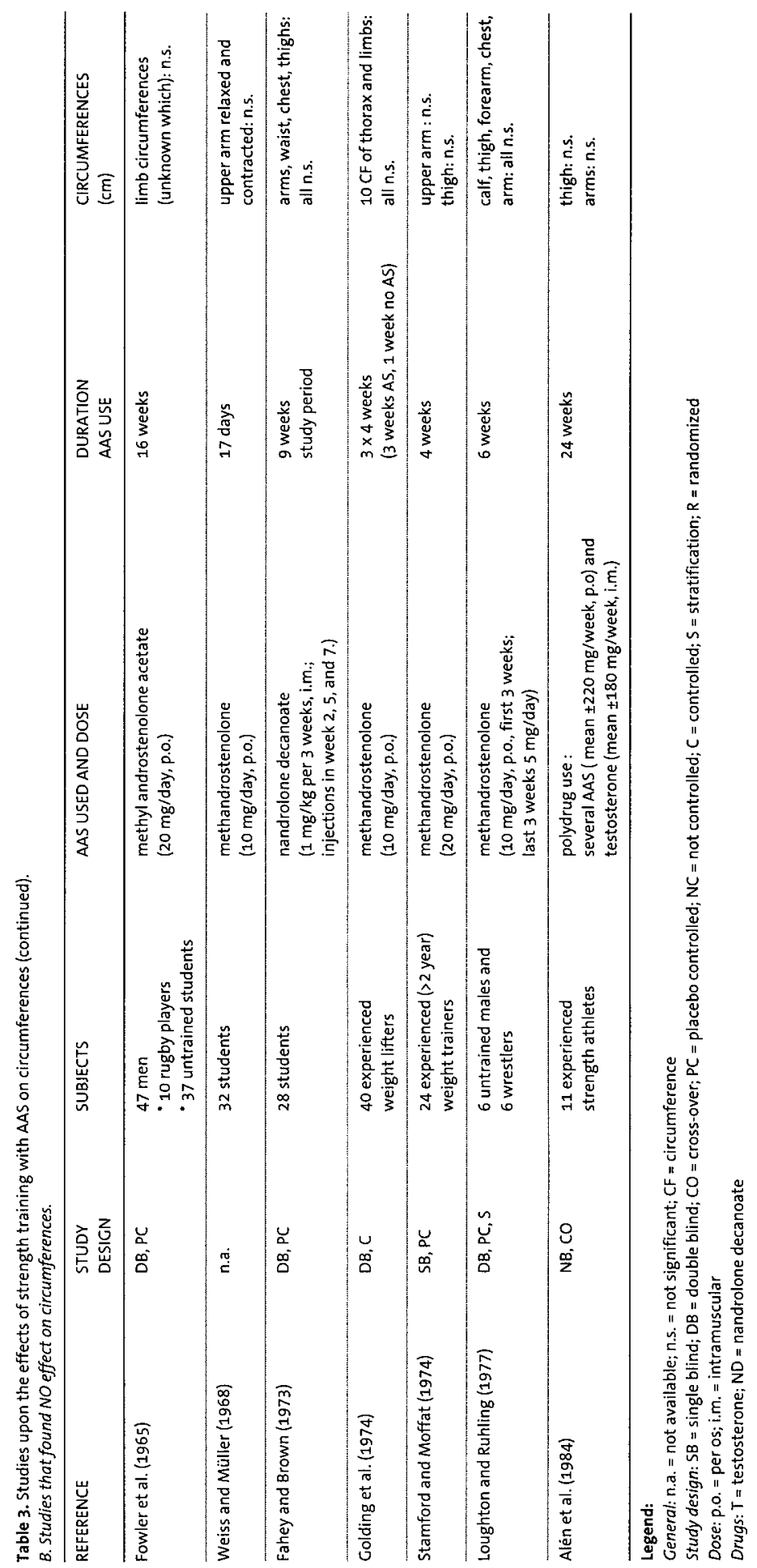




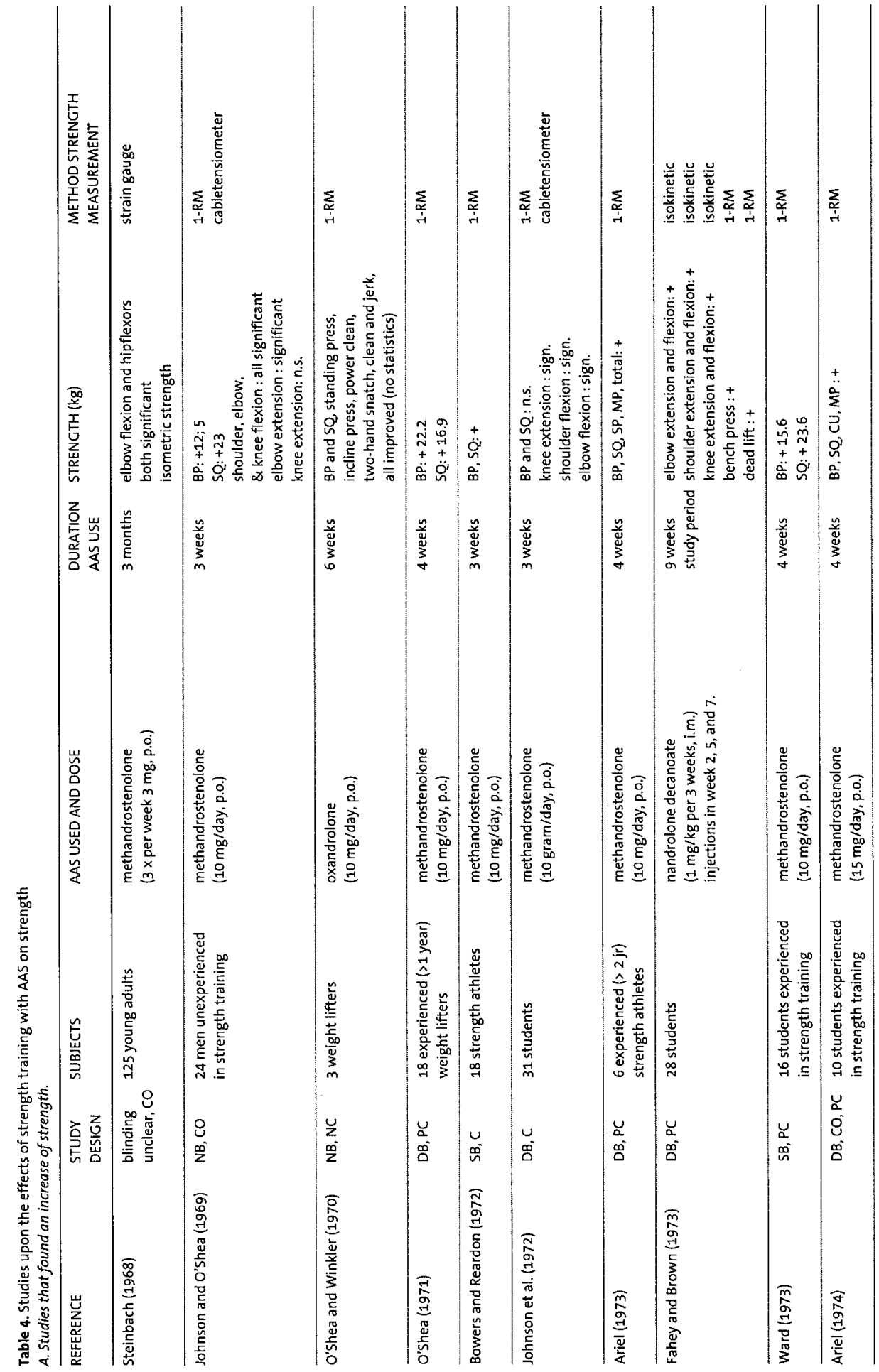




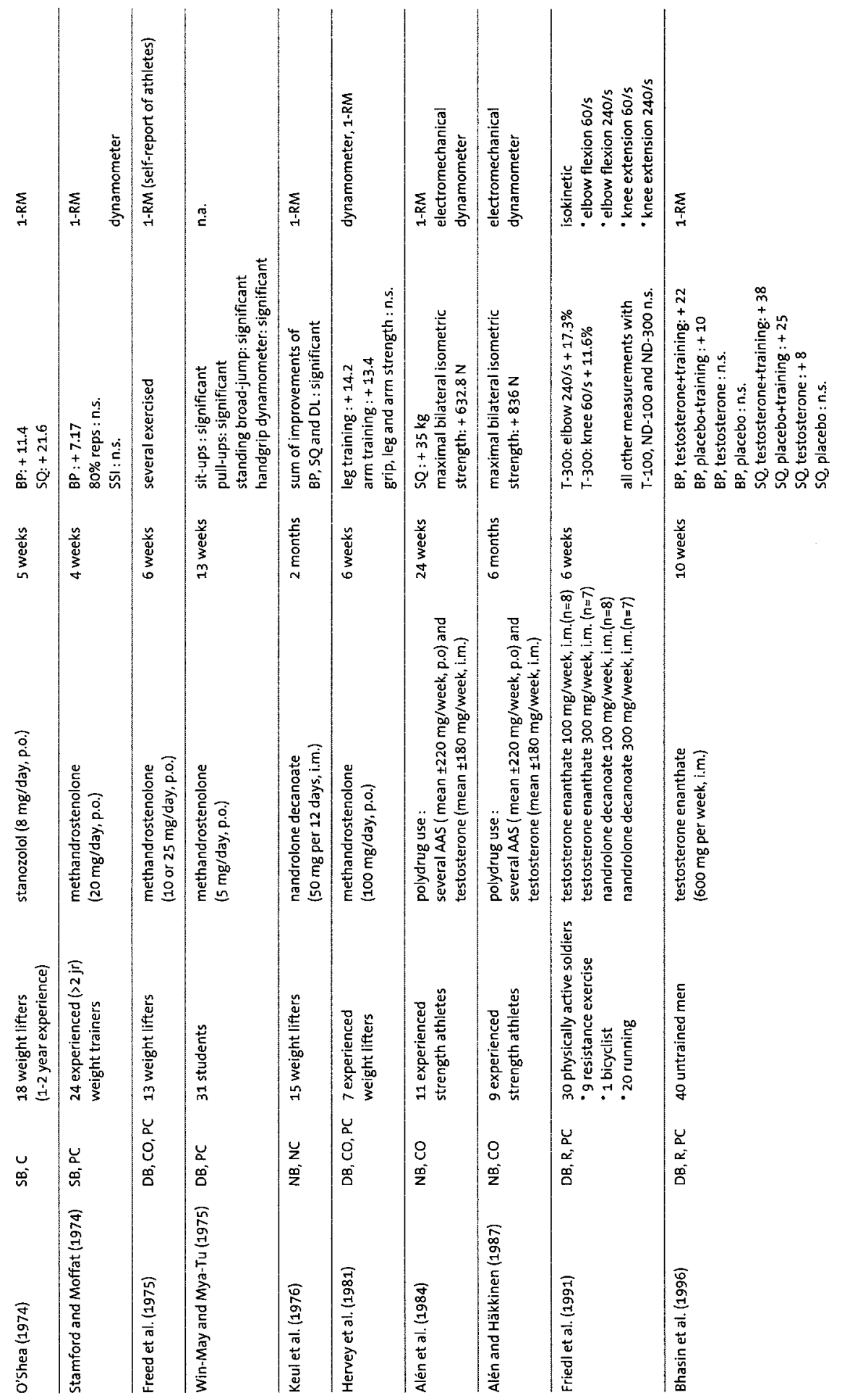




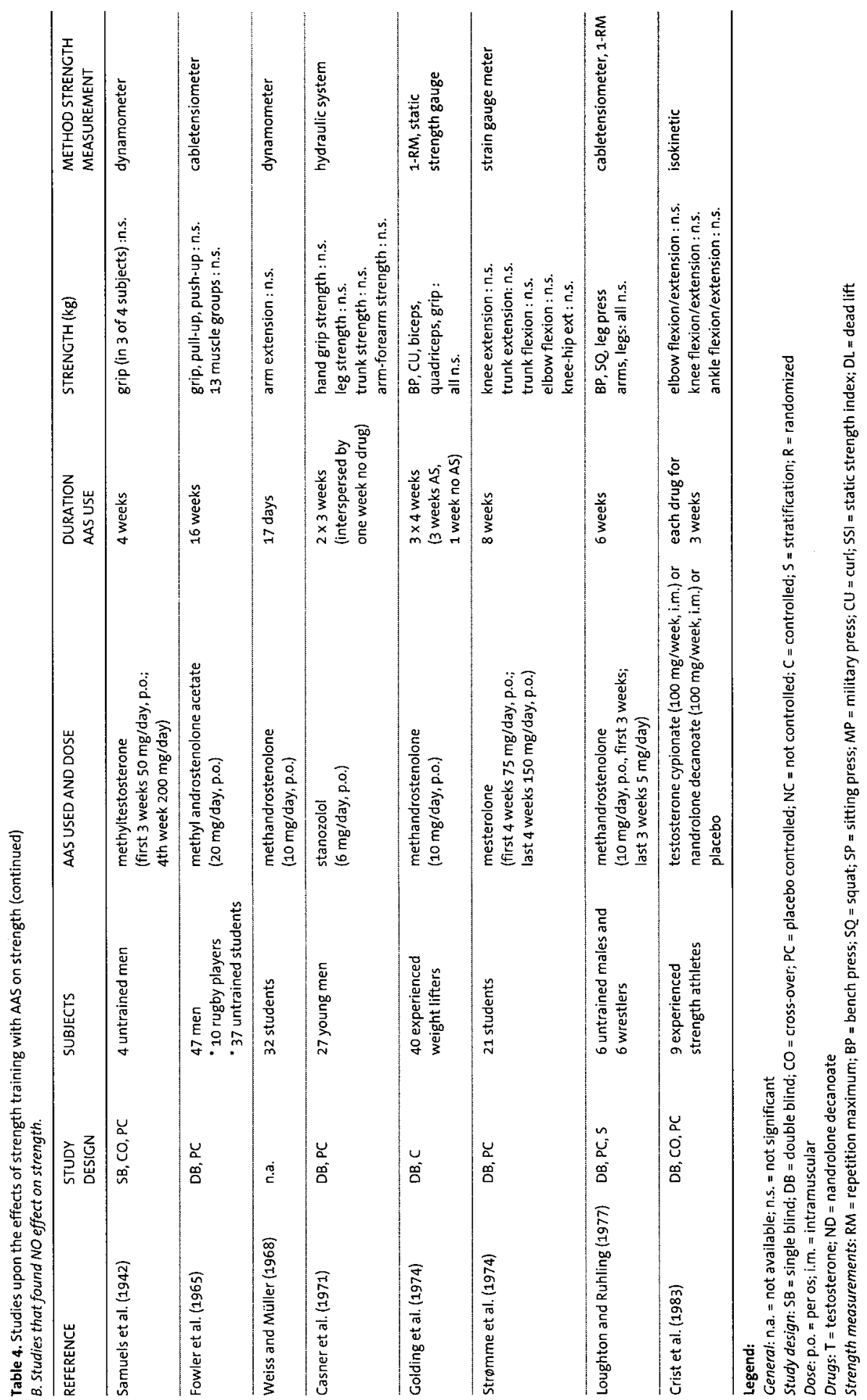


Since in animal studies AAS were found to reduce fat mass, athletes concluded that this may occur in humans as well. However, until now research could not support this claim, but revealed the opposite $(4,61,70$, $75,82,88,125,230$ ) (Table 2). Although in two studies a reduction in percentage fat could be observed, this was not reflected in a decrease of fat mass (2) (223). The change in percentage fat can be attributed to the increase of lean body mass (Table 2). On the other hand, from personal observations it is known that strength athletes combine low caloric intake with concurrent AAS intake. The rationale for such regimens is that the athletes aim to reduce fat mass with simultaneous maintenance of muscle mass.

Several studies revealed that body dimensions may be subject to alterations due to AAS administration. Measurements of circumferences demonstrated that the largest gains can be found at the neck, thorax, shoulders and upper $\operatorname{arm}(82,109,125,230)$. However, other studies did not find alterations of circumferences $(4,70,135,198)$. MRI measurements demonstrated that testosterone administration may lead to increments of approximately $15 \%$ of the area of the $\mathrm{m}$. triceps brachii and $\mathrm{m}$. quadriceps (33). In Table 3 the results of these studies are summarised.

Because of the relationship between strength and fast twitch muscle fibres it has been assumed that AAS would affect fast twitch muscle fibres more than slow twitch fibres. However, several studies in athletes found increments of slow twitch muscle fibres, whereas the fast twitch fibres remained unaltered $(4,95,125)$. Since it is likely that muscle fibre hyperplasia can occur $(14,194)$, we hypothesise that the effect on fast twitch muscle fibres might be attributed to hyperplasia rather than to hypertrophy. However, solid evidence is not available yet.

\section{Strength}

Strength is an important quality for many sports. Strength is relevant not only in specific strength sports, but also in many others such as rowing, sprinting and cycling. Many researchers have investigated the effects of AAS on strength $(2,4,18-20,33,38,48,61,70,76,80,82,88,98,108,109,112$, $135,157-159,187,198,200,207,223,225,230$ ) (Table 4). Several of these studies do not meet the quality standards for scientific research. But looking at the well designed studies it can be concluded that AAS enhance the effects of strength training. The observed improvements were in the range of 5-20\% of baseline strength, largely depending on the drugs and dose used as well as the administration period. Although most research has focused on absolute strength determined by one repetition maximum or isokinetic strength, one study tested the effects on canoeing capacities. Rademacher et al (1989) reported that in canoeists 6 weeks Oral-Turinabol administration improved strength and performance measured by canoe ergometry significantly (174). 
For many years it was assumed that only in experienced strength athletes AAS may exert significant effects, based on the studies of Hervey and co-workers $(97,98)$. Recently, however, Bhasin et al (1996) demonstrated that even in novice athletes a ten week strength training program accompanied by testosterone administration may improve strength more than does strength training alone (33). Nevertheless, it is impossible to predict which drugs and dose will exert the best improvements in strength. For example, methandrostenolone is the most frequently investigated drug. Studies differed with respect to dose and duration of drug administration. Some investigations showed improvements on short term and low dose (109, 158), whereas others found no alterations in some strength measurements after long term and high dose methandrostenolone administration (98, 135). The effects of injectable testosterone enanthate, however, have been demonstrated to be dose dependent (82). Additionally, androgenic substances seem to affect strength more than anabolic agents (82). Furthermore, it remains debatable whether polydrug regimens are superior to single drug administration $(2,4,33,82)$.

\section{Haematology and endurance performance}

From times immemorial AAS were registered for the treatment of several kinds of anaemia. In patients long term treatment with AAS has been demonstrated to improve serum haemoglobin concentrations (100). Because of the relationship between haemoglobin and endurance performance athletes started to self-administer AAS. However, only two investigations were able to register AAS induced alterations of haematology in athletes $(1,94)$. Alen $(1985)$ described increments of serum haemoglobin concentrations, haematocrit, mean corpuscular haemoglobin concentration $(\mathrm{MCHC})$ and mean corpuscular haemoglobin $(\mathrm{MCH})$, the number of white blood cells and platelets in athletes after 6 months self-administration of high doses AAS, whereas mean red cell volume (MCV) remained unaltered (1). Recently, Hartgens et al (1995) found after 8 weeks AAS use an increase of platelet count, whereas all other haematological parameters remained unaffected (94).

The majority of studies performed demonstrated that AAS were not able to improve endurance performance in athletes $(38,70,97,108,110,207,230)$. In two studies, however, an improvement of aerobic capacity was noticed $(109,112)$. Remarkably, the volunteers in both studies were strength athletes who did not train for endurance performance $(109,112)$. On the other hand, since the availability of recombinant human erythropoietin the use of AAS for this purpose has been abandoned. 


\section{Recovery}

Many athletes report that AAS administration enhances recovery time in heavy training periods. Unfortunately, the research done on this issue only studied some indirect parameters that are associated with recovery time $(37,112,144,145,182,200)$. The report of Keul and co-workers (1976) showed that heart rate and serum lactate increased significantly slower during ergometer work when on nandrolone decanoate. Additionally, after completion of the exercise session the return of the heart rate of lactate level to regular resting values was faster in the AAS users (112). On the other hand, administration of injectable testosterone enanthate had no effect on serum levels of urea, ammonia, creatinine, CK and GOT indicating that testosterone enanthate did not affect regeneration in well-trained endurance athletes $(107,221)$. Rozenek et al (1989) found higher androgen/cortisol ratios and lower plasma lactate levels in AAS users compared to non-users after completion a strength training work out. They suggested that these factors explained the lower subjective level of fatigue after training sessions in AAS users (182). Boone et al (1989) concluded that AAS administration resulted in a diminished creatine phosphokinase (CK) response and an altered stress response to a single bout of resistance exercise (37).The CK response observed was in line with the previous findings of McKillop and co-workers $(144,145)$. Since research in this area is very limited definite conclusions can not be drawn yet.

\section{UNTOWARD EFFECTS}

It seems redundant to mention that AAS may affect health status. On the other hand the many case reports in the literature indicate that a substantial number of athletes will not be deterred by the side effects and will accept the risks of (major) health damage. The side effects can be divided in subjective and objective. First we will describe studies that focused on subjective perceived side effects. Later we will discuss the undesired health effects that are open to objectification.

\section{Self-reported adverse effects}

Only a few reports investigating the self-experienced adverse effects in AAS using athletes have been published until now $(62,201,203,219,238)$. These reports employing questionnaires showed clearly that the majority of athletes experienced undesired health effects when on AAS, but also after drug withdrawal. The side effects reported in at least $40 \%$ of the male subjects in these studies included increased sexual drive $(62,203,238)$, occurrence of acne (238), increase of body hair (238), increase of aggressive behaviour (203). Furthermore, many other side effects affecting several body systems were mentioned by the steroid users. These include fluid 
retention, elevated blood pressure, sleeplessness, increased irritability, decreased libido, increased appetite, enhanced transpiration, increased feeling of well-being, depressive mood states, loss of head hair and the occurrence of gynaecomastia.

Data of female athletes are very scanty $(62,201)$. Strauss et al (1985) interviewed ten females who all reported lowering of the voice by AAS use. Furthermore, 9 of 10 subjects admitted increased growth of facial hair, enlargement of the clitoris and an increase of aggressiveness and appetite (201). Recently, in the study by De Boer et al. (1996) 9 out of 10 interviewed female athletes had experienced side-effects due to steroid use (62). The side-effects reported were acne (50\%), fluid retention (40\%) and alteration of libido (50\%). Other side-effects were only mentioned by less than $20 \%$ of the women (62). The discrepancy between the reported side-effects in both studies can, at least in part, be attributed to the difference in substances and dosages used. The subjects in the study of Strauss et al (1985) self-administered more androgenic agents and used much higher doses than the female bodybuilders of DeBoer's study, and therefore may be responsible for the masculinizing effects $(62,201)$. Of great concern is that athletes are not aware of many side effects during steroid administration, since several unwanted health effects may be detected only after thorough medical examination including blood analysis.

\section{Reproductive system}

Since AAS are derived from testosterone they will exert important effects on the sex hormones and the reproductive system. They affect the hypothalamic-pituitary-gonadal axis, that acts as a feedback system. Consequently, exogenous administration of AAS will disturb the regular endogenous production of testosterone and gonadotrophins. In males suppression of gonadotrophin production induces testicular atrophy and reduces semen production. Studies have demonstrated that the use of AAS may lower serum gonadotrophin concentrations dramatically $(8,9,33)$. A decline can be observed already within 24 hours (12) ]. Serum testosterone levels will decrease too (34), except when exogenous testosterone is administered (9). Administration of high doses testosterone will induce supraphysiological levels of serum total and free testosterone and estradiol $(8,9,33,141)$. Serum concentrations of androstenedione and dihydrotestosterone closely follow the same pattern (183). The high serum levels of estradiol, androstenedione and dihydrotestosterone can be explained by peripheral conversion of AAS (140).

AAS administration will reduce quantity and quality of semen production in male athletes and may lead to infertility within months $(10,190)$. This is in agreement with the results of research for contraceptive purposes in males, although this method of contraception is still experimental and not reliable yet (234). Once the steroids are stopped the time needed for full recovery of 
reproductive function is not exactly known. After long term AAS abuse full recovery may take at least 4 to 5 months $(8,9,138)$. However, Alen and co-workers reported that in some individuals complete recovery of normal reproductive function may last more than a year (10). Long term administration of high doses AAS may provoke hypogonadotrophic hypogonadism, characterised by testicular atrophy, oligo- or azoospermia, low serum concentrations of luteinising hormone and follicle stimulating hormone, and of endogenous testosterone and precursors $(138,228)$. After drug withdrawal treatment of hypogonadotrophic hypogonadism with human chorionic gonadotrophin resulted in a testicular responsiveness comparable to that in prepubertal boys (138).

In males gynaecomastia may be observed as a result of AAS administration. Development of gynaecomastia is associated with the peripheral conversion of AAS to estrogens, due to the huge amounts of AAS administered (154, $197,229)$. In the early stages spontaneous regression can be expected, but in chronic cases surgical correction may be appropriate $(178,229)$. A common practice among strength athletes is to take tamoxiphene for the prevention of gynaecomastia although scientific data do not support the effectiveness of this preventive strategy (84).

In females AAS will induce male characteristics. In one study female bodybuilders reported the development of acne vulgaris, changes in libido and alterations of the voice as most pronounced side effects in the first weeks of AAS use (62). Long term AAS administration may induce loss of hair of the head, alterations of pubic hair growth and enlargement of the clitoris. Furthermore, menstrual irregularities and a reduction of the breasts usually occur. Finally, adolescents may be prone to early closure of growth plates resulting in premature stop of length growth (229).

\section{Cardiovascular system}

In recent years the abuse of AAS has been associated with the occurrence of serious cardiovascular events in healthy young athletes $(65,67,72,136,147$, $150,155)$. Research in this area mainly focused on risk factors for cardiovascular disease as well as echocardiographic examinations.

Blood pressure. Several studies investigating different AAS regimens did not show alterations of the blood pressure in healthy strength athletes ( 83 , $116,125,214,220)$. In other investigations, however, an elevation of systolic or diastolic blood pressure has been observed due to AAS administration (12, $80,116,125,129,179)$. The most pronounced increase of diastolic pressure has been reported by Kuipers et al (1991). They found an increase from 74 to $86 \mathrm{~mm} \mathrm{Hg}$ due to 10 weeks AAS self-administration (125). Increments of systolic blood pressure of about $10 \mathrm{~mm} \mathrm{Hg}$ (129) and $12 \mathrm{~mm} \mathrm{Hg}$ (125) in normotensive strength athletes due to AAS have been reported. An elevation of blood pressure may already be present within 4 weeks on steroids 
(179). After drug cessation the blood pressure seems to return to pre-steroid levels within several weeks (125). These studies suggest that that higher doses of AAS seem to be more likely to induce blood pressure elevations. Furthermore, androgens seem to affect blood pressure more than anabolic agents although the exact mechanism remains to be established $(125,179$, 181).

Lipoprotein metabolism. The response of lipids and lipoproteins to AAS administration is not determined in detail yet. The effects of AAS on serum total cholesterol metabolism are still equivocal. Most studies reported no alterations of serum total cholesterol levels $(6,7,60,80,113,125,159,166$, 224). However, some studies found that AAS were able to induce an increase of serum total cholesterol levels $(53,55,103)$, whereas others observed a decrease $(25,153)$.

In this light nandrolone decanoate seems to be the most confusing steroid. Short term use of therapeutical and supratherapeutical doses of nandrolone decanoate do not seem to elevate serum cholesterol levels $(83,125)$. Contradictory, the use of a relative low doses has been demonstrated to induce a slight, but significant increase of serum total cholesterol levels during short term and long term administration $(83,125)$. In strength athletes testosterone enanthate by intramuscular injection has no effect on serum total cholesterol levels after three weeks administration (239), but after six weeks a reduction of total cholesterol may be present (213). On the other hand, supratherapeutical doses of another testosterone substance, i.e. testosterone cypionate, do not exert significant effects on serum total cholesterol levels at all (122).

HDL-cholesterol and its subfractions have been recognised as independent risk factors for the occurrence of cardiovascular disease (69). AAS can induce remarkable reductions of the serum levels of these lipoproteins already within a few days on steroids (213). After an initial strong negative effect the decrease of the serum HDL-cholesterol and its subfractions continues at a more moderate level $(7,116,125,129,213)$. The 17-alkylated androgens (such as stanozolol, oxymetholone and methandrostenolone) exert more pronounced deleterious effects than other AAS $(16,57,213)$. Short term administration of androgens, like testosterone enanthate and cypionate, depress serum HDL-cholesterol levels significantly $(122,213)$. Parenteral administration of nandrolone decanoate for two months does not affect HDL-cholesterol and subfractions in healthy athletes $(85,125)$. In clinical studies, however, this steroid was found to affect HDL-cholesterol metabolism unfavourably in male haemodialysis patients when administered for more than 6 months (212). In women with postmenopausal osteoporosis even after three weeks a reduction of serum HDL-cholesterol levels were noticed (133). 
After steroid withdrawal the disturbed lipids and lipoprotein profiles seem to recover, although at least 4 to 12 weeks are needed for return to baseline values $(7,55,125,153)$.

In general, the administration of multiple AAS will increase serum LDL-cholesterol levels $(116,129,213)$. The elevation parallels the decrease of HDL-cholesterol and may be observed within a few days after the start of steroid use (213). Single anabolic steroid administration may exert different effects on serum LDL levels depending on the steroid and route of administration. Oral administration of stanozolol increased LDL levels (213), whereas the intramuscular injections of testosterone cypionate or testosterone enanthate did not alter LDL levels $(122,239)$.

The effects on triglyceride metabolism appear to be more unequivocal. Most studies in athletes did not observe any alteration of serum triglycerides levels due to AAS administration $(7,116,125,213,239)$, although in one study an elevation has been observed (122).

In conclusion, the effects on plasma lipids seem to vary considerably with type of AAS administered and with route of administration. Both alkylated AAS and testosterone esters have been demonstrated to suppress serum HDL-cholesterol levels, as well as HDL2- and HDL3-cholesterol. Polydrug regimens influence lipoprotein metabolism more pronounced than the administration of a single steroid. Moreover, short-term administration nandrolone decanoate, even at high doses, does not affect lipoprotein metabolism in young athletes. On the other hand, in patients long term use of nandrolone alters lipoprotein levels considerably.

Heart structure and function. The introduction of echocardiography was important for investigating the physiological responses of the heart to exercise and training. Seven cross-sectional studies reported differences in one or more echocardiographic variables measured between AAS users and non-using strength athletes $(52,63,68,146,185,220,236)$, whereas five studies did not register any difference $(160,186,196,214,240)$ (Table 5). Steroid users had larger left ventricular mass and/or left ventricular index $(52,63,68,146,185,236)$. Some studies observed larger posterior wall and interventricular septum in AAS users $(68,146,185,220)$. From the majority of studies it seems that the left ventricular cavity during diastole and systole is not subject to alterations under steroid use $(63,146,160,186,214,236$, 240).

Until now five prospective echocardiographic studies have been published $(63,160,185,196,240)$ (Table 6). Only one study reported changes in echocardiographic variables under steroids (185). Sachtleben et al (1993) observed significant changes of left ventricular mass, interventricular septum thickness and left ventricular end-diastolic diameter, but the left 

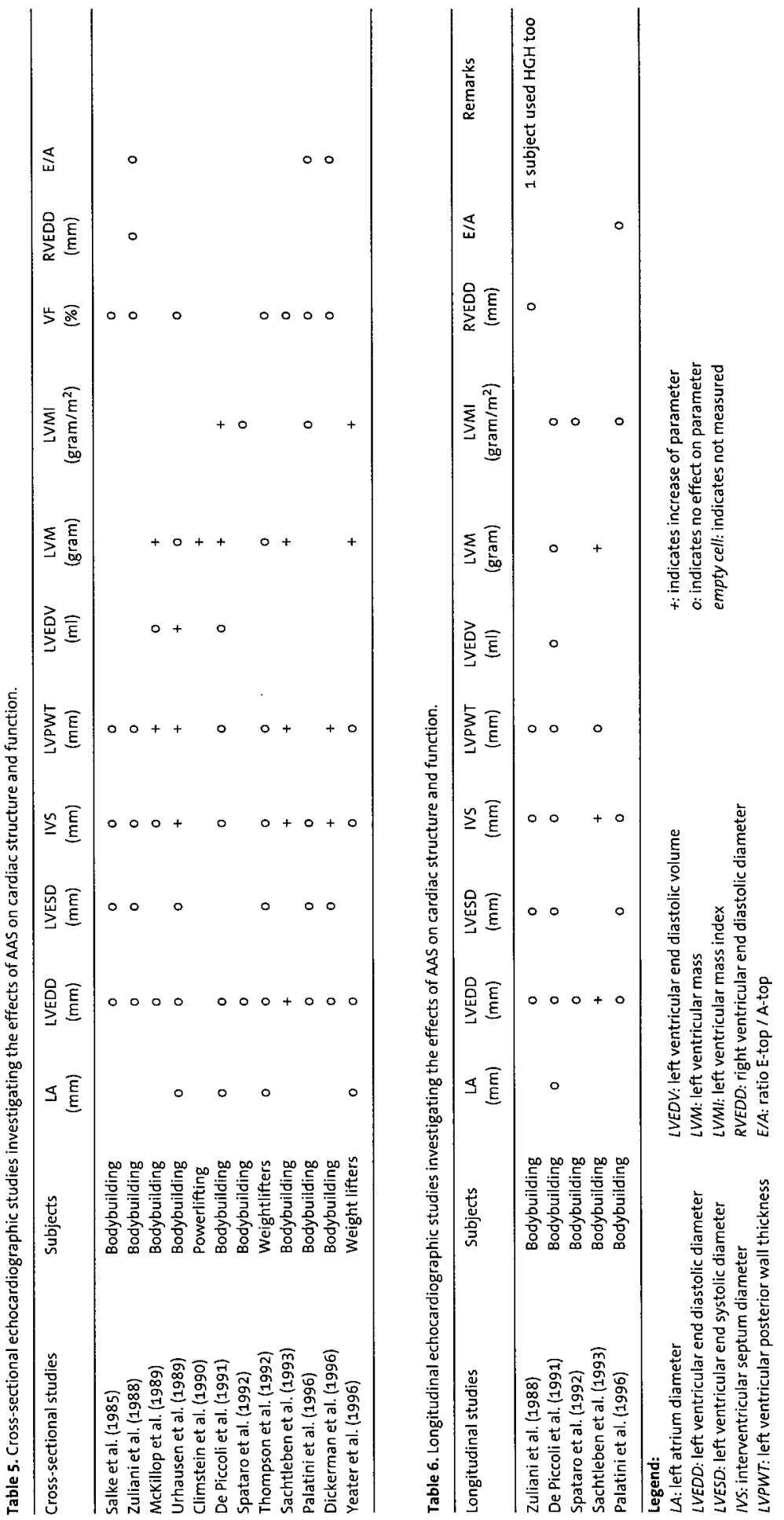
ventricular posterior wall thickness remained unaffected by AAS (185). The researchers, however, did not pay attention to an increase in work load of the AAS users during the study period. Therefore, these results must be interpreted with caution, especially since all other studies unanimously reported no changes in any echocardiographic variable measured during AAS administration $(63,160,196,240)$. Although the study designs were not blinded, these results indicate that changes in heart structure and function are not to be expected when an athlete takes AAS. On the other hand, echocardiography might be not sensitive enough to detect early and small changes since animal studies clearly have shown that short term use of androgens and anabolic agents may exert strong hazardous effects on cardiac structure and function $(15,28,29,111,130,151,165,175-177,209$, 210, 216)

\section{Hepatic effects}

Liver function disturbances and diseases due to AAS treatment in patients as well as in AAS abusing athletes have been of great concern. Animal studies clearly have shown the hazardous effects of AAS on the liver $(39,90)$. From trials it is plausible that AAS can induce serious liver disorders such as subcellular changes of hepatocytes, impaired excretion function, cholestasis, peliosis hepatis and hepatocellular hyperplasia and carcinomas in humans as well $(105,106,195,232)$. Additionally, several case reports have associated the occurrence of aforementioned liver disorders with the abuse of AAS in young, healthy athletes $(46,58,89,120)$. These disease conditions are mainly attributed to the administration of 17-alpha-alkylated steroids, i.e. methyl testosterone, oxymetholone, fluoxymesterone, norethanalone and methandrostenolone $(106,195,229)$. Injectable testosterone cypionate and enanthate preparations do not appear to affect liver function enzymes, whereas (nor-)testosterone esters may induce parenchymal lesions of the liver (106). Some researchers proposed that the occurrence of AAS induced liver disease may be dependent on the liver condition before starting drug administration (229).

Several studies have investigated the effects on serum liver enzyme activities in athletes. In most studies the common liver enzymes aspartate amino transferase (ASAT), alanine amino transferase (ALAT), gamma-glutamyl transpeptidase (GGT), lactate dehydrogenase (LDH) and alkaline phosphatase (AP) were studied. Monitoring of liver function enzymes during AAS administration provided equivocal results. However, the majority of longitudinal studies reported no changes due to AAS $(1,61,97,112,125,158,198$, 202), although elevations of ASAT or ALAT have been observed within several weeks on steroids in some studies $(80,109,129,215)$. These elevations were attributed to the intake of oral steroids and tended to return to baseline levels within several weeks after cessation $(1,80)$. On the other hand, serum levels of gamma-GT, alkaline phosphatase and LDH remained unaf- 
fected in all studies $(1,125,129,158)(66)$. Recently, Dickerman et al (1999) stated that elevations of serum aminotransferase levels may represent muscle damage rather than hepatic dysfunction because of the close relationship to increments of serum creatine kinase levels. They demonstrated that gamma-glutamyl transpeptidase was the most distinctive enzyme for the detection of hepatic dysfunction in exercising volunteers. Therefore, the authors recommended for evaluation of hepatic function in AAS users to determine CK an GGT levels in addition to ASAT and ALAT (66).

\section{Psyche and behaviour}

At the beginning of AAS abuse by athletes the medical society (and others) were properly concerned about the untoward physical effects. Later it became obviously that these agents exert profound effects on psyche and behaviour. From animal and human studies the relationship between endogenous male sex hormones on the one side and psychological function and/or behaviour on the other side has been assessed thoroughly. Although in several animal species a relationship between endogenous testosterone levels and aggressive behaviour was likely to be present, the findings in humans, however, were less consistent (24). From clinical studies it appeared that aggressive behaviour and endogenous testosterone levels did not correlate very well $(17,235)$. The first observations of psychological function alterations due to AAS abuse were in case-reports describing athietes abusing huge amounts of such steroids (13, 40, 168, 169). For example, self-administration of AAS was associated with the occurrence of schizophrenia (13), steroid dependence (40), affective and psychotic symptoms (168) and homicide and near-homicide (169). More recently, many other psychological changes due to AAS abuse have been reported in the literature $(24,172,233)$.

One of the first reports investigating the effects of AAS on psyche and behaviour in athletes was performed by Lindstrom et al (1990). In their survey male bodybuilders reported mood changes and an increased libido when on steroids (131). Many manuscripts have been published since then. Self-reports of athletes as well as survey studies indicated that AAS users seem to be subject to an increase of aggression and / or hostility $(23,50,51$, $62,93,121,152,161,163,164,170,208)$. On the other hand, some investigations did not observe such a relationship $(33,137)$ and in one study female strength athletes were found to demonstrate even lower hostility with anabolic steroids (22).

Mood disturbances may occur among AAS users, although some researchers could not demonstrate effects on $\operatorname{mood}(33,42,45,131,161,163,170,208)$. Mood changes associated with AAS abuse included depression $(42,163,164$, 170), paranoia (164), (hypo-) mania $(170,208)$, and psychotic features (164). 
Some studies indicated that the occurrence and seriousness of mood disturbances are dose dependent $(170,208)$.

The relationship between body image and AAS use were subject of a small number of studies. These investigations demonstrated that AAS users are often dissatisfied with their body and posses low self-esteem (35). This may lead to the so called "reverse anorexia syndrome" $(42,171,191)$. This syndrome refers to athletes (in general bodybuilders are involved) who believe to have a small and disproportionate body and these subjects, therefore, might be more susceptible for starting AAS $(42,171)$. Furthermore, AAS using bodybuilders and weightlifters were found to posses a more narcistic personality compared to non-users (172).

During the last decade AAS dependence and the withdrawal effects of AAS have been subject to research. Brower et al (1991) reported that more than half of the AAS users demonstrated symptoms consistent with a diagnosis of dependence (41). More recent research, however, could not confirm such a high percentage addictive AAS users, but reported that AAS dependence may exist in approximately $25 \%$ of the users $(137,149,170)$. Withdrawal effects seems to occur only in a small number of the AAS users $(42,149,168)$.

\section{Other adverse effects}

First, AAS may disturb endocrine function. Deregulation of glucose metabolism secondary to insulin resistance $(54,231)$ and impairment of thyroid function $(8$, 64 ) have been observed. Second, the effects on skin may be profound. Kiraly et al. found enlargement of sebaceous glands, increase of sebaceous production and elevation of skin surface lipid cholesterol levels due to AAS $(113-115,192)$. Furthermore, these agents were found to reduce immune function (47) and to affect the haemostatic system $(71,73,102,162)$, although the clinical relevance of these observations needs to be determined yet.

Since strength athletes are used to self-administer huge amounts of these drugs it is inevitable that dramatic side-effects may occur in some subjects. In case-studies AAS have been reported to affect the musculoskeletal system by causing bone fractures $(211)$, tendon pathology $(127)(123,132,199)$ and rhabdomyolysis $(36,92,139)$. In several case-reports dermatological sideeffects have been reported including occurrence of acne vulgaris(56), acne fulminans (143), hereditary coproporphyria (126), linear keloid formation (193) and exacerbations of psoriasis (128). The actual side effects have to be established since, contradictory, in experimental clinical trials AAS are used in the treatment of several dermatological disease conditions (96). Alterations of the prostate and bladder have been attributed to these steroids (227). Also, several malignant diseases in young athletes have been associated with AAS use, e.g. Wilms' tumor (173), renal cell carcinoma (44) and adenocarcinoma of the prostate (180). Even very rare disease conditions, like sleep apneu syndrome (Pickwick disease), were linked to AAS administration too (188). 


\section{MECHANISM OF ACTION}

The mechanism of action of AAS may differ between compounds due to variations in the steroid molecules. These variations are responsible for differences in the specificity of binding to receptor proteins or to interaction with various steroid metabolising enzymes $(27,59,229)$. With respect to interactions with intracellular steroid receptor proteins several pathways can be distinguished $(27,184)$. First, binding with high affinity to androgen receptors and these steroids are therefore recognised as strong androgens (e.g. 19-nortestosterone, methenolone) $(184,218)$. Second, several compounds are characterised by binding with low affinity to androgens and therefore are weak androgenic substances (e.g. stanozolol, fluoxymesterolone) (184, 218). Third, some AAS (e.g. oxymetholone) do not bind to the androgen receptor at all (184). These steroids are supposed to act after biotransformation to more active compounds or via alternative mechanisms of action. Furthermore, it has been established for AAS that other mechanisms may be involved $(134,229)$.

The enzyme 5-alpha-reductase has been recognised to play an important role in the mechanism of action. This enzyme converts AAS into the more active compound dihydrotestosterone (229). After diffusion into the cells of target tissue AAS may be subject to two main pathways. The steroid binds directly or after conversion to the more active compound dihydrotestosterone to specific receptors for androgens (218). This results in the formation of a steroid-receptor complex in the cell nucleus. The steroidreceptor complex stimulates the protein synthesis by interaction with RNA and DNA $(49,228)$.

The most important organ systems with high 5-alpha-reductase activity are the male accessory sex glands, the skin, the prostate, the lungs, the brain, fat cells and bone. Therefore, these organs posses a high affinity to androgenic rather than to anabolic compounds. Conversely, there are organs (e.g. heart and skeletal muscle) that posses a low 5-alpha-reductase activity and exert a stronger response to anabolic substances.

Another enzyme, aromatase, seems to play a limited role under normal circumstances. This enzyme is located inside the cell and is responsible for conversion of AAS in the female sex hormones, like estradiol and oestron. Female sex hormones bind to oestrogen receptors and form estrogenreceptor complexes. These complexes exert their effects in fat tissue, Leydig and Sertoli tissue and in some nuclei in the central nervous system. This mechanisms will probably only be activated when the androgen receptor system is saturated by the circulating androgens and anabolic steroids. On the other hand, AAS may act antagonistic to estrogens when supraphysiological serum levels of AAS are present. This will lead to saturation and down-regulation of the androgen receptors. The excess of AAS will then try to bind to the estrogen receptors in competition with the estrogens avail- 
able. Therefore, the net outcome of these two conflicting pathways is not exactly predictable.

Complementary to the competitive antagonism with the estrogen receptors a similar competitive antagonism has been described with respect to glucocorticoid receptors (142). Glucocorticoid are substances with catabolic properties that will be released in the serum as a result of (strong) physical or mental stress. Examples are exercise training, surgery, psychological problems etc. By binding to the glucocorticoid receptors the AAS are able to counteract the breakdown of proteins by the glucocorticoids (99). This competitive antagonism may also play a role in the treatment of osteoporosis by reduction of bone breakdown and stimulation of bone formation. Recently, evidence has come available that AAS stimulate proliferation and differentiation of osteoblastic cells and have the capacity to counteract bone breakdown. Testosterone has been found to correct calcium balance and bone formation, as well as to play a role in the reduction of bone resorption.

Finally, AAS may influence the haematological system. Two main pathways have been considered to be available. First, anabolic steroids stimulate erythropoiesis directly and erythropoietin synthesis in the kidney (32). Second, the effects of androgens have been demonstrated to promote erythropoietic stem cell differentiation and to increase the sensitivity of erythroid progenitors $(26,31)$. Since the introduction of recombinant human erythropoietin in the 1980s the administration of AAS for the these effects has been retreated in the background both by clinicians and athletes.

\section{CONCLUSIONS AND FUTURE DIRECTIONS}

It has been well established that in humans AAS may increase muscular strength and lean body mass in athletes, whereas endurance performance and fat mass appear to be unaffected by these substances. Because of the wide-spread use of large doses of AAS the untoward effects are of great concern. The effects on the reproductive system appear to be very profound and may lead to libido changes and (temporary) infertility. AAS affect risk factors of cardiovascular disease unfavourably, especially of the lipoprotein profile. The effects on blood pressure and cardiac structure and function are still subject of research. Unlike the amounts of AAS used by athletes the adverse effects on liver function seems to be limited. Recently, it has become apparent that AAS may exert strong effects on psyche and behaviour.

Future research should primarily focus on the short-term and long-term effects of intermittent AAS abuse on health, the effects on health after AAS withdrawal as well as on the long-term health effects in recalcitrant AAS users. Research of alterations of the reproductive system, the cardiovascular system, as well as of psyche and behaviour should have a high priority. 


\section{REFERENCES}

1. Alen, M. Androgenic steroid effects on liver and red cells. Br J Sports Med 19: 15-20, 1985.

2. Alen, $\mathbf{M}$., and $K$. Hakkinen. Androgenic steroid effects on serum hormones and on maximal force development in strength athletes. J Sports Med Phys Fitness 27: 38-46, 1987.

3. Alen, M., K. Hakkinen, and P. V. Komi. Changes in muscle power production capacity in power athletes self-administering androgenic anabolic steroids. Duodecim 100: 1096-104, 1984.

4. Alen, M., K. Hakkinen, and P. V. Komi. Changes in neuromuscular performance and muscle fiber characteristics of elite power athletes self-administering androgenic and anabolic steroids. Acta Physiol Scand 122: 535-44, 1984.

5. Alen, M., and P. Rahkila. Anabolic-androgenic steroid effects on endocrinology and lipid metabolism in athletes. Sports Med 6: 327-32, 1988.

6. Alen, M., and P. Rahkila. Reduced high-density lipoprotein-cholesterol in power athletes: use of male sex hormone derivates, an atherogenic factor. Int J Sports Med 5: 341-2, 1984.

7. Alen, M., P. Rahkila, and J. Marniemi. Serum lipids in power athletes self-administering testosterone and anabolic steroids. Int J Sports Med 6: 139-44, 1985.

8. Alen, M., P. Rahkila, M. Reinila, and R. Vihko. Androgenic-anabolic steroid effects on serum thyroid, pituitary and steroid hormones in athletes. Am J Sports Med 15: 357-61, 1987.

9. Alen, M., M. Reinila, and R. Vihko. Response of serum hormones to androgen administration in power athletes. Med Sci Sports Exerc 17: 354-9, 1985.

10. Alen, $\mathbf{M}$., and J. Suominen. Effect of androgenic and anabolic steroids on spermatogenesis in power athletes. Int J Sports Med: 5(suppl.): 189-192, 1984.

11. Anderson, R. A., A. M. Wallace, and F. C. Wu. Comparison between testosterone enanthate-induced azoospermia and oligozoospermia in a male contraceptive study. III. Higher 5 alpha-reductase activity in oligozoospermic men administered supraphysiological doses of testosterone. J Clin Endocrinol Metab 81: 902-8, 1996.

12. Anderson, R. A., and F. Wu. Comparison between testosterone enanthate-induced azoospermia and oligozouspermia in a male contraceptive study. II. Pharmacokinetics and pharmacodynamics of once weekly administration of testosterone enanthate. $J$ Clin Endocrinol Metab 81: 896-901, 1996.

13. Annitto, W. J., and W. A. Layman. Anabolic steroids and acute schizophrenic episode. J Clin Psychiatry 41: 143-4, 1980.

14. Appell, H.-J., S. Forsberg, and W. Hollmann. Satellite cell activation in human skeletal muscle after training: evidence for muscle fiber neoformation. Int J Sports Med 9: 297-299, 1988.

15. Appell, H.-J., B. Heller-Umpfenbach, M. Feraudi, and H. Weicker. Ultrastructural and morphometric investigations on the effects of training and administratio of anabolic steroids on the myocardium of guinea pigs. Int J Sports Med 4: 268-274, 1983.

16. Applebaum-Bowden, D., S. M. Haffner, and W. R. Hazzard. The dyslipoproteinemia of anabolic steroid therapy: increase in hepatic triglyceride lipase precedes the decrease in high density lipoprotein cholesterol. Metabolism 36: 949-952, 1987.

17. Archer, J. The influence of testosterone and human aggression. BrJPsychol 82: 1-28, 1991.

18. Ariel, G. The effect of anabolic steroid upon skeletal muscle contractile force. J Sports Med Phys Fitness 13: 187-90, 1973.

19. Ariel, G. Prolonged effects of anabolic steroid upon muscular contractile force. Med Sci Sports 6: 62-4, 1974.

20. Ariel, G. Residual effect of an anabolic steroid upon isotonic muscular force. J Sports Med Phys Fitness 14: 103-11, 1974.

21. Ariel, G., and W. Saville. Anabolic steroids: the physiological effects of placebos. Medicine and Science in Sports 4: 124-126, 1972. 
22. Bahrke, M. S., and R. H. Strauss. Selected psychological characteristics of female anabolic-androgenic (AAS) users (abstract). Med Sci Sports Exerc 24: S136, 1992.

23. Bahrke, M. S., J. E. Wright, R. H. Strauss, and D. H. Catlin. Psychological moods and subjectively perceived behavioral and somatic changes accompanying anabolic-androgenic steroid use. Am J Sports Med 20: 717-24, 1992.

24. Bahrke, M. S., C. r. Yesalis, and J. E. Wright. Psychological and behavioural effects of endogenous testosterone and anabolic-androgenic steroids. An update. Sports Med 22: 367-90, 1996.

25. Baldo-Enzi, G., F. Giada, G. Zuliani, L. Baroni, E. Vitale, G. Enzi, P. Magnanini, and R. Fellin. Lipid and apoprotein modifications in body builders during and after self-administration of anabolic steroids. Metabolism 39: 203-8, 1990.

26. Ballal, S. H., D. T. Domoto, D. C. Polack, P. Marciulonis, and K. J. Martin. Androgens potentiate the effects of erythropoietin in the treatment of anemia of end-stage renal disease. Am J Kidney Dis 17: 29-33, 1991.

27. Bartsch, W. Anabolic steroids - action on cellular level. In: Anabolic-androgenic steroids towards the year 2000 , edited by H. Kopera. Vienna: Blackwell-MZV, 1993, p. 29-39.

28. Behrendt, H. Effect of anabolic steroids on rat heart muscle cells. I. Intermediate filaments. Cell Tissue Res 180: 303-15, 1977.

29. Behrendt, H., and H. Boffin. Myocardial cell lesions caused by an anabolic hormone. Cell Tissue Res 181: 423-6, 1977.

30. Berger, J. R., L. Pall, and D. Winfield. Effect of anabolic steroids on HIV-related wasting myopathy. South Med J 86: 865-6, 1993.

31. Berns, J. S., M. R. Rudnick, and R. M. Cohen. Androgens potentiate the effects of erythropoietin in the treatment of anemia of end-stage renal disease [letter; comment]. Am J Kidney Dis 18: 143, 1991.

32. Berns, J. S., M. R. Rudnick, and R. M. Cohen. A controlled trial of recombinant human erythropoietin and nandrolone decanoate in the treatment of anemia in patients on chronic hemodialysis. Clin Nephrol 37: 264-7, 1992.

33. Bhasin, S., T. W. Storer, N. Berman, C. Callegri, B. Clevenger, J. Phillips, T. J. Bunnell, R. Tricker, A. Shirazi, and R. Casaburi. The effects of supraphysiologic doses of testosterone on muscle size and strength in normal men. New Engl J Med 335: 1-7, 1996.

34. Bijlsma, J. W., S. A. Duursma, J. H. Thijssen, and O. Huber. Influence of nandrolondecanoate on the pituitary-gonadal axis in males. Acta Endocrinol Copenh 101: 108-12, 1982.

35. Blouin, A. G., and G. S. Goldfield. Body image and steroid use in male bodybuilders. International Journal of Eating Disorders 18: 159-165, 1995.

36. Bolgiano, E. B. Acute rhabdomyolysis due to body building exercise. Report of a case. $J$ Sports Med Phys Fitness 34: 76-8, 1994.

37. Boone Jr, J. B., C. P. Lambert, M. G. Flynn, T. J. Michaud, J. A. Rodriguez- Zayas, and F. F. Andres. Resistance exercise effects on plasma cortisol, testosterone and creatine kinase activity in anabolic-androgenic steroid users. Int J Sports Med 11: 293-7, 1990.

38. Bowers, R. W., and J. P. Reardon. Effects of methandrostenolone (Dianabol) on strength development and aerobic capacity. Med Sci Sports 4: 54 (abstract), 1972.

39. Bronson, F. H., and C. M. Matherne. Exposure to anabolic androgenic steroids shortens life span of male mice. Med Sci Sports Exerc. May 29: 615-619, 1997.

40. Brower, K. J., F. C. Blow, G. A. Eliopulos, and T. P. Beresford. Anabolic androgenic steroids and suicide [letter]. Am J Psychiatry 146: 1075, 1989.

41. Brower, K. J., F. C. Blow, J. P. Young, and E. M. Hill. Symptoms and correlates of anabolic-androgenic steroid dependence. British Journal of Addiction 86: 759-768, 1991.

42. Brower, K. J., G. A. Eliopulos, F. C. Blow, D. H. Catlin, and T. P. Beresford. Evidence for physical and psychological dependence on anabolic-androgenic steroids in eight weightlifters. Am J Psychiatry 147: 510-512, 1990. 
43. Brown, B. S., and A. H. Pilch. The effects of exercise and dianabol upon selected performances and physiological parameters in the male rat. Med Sci Sports 4: 159-65, 1972.

44. Bryden, A. A., P. J. Rothwell, and P. H. O'Reilly. Anabolic steroid abuse and renal-cell carcinoma [letter]. Lancet 346: 1306-7, 1995.

45. Burnett, K. F., and M. E. Kleiman. Psychological characteristics of adolescent steroid users. Adolescence 29: 81-9, 1994.

46. Cabasso, A. Peliosis hepatis in a young adult bodybuilder. Med Sci Sports Exerc 26: 2-4, 1994.

47. Calabrese, L. H., S. M. Kleiner, B. P. Barna, C. I. Skibinski, D. T. Kirkendall, R. G. Lahita, and J. A. Lombardo. The effects of anabolic steroids and strength training on the human immune response. Med Sci Sports Exerc 21: 386-92, 1989.

48. Casner, S. J., R. G. Early, and B. R. Carlson. Anabolic steroid effects on body composition in normal young men. J Sports Med Phys Fitness 11: 98-103, 1971.

49. Chang, C., A. Saltzman, S. Yeh, W. Young, E. Keller, H. J. Lee, C. Wang, and A. Mizokami. Androgen receptor: An overview. Crit Rev Eukaryotic Gene Expr 5: 97-125, 1995.

50. Choi, P. Y., A. C. Parrott, and D. Cowan. High-dose anabolic steroids in strength athletes: Effects upon hostility and aggression. Human Psychopharmacology Clinical and Experimental 5: 349-356, 1990.

51. Choi, P. Y., and H. J. Pope. Violence toward women and illicit androgenic-anabolic steroid use. Ann Clin Psychiatry 6: 21-5, 1994.

52. Climstein, M., P. O'Shea, C. Zauner, and H. Neuman. The effects of anabolic steroids on left ventricular performance of elite powerlifters and endurance athletes (abstract). Med Sci Sports Exerc 23: S 64, 1990.

53. Cohen, J. C., W. M. Faber, A. Benade, and T. D. Noakes. Altered serum lipoprotein profiles in male and female power lifters ingesting anabolic steroids. Physician Sportsmed 14: 131-136, 1986.

54. Cohen, J. C., and R. Hickman. Insulin resistance and diminished glucose tolerance in powerlifters ingesting anabolic steroids. J Clin Endocrinol Metab 64: 960-3, 1987.

55. Cohen, J.C., T. D. Noakes, and A. Benade. Hypercholesterolemia in male power lifters using anabolic-androgenic steroids. Physician Sportsmed 16: 49-56, 1988.

56. Collins, P., and J. A. Cotterill. Gymnasium acne. Clin Exp Dermatol 20, 1995.

57. Costill, D. L., D. R. Pearson, and W. J. Fink. Anabolic steroid use among athletes: changes in HDL-C levels. Physician Sportsmedicine 12: 113-117, 1984.

58. Creagh, T.M., A. Rubin, and D. J. Evans. Hepatic tumours induced by anabolic steroids in an athlete. J Clin Pathol 41: 441-3, 1988.

59. Creutzberg, E. C., and A. M. Schols. Anabolic steroids. Curr Opin Clin Nutr Metab Care 2: 243-53, 1999.

60. Crist, D. M., G. T. Peake, and P. J. Stackpole. Lipemic and lipoproteinemic effects of natural and synthetic androgens in humans. Clin Exper Pharmacol Physiol 13: 513-518, 1986.

61. Crist, D. M., P. J. Stackpole, and G. T. Peake. Effects of androgenic-anabolic steroids on neuromuscular power and body composition. J Appl Physiol 54: 366-70, 1983.

62. De Boer, A., S. F. van Haren, F. Hartgens, D. de Boer, and A. J. Porsius. Onderzoek naar het gebruik van prestatieverhogende middelen bij bodybuilders in Nederland. Nederlands Centrum voor Dopingvraagstukken, Universiteit Utrecht, 1996.

63. De Piccoli, B., F. Giada, A. Benettin, F. Sartori, and E. Piccolo. Anabolic steroid use in body builders: an echocardiographic study of left ventricle morphology and function. Int J Sports Med 12: 408-12, 1991.

64. Deyssig, R., and $\mathbf{M}$. Weissel. Ingestion of androgenic-anabolic steroids induces mild thyroidal impairment in male body builders. J Clin Endocrinol Metab 76: 1069-71, 1993.

65. Dickerman, R. D., W. J. McConathy, F. Schaller, and N. Y. Zachariah. Cardiovascular complications and anabolic steroids [letter]. Eur Heart J 17, 1996. 
66. Dickerman, R. D., R. M. Pertusi, N. Y. Zachariah, D. R. Dufour, and W. J. McConathy. Anabolic steroid-induced hepatotoxicity: is it overstated? Clin J Sport Med 9: 34-9, 1999.

67. Dickerman, R. D., F. Schaller, I. Prather, and W. J. McConathy. Sudden cardiac death in a 20-year-old bodybuilder using anabolic steroids. Cardiology 86: 172-3, 1995.

68. Dickerman, R. D., F. Schaller, N. Y. Zachariah, and W. J. McConathy. Left ventricular size and function in elite bodybuilders using anabolic steroids. Clin J Sport Med 7: 90-3, 1997.

69. Durstine, J. L., and W. L. Haskell. Effects of exercise training on plasma lipids and lipoproteins. In: Exercise and Sport Sciences Reviews, edited by J. O. Holloszy. Baltimore: Williams \& Wilkins, 1994, p. 477-522.

70. Fahey, T. D., and C. H. Brown. The effects of an anabolic steroid on the strength, body composition, and endurance of college males when accompanied by a weight training program. Med Sci Sports 5: 272-6, 1973.

71. Ferenchick, G., D. Schwartz, M. Ball, and K. Schwartz. Androgenic-anabolic steroid abuse and platelet aggregation: a pilot study in weight lifters. Am J Med Sci 303: 78-82, 1992.

72. Ferenchick, G. S., and S. Adelman. Myocardial infarction associated with anabolic steroid use in a previously healthy 37-year-old weight lifter. Am Heart J 124: 507-8, 1992.

73. Ferenchick, G. S., S. Hirokawa, E. F. Mammen, and K. A. Schwartz. Anabolic-androgenic steroid abuse in weight lifters: evidence for activation of the hemostatic system. Am J Hematol 49: 282-8, 1995.

74. Ferreira, I. M., I. T. Verreschi, L. E. Nery, R. S. Goldstein, N. Zamel, D. Brooks, and J. R. Jardim. The influence of 6 months of oral anabolic steroids on body mass and respiratory muscles in undernourished COPD patients. Chest 114: 19-28, 1998.

75. Forbes, G. B., C. R. Porta, B. E. Herr, and R. C. Griggs. Sequence of changes in body composition induced by testosterone and reversal of changes after drug is stopped. JAMA 267: 397-399, 1992.

76. Fowler, W. M., G. W. Gardner, and G. H. Egstrom. Effect of an anabolic steroid on physical performance of young men. J. Appl. Physiol. 20: 1038-1040, 1965.

77. Fox, R. W. Update on urticaria and angioedema. Allergy Proc 16: 289-292, 1995.

78. Freed, D., A. J. Banks, and D. Longson. Anabolic steroids in athletics. Br Med J 3, 1972.

79. Freed, D. L., and A. J. Banks. A double-blind crossover trial of methandienone (Dianabol, CIBA) in moderate dosage on highly trained experienced athletes. Br J Sports Med 9: 78-82, 1975.

80. Freed, D. L. J., A. J. Banks, D. Longson, and D. M. Burley. Anabolic steroids in athletics: crossover double-blind trial on weightlifters. Br. Med. J. 2: 471-473, 1975.

81. Friedl, K. E. Effects of anabolic steroids on physical health. In: Anabolic steroids in sport and exercise, edited by C. E. Yesalis. Champaign: Human Kinetics, 1993, p. 107-150.

82. FriedI, K. E., J. R. Dettori, C. J. Hannan, T. H. Patience, and S. R. Plymate. Comparison of the effects of high dose testosterone and 19-nortestosterone to a replacement dose of testosterone on strength and body composition in normal men. J Steroid Biochem Mol Biol 40: 607-12, 1991.

83. Friedl, K. E., C. J. Hannan, R. E. Jones, and S. R. Plymate. High-density lipoprotein cholesterol is not decreased if an aromatizable androgen is administered. Metabolism 39:: 69-74, 1990.

84. Friedl, K. E., and C. E. Yesalis. Self-treatment of gynecomastia in bodybuilders who use anabolic steroids. Physician Sportsmed 17: 67-79, 1989.

85. Glazer, G., and A. L. Suchman. Lack of demonstrated effect of nandrolone on serum lipids. Metabolism 43: 204-10, 1994.

86. Gold, J., H. A. High, Y. Li, H. Michelmore, N. J. Bodsworth, R. Finlayson, V. L. Furner, B. J. Allen, and C. J. Oliver. Safety and efficacy of nandrolone decanoate for treatment of wasting in patients with HIV infection. Aids 10: 745-752, 1996. 
87. Golding, L. A., J. E. Freydinger, and S. S. Fishel. The effect of an androgenic-anabolic steroid and a protein supplement on size, strength, weight, and body composition in athletes. In: The medical aspects of sports, edited by T. Craig, 1974, p. 25-8.

88. Golding, L. A., J. E. Freydinger, and S. S. Fishel. Weight, size and strength - unchanged with steroids. Physician Sportsmed 2: 39-43, 1974.

89. Goldman, B. Liver carcinoma in an athlete taking anabolic steroids [letter]. J Am Osteopath Assoc 85, 1985.

90. Gragera, R., A. Saborido, F. Molano, L. Jimenez, E. Muniz, and A. Megias. Ultrastructural changes induced by anabolic steroids in liver of trained rats. Histol Histopathol 8: 449-55, 1993.

91. Griggs, R. C., W. Kingston, R. F. Jozefowicz, B. E. Herr, G. Forbes, and D. Halliday. Effect of testosterone on muscle mass and muscle protein synthesis. J Appl Physiol 66: 498-503, 1989.

92. Hageloch, W., H. J. Appell, and H. Weicker. Rhabdomyolyse bei Bodybuilder unter Anabolika-Einnahme. Sportverletz Sportschaden 2: 122-5, 1988.

93. Hannan, C. J., K. E. Friedl, A. Zold, T. M. Kettler, and S. R. Plymate. Psychological and serum homovanillic acid changes in men administered androgenic steroids. Psychoneuroendocrinology 16: 335-43, 1991.

94. Hartgens, F., K. Hamulyak, C. Pernot, K. Depuydt, T. Gordijn, H. A. Keizer, and H. Kuipers. Effects of high doses androgenic-anabolic steroids on haematologic parameters in bodybuilders. 8th FIMS European Sports Medicine Congress, Granada (Spain), 1995, p. 80.

95. Hartgens, F., H. Kuipers, J. Wijnen, and H. A. Keizer. Body composition, cardiovascular risk factors and liver function in long term androgenic-anabolic steroids using bodybuilders three months after drug withdrawal. Int. J. Sports Med. 17: 429-433, 1996.

96. Helfman, T., and V. Falanga. Stanozolol as a novel therapeutic agent in dermatology. $J \mathrm{Am}$ Acad Dermatol 33: 254-8, 1995.

97. Hervey, G. R., I. Hutchinson, A. V. Knibbs, L. Burkinshaw, P. R. Jones, N. G. Norgan, and M. J. Levell. "Anabolic" effects of methandienone in men undergoing athletic training. Lancet 2 : 699-702, 1976.

98. Hervey, G. R., A. V. Knibbs, L. Burkinshaw, D. 8. Morgan, P. R. Jones, D. R. Chettle, and D. Vartsky. Effects of methandienone on the performance and body composition of men undergoing athletic training. Clin Sci 60: 457-61, 1981.

99. Hickson, R. C., S. M. Czerwinski, M. T. Falduto, and A. P. Young. Glucocorticoid antagonism by exercise and androgenic-anabolic steroids. Med Sci Sports Exerc 22: 331-340, 1990.

100. Hinterberger, W., and $\mathbf{H}$. Vierhapper. Anabolic steroids and blood cell production. Wien Med Wochenschr 143: 380-2, 1993.

101. Holma, P. Effect of an anabolic steroid (metandienone) on central and peripheral blood flow in well-trained male athletes. Ann Clin Res 9: 215-21, 1977.

102. Huie, M. J. An acute myocardial infarction occurring in an anabolic steroid user (case study). Med Sci Sports Exerc 26: 408-13, 1994.

103. Hurley, B. F., D. R. Seals, J. M. Hagberg, A. C. Goldberg, S. M. Ostrove, J. O. Holloszy, W. G. Wiest, and A. P. Goldberg. High-density-lipoprotein cholesterol in bodybuilders $\mathrm{V}$ powerlifters. Negative effects of androgen use. Jama 252: 507-13, 1984.

104. International Olympic Committee. Statistics 1997 of the IOC accredited laboratories. Lausanne:, 1998.

105. Ishak, K. G. Hepatic lesions caused by anabolic and contraceptive steroids. Semin Liver Dis 1: 116-28, 1981.

106. Ishak, K. G., and H. J. Zimmerman. Hepatotoxic effects of the anabolic/androgenic steroids. Semin Liver Dis 7: 230-236, 1987. 
107. Jakob, E., R. Hoffman, F. Fuchs, J. Stüwe-Schlobies, M. Donike, and J. Keul. Testosteronapplikation und Leistungsfähigkeit bei Skilanglaufern. Deutsche Zeitschrift für Sportmedizin 39: 41-45, 1988.

108. Johnson, L. C., G. Fisher, L. J. Silvester, and C. C. Hofheins. Anabolic steroid: effects on strength, body weight, oxygen uptake and spermatogenesis upon mature males. Med Sci Sports 4: 43-5, 1972.

109. Johnson, L. C., and J. P. O'Shea. Anabolic steroid: effects on strength development. Science 164: 957-9, 1969.

110. Johnson, L. C., E. S. Roundy, P. E. Allsen, A. G. Fisher, and L. F. Silvester. Effect of anabolic steroid treatment on endurance. Med Sci Sports 7: 287-9, 1975.

111. Karhunen, M. K., M. P. Ramo, and R. Kettunen. Anabolic steroids alter the haemodynamic effects of endurance training and deconditioning in rats. Acta Physiol Scand 133: 297-306, 1988.

112. Keul, J., B. Deus, and W. Kindermann. Anabole Hormone: Schädigung, Leistungsfähigkeit und Stoffwechsel. Med Klin 71: 497-503, 1976.

113. Kiraly, C. L. Androgenic-anabolic steroid effects on serum and skin surface lipids, on red cells, and on liver enzymes. Int I Sports Med 9: 249-52, 1988.

114. Kiraly, C. L., M. Alen, J. Korvola, and M. Horsmanheimo. The effect of testosterone and anabolic steroids on the skin surface lipids and the population of Propionibacteria acnes in young postpubertal men. Acta Derm Venereol Stockh 68: 21-6, 1988.

115. Kiraly, C. L., Y. Collan, and M. Alen. Effect of testosterone and anabolic steroids on the size of sebaceous glands in power athletes. Am J Dermatopathol 9: 515-9, 1987.

116. Kleiner, S. M., L. H. Calabrese, K. M. Fiedler, H. K. Naito, C. I. Skibinski, and K. C. t. F. K. Fielder. Dietary influences on cardiovascular disease risk in anabolic steroid-using and nonusing bodybuilders. J Am Coll Nutr 8: 109-19, 1989.

117. Kochakian, C. D. Anabolic-androgenic steroids. Berlin: Springer Verlag, 1976.

118. Kochakian, C. D. History, chemistry and pharmacodynamics of anabolic-androgenic steroids. Wien Med Wochenschr 143: 359-63, 1993.

119. Kopera, $\mathbf{H}$. The history of anabolic steroids and a review of clinical experience with anabolic steroids. Acta Endocrinol Supp/ Copenh 271: 11-8, 1985.

120. Kosaka, A., H. Takahashi, Y. Yajima, M. Tanaka, K. Okamura, R. Mizumoto, and K. Katsuta. Hepatocellular carcinoma associated with anabolic steroid therapy: Report of a case and review of the Japanese literature. J Gastroenterol 31: 450-454, 1996.

121. Kouri, E. M., S. E. Lukas, J. H. Pope, and P. S. Oliva. Increased aggressive responding in male volunteers following the administration of gradually increasing doses of testosterone cypionate. Drug Alcohol Depend 40: 73-79, 1995.

122. Kouri, E. M., J. H. Pope, and P. S. Oliva. Changes in lipoprotein-lipid levels in normal men following administration of increasing doses of testosterone cypionate. Clin I Sport Med 6 : 152-157, 1996.

123. Kramhoft, $\mathbf{M}$., and S. Solgaard. Spontaneous rupture of the extensor pollicis longus tendon after anabolic steroids. J Hand Surg Br 11: 87, 1986.

124. Kuipers, H., B. F. Peeze, F. Hartgens, J. A. Wijnen, and H. A. Keizer. Muscle ultrastructure after strength training with placebo or anabolic steroid. Can J Appl Physiol 18: 189-96, 1993.

125. Kuipers, H., J. A. G. Wijnen, F. Hartgens, and S. M. M. Willems. Influence of anabolic steroids on body composition, blood pressure, lipid profile and liver function in bodybuilders. Int I Sports Med 12: 413-418, 1991.

126. Lane, P. R., K. L. Massey, L. J. Worobetz, M. N. Jutras, and P. R. Hull. Acute hereditary coproporphyria induced by the androgenic/anabolic steroid methandrostenolone (Dianabol). J Am Acad Dermatol 30: 308-12, 1994. 
127. Laseter, J. T., and J. A. Russell. Anabolic steroid-induced tendon pathology: a review of the literature. Med Sci Sports Exerc 23: 1-3, 1991.

128. Lear, J. T., and J. English. Anabolic steroids and psoriasis exacerbation [2]. Br J Dermatol 134: 809, 1996.

129. Lenders, J. W., P. N. Demacker, J. A. Vos, P. L. Jansen, A. J. Hoitsma, t. L. A. van, and T. Thien. Deleterious effects of anabolic steroids on serum lipoproteins, blood pressure, and liver function in amateur body builders. Int J Sports Med 9: 19-23, 1988.

130. Liang, M. T., D. J. Paulson, S. J. Kopp, T. Glonek, P. Meneses, L. W. Gierke, and F. N. Schwartz. Effects of anabolic steroids and endurance exercise on cardiac performance. Int $J$ Sports Med 14: 324-9, 1993.

131. Lindstrom, M., A. L. Nilsson, P. L. Katzman, L. Janzon, and J. F. Dymling. Use of anabolic-androgenic steroids among body builders-frequency and attitudes.J/ntern Med 227: 407-11, 1990.

132. Liow, R., and S. Tavares. Bilateral rupture of the quadriceps tendon associated with anabolic steroids. Br J Sports Med 29: 77-79, 1995.

133. Lippi, G., G. Guidi, O. Ruzzenente, V. Braga, and S. Adami. Effects of nandrolone decanoate (Decadurabolin) on serum $L p(a)$, lipids and lipoproteins in women with postmenopausal osteoporosis. Scand J Clin Lab Invest 57: 507-11, 1997.

134. Lombardo, J. A. Anabolic-androgenic steroids. Nida Res Monogr 102: 60-73, 1990.

135. Loughton, S. J., and R. O. Ruhling. Human strength and endurance responses to anabolic steroid and training. J Sports Med Phys Fitness 17: 285-96, 1977.

136. Luke, J. L., A. Farb, R. Virmani, and R. H. Sample. Sudden cardiac death during exercise in a weight lifter using anabolic androgenic steroids: pathological and toxicological findings. $J$ Forensic Sci 35: 1441-7, 1990.

137. Malone, D. J., R. J. Dimeff, J. A. Lombardo, and R. H. Sample. Psychiatric effects and psychoactive substance use in anabolic-androgenic steroid users. Clin J Sport Med 5: 25-31, 1995.

138. Martikainen, H., M. Alen, P. Rahkila, and R. Vihko. Testicular responsiveness to human chorionic gonadotrophin during transient hypogonadotrophic hypogonadism induced by androgenic/anabolic steroids in power athletes. J Steroid Biochem 25: 109-12, 1986.

139. Masar, P.P., S. Kramer, and M. Vogt. Rhabdomyolysis in body building. Report of a case and literature review. Schweiz Rundsch Med Prax 81: 1055-8, 1992.

140. Matsumine, H., K. Hirato, T. Ynaihara, T. Tamada, and m. Yoshida. Aromatization by skeletal muscle. J Clin Endocrinol Metab 63: 717-720, 1986.

141. Mauss, J., G. Börsch, K. Bormacher, E. Richter, G. Leyendecker, and W. Nocke. Effect of long-term testosterone oenanthate administration on male reproductive function: clinical evaluation, serum $\mathrm{FSH}, \mathrm{LH}$, testosterone, and seminal fluid analyses in normal men. Acta Endocrinol 78: 373-384, 1975.

142. Mayer, M., and F. Rosen. Interaction of anabolic steroids with glucocorticoid receptor sites in rat muscle cytosol. Am J Physiol 229: 1381-1386, 1975.

143. Mayerhausen, W., and B. Riebel. Acne fulminans following use of anabolic steroids. $Z$ Hautkr 64: 875-6, 1989.

144. McKillop, G., F. C. Ballantyne, W. Borland, and D. Ballantyne. Acute metabolic effects of exercise in bodybuilders using anabolic steroids. Br I Sports Med 23: 186-7, 1989.

145. McKillop, G., F. C. Ballantyne, W. Borland, R. Scullion, J. W. Kay, G. S. Fell, and D. Ballantyne. The short-term metabolic effects of strenuous exercise in bodybuilders. $B r J$ Sports Med 22: 107-8, 1988.

146. McKillop, G., I. C. Todd, and D. Ballantyne. The effects of body building and anabolic steroids on left ventricular structure and function. J Cardiovasc Technol 8: 23-29, 1989.

147. McKillop, G., I. C. Todd, and D. Ballantyne. Increased left ventricular mass in a bodybuilder using anabolic steroids. Br J Sports Med 20: 151-2, 1986. 
148. Melchert, R. B., and A. A. Welder. Cardiovascular effects of androgenic-anabolic steroids. Med. Sci. Sports Exerc. 27: 1252-1262, 1995.

149. Midgley, S. J., N. Heather, and J. B. Davies. Dependence-producing potential of anabolic-androgenic steroids. Addiction Research 7: 539-550, 1999.

150. Mochizucki, R. M., and K. J. Richter. Cardiomyopathy and cerebrovascular accident associated with anabolic-androgenic steroid use. Physician and Sportsmedicine 16: 109-114, 1988.

151. Morano, 1. Influence of exercise and Dianabol on the degradation rate of myofibrillar proteins of the heart and the three fiber types of skeletal muscle of female guinea pigs. Int. J. Ssports Med. 5: 317-319, 1984.

152. Moss, H., G. Panazak, and R. Tarter. Personality, mood, and psychiatric symptoms among anabolic steroid users. Am J Addictions 1: 315-324, 1992.

153. Müller, R. W., and W. Hollmann. Akute Lipoproteibeeinflüssung durch ein anaboles Steroid bei Kraftsportlern. Deutsche Zeitschrift für Sportmedizin 39: 35-40, 1988.

154. Neild, D. Gynaecomastia in bodybuilders [comment]. Br J Clin Pract 49: 172, 1995.

155. Nieminen, M. S., M. P. Ramo, M. Viitasalo, P. Heikkila, J. Karjalainen, Mantysaari, M, and J. Heikkila. Serious cardiovascular side effects of large doses of anabolic steroids in weight lifters. Eur. Heart J. European Heart Journal 17: 1576-1583, 1996.

156. Nieschlag, E., and H.M. Behre. Testosterone: action-deficiency-substitution. Berlin: Springer Verlag, 1990.

157. O'Shea, J. P. A biochemical evaluation of the effects of stanozolol on adrenal, liver and muscle function in humans. Nutr Rep int 10: 381-388, 1974.

158. O'Shea, J. P. The effects of an anabolic steroid on dynamic strength levels of weightlifters. Nutr Rep Int 4: 363-70, 1971.

159. O'Shea, J. P., and W. Winkler. Biochemical and physical effects of an anabolic steroid in competitive swimmers and weightlifters. Nutr Rep Int 2: 351-362, 1970.

160. Palatini, P., F. Giada, G. Garavelli, F. Sinisi, L. Mario, M. Michieletto, and E. G. Baldo. Cardiovascular effects of anabolic steroids in weight-trained subjects. I Clin Pharmacol 36: 1132-40, 1996.

161. Parrott, A. C., P. Y. Choi, and M. Davies. Anabolic steroid use by amateur athletes: effects upon psychological mood states. J Sports Med Phys Fitness 34: 292-8, 1994.

162. Pernot, C., F. Hartgens, H. A. Keizer, H. Kuipers, and K. Hamulyak. Effects of self-administration of high doses androgenic-anabolic steroids on fibrinolytic activity in non elite bodybuilders. Fibrinolyse Congress, Leiden, 1996.

163. Perry, P. J., K. H. Andersen, and W. R. Yates. Illicit anabolic steroid use in athletes. A case series analysis. Am J Sports Med 18: 422-8, 1990.

164. Perry, P. J., W. R. Yates, and K. H. Andersen. Psychiatric symptoms associated with anabolic steroids: A controlled, retrospective study. Annals of Clinical Psychiatry 2: 11-17, 1990.

165. Pesola, M. K. Reversibility of the haemodynamic effects of anabolic steroids in rats. Eur J Appl Physiol 58: 125-31, 1988.

166. Peterson, G. E., and T. D. Fahey. HDL-C in five elite athletes using anbolic-androgenic steroids. Physician and Sportsmedicine 12: 120-130, 1984.

167. Pope, H. G., and D. L. Katz. Psychiatric effects of anabolic steroids. Psychiatric Annals 22: 24-29, 1992.

168. Pope, H. G. J., and D. L. Katz. Affective and psychotic symptoms associated with anabolic steroid use. Am J Psychiatry 145: 487-490, 1988.

169. Pope, H. G. J., and D. L. Katz. Homicide and near-homicide by anabolic steroid users [see comments]. J Clin Psychiatry 51: 28-31, 1990.

170. Pope, H. J., and D. L. Katz. Psychiatric and medical effects of anabolic-androgenic steroid use. A controlled study of 160 athletes. Arch Gen Psychiatry 51: 375-82, 1994. 
171. Pope, H. J., D. L. Katz, and J. I. Hudson. Anorexia nervosa and "reverse anorexia" among 108 male bodybuilders. Compr Psychiatry 34: 406-9, 1993.

172. Porcerelli, J. H., and B. A. Sandler. Narcissism and empathy in steroid users. American Journal of Psychiaty 152: 1672-1674, 1995.

173. Prat, J., G. F. Gray, P. D. Stolley, and J. W. Coleman. Wilms tumor in an adult associated with androgen abuse. Jama 237: 2322-3, 1977.

174. Rademacher, G., J. Gedrat, R. Häcker, and H. Buhl. Die Beeinflussung des Adaptationsverhalten ausgewählter Funktionssysteme von Ausdauersportlern während einer kraftbetohnten Trainingsphase durch die zusätzliche Gabe von Oral-Turinabol ${ }^{\infty}$. In: Hormonelle Regulation und psychophysische Belastung im Leistungssport, edited by $R$. Häcker and H. de Marées. Köln: Deutscher Ärzte-Verlag, 1991, p. 77-84.

175. Ramo, P. Anabolic steroids alter the haemodynamic responses of the canine left ventricle. Acta Physiol Scand 130: 209-17, 1987.

176. Ramo, P., R. Kettunen, and L. Hirvonen. The effects of anabolic steroids and endurance training on systolic time intervals in the dog. Acta Physiol Scand 129: 543-8, 1987.

177. Ramo, P., R. Kettunen, J. Timisjarvi, T. Takala, and L. Hirvonen. Anabolic steroids alter the haemodynamic effects of endurance training on the canine left ventricle. Pflugers Arch 410: 272-8, 1987.

178. Reyes, R. J., S. Zicchi, H. Hamed, M. A. Chaudary, and I. S. Fentiman. Surgical correction of gynaecomastia in bodybuilders. Br J Clin Pract 49: 177-9, 1995.

179. Riebe, D., B. Fernhall, and P. D. Thompson. The blood pressure response to exercise in anabolic steroid users. Med Sci Sports Exerc 24: 633-7, 1992.

180. Roberts, J. T., and D. M. Essenhigh. Adenocarcinoma of prostate in 40-year-old body-builder [letter]. Lancet 2, 1986.

181. Rockhold, R. W. Cardiovascular toxicity of anabolic steroids. Annu Rev Pharmacol Toxicol 33: 497-520, 1993.

182. Rozenek, R., C. H. Rahe, H. H. Kohl, D. N. Marple, G. D. Wilson, and M. H. Stone. Physiological responses to resistance-exercise in athletes self-administering anabolic steroids. $J$ Sports Med Phys Fitness 30: 354-60, 1990.

183. Ruokonen, A., M. Alen, N. Bolton, and R. Vihko. Response of serum testosterone and its precursor steroids, SHBG and CBG to anabolic steroid and testosterone self-administration in man. J Steroid Biochem 23: 33-8, 1985.

184. Saartok, T., E. Dahlberg, and J.-A. Gustafsson. Relative binding affinity of anabolic-androgenic steroids: comparison of the binding to the androgen receptors in skeletal muscle and in prostate, as well as to sex hormone-binding globuline. Endocrinology 114: 2100-2106, 1984.

185. Sachtleben, T. R., K. E. Berg, B. A. Elias, J. P. Cheatham, G. L. Felix, and P. J. Hofschire. The effects of anabolic steroids on myocardial structure and cardiovascular fitness. Med Sci Sports Exerc 25: 1240-5, 1993.

186. Salke, R. C., T. W. Rowland, and E. J. Burke. Left ventricular size and function in body builders using anabolic steroids. Med Sci Sports Exerc 17: 701-4, 1985.

187. Samuels, L. T., A. F. Henschel, and A. Keys. Influence of methyl testosterone on muscular work and creatine metabolism in normal young men. J Clin Endocr 2: 649-654, 1942.

188. Sandblom, R., A. Matsumoto, R. Schoene, and et al. Obstructive sleep apnoea by testosterone administration. New Engl J Med 308: 508-510, 1983.

189. Schols, A., P. B. Soeters, R. Mostert, R. J. Pluymers, and E. Wouters. Physiologic effects of nutritional support and anabolic steroids in patients with chronic obstructive pulmonary disease: A placebo-controlled randomized trial. Am. J. Respir. Crit. Care Med. 152: 1268-1274, 1995.

190. Schürmeyer, T., L. Belkien, U. A. Knuth, and E. Nieschlag. Reversible azoospermia induced by the anabolic steroid 19-nortestosterone. Lancet 1: 417-420, 1984. 
191. Schwerin, M. J., K. J. Corcoran, L. Fisher, D. Patterson, W. Askew, T. Olrich, and S. Shanks. Social physique anxiety, body esteem, and social anxiety in bodybuilders and self-reported anabolic steroid users. Addict Behav 21: 1-8, 1996.

192. Scott, M. d., and A. M. Scott. Effects of anabolic-androgenic steroids on the pilosebaceous unit. Cutis 50: 113-6, 1992.

193. Scott, M. J., M. r. Scott, and A. M. Scott. Linear keloids resulting from abuse of anabolic androgenic steroid drugs. Cutis 53: 41-3, 1994.

194. Sjostrom, M., J. Lexell, A. Eriksson, and C. C. Taylor. Evidence of fibre hyperplasia in human skeletal muscles from healthy young men? A left-right comparison of the fibre number in whole anterior tibialis muscles. Eur J Appl Physiol 62: 301-4, 1991.

195. Soe, K. L., M. Soe, and C. Gluud. Liver pathology associated with the use of anabolic-androgenic steroids. Liver 12: 73-9, 1992.

196. Spataro, A., G. Caselli, A. Pelliccia, A. Biffi, C. Iranquilii, F. Fernando, and G. Marcello. Anabolic steroids do not increase left ventricular mass index in well trained athletes (abstract). Med Sci Sports Exerc 24: S29, 1992.

197. Spiga, L., G. Gorrini, L. Ferraris, G. Odaglia, and G. Frassetto. Unilateral gynecomastia induced by the use of anabolic steroids. A clinical case report. Minerva Med 83: 575-80, 1992.

198. Stamford, B. A., and R. Moffatt. Anabolic steroid: effectiveness as an ergogenic aid to experienced weight trainers. J Sports Med Phys Fitness 14: 191-7, 1974.

199. Stannard, J. P., and A. L. Bucknell. Rupture of the triceps tendon associated with steroid injections. Am J Sports Med 21: 482-5, 1993.

200. Steinbach, $M$. Über den Einfluß anaboler Wirkstoffe auf Körpergewicht, Muskelkraft und Muskeltraining. Sportartz und Sportmedizin 19: 485-492, 1968.

201. Strauss, R. H., M. T. Liggett, and R. R. Lanese. Anabolic steroid use and perceived effects in ten weight-trained women athletes. JAMA 253: 2871-3, 1985.

202. Strauss, R. H., J. E. Wright, and G. A. M. Finerman. Anabolic steroid use and health status among forty-two weight trained male athletes. Med Sci Sports Exerc 14: 119 (abstract), 1982.

203. Strauss, R. H., J. E. Wright, G. A. M. Finerman, and D. H. Catlin. Side effects of anabolic steroids in weight trained men. Physician Sportsmed 11: 87-96, 1983.

204. Strawford, A., T. Barbieri, R. Neese, L. M. Van, M. Christiansen, R. Hoh, G. Sathyan, R. Skowronski, J. King, and $M$. Hellerstein. Effects of nandrolone decanoate therapy in borderline hypogonadal men with HIV-associated weight loss. J Acquir Immune Defic Syndr Hum Retrovirol 20: 137-46, 1999.

205. Strawford, A., T. Barbieri, L. M. Van, E. Parks, D. Catlin, N. Barton, R. Neese, M. Christiansen, J. King, and M. K. Hellerstein. Resistance exercise and supraphysiologic androgen therapy in eugonadal men with HIV-related weight loss: a randomized controlled trial [see comments]. JAMA 281: 1282-90, 1999.

206. Strawford, A., T. Barbieri, M. Van Loan, E. Parks, D. Catlin, N. Barton, R. Neese, $M$. Christiansen, J. King, and $\mathbf{M}$. K. Hellerstein. Resistance exercise and supraphysiologic androgen therapy in eugonadal men with HIV-related weight loss: a randomized controlled trial [see comments]. JAMA 281: 1282-90, 1999.

207. Strømme, S. B., H. D. Meen, and A. Aakvaag. Effects of an androgenic-anabolic steroid on strength development and plasma testosterone levels in normal males. Med Sci Sports 6 : 203-208, 1974.

208. Su, T. P., M. Pagliaro, P. J. Schmidt, D. Pickar, O. Wolkowitz, and D. R. Rubinow. Neuropsychiatric effects of anabolic steroids in male normal volunteers. Jama 269: 2760-4, 1993.

209. Takala, T., P. Ramo, K. Kiviluoma, V. Vihko, H. Kainulainen, and R. Kettunen. Effects of training and anabolic steroids on collagen synthesis in dog heart. Eur J App/ Physiol Occup Physiol 62: 1-6, 1991. 
210. Takala, T. E., K. Kiviluoma, M. Kihlstrom, P. Ramo, and V. Vihko. Effects of physical training, methandione and their combination on the lysosomal hydrolytic activities in dog heart. Int J Sports Med 13: 52-5, 1992.

211. Tannenbaum, S. D., and H. Rosler. Proximal humeral fracture in weight lifter using anabolic steroids. Arch Phys Med Rehabil 70: A-89, 1989.

212. Teruel, J. L., M. A. Lasuncion, M. Rivera, A. Aguilera, H. Ortega, A. Tato, R. Marcen, and J. Ortuno. Nandrolone decanoate reduces serum lipoprotein(a) concentrations in hemodialysis patients. American Journal Of Kidney Diseases. Apr 29: 569-575, 1997.

213. Thompson, P. D., E. M. Cullinane, S. P. Sady, C. Chevenert, A. L. Saritelli, M. A. Sady, and P. N. Herbert. Contrasting effects of testosterone and stanozolol on serum lipoprotein levels. JAMA 261: 1165-1168, 1989.

214. Thompson, P. D., A. Sadaniantz, E. M. Cullinane, K. S. Bodziony, D. H. Catlin, B. G. Torek, and P. S. Douglas. Left ventricular function is not impaired in weight-lifters who use anabolic steroids. J Am Coll Cardiol 19: 278-82, 1992.

215. Thomson, D. P., D. R. Pearson, and D. L. Costill. Use of anabolic steroids by national level athletes. Med Sci Sports Exerc 13: 111, 1981.

216. Tingus, S. J., and R. C. Carlsen. Effect of continuous infusion of an anabolic steroid on murine skeletal muscle. Med Sci Sports Exerc 25: 485-94, 1993.

217. Todd, T. Anabolic steroids: the gremlins of sport. J Sport History 14: 87-107, 1987.

218. Toth, $\mathbf{M}$., and T. Zakar. Relative binding affinities of testosterone, 19-nortestosterone and their 5-alpha-reduced derivates to the androgen receptor and to androgen-binding proteins: a suggested role of 5-alpha-reductive steroid metabolism in the dissociation of "myotropic" and "androgenic" activities of 19-nortestosterone. I Steroid Biochem 17: 653-660, 1982.

219. Tricker, R., M. R. O'Neill, and D. Cook. The incidence of anabolic steroid use among competitive bodybuilders. Journal of Drug Education 19: 313-325, 1989.

220. Urhausen, A., R. Holpes, and W. Kindermann. One- and two-dimensional echocardiography in bodybuilders using anabolic steroids. Eur J Appl Physio/ 58: 633-40, 1989.

221. Urhausen, A., R. Stein, and W. Kindermann. Metabolismus und hormonelles Verhalten bei Ausdauertrainierten unter Testosteronapplikation. Deutsche Zeitschrift für Sportmedizin 40: 312-20, 1989.

222. Wade, N. Anabolic steroids: doctors denounce them, but athletes aren't listening. Science 176: 1399-1403, 1972.

223. Ward, P. The effect of an anabolic steroid on strength and lean body mass. Med Sci Sports 5 : 277-82, 1973.

224. Webb, O. L., P. M. Laskarzewski, and C. J. Glueck. Severe depression of high-density lipoprotein cholesterol levels in weight lifters and body builders by self-administered exogenous testosterone and anabolic-androgenic steroids. Metabolism 33: 971-5, 1984.

225. Weiss, U., and H. Müller. Zür Frage der beeinflüssung des Krafttrainings durch anabole Hormone. Schweizerische Zeitschrift für Sportmedizin: 79-89, 1968.

226. Welle, S., R. Jozefowicz, G. Forbes, and R. C. Griggs. Effect of testosterone on metabolic rate and body composition in normal men and men with muscular dystrophy. I Clin Endocrinol Metab 74: 332-335, 1992.

227. Wemyss-Holden, S. A., F. C. Hamdy, and K. J. Hastie. Steroid abuse in athletes, prostatic enlargement and bladder outflow obstruction-is there a relationship? Br JUrol 74: 476-8, 1994.

228. Wilson, J. Androgens. In: Goodman and Cilman's The pharmacological basis of therapeurics (9th edition), edited by J. Hardman and L. Limbird. New York: McGraw-Hill, 1996, p. 1441-1457.

229. Wilson, J. D. Androgen abuse by athletes. Endocr Rev 9: 181-99, 1988. 
230. Win-May, M., and M. Mya-Tu. The effect of anabolic steroids on physical fitness. J Sports Med Phys Fitness 15: 266-71, 1975.

231. Woodard, T. L., G. A. Burghen, A. E. Kitabchi, and J. A. Wilimas. Glucose intolerance and insulin resistance in aplastic anemia treated with oxymetholone. J Clin Endocrinol Metab 53: 905-908, 1981.

232. Wright, J. E. Anabolic steroids and athletics. Exerc Sport Sci Rev 8: 149-202, 1980.

233. Wroblewska, A. M. Androgenic-anabolic steroids and body dysmorphia in young men. I Psychosom Res 42: 225-34, 1997.

234. Wu, F. Male contraception. Bailliere's Clin Obstet Gynaecol 10: 1-23, 1996.

235. Wu, F. W. Treatment of infertility: Infertility in men. Prescr J 36: 55-61, 1996.

236. Yeater, R., C. Reed, I. Ullrich, A. Morise, and M. Borsch. Resistance trained athletes using or not using anabolic steroids compared to runners: Effects on cardiorespiratory variables, body composition, and plasma lipids. BrJ Sports Med 30: 11-14, 1996.

237. Yesalis, C., S. Courson, and J. Wright. History of anabolic steroid use in sport and exercise. In: Anabolic steroids in sports and exercise, edited by C. Yesalis. Champaign, IL: Human Kinetics, 1993, p. 35-47.

238. Yesalis, C. E., R. T. Herrick, R. T. Buckley, K. E. FriedI, D. Brannon, and J. E. Wright. Self-repoted use of anabolic-androgenic steroids by elite power lifters. physician sports med 16: 90-100, 1988.

239. Zmuda, J. M., M. C. Fahrenbach, B. T. Younkin, L. L. Bausserman, R. B. Terry, D. H. Catlin, and P. D. Thompson. The effect of testosterone aromatization on high-density lipoprotein cholesterol level and postheparin lipolytic activity. Metabolism 42: 446-50, 1993.

240. Zuliani, U., B. Bernardini, A. Catapano, M. Campana, G. Cerioli, and M. Spattini. Effects of anabolic steroids, testosterone, and $\mathrm{HGH}$ on blood lipids and echocardiographic parameters in body builders. Int J Sports Med 10: 62-6, 1989. 


\section{CHAPTER 3}

\section{Androgenic-anabolic steroid-induced body changes in strength athletes}

Fred Hartgens

Wouter D. Van Marken Lichtenbelt

Spike Ebbing

Niels Vollaard

Gerard Rietjens

Harm Kuipers

Netherlands Centre for Doping Affairs, Capelle aan den IJssel

Dept of Human Biology, Maastricht University, Maastricht

Dept of Movement Sciences, Maastricht University, Maastricht

The Physician and Sportsmedicine 29(1):49-66, 2001 


\section{ABSTRACT}

Background: Some strength athletes use androgenic-anabolic steroids (AAS) to improve body dimensions, though the drugs' long and short-term effects have not been definitively established.

Objective: This study sought to investigate the short- and long-term effects of AAS self-administration on body dimensions and total and regional body composition.

Design: This prospective, unblinded study involved 35 experienced male strength athletes: 19 AAS users (drugs were self-administered) and 16 nonuser controls engaged in their usual training regimens. At baseline, 8 weeks, and 6 weeks after AAS withdrawal (for AAS users) circumferences were measured at 10 sites, and skinfolds measured at 8 sites. To assess differences in AAS regimens, 9 subjects took AAS for 8 weeks (short-AAS) and 10 athletes took AAS for 12 to 16 weeks (long-AAS). Body composition and anthropometry were assessed at baseline, at the end of AAS use, and 6 weeks later. Lean body mass (LBM) was calculated from body weight and percentage fat. Total and regional body composition was measured by dual-energy $\mathrm{x}$-ray absorptiometry.

Results: AAS use increased users' body weight by $4.4 \mathrm{~kg}$ and LBM by $4.5 \mathrm{~kg}$, and produced increases in several circumferences. Percentage of fat decreased (17.0 to $16.0 \%$ ), but fat mass remained unchanged. Changes persisted 6 weeks after drug withdrawal but were not less than those taken at 8 weeks. Bone-free lean mass of all regional body parts increased in subjects taking AAS but fat mass was unaffected. Short- and long-term AAS users did not differ in any parameter measured at 8 weeks or after drug withdrawal.

Conclusions: In AAS users, 8 weeks of self-administered AAS increased body weight, lean body mass, and limb circumferences, but decreased percentage fat compared with controls. Changes remained 6 weeks after drug withdrawal, though for some measurements only partially. AAS stimulated the bone-free lean mass of all body parts, but it did not affect fat mass. Short-term and long-term AAS administration produced comparable effects. 


\section{INTRODUCTION}

The use of androgenic-anabolic steroids (AAS) in athletes seems to be widespread. As reported by laboratories accredited by the International Olympic Committee these drugs have been the most frequently detected substances in urine samples of athletes (1). AAS use by elite athletes is of great concern for national and international sports federations because the drugs give users an unfair advantage and produce potentially deleterious health effects $(2,3)$ AAS use is not limited to elite athletes, however, and may be more extensive among recreational and amateur strength athletes, even though the media devote less attention to use in these groups.

Strength athletes often progress to self-administration of AAS to increase muscle mass and strength. Weight lifters and power lifters strive primarily for strength, whereas bodybuilders train for optimal muscle mass and body dimensions (2). Consequently, in all strength athletes increased muscle mass is desirable. Until now only a few studies have investigated the effects of AAS on muscle mass and body dimensions. Unfortunately, data are equivocal, and many questions remain to be answered.

Our study sought answers to three questions: 1) Which body measurements and composition are altered in strength athletes when they use several AAS simultaneously? 2) Does self-administration of AAS exert distinct effects on the separate components of regional body composition? and (3) What impact does the duration of AAS use have on anthropometry and body composition?

\section{METHODS}

\section{Subjects and their AAS use}

Strength athletes were recruited with advertisements from local gyms. Inclusion criteria were: male, at least 3 years of strength training experience, and age between 20 and 45 years. Candidates excluded were those who smoked or had hypertension, diabetes mellitus, liver disease or abnormal liver enzyme levels, hereditary hypercholesterolemia, elevated serum cholesterol levels $(>6.5 \mathrm{mmol} / \mathrm{L})$, or infertility. Before participating, all subjects completed a questionnaire containing questions about medical history, health status, training experience and status, nutrition, nutritional supplement use, and AAS use

After the initial screening, each strength athlete underwent a full medical examination by a physician for evaluation of their health status and to screen for possible missed exclusion criteria. During the examination, we provided extensive oral and written information about the study to each subject. All subjects signed an informed consent form approved by the Ethical Committee of Maastricht University (Maastricht, The Netherlands). 
Table 1. Baseline physical and training characteristics of the strength athletes

\begin{tabular}{lll}
\hline & $\begin{array}{l}\text { AAS group } \\
(\mathrm{n}=19)\end{array}$ & $\begin{array}{l}\text { Controls } \\
(\mathrm{n}=16)\end{array}$ \\
\hline Age (years) & $31.3 \pm 7.0$ & $32.8 \pm 5.3$ \\
Height (cm) & $176 \pm 9$ & $177 \pm 7$ \\
Body weight (kg) & $84.0 \pm 9.9$ & $88.5 \pm 11.2$ \\
Fat percentage (\%) & $17.0 \pm 5.7$ & $19.4 \pm 3.6$ \\
Training history (years) & $10.0 \pm 7.3$ & $8.8 \pm 3.6$ \\
Training (hours/week) & $8.8 \pm 2.5$ & $8.2 \pm 2.3$ \\
\hline
\end{tabular}

Table 2. Subjects and duration, route and total of androgenic-anabolic steroids administered.

\begin{tabular}{|c|c|c|c|c|}
\hline Nr. ID & $\begin{array}{l}\text { Duration } \\
\text { AAS use }\end{array}$ & $\begin{array}{l}\text { AAS used and route } \\
\text { of administration }\end{array}$ & Generic names & $\begin{array}{l}\text { Total amount } \\
\text { of drugs used }\end{array}$ \\
\hline 1. $\mathrm{BC} 101$ & 16 weeks & $\begin{array}{l}\text { Stromba (i.m.) } \\
\text { Deca-Durabolin (i.m.) } \\
\text { Primobolan (p.o.) } \\
\text { Primobolan (i.m.) } \\
\text { Masteron (p.o.) } \\
\text { Proviron (p.o.) }\end{array}$ & $\begin{array}{l}\text { stanozolol } \\
\text { nandrolone decanoate } \\
\text { metenolone } \\
\text { metenolone } \\
\text { drostanolone } \\
\text { mesterolone }\end{array}$ & $\begin{array}{l}500 \mathrm{mg} \\
350 \mathrm{mg} \\
375 \mathrm{mg} \\
1400 \mathrm{mg} \\
14 \mathrm{mg} \\
350 \mathrm{mg}\end{array}$ \\
\hline 2. $\mathrm{SS} 102$ & 16 weeks & $\begin{array}{l}\text { Stromba (i.m.) } \\
\text { Deca-Durabolin (i.m.) } \\
\text { Primobolan (p.o.) } \\
\text { Primobolan (i.m.) } \\
\text { Masteron (p.o.) } \\
\text { Proviron (p.o.) }\end{array}$ & $\begin{array}{l}\text { stanozolol } \\
\text { nandrolone decanoate } \\
\text { metenolone } \\
\text { metenolone } \\
\text { drostanolone } \\
\text { mesterolone }\end{array}$ & $\begin{array}{l}500 \mathrm{mg} \\
350 \mathrm{mg} \\
375 \mathrm{mg} \\
1400 \mathrm{mg} \\
14 \mathrm{mg} \\
350 \mathrm{mg}\end{array}$ \\
\hline 3. $\mathrm{MB} 108$ & 8 weeks & $\begin{array}{l}\text { Deca-Durabolin (i.m.) } \\
\text { Parabolan (i.m) } \\
\text { Dianabol (p.o.) } \\
\text { Pregnyl (i.m.) }\end{array}$ & $\begin{array}{l}\text { nandrolone decanoate } \\
\text { trenbolone acetate } \\
\text { methandrostenolone } \\
\text { choriongonadotrophine }\end{array}$ & $\begin{array}{l}1600 \mathrm{mg} \\
228 \mathrm{mg} \\
940 \mathrm{mg} \\
9000 \mathrm{lU}\end{array}$ \\
\hline 4. JD111 & 12 weeks & $\begin{array}{l}\text { Testoviron (i.m.) } \\
\text { Strombaject (i.m.) } \\
\text { Decadurabolin (i.m.) }\end{array}$ & $\begin{array}{l}\text { testosterone enanthate } \\
\text { stanozolol } \\
\text { nandrolone decanoate }\end{array}$ & $\begin{array}{l}1250 \mathrm{mg} \\
700 \mathrm{mg} \\
100 \mathrm{mg}\end{array}$ \\
\hline 5. ES112 & 16 weeks & $\begin{array}{l}\text { Strornbaject (i.m.) } \\
\text { Stromba (p.o.) } \\
\text { Omnadren (i.m.) } \\
\text { Deca-Durabolin (i.m.) } \\
\text { Primobolan (i.m.) }\end{array}$ & $\begin{array}{l}\text { stanozolol } \\
\text { stanozolol } \\
\text { testosterone propionate } \\
\text { nandrolone decanoate } \\
\text { metenolone }\end{array}$ & $\begin{array}{l}750 \mathrm{mg} \\
450 \mathrm{mg} \\
375 \mathrm{mg} \\
875 \mathrm{mg} \\
300 \mathrm{mg}\end{array}$ \\
\hline 6. JN113 & 8 weeks & $\begin{array}{l}\text { Dianabol (p.o.) } \\
\text { Deca-Durabolin (i.m.) } \\
\text { Masteron (i.m.) }\end{array}$ & $\begin{array}{l}\text { methandrostenolone } \\
\text { nandrolone decanoate } \\
\text { drostanolone }\end{array}$ & $\begin{array}{l}960 \mathrm{mg} \\
300 \mathrm{mg} \\
300 \mathrm{mg}\end{array}$ \\
\hline 7. GS115 & 16 weeks & $\begin{array}{l}\text { Clenbuterol (p.o.) } \\
\text { Winstrol (p.o.) } \\
\text { Deca-Durabolin (i.m.) } \\
\text { Stromba (p.o.) } \\
\text { Stromba (i.m.) } \\
\text { Parabolan (i.m.) } \\
\text { Pregnyl (i.m.) } \\
\text { Undestor (i.m.) } \\
\text { Nolvadex (p.o.) }\end{array}$ & $\begin{array}{l}\text { clenbuterol } \\
\text { stanozolol } \\
\text { nandrolone decanoate } \\
\text { stanozolol } \\
\text { stanozolol } \\
\text { trenbolone acetate } \\
\text { choriongonadotrophine } \\
\text { testosterone undecanoate } \\
\text { tamoxiphene }\end{array}$ & $\begin{array}{l}\text { This subject used these } \\
\text { drugs from the start in } \\
\text { a stacking way but did } \\
\text { not know each exact } \\
\text { dose for drug } \\
\text { The subject himself } \\
\text { qualified the dosages } \\
\text { used as "high" for each } \\
\text { drug }\end{array}$ \\
\hline 8. FB121 & 8 weeks & $\begin{array}{l}\text { Deca-Durabolin (i.m.) } \\
\text { Strombaject (i.m.) } \\
\text { Pregnyl (i.m.) }\end{array}$ & $\begin{array}{l}\text { nandrolone decanoate } \\
\text { stanozolol } \\
\text { choriongonadotrophine }\end{array}$ & $\begin{array}{l}2000 \mathrm{mg} \\
750 \mathrm{mg} \\
13500 \mathrm{IU}\end{array}$ \\
\hline
\end{tabular}


Table 2. (continued)

\begin{tabular}{|c|c|c|c|c|}
\hline Nr. ID & $\begin{array}{l}\text { Duration } \\
\text { AAS use }\end{array}$ & $\begin{array}{l}\text { AAS used and route } \\
\text { of administration }\end{array}$ & Generic names & $\begin{array}{l}\text { Total amount } \\
\text { of drugs used }\end{array}$ \\
\hline 9. RT122 & 16 weeks & $\begin{array}{l}\text { Stromba (p.o.) } \\
\text { Dianabol (p.o.) } \\
\text { Testosterone (i.m.) }\end{array}$ & $\begin{array}{l}\text { stanozolol } \\
\text { methandrostenolone } \\
\text { testosterone heptilate }\end{array}$ & $\begin{array}{l}1080 \mathrm{mg} \\
1240 \mathrm{mg} \\
3000 \mathrm{mg}\end{array}$ \\
\hline 10. GR124 & 8 weeks & $\begin{array}{l}\text { Dianabol (p.o.) } \\
\text { Proviron (p.o.) } \\
\text { Primobolan (i.m.) } \\
\text { Deca-Durabolin (i.m.) } \\
\text { Sustanon (i.m.) } \\
\text { Parabolan (i.m.) } \\
\text { Strombaject (i.m.) } \\
\text { Boldane (i.m.) } \\
\text { Stromba (p.o.) }\end{array}$ & $\begin{array}{l}\text { methandrostenolone } \\
\text { mesterolone } \\
\text { metenolone } \\
\text { nandrolone decanoate } \\
\text { testosterone (phenyl-) } \\
\text { propionate/isohexanoate } \\
\text { trenbolone acetate } \\
\text { stanozolol } \\
\text { boldenone } \\
\text { stanozolol }\end{array}$ & $\begin{array}{l}560 \mathrm{mg} \\
1400 \mathrm{mg} \\
800 \mathrm{mg} \\
400 \mathrm{mg} \\
1750 \mathrm{mg} \\
\\
602 \mathrm{mg} \\
250 \mathrm{mg} \\
300 \mathrm{mg} \\
420 \mathrm{mg}\end{array}$ \\
\hline 11. PW125 & 8 weeks & $\begin{array}{l}\text { Proviron (p.o.) } \\
\text { Primobolan (i.m.) }\end{array}$ & $\begin{array}{l}\text { mesterolone } \\
\text { metenolone }\end{array}$ & $\begin{array}{l}5600 \mathrm{mg} \\
1600 \mathrm{mg}\end{array}$ \\
\hline 12. MD139 & 12 weeks & $\begin{array}{l}\text { Synasteron (p.o.) } \\
\text { Deca-Durabolin (i.m.) }\end{array}$ & $\begin{array}{l}\text { oxymetenolone } \\
\text { nandrolone decanoate }\end{array}$ & $\begin{array}{l}3500 \mathrm{mg} \\
1625 \mathrm{mg}\end{array}$ \\
\hline 13. CL148 & 8 weeks & Deca-Durabolin (i.m.) & nandrolone decanoate & $2600 \mathrm{mg}$ \\
\hline 14. FL151 & 12 weeks & $\begin{array}{l}\text { Stromba (p.o.) } \\
\text { Stromba (i.m.) } \\
\text { Testoviron (i.m.) } \\
\text { Testex Leo (i.m.) } \\
\text { Pregnyl (i.m.) }\end{array}$ & $\begin{array}{l}\text { stanozolol } \\
\text { stanozolol } \\
\text { testosterone enanthate } \\
\text { testosterone cypionate } \\
\text { choriongonadotrophine }\end{array}$ & $\begin{array}{l}1036 \mathrm{mg} \\
850 \mathrm{mg} \\
3750 \mathrm{mg} \\
5000 \mathrm{mg} \\
4500 \mathrm{lU}\end{array}$ \\
\hline 15. RD161 & 8 weeks & $\begin{array}{l}\text { Dianabol (p.o.) } \\
\text { Testosterone (i.m.) } \\
\text { Parabolan (i.m.) } \\
\text { Pregnyl (i.m.) }\end{array}$ & $\begin{array}{l}\text { methandrostenolone } \\
\text { testosterone cypionate } \\
\text { trenbolone acetate } \\
\text { choriongonadotrophine }\end{array}$ & $\begin{array}{l}980 \mathrm{mg} \\
750 \mathrm{mg} \\
880 \mathrm{mg} \\
4500 \mathrm{IU}\end{array}$ \\
\hline 16. HK401 & 8 weeks & $\begin{array}{l}\text { Dianabol (p.o.) } \\
\text { Primobolan (p.o.) } \\
\text { Proviron (p.o.) }\end{array}$ & $\begin{array}{l}\text { methandrostenolone } \\
\text { metenolone } \\
\text { mesterolone }\end{array}$ & $\begin{array}{l}1115 \mathrm{mg} \\
1850 \mathrm{mg} \\
675 \mathrm{mg}\end{array}$ \\
\hline 17. GT402 & 16 weeks & $\begin{array}{l}\text { Stromba (p.o.) } \\
\text { Anapolon (p.o.) }\end{array}$ & $\begin{array}{l}\text { stanozolol } \\
\text { oxymetholone }\end{array}$ & $\begin{array}{l}2170 \mathrm{mg} \\
1225 \mathrm{mg}\end{array}$ \\
\hline 18. DV403 & 8 weeks & $\begin{array}{l}\text { Deca-Durabolin (i.m.) } \\
\text { Spiropent (p.o.) } \\
\text { Testoviron (i.m.) } \\
\text { Testex Leo (i.m.) } \\
\text { Masteron (i.m.) } \\
\text { Strombaject (i.m.) } \\
\end{array}$ & $\begin{array}{l}\text { nandrolone decanoate } \\
\text { clenbuterol } \\
\text { testosterone enanthate } \\
\text { testosterone cypionate } \\
\text { drostanolone } \\
\text { stanozolol }\end{array}$ & $\begin{array}{l}4400 \mathrm{mg} \\
1.68 \mathrm{mg} \\
2500 \mathrm{mg} \\
1000 \mathrm{mg} \\
300 \mathrm{mg} \\
1200 \mathrm{mg} \\
\end{array}$ \\
\hline 19. EK404 & 12 weeks & $\begin{array}{l}\text { Strombaject (i.m.) } \\
\text { Testosterone (i.m.) } \\
\text { Spiropent (p.o.) } \\
\text { Anadrol (p.o.) } \\
\text { Pregnyl (i.m.) } \\
\text { Nolvadex (p.o.) }\end{array}$ & $\begin{array}{l}\text { stanozolol } \\
\text { testosterone } \\
\text { clenbuterol } \\
\text { oxymetholone } \\
\text { choriongonadotrophine } \\
\text { tamoxiphene }\end{array}$ & $\begin{array}{l}1150 \mathrm{mg} \\
5500 \mathrm{mg} \\
1.00 \mathrm{mg} \\
1900 \mathrm{mg} \\
1500 \mathrm{IU} \\
440 \mathrm{mg}\end{array}$ \\
\hline
\end{tabular}


Thirty-five strength athletes participated in this study. Most athletes $(n=28)$ performed strength training mainly for esthetic purposes and characterized their training regimen as bodybuilding training; only 7 of these subjects participated in bodybuilding contests. Seven participants were competitors: 3 engaged in strength training as a part of their boxing training in addition to using AAS for esthetic reasons, and 4 athletes were principally involved in resistance training for power lifting competition.

Among the subjects, 19 subjects had decided to begin using AAS to supplement their regular strength training regimen (AAS group). The remaining 16 volunteers who had not used nor were willing to take AAS, served as controls (CO group). The physical and training characteristics of both groups are presented in table 1.

Assessing AAS status. Before entering the study, AAS group members were expected not to have used AAS for at least the previous 3 months. This was verified from information that each subject provided and was corroborated by urinalysis before the start of the study. Interviews revealed that AAS subjects had been drug-free for $8.1 \pm 6.4$ months (range, 3 to 30 months). All but one of the AAS group had previously used AAS. The average participant had started using AAS 4.8 years (range, 1 to 14 years) before the study, and the mean number of AAS cycles self-administered was 7.1 (range 1 to 30 cycles).

Study disclaimer. Although several subjects had received a prescription for steroids from a physician, most AAS users bought the drugs on the black market. Users devised AAS regimens based on information provided by other strength athletes and on their own insights and beliefs. Table 2 presents the details of AAS use in participants. Readers should note that the investigators did not provide AAS, that researchers did not attempt to influence which AAS was used, and the researchers did not have any role in AAS administration.

Study design. We conducted a non-blinded study that was divided in three experiments to investigate the objectives set (figure 1).

\section{Experiment 1: Total body composition and anthropometry}

Experiment 1 was designed to investigate changes of body composition and anthropometric measurements in strength athietes induced by self-administered AAS. Body composition and dimensions were assessed by taking skinfold thicknesses and circumferences, respectively. Measurements were taken before the start of AAS use (baseline) and after 8 weeks of AAS use. in all AAS users, measurements were also taken 6 weeks after drug cessation, regardless of the length of AAS self-administration. In controls, the same measurements were done at the start of the study and after 8 weeks strength training. 
Figure 1. Designs of the three experiments

Experiment 1. Total body composition and anthropometry.

Subjects: 19 AAS users ( 9 subjects administered 8 weeks AAS and 10 subjects used for $12-16$ weeks) and 16 non-users.

AAS use for 8 weeks

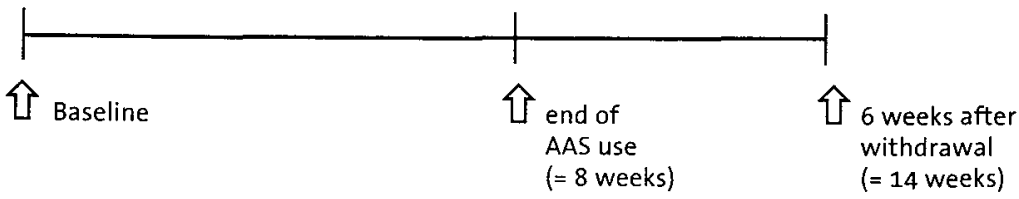

AAS use for $12-16$ weeks
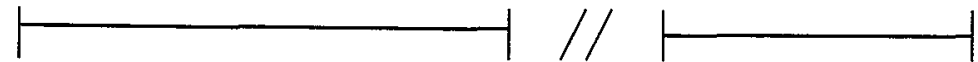

亿 Baseline

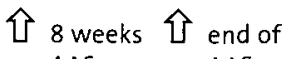

仓 6 weeks after

AAS use

AAS use withdrawal

Controls

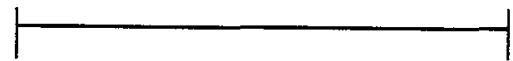

仓 Baseline 仓 8 weeks

Experiment 2. Regional alterions of body composition (DEXA measurements).

Subjects: 6 AAS users and 5 non-users.

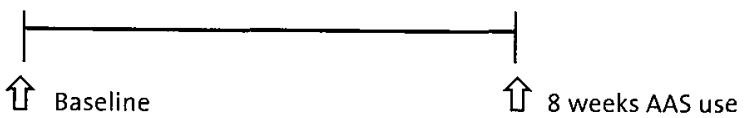

Experiment 3. Impact duration AAS self-administration.

Subjects were 19 AAS users: 9 short course and 10 long course

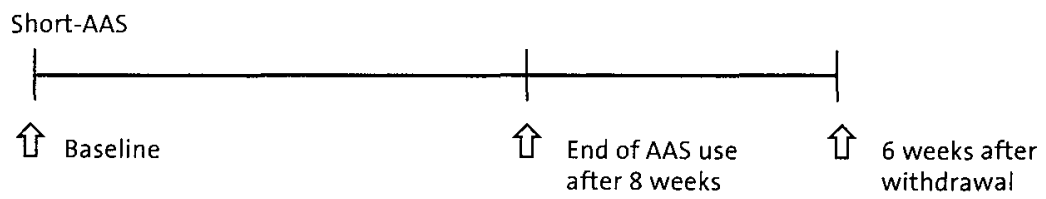

Long-AAS

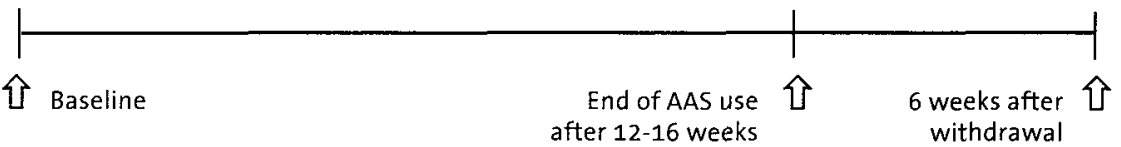

Legend.

$\widehat{U}$ indicates measurement

/ indicates that the duration of AAS self-administration varied between subjects from 12 to

16 weeks 


\section{Experiment 2: Regional alterations of body composition}

Eleven strength athletes (6 AAS, 5 CO) from experiment 1 were randomly selected to participate in experiment 2. Subjects' body composition was determined with dual-energy $x$-ray absorptiometry (DEXA), in addition to the regular body composition and anthropometric measurements taken in experiment 1. In 6 strength athletes, we performed DEXA measurements at baseline and after 8 weeks of AAS self-administration. In 5 controls, body composition measurements by DEXA were carried out only at the start of the study.

\section{Experiment 3: Impact of duration of AAS self-administration}

Before the start of the study we divided the AAS users from experiment 1 into two subgroups based on their intended AAS course duration. Nine subjects had decided to take these drugs for 8 weeks (short-AAS), while the remaining 10 athletes intended to use AAS for 12 to 16 weeks (long-AAS). Anthropometric measurements and determination of body composition were carried out at baseline, at the end of the drug administration, and 6 weeks after AAS withdrawal.

Measurements. Height was measured with an anthropometer. Body weight was determined to the nearest $0.1 \mathrm{~kg}$ using a bascule. Skinfolds were measured with a Holtain caliper at eight sites: biceps, triceps, subscapular, pectoral, suprailiac, umbilicus, thigh, and calf. All measurements were taken twice by an experienced investigator. The mean of both measurements was recorded. To avoid interobserver error, a single investigator took measurements in the same subject throughout the study. The percentage of fat was estimated from skinfold measurements according to the method of Durnin and Womersly (4). Lean body mass and fat mass were calculated using body weight and percentage fat.

Eleven circumference measurements at 10 sites were taken with a tape measure: neck, thorax, waist, buttocks, upper arm (relaxed), upper arm (contracted), forearm, wrist, thigh (just below the buttocks), thigh ( $2 / 3$ the distance from the major trochanter and lateral site of the knee joint), and calf. An experienced investigator took all measurements twice, and the mean of both measurements was recorded.

Total and regional body composition measurements were performed using DEXA apparatus (DPX-L, Lunar Corp, Madison, Wisconsin, USA) at a fast scan speed with a whole-body resolution of $4.8 \times 9.6 \mathrm{~mm}$. To determine the composition of regional body segments and limbs, DEXA measurements were divided in discrete values for arms, legs, and trunk on the basis of anatomic landmarks. As determined by Mazess et al. the precision of these measurements is $1.5 \%$ for the arms, $0.8 \%$ for the legs, and $1.1 \%$ for the trunk (5). Total mass, fat mass, and bone-free lean mass were determined using Lunar software (version $1.3 \mathrm{z}$ ) for each body region (arms, trunk, and legs). 
Monitoring and compliance. Information about the subjects' training and nutritional habits was collected before the start of the study and in week 8. Subjects' nutritional intake was determined with a 3-day diary. Training data were obtained by a 1-week log. For long-term-use (12 to 16 weeks) strength athletes, nutritional and training data were also obtained at the end of the AAS administration. In all AAS users, these data were collected 6 weeks after drug cessation.

To gauge subjects' compliance with drug administration or abstinence before the start of the study and after 8 weeks, urine samples from all athletes were obtained for drug testing (Netherlands institute for Drug and Doping Research, Utrecht, The Netherlands). For the long-AAS group, urine samples were taken at the end of the drug-use period. All AAS-using strength athletes submitted urine samples 6 weeks after drug withdrawal. From all samples taken, about one-third were randomly chosen for analysis.

Statistical analysis. Descriptive statistics were calculated for all measurements using Statview software (Abacus, USA, 1994). Data are presented as mean plus or minus standard deviation (SD). The Mann-Whitney U-test was used to compare differences in the observed changes between groups. The Wilcoxon signed rank test was used for analysis of intragroup changes after drug withdrawal (experiment 1) and of DEXA measurements of subjects taking AAS (experiment 2). The level of significance was set at 0.05 for all analyses.

\section{RESULTS}

Total body composition and anthropometry. After 8 weeks, the AAS group had a significant increase of approximately $4.5 \mathrm{~kg}$ in body weight and lean body mass, whereas the controls exhibited no significant change. Mean body weight increased from $84.0 \pm 9.9$ to $88.4 \pm 10.7 \mathrm{~kg}$, and lean body mass rose from $69.6 \mathrm{~kg}$ to $74.1 \mathrm{~kg}$. The percentage fat during AAS use was significantly reduced from $17.0 \%$ to $16.0 \%$, but this was not reflected in a loss of fat mass. Gains in body weight and lean body mass were still partly present 6 weeks after drug withdrawal (table 3). In both groups, no significant increase in skinfold measurements or their sums were observed during the study.

In the AAS group, increases in the circumferences of neck, upper arm, forearm, wrist, thigh, and lower leg were significantly larger than in the control group. Circumference changes of the thorax, waist, and buttocks did not reach significance compared with those of controls. Although the circumferences were slightly reduced after drug withdrawal, they were still increased compared with baseline levels (table 3 ). 
Table 3. Circumferences of limbs and trunk of the AAS using ( $n=19)$ and natural $(n=16)$ strength athletes at baseline, after 8 weeks and 6 weeks after drug cessation (experiment 1).

\begin{tabular}{|c|c|c|c|c|}
\hline & & Baseline & 8 weeks & $\begin{array}{l}6 \text { weeks after } \\
\text { drug cessation }\end{array}$ \\
\hline \multirow[t]{2}{*}{$\overline{\text { Neck }}$} & AAS & $39.2 \pm 1.9$ & $40.5 \pm 2.1^{\# \# \#}$ & $40.2 \pm 1.9^{* *}$ \\
\hline & Natural & $39.6 \pm 2.2$ & $39.6 \pm 2.2$ & n.a. \\
\hline \multirow[t]{2}{*}{ Thorax } & AAS & $95.8 \pm 6.5$ & $98.4 \pm 6.4$ & $98.1 \pm 6.5^{* *}$ \\
\hline & Natural & $98.5 \pm 7.3$ & $99.9 \pm 7.2$ & n.a. \\
\hline \multirow[t]{2}{*}{ Waist } & AAS & $84.8 \pm 7.1$ & $86.3 \pm 7.1$ & $85.1 \pm 7.2$ \\
\hline & Natural & $86.8 \pm 5.4$ & $87.1 \pm 6.4$ & n.a. \\
\hline \multirow[t]{2}{*}{ Buttocks } & AAS & $98.7 \pm 5.6$ & $100.6 \pm 5.5$ & $100.0 \pm 5.5^{* *}$ \\
\hline & Natural & $99.3 \pm 4.8$ & $100.0 \pm 4.9$ & n.a. \\
\hline \multirow{2}{*}{$\begin{array}{l}\text { Upper arm } \\
\text { (relaxed) }\end{array}$} & AAS & $36.6 \pm 3.0$ & $38.5 \pm 3.3^{\# \# \# ~}$ & $37.8 \pm 3.4^{* *}$ \\
\hline & Natural & $38.9 \pm 3.7$ & $39.0 \pm 3.8$ & n.a. \\
\hline \multirow{2}{*}{$\begin{array}{l}\text { Upper arm } \\
\text { (contracted) }\end{array}$} & AAS & $40.1 \pm 3.3$ & $41.6 \pm 3.1^{\# \#}$ & $41.5 \pm 3.5^{* * *}$ \\
\hline & Natural & $42.0 \pm 3.6$ & $42.4 \pm 3.7$ & n.a. \\
\hline \multirow[t]{2}{*}{ Forearm } & AAS & $31.3 \pm 1.9$ & $32.4 \pm 2.1^{\# \# \#}$ & $32.6 \pm 2.8^{* *}$ \\
\hline & Natural & $32.8 \pm 2.8$ & $32.7 \pm 2.2$ & n.a. \\
\hline \multirow[t]{2}{*}{ Wrist } & AAS & $18.2 \pm 1.0$ & $18.5 \pm 1.1^{\#}$ & $18.3 \pm 1.0$ \\
\hline & Natural & $18.3 \pm 0.8$ & $18.3 \pm 0.9$ & n.a. \\
\hline \multirow[t]{2}{*}{ Thigh (1) } & AAS & $61.5 \pm 5.5$ & $63.7 \pm 5.1^{\# \#}$ & $62.7 \pm 5.1^{*}$ \\
\hline & Natural & $63.4 \pm 4.6$ & $63.4 \pm 4.8$ & n.a. \\
\hline \multirow[t]{2}{*}{ Thigh (2) } & AAS & $50.0 \pm 3.4$ & $52.2 \pm 4.4^{\# \#}$ & $50.8 \pm 3.6^{*}$ \\
\hline & Natural & $51.8 \pm 3.3$ & $51.6 \pm 2.9$ & n.a. \\
\hline \multirow[t]{2}{*}{ Lower leg } & AAS & $38.7 \pm 2.2$ & $39.6 \pm 2.2^{\# \# \#}$ & $39.1 \pm 2.2^{*}$ \\
\hline & Natural & $40.2 \pm 2.6$ & $40.2 \pm 2.7$ & n.a. \\
\hline
\end{tabular}

Legend.

Data are presented as mean \pm s.d. N.A. indicates data are not available.

Mann Whitney test for interaction : ${ }^{\#}=p<0.05 ;{ }^{\# \#}=p<0.01 ;{ }^{\# \#}=p<0.001$ (difference compared to change in Natural group)

Wilcoxontest for comparison data after withdrawal and baseline: $:^{*}=0<0.05 ;{ }^{* *}=p<0.01 ;{ }^{* * *}=$ $p<0.001$ (compared to baseline values)

Regional body composition changes. Baseline DEXA measurements of body segment composition was not significantly different between the AAS users and control athletes. After 8 weeks of AAS use, the weight of the arm was significantly increased but the weight of the trunk and legs remained unchanged. Bone-free lean masses of the arms, trunk, and legs were significantly greater during AAS use than at baseline (table 4). AAS use did not affect the fat mass of the arms, legs, and trunk. Total bone mineral density and bone mineral content did not change significantly. 
Table 4. Effects on the composition of body parts induced by AAS (experiment 2).

\begin{tabular}{|c|c|c|c|c|c|}
\hline & & Natural & $\begin{array}{l}\text { AAS } \\
\text { baseline }\end{array}$ & $\begin{array}{l}\text { AAS } \\
8 \text { weeks }\end{array}$ & $\begin{array}{l}\text { difference } \\
\text { AAS baseline vs } \\
\text { AAS } 8 \text { weeks } \\
\text { ( } p \text {-value) }\end{array}$ \\
\hline \multirow[t]{3}{*}{ ARMS } & total mass (g) & $\begin{array}{l}10013 \\
\pm 1993\end{array}$ & $\begin{array}{l}10470 \\
\pm 1723\end{array}$ & $\begin{array}{l}11320 \\
\pm 1910\end{array}$ & 0.028 \\
\hline & fat mass $(\mathrm{g})$ & $\begin{array}{l}1370 \\
\pm 838\end{array}$ & $\begin{array}{l}1721 \\
\pm 1240\end{array}$ & $\begin{array}{l}1317 \\
\pm 828\end{array}$ & n.s. \\
\hline & bone-free lean mass $(\mathrm{g})$ & $\begin{array}{l}8642 \\
\pm 1296\end{array}$ & $\begin{array}{l}8750 \\
\pm 1066\end{array}$ & $\begin{array}{l}10004 \\
\pm 1129\end{array}$ & 0.03 \\
\hline \multirow[t]{3}{*}{ LECS } & total mass $(\mathrm{g})$ & $\begin{array}{l}25699 \\
\pm 4866\end{array}$ & $\begin{array}{l}24228 \\
\pm 3390\end{array}$ & $\begin{array}{l}25390 \\
\pm 2768\end{array}$ & n.s. \\
\hline & fat mass $(\mathrm{g})$ & $\begin{array}{l}4649 \\
\pm 1755\end{array}$ & $\begin{array}{l}3785 \\
\pm 1600\end{array}$ & $\begin{array}{l}3605 \\
\pm 1101\end{array}$ & n.s. \\
\hline & bone-free lean mass $(\mathrm{g})$ & $\begin{array}{l}21050 \\
\pm 3443\end{array}$ & $\begin{array}{l}20443 \\
\pm 2436\end{array}$ & $\begin{array}{l}21785 \\
\pm 2134\end{array}$ & 0.03 \\
\hline \multirow[t]{3}{*}{ TRUNK } & total mass (g) & $\begin{array}{l}35762 \\
\pm 4269\end{array}$ & $\begin{array}{l}37798 \\
\pm 4845\end{array}$ & $\begin{array}{l}39375 \\
\pm 4372\end{array}$ & n.s. \\
\hline & fat mass $(\mathrm{g})$ & $\begin{array}{l}6824 \\
\pm 1778\end{array}$ & $\begin{array}{l}7073 \\
\pm 3119\end{array}$ & $\begin{array}{l}6490 \\
\pm 2670\end{array}$ & n.s. \\
\hline & bone-free lean mass $(\mathrm{g})$ & $\begin{array}{l}28938 \\
\pm 3257\end{array}$ & $\begin{array}{l}30725 \\
\pm 2602\end{array}$ & $\begin{array}{l}32885 \\
\pm 1936\end{array}$ & 0.046 \\
\hline
\end{tabular}

\section{Statistical analysis:}

Data presented as mean \pm s.d.

Paired data of the AAS group were analysed with Wilcoxon signed rank test

Length of AAS regimen. No significant differences were observed in body weight, percentage of fat, fat mass, lean body mass, and circumferences between short-AAS and long-AAS users. Similarly, 6 weeks after drug withdrawal these parameters were not different between groups.

Training, nutrition, and compliance. Throughout the entire study, weekly training hours and regimens between groups in the three experiments remained comparable. The same was true for nutritional intake. Urinalysis revealed compliance within the groups: urine samples from the AAS users contained steroid metabolites, and samples of the CO group did not contain steroid metabolites. 


\section{DISCUSSION}

AAS induced changes. Experienced strength athletes who use a selfcomposed course of AAS for 8 weeks exhibited increased total body weight and total lean body mass compared with those who did strength training alone; total fat mass remained unaffected. Among regional body segments (arms, legs, and trunk) in these athletes, only arm weight increased significantly. However, lean mass was significantly increased in all regional body parts, and these findings are reflected in the increased arm and leg circumferences. Increases were for the most part still present 6 weeks after drug cessation. These findings are relevant because until now scientific data concerning AAS effects on anthropometry and body composition were equivocal.

From cross-sectional studies, one might infer that AAS-using strength athletes differ in body composition from nonusing athletes $(6,7)$. These observations have been supported by longitudinal studies. The most pronounced effects on body weight and lean body mass were found in athletes who self-administered several AAS simultaneously in high doses $(8,9)$. Such regimens may increase body weight by an average of about 5.2 $\mathrm{kg}$. Lean body mass increases may be even larger, especially after long-term administration $(8,10)$.

The present study indicates that the use of a single AAS seems to induce less remarkable effects than multiple-drug regimens $(9,11-13)$. This is in line with an observation of Forbes (1985) who had previously described a positive relationship between the total dose of AAS used and the increase of lean body mass (14). On the other hand, recent research $(9,11,15,16)$ that compared the effects of different doses of a single AAS indicates that such a relationship might be less ambiguous than that proposed by Forbes.

Previous methods and DEXA. One factor that may have contributed to the consistent results is the method used to determine body composition. No alterations were seen in studies (17-20) that investigated body composition with underwater weighing. In these studies, the effect of a single drug was analyzed, and, unfortunately, no reports are available on underwater weighing assessment of body composition in multiple-drug-using athletes. Although previous studies assessed the traditional two-compartment model either with skinfold measurements or with underwater weighing, our study employed DEXA to assess a three-compartment model for body composition alterations.

DEXA was designed primarily to estimate bone mineral content and density in humans (21). Determination of body composition by DEXA is based on the difference in attenuation of $x$-rays between soft and bone tissue as well as the difference in attenuation between fat and lean tissue. This method provides a three-compartment model that divides the body into total bone mineral content, bone-free lean mass, and fat mass. An advantage of DEXA over hydrodensitometry is that DEXA appears to be less affected by 
hydration status $(21,22)$. This may be an important advantage in estimating body composition in athletes since hydration status may be affected by training.

Assessing regional body changes. Because of the documented DEXA accuracy for total and regional body dimension measurement $(5,23)$ and the AAS potential for inducing regional changes in body composition, strength athletes may have particular interest in these tools. DEXA measurements in this study reveal an increase in bone-free lean mass of all body parts measured in bodybuilders using AAS. One interesting finding was that the increase in the bone-free mass of the arms was approximately twice that in the leg or trunk ( $14 \%$ versus about $7 \%$ ). This finding could not be attributed to differences in training regimens because the training diaries revealed comparable regimens in both groups. On the other hand, in another study (16) the administration a single anabolic steroid (nandrolone decanoate) induced the largest gain of bone-free lean mass in the legs and trunk. Since both studies are complementary, one possibility might be that different AAS regimens may affect specific areas more than others.

Although evidence has shown that AAS increases lean body mass (24-26), no one has determined what constitutes the change in lean mass. Previous research associated AAS-induced lean body mass alterations with increments of blood volume and water retention $(12,27,28)$. In a recent study $(29)$, we were able to investigate the effects of AAS on body composition with a four-compartment model. That study revealed that total body water increased from AAS use but the ratio between extracellular and intracellular water remained unaffected. In addition, lean mass hydration status was not influenced by AAS. Thus, the most likely explanation for the gain of lean mass can be explained by muscle increase rather than from water retention (29).

Dispelling steroid-use myths. Among strength athletes, long-term AAS administration is generally believed to produce better results than short-term use. Additionally, these athletes claim that after long-term AAS use the gains in body composition parameters will persist longer than after short-term administration. These beliefs are not supported by the present study. The effects on body composition and anthropometric variables after short- and long-term AAS use were comparable. The same applied for residual changes seen after drug withdrawal. Therefore, we conclude that duration of AAS administration in itself is not the key factor for optimal and longstanding effects on body composition.

Health hazards. From a medical point of view, long-term AAS administration is of great concern. Several investigators $(9,30,31)$ have reported that AAS induce an unfavorable lipoprotein profile and thus increase the risk for cardiovascular diseases. Recent research has demonstrated that duration of AAS use has a strong impact on the lipoprotein profile changes (32). Extended AAS administration provokes more dramatic side effects on the 
lipoprotein profile compared with short-term AAS use, and the time required for full reversal of these side effects was prolonged after long-term use (32). Consequently, long-term users are more prone to have cardiovascular events.

Most strength athletes are convinced that after drug abstinence the effects on body composition will persist for some time. Our results show that 6 weeks after drug withdrawal the changes of circumferences were still significantly increased over baseline values, though slight decreases were seen compared with values at the end of AAS use. Many AAS users take on average two to three courses in 1 year $(6,33)$. Their approach is to start a new AAS course when they assume that the side effects have disappeared but the desired effects on body composition and strength are still present to some extent. There are indications that such procedures may be effective (6), but the effects of such procedures on health status are unknown and remain of great concern.

Summary. This study has demonstrated that in athletes the administration of a self-composed, 8-week course of AAS combined with strength training increased body weight, lean body mass, and limb circumferences more than did strength training alone. Arm mass, but not trunk and leg mass, was increased by AAS use. DEXA analysis showed that AAS stimulated the bone-free lean mass of all body parts, but the effects on the arms were the most pronounced. Fat mass was not affected by AAS use. The increments in total body weight, lean body mass, and girths were still largely evident 6 weeks after drug withdrawal. There was no relationship between the duration of AAS use and the extent of changes in body composition and anthropometric variables. 


\section{REFERENCES}

1. International Olympic Committee. Statistics 1997 of the IOC accredited laboratories. Lausanne, International Olympic Committee, 1998

2. Yesalis $\mathbf{C}$. Anabolic steroids in sport and exercise (2nd ed.). Champaign IL: Human Kinetics, 2000

3. Vogels T., Brugman E., Coumans B., Danz M.J, Hirasing R.A., van Kernebeek E. Lijf, sport en middelen. Nederlands Instituut voor Praeventieve Gezondheidszorg TNO, Leiden, 1994

4. Durnin J.V.G.A., Womersley J.. Body fat assessed from total density and its estimation from skinfold thickness: measurements on 481 men and women aged from 16 to 72 years. $\mathrm{Br} \mathrm{J}$ Nutr 32: 77-97, 1974.

5. Mazess R.B., Barden H.S., Bisek J.P., et al. Dual-energy $x$-ray absorptiometry for total-body and regional bone-mineral and soft-tissue composition. Am J Clin Nutr 51 (6): 1106-12, 1990.

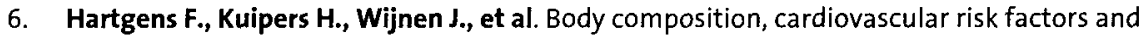
liver function in long term androgenic-anabolic steroids using bodybuilders three months after drug withdrawal. Int I Sports Med 17 (6): 429-433, 1996.

7. Kouri E.M., Pope H.J., Katz D.L., et al. Fat-free mass index in users and nonusers of anabolic-androgenic steroids. Clin J Sport Med 5 (4): 223-228, 1995.

8. Alen M., Hakkinen K., Komi P.V.. Changes in neuromuscular performance and muscle fiber characteristics of elite power athletes self-administering androgenic and anabolic steroids. Acta Physiol Scand 122 (4): 535-44, 1984.

9. Kuipers H., Wijnen J.A.G., Hartgens F., et al. Influence of anabolic steroids on body composition, blood pressure, lipid profile and liver function in bodybuilders. Int J Sports Med 12: 413-418, 1991.

10. Alen M., Hakkinen K.. Physical health and fitness of an elite bodybuilder during 1 year of self-administration of testosterone and anabolic steroids: a case study. Int J Sports Med 6 (1): 24-9, 1985.

11. Friedl K.E., Dettori J.R., Hannan C.J., et al. Comparison of the effects of high dose testosterone and 19-nortestosterone to a replacement dose of testosterone on strength and body composition in normal men. J Steroid Biochem Mol Biol 40 (4-6): 607-12, 1991.

12. Hervey G.R., Hutchinson I., Knibbs A.V., et al. "Anabolic" effects of methandienone in men undergoing athletic training. Lancet 2 (7988): 699-702, 1976.

13. Win-May M., Mya-Tu M. The effect of anabolic steroids on physical fitness. J Sports Med Phys Fitness 15 (3): 266-71, 1975.

14. Forbes G.B.. The effect of anabolic steroids on lean body mass: the dose-response curve. Metabolism 34 (6): 571-573, 1985.

15. Bhasin S., Storer T.W., Berman N., et al. The effects of supraphysiologic doses of testosterone on muscle size and strength in normal men. New Engl J Med 335 (1): 1-7, 1996.

16. Hartgens F., Van Marken Lichtenbelt W., Ebbing S., et al. Body composition and anthropometry in bodybuilders: regional changes due to nandrolone decanoate administration. Int I Sports Med 2001 (in press).

17. Casner S.J., Early R.G., Carison B.R.. Anabolic steroid effects on body composition in normal young men. J Sports Med Phys Fitness 11 (2): 98-103, 1971.

18. Crist D.M., Stackpole P.J., Peake G.T.. Effects of androgenic-anabolic steroids on neuromuscular power and body composition. J Appl Physiol 54 (2): 366-70, 1983.

19. Fahey T.D., Brown C.H.. The effects of an anabolic steroid on the strength, body composition, and endurance of college males when accompanied by a weight training program. Med Sci Sports 5 (4): 272-6, 1973.

20. Golding L.A., Freydinger J.E., Fishel S.S. Weight, size and strength - unchanged with steroids. Physician Sportsmed 2: 39-43, 1974. 
21. Lohman T. Advances in body composition assessment. Champaign IL: Human Kinetics Publishers, 1992.

22. Heyward V.H.. Evaluation of body composition. Sports Med 22 (3): 146-156, 1996.

23. Fuller N.J., Laskey M.A., Elia M. Assessment of the composition of major body regions by dual-energy $X$-ray absorptiometry (DEXA), with special reference to limb muscle mass. Clin Physiol 12 (3): 253-66, 1992.

24. Lovejoy J.C., Bray G.A., Bourgeois M.O., et al. Exogenous androgens influence body composition and regional body fat distribution in obese postmenopausal women - A clinical research center study. J Clin Endocrinol Metab 81 (6): 2198-2203, 1996.

25. Lovejoy J.C., Bray G.A., Greeson C.S., et al. Oral anabolic steroid treatment, but not parenteral androgen treatment, decreases abdominal fat in obese, older men. Int J Obes Relat Metab Disord 19 (9): 614-24. 1995.

26. Marin P., Holmang S., Jonsson L., et al. The effects of testosterone treatment on body composition and metabolism in middle-aged obese men. Int J Obes Relat Metab Disord 16 (12): 991-7, 1992.

27. Hervey G.R., Knibbs A.V., Burkinshaw L., et al. Effects of methandienone on the performance and body composition of men undergoing athletic training. Clin Sci 60 (4): 457-61, 1981.

28. Holma P. Effect of an anabolic steroid (metandienone) on central and peripheral blood flow in well-trained male athletes. Ann Clin Res 9 (4): 215-21, 1977.

29. Van Marken Lichtenbelt W., Hartgens F., Ebbing S., et al. Body builders' body composition: effect of androgenic-anabolic steroids. Submitted 2000.

30. Alen M., Rahkila P., Marniemi J.. Serum lipids in power athletes self-administering testosterone and anabolic steroids. Int J Sports Med 6 (3): 139-44, 1985.

31. Lenders J.W., Demacker P.N., Vos J.A., et al. Deleterious effects of anabolic steroids on serum lipoproteins, blood pressure, and liver function in amateur body builders. Int $J$ Sports Med 9 (1): 19-23, 1988.

32. Hartgens F., Rietjens G., Keizer H.A., et al. Effects of androgenic-anabolic steroids on apolipoproteins and lipoprotein(a). Submitted.

33. De Boer A., van Haren S.F., Hartgens F., et al. Onderzoek naar het gebruik van prestatieverhogende middelen bij bodybuilders in Nederland. Nederlands Centrum voor Dopingvraagstukken, Universiteit Utrecht, 1996. 


\title{
CHAPTER 4
}

\section{Body composition and anthropometry in bodybuilders: regional changes due to nandrolone decanoate administration}

\author{
Fred Hartgens \\ Wouter D. Van Marken Lichtenbelt \\ Spike Ebbing \\ Niels Vollaard \\ Gerard Rietjens \\ Harm Kuipers
}

Netherlands Centre for Doping Affairs, Capelle aan den IJssel

Dept of Human Biology, Maastricht University, Maastricht

Dept of Movement Sciences, Maastricht University, Maastricht

International Journal of Sports Medicine 22(3): 235-241, 2001 


\begin{abstract}
Introduction: The purpose of the present study was to investigate regional changes in body composition and anthropometric variables induced by nandrolone decanoate in bodybuilders.

Methods: In a randomised, double blind, placebo controlled design 16 subjects received weekly intramuscular injections containing $200 \mathrm{mg}$ nandrolone decanoate (ND) or placebo. Composition of total body and body parts were assessed using dual energy X-ray absorptiometry (DEXA), skinfolds and circumferences. Measurements were performed at baseline, after 8 weeks ND administration period and 6 weeks after drug withdrawal.

Results: DEXA revealed that total body mass (from $76.16 \pm 2.70$ to $78.73 \pm 4.07 \mathrm{~kg}, \mathrm{p}<0.5$ ) and bone-free lean mass (from $59.54 \pm 2.36$ to $63.06 \pm 2.99 \mathrm{~kg}, \mathrm{p}<0.025$ ) increased significantly during ND administration, whereas bone mineral mass remained unchanged. Six weeks after drug cessation bone-free lean mass was still increased compared to baseline levels. During ND administration significant increments of bone-free lean mass of the trunk $(+2.03 \mathrm{~kg})$ and legs $(+1.08 \mathrm{~kg})$ could be observed. Percentage fat of the legs decreased during the drug intervention period $(-1.9 \%)$ and remained lowered six weeks after drug withdrawal. No alteration in any variable of the arms was observed. Skinfolds did not change during the entire study period in both groups. After 8 weeks ND administration circumference of the neck was increased $(+0.9 \mathrm{~cm})$ significantly although all circumferences underwent non-significant gains.

Conclusions: The intramuscular administration of nandrolone decanoate (200 $\mathrm{mg}$ per week) during eight weeks induced an increase of body weight and bone-free lean body mass in bodybuilders that was mainly situated in the trunk and legs as determined by DEXA. The changes in the trunk were reflected in the circumferences, but not the alterations in the legs. Skinfolds were not able to detect changes of fat mass of body parts. DEXA revealed that total fat mass and total percentage fat remained unaffected by drug administration, while percentage fat of the legs decreased and remained lowered after drug cessation. These data indicate that changes of the composition of body parts induced by ND are elucidated less accurately by circumferences or skinfolds rather than by DEXA.
\end{abstract}




\section{INTRODUCTION}

Bodybuilding is aimed to maximize muscle mass and definition. Since androgenic-anabolic steroids may affect body composition the use of these drugs among bodybuilders is widespread (40). One of the most frequently used androgenic-anabolic steroids by strength athletes is nandrolone decanoate. This steroid is a 19-nortestosterone ester that is dissolved in an oil vehicle and after intramuscular injection the release into the human body is sustained. Strength athletes are convinced that nandrolone decanoate increases body weight and lean mass more than does strength training alone, although scientific data do not support these claims unequivocally ( 9 , $11,25)$. On the other hand, in clinical trials it has been demonstrated that this drug increases lean body mass and reduces fat mass in patients suffering from COPD, osteoporosis, obesitas, hypogonadism, immunodeficiency and renal insufficiency $(18,19,21,28,34-36)$. Furthermore, there are indications that nandrolone decanoate may induce regional changes in fat mass and lean mass in patients (28).

In studies investigating the effects of AAS in athletes, body composition was estimated using the two compartment model. This model divides the body into two compartments, i.e. fat and lean mass. The majority of the studies estimated percentage fat from skinfolds, whereas hydrodensitometry was used in the remainder $(17,26)$. However, recent data indicate that hydrodensitometric measurements in muscular men may be less accurate (33). In recent years more advanced methods for determination of body composition have been developed and validated $(12,13,24)$. Dual energy $X$-ray absorptiometry (DEXA) is one of these relatively new methods. DEXA is based on measurement of the attenuation of two x-ray beams crossing the tissue. This makes it possible to distinguish between soft tissue and bone mass and between fat and bone-free lean mass and bone mineral mass (13, 24). Furthermore, DEXA has the opportunity to assess body composition of specific body regions $(7,13)$. An important difference between DEXA and hydrodensitometry is that DEXA measurements are barely influenced by hydration status. This may provide a significant advantage in estimating body composition in athletes and enables assessment of regional changes.

Although the abuse of AAS has become common property among strength athletes and in gyms, the potential risks on health status are of great concern. However, there is still a great lack of knowledge about the effects of these substances on athletic performance. The same holds for the side-effects of AAS abuse, especially the long-term side effects and the administration of high doses. To enhance knowledge about the abuse of these substances in athletes we started a large study. The main purposes of this study were to investigate the effects of AAS on the heart and the cardiovascular system, risk factors for cardiovascular diseases, haemostatic system, liver function, psyche and behavior, body composition and skeletal 
muscle. To investigate adequately the issues mentioned we divided the entire study in several smaller studies. The purpose of the present study was to investigate regional changes in body composition and anthropometric variables induced by a frequently used anabolic steroid (nandrolone decanoate) in well trained, recreational bodybuilders, employing DEXA, circumferences and skinfolds.

\section{MATERIAL AND METHODS}

\section{Study design}

The study was approved by the Ethical Committee of Maastricht University. The study was conducted as a randomised, double blind, placebo controlled investigation. After written informed consent was obtained the subjects were randomly assigned to the verum or placebo group. The verum group received weekly intramuscular injections containing $200 \mathrm{mg}$ nandrolone decanoate (Deca-Durabolin ${ }^{*}$, Organon B.V., The Netherlands) for eight weeks, whereas the other bodybuilders were injected with placebo consisting of arachis oil every week. All subjects visited our laboratory for drug administration once a week.

All measurements were performed before the start of the study (baseline), after 8 weeks administration of nandrolone decanoate or placebo as well as 6 weeks after drug cessation.

Every second week a questionnaire with possible side effects (containing physical and psychological issues as well as dummies) was filled out by each subject. There were no differences in experienced side-effects between both groups. Additionally, biweekly each volunteer was asked to tell if he received nandrolone or placebo. In both groups half of the subjects had the opinion that nandrolone was administered. The remaining part in each group was convinced that they received placebo.

\section{Subjects}

Subjects were recruited by flyers in local gyms. Bodybuilders who met the inclusion criteria were admitted to the study. Inclusion criteria were: male, bodybuilding training experience of at least 3 years, at least 4 strength training work outs per week or 8 hours strength training weekly, and age between 20 and 45 years. The following exclusion criteria were set: hypertension, diabetes mellitus, liver disease or abnormal liver enzyme serum levels, hereditary hypercholesterolaemia, elevated serum cholesterol $(>6,5$ mmol/l), infertility and smoking.

Before entering the study all subjects underwent a full medical examination by a physician for evaluation of their health status and to screen for exclu- 
Table 1. Physical and training characteristics of the bobybuilders at the start of the study. Presented are mean \pm SD.

\begin{tabular}{lll}
\hline & $\begin{array}{l}\text { ND group } \\
(\mathrm{n}=9)\end{array}$ & $\begin{array}{l}\text { Placebo group } \\
(\mathrm{n}=7)\end{array}$ \\
\hline Age (years) & $32.7 \pm 8.0$ & $31.0 \pm 8.1$ \\
Height (cm) & $175 \pm 10$ & $177 \pm 7$ \\
Body weight (kg) & $76.0 \pm 12.1$ & $83.8 \pm 9.0$ \\
Training history (years) & $7.3 \pm 5.6$ & $6.4 \pm 2.8$ \\
Training (hours/week) & $7.4 \pm 2.1$ & $9.1 \pm 2.0$ \\
\hline
\end{tabular}

sion criteria. Seventeen bodybuilders were willing to participate in this study. After randomisation one subject withdraw from participation due to lack of time because of changing job. Eventually, sixteen bodybuilders completed the study. Physical and training characteristics of the subjects are described in table 1.

Four athletes had previous experience with AAS use. Before entering this study all subjects were expected to be free of AAS administration for at least three months. This was checked by information provided by each subject during the medical examination and by urine analysis before the start of the study.

\section{Measurements}

Dual Energy X-ray Absorptiometry (DEXA). Determination of body composition was performed by DEXA equipment (Lunar Corporation, Madison, USA, software version 1.3.z). Measurements of regional body composition were performed on the basis of anatomical landmarks as described before (31). Determined were the absolute and relative amounts of fat, bone-free lean mass and bone mineral mass of the whole body as well as of regional parts. The regional parts measured were arms, legs and trunk. As established by Mazess et al (1990) the precision of the measurements is $1.5 \%$ for the arms, $0.8 \%$ for the legs and $1.1 \%$ for the trunk (31).

Skinfolds. With a Holtain caliper skinfolds were measured at 8 sites, namely biceps, triceps, subscapular, pectoral, supra-iliacal, umbilicus, thigh, calf. All measurements were performed twice by an experienced investigator. The mean of both measurements was registered.

Circumferences. At 11 sites circumferences were measured with a cotton tape. Measured were circumferences of neck, thorax, waist, buttocks, upper arm (relaxed), upper arm (contracted), forearm, wrist, thigh (just below the buttocks), thigh ( $2 / 3$ distance major trochanter and lateral site of the knee joint) and lower leg. All measurements were performed twice by an experienced investigator. The mean of both measurements was registered. 
Nutrition, training and urine analyses. To monitor training and nutritional habits from each subject dietary and training data were collected in the week before the start of the study, in week 8 and in week 14. Bodybuilders' nutritional intake was determined by means of a three day diary. Analysis of the personal dietary diaries revealed that intake of macro and micro nutrients was unchanged during the entire study period. Training data were obtained by means of a one week log book. The training logs showed that weekly training work load did not change throughout the study period.

In all subjects urine samples were collected before the start of the experiment, after four and eight weeks study period as well as six weeks after drug cessation. Eventually, about one third of all samples, at random, were analysed by the Netherlands Institute for Drugs and Doping Research, Utrecht, The Netherlands. Baseline urine samples of all subjects did not contain any anabolic substance. During the study no indications for anabolic steroid use could be detected. On the other hand, in the samples of the experimental group the presence of nandrolone could be demonstrated clearly.

Statistical analysis. For statistical analysis Statview software (Abacus, USA, 1994) was used. Descriptive statistics were performed for all measurements. Data are presented as mean \pm SEM unless otherwise mentioned. For analysis of intervention effects ANCOVA was used with baseline measurements as covariate. Level of significance was set at $P<0.05$.

\section{RESULTS}

\section{Physical, training and nutritional characteristics}

At baseline both groups were comparable with respect to physical and training characteristics (Table 1). During the study period training characteristics did not change significantlly between both groups. In addition, before the start of the study the nutritional intake in both groups was comparable and remained unchanged throughout the study.

\section{Body composition}

Total. During nandrolone decanoate administration a significant increase of total body mass (from $76.16 \pm 2.70$ to $78.73 \pm 4.07 \mathrm{~kg}, \mathrm{p}<0.5$ ) and bone-free lean mass (from $59.54 \pm 2.36$ to $63.06 \pm 2.99 \mathrm{~kg}, p<0.025$ ) was observed, whereas bone mineral mass remained unchanged. Six weeks after drug cessation only bone-free lean mass was still increased compared to baseline levels $(p<0.05)$. Nandrolone decanoate did not alter total bone mineral mass, total body fat mass, total tissue percentage fat nor total 
regional percentage fat. In the placebo group no significant alterations were observed.

Trunk. After 8 weeks ND administration bone-free lean mass was increased significantly with $2.03 \mathrm{~kg}(\mathrm{p}<0.025)$. Six weeks after drug cessation bone-free lean mass was not significantly different from baseline value. All other parameters did not alter during drug administration. In the placebo group no significant change of any parameter of the trunk has been observed (Table 2).

Legs. In the legs the bone-free lean mass as determined by DEXA measurements increased significantly $(p<0.025)$ during ND administration, whereas 6 weeks after drug cessation a non-significant increase of approximately $3 \%$ still existed. Percentage fat of the legs decreased significantly during the drug intervention period (from $17.3 \pm 1.3$ to $15.4 \pm 1.0 \%, p<0.025$ ) and remained lowered six weeks after drug withdrawal. Fat mass and bone mineral mass of the legs did not alter significantly. Throughout the whole study period all measurements of the placebo group remained unchanged (Table 2).

Arms. DEXA measurements of the arm revealed no significant changes in regional percentage fat, tissue mass, bone-free lean mass, bone mineral mass and fat mass in both groups during the entire study period (Table 2). Skinfolds. In both groups no significant change of any skinfold nor from the total sum of all skinfolds could be observed during the entire study period. Data are not presented.

Circumferences. Although most circumferences of the ND group seemed to increase more than in the placebo group, only changes of the circumferences of neck and thorax reached statistical significance (Table 3). At the end of drug administration only the neck circumference was increased compared to changes in the placebo group. All other circumferences did not show significant alterations between both groups during the entire study period. In the placebo group no significant change in any circumference could be observed compared to baseline values (Table 3). 
Table 2. DEXA measurements of bone-free lean mass, fat mass and percentage fat of body regions in the bodybuilders at baseline, after 8 weeks drug administration and after drug withdrawal.

A. Bone-free lean mass of body regions

\begin{tabular}{lllll}
\hline & & baseline & 8 weeks & 14 weeks \\
\hline Trunk & ND & $27.80 \pm 0.74$ & $+2.03^{* *}$ & +0.59 \\
& Placebo & $29.78 \pm 1.21$ & +0.70 & +0.72 \\
Legs & ND & $19.94 \pm 0.90$ & $+1.08^{* *}$ & +0.69 \\
& Placebo & $21.95 \pm 0.93$ & +0.03 & -0.26 \\
\multirow{2}{*}{ Arms } & ND & $8.14 \pm 0.43$ & +0.28 & +0.23 \\
& Placebo & $9.48 \pm 0.49$ & +0.03 & +0.05 \\
\hline
\end{tabular}

Baseline data are presented as mean \pm SEM in $\mathrm{kg}$. Changes (in $\mathrm{kg}$ ) at 8 and 14 weeks are compared to baseline values.

** indicates significant $(P<0.025)$ change compared to placebo administration

\section{B. Fat mass of body regions}

\begin{tabular}{lllll}
\hline & & baseline & 8 weeks & 14 weeks \\
\hline Trunk & ND & $6.84 \pm 0.86$ & -0.29 & -0.16 \\
& Placebo & $7.94 \pm 0.88$ & -0.02 & -0.06 \\
Legs & ND & $4.53 \pm 0.54$ & -0.44 & -0.67 \\
& Placebo & $5.60 \pm 1.07$ & -0.16 & -0.36 \\
\multirow{2}{*}{ Arms } & ND & $1.27 \pm 0.19$ & -0.11 & -0.09 \\
& Placebo & $1.48 \pm 0.26$ & -0.02 & +0.15
\end{tabular}

Baseline data are presented as mean \pm SFM in $\mathrm{kg}$. Data at 8 and 14 weeks are presented in absolute change $(\mathrm{kg})$ compared to baseline values.

C. Percentage fat of body regions

\begin{tabular}{lllll}
\hline & & baseline & 8 weeks & 14 weeks \\
\hline Trunk & ND & $18.6 \pm 1.6$ & -1.4 & -1.0 \\
& Placebo & $20.2 \pm 1.8$ & -0.4 & -0.5 \\
\multirow{2}{*}{ Legs } & ND & $17.3 \pm 1.3$ & $-1.9^{* *}$ & -2.4 \\
& Placebo & $18.7 \pm 2.9$ & -0.3 & -0.7 \\
\multirow{2}{*}{ Arms } & ND & $12.4 \pm 1.5$ & -1.3 & -1.0 \\
& Placebo & $12.6 \pm 1.9$ & -0.2 & +0.5 \\
\hline
\end{tabular}

Baseline data are presented as mean \pm SEM in percentages. Data at 8 and 14 weeks are presented in absolute change compared to baseline values.

** indicates significant $(P<0.025)$ change compared to placebo administration 
Table 3. Changes in circumferences of limbs and trunk after 8 weeks drug administration and 6 weeks after drug cessation (week 14) with respect to baseline values.

Presented are mean \pm SEM at baseline and changes during the study period (in $\mathrm{cm}$ ).

\begin{tabular}{|c|c|c|c|c|}
\hline & & baseline & 8 weeks & 14 weeks \\
\hline \multirow[t]{2}{*}{ Neck } & ND & $38.3 \pm 1.9$ & $+0.9^{*}$ & +0.7 \\
\hline & Placebo & $40.2 \pm 0.9$ & -0.2 & -0.3 \\
\hline \multirow{2}{*}{ Thorax } & ND & $92.4 \pm 7.7$ & +2.0 & +0.6 \\
\hline & Placebo & $98.0 \pm 2.6$ & +1.6 & +0.1 \\
\hline \multirow[t]{2}{*}{ Waist } & ND & $79.7 \pm 6.0$ & +1.1 & +0.8 \\
\hline & Placebo & $85.2 \pm 3.4$ & +0.1 & 0 \\
\hline \multirow{2}{*}{ Buttocks } & ND & $94.4 \pm 6.2$ & +1.4 & +1.0 \\
\hline & Placebo & $97.3 \pm 4.1$ & +0.6 & +0.6 \\
\hline \multirow[t]{2}{*}{ Upper arm (relaxed) } & ND & $34.3 \pm 2.4$ & +0.8 & +0.5 \\
\hline & Placebo & $37.7 \pm 3.2$ & +0.3 & +0.2 \\
\hline \multirow[t]{2}{*}{ Upper arm (contracted) } & ND & $37.6 \pm 2.4$ & +1.0 & +1.0 \\
\hline & Placebo & $40.5 \pm 3.7$ & +0.7 & +0.6 \\
\hline \multirow[t]{2}{*}{ Forearm } & ND & $30.0 \pm 2.1$ & +0.6 & +0.3 \\
\hline & Placebo & $31.9 \pm 1.6$ & +0.2 & +0.3 \\
\hline \multirow[t]{2}{*}{ Wrist } & ND & $17.9 \pm 1.2$ & -0.1 & -0.1 \\
\hline & Placebo & $18.2 \pm 0.7$ & 0 & +0.1 \\
\hline \multirow[t]{2}{*}{ Thigh (1) } & ND & $57.9 \pm 4.2$ & +1.4 & +1.9 \\
\hline & Placebo & $60.7 \pm 4.0$ & +1.0 & +1.1 \\
\hline \multirow[t]{2}{*}{ Thigh (2) } & ND & $45.5 \pm 3.2$ & +0.7 & +0.2 \\
\hline & Placebo & $48.2 \pm 4.2$ & -0.6 & -1.2 \\
\hline \multirow[t]{2}{*}{ Lower leg } & ND & $37.4 \pm 1.8$ & +0.3 & +0.3 \\
\hline & Placebo & $38.4 \pm 2.9$ & -0.2 & -0.3 \\
\hline
\end{tabular}

* indicates significant change compared to the placebo group with respect to baseline values.

\section{DISCUSSION}

Administration of nandrolone decanoate during 8 weeks (200 mg per week, intramuscularly) increased total body mass and total bone-free lean mass, but did not exert any effect on total fat mass and bone mineral mass as determined by DEXA. The results of previous studies investigating effects of ND on body composition in strength athletes were equivocal $(9,11,25)$. Two studies found an increase of body weight and total lean body mass during administration of nandrolone decanoate $(11,25)$, whereas in a study by Crist and coworkers no change of these parameters could be observed (9). The most likely explanation for this discrepancy seems to be the dose and duration of nandrolone decanoate administration, although the method used for determination body composition may be important as well. In the study by 
Crist et al (1983) the subjects received a relatively low dose (100 mg per week) of ND intramuscularly during a short period of 3 weeks and body composition was determined by underwater weighing (9). Friedl et al (1991) and Kuipers et al (1991) administered higher doses for at least six weeks, whereas in these studies body composition was assessed by skinfold measurements $(11,25)$.

In clinical studies it has been shown that long term administration of nandrolone decanoate in therapeutic doses may increase lean body mass in patients suffering from COPD, osteoporosis, obesitas, immunodeficiency or renal insufficiency $(18,19,28,35)$. Also a reduction of fat mass could be observed in some patients treated with $\operatorname{ND}(18,19,28,30)$. It has also been demonstrated that other androgenic-anabolic steroids, like oxandrolone and testosterone, may induce similar alterations of body composition in patients $(4,28)$, although a reduction of fat mass is not an unequivocal outcome in all clinical studies $(5,15)$.

In studies where strength athletes composed their own course of AAS by administration of several drugs simultaneously, total body mass and lean mass increased more than in the studies using a double blind design (1-3, 25). This may indicate that the total amount of AAS used, the weekly dose and the duration of use may play a role. On the other hand, the method used for estimating body composition may be another important factor. In the double blind studies that determined body composition by hydrostatic weighing no significant effect on lean body mass was observed $(8-10,14)$. A difference between DEXA and hydrodensitometry is that DEXA measurements are barely influenced by hydration status and bone mineral content. This may provide an advantage in estimating body composition in athletes especially when AAS are used, since such drugs may influence total body water content, hydration status and bone mineral content.

DEXA measurements revealed that the bone-free lean mass of the trunk increased more (average $+2.03 \mathrm{~kg}$ ) than the bone-free lean mass of the legs (mean $+1.08 \mathrm{~kg}$ ) during ND administration. In the arms no significant change could be observed. This observation is of special interest for bodybuilders since optimising body composition and increasing muscle mass and definition are the main goals of their training program. The actual training regimen may be important for the effects on body mass and regional changes in lean mass. Therefore, bodybuilders perform a different strength training regimen compared to other resistive athletes, such as power lifting or weight lifting training. Bodybuilding training is characterized by performing multiple sets of relatively low resistance and relatively few sets with submaximal and maximal weights.

Although in previous investigations in strength athletes changes in regional body dimensions were studied, until now no attention was paid to changes 
in the composition of body parts. On the other hand, our observation is in line with the results from a clinical study reporting that nandrolone decanoate may induce regional changes in lean mass and fat mass in some patients (28). In another study the same investigators reported that the effects of two different AAS on fat mass were unequal. Their results indicated that the anabolic steroid oxandrolone (per os) exerted a more pronounced effect on subcutaneous and visceral abdominal fat in older obese men in comparison to parenteral administration of testosterone (29). Although the fat mass in the ND group remained unaffected, the percentage fat of the legs decreased in this group and remained lowered after drug cessation. However, it is very difficult to conduct a study with equivalent doses of different AAS since the interindividual response on different drugs may be variable. Also, the route of administration may play a role. Since our results may have impact for the training and AAS administration in strength athletes, they have to be handled with restraints until more data about this topic become available.

In this study no significant change of any skinfold nor estimated percentage fat (according to Durnin and Womersly, 1974) was observed. In addition, the total sum of the eight skinfolds measured remained unaffected during and after drug administration. Other investigators reported comparable observations in strength athletes receiving different doses of nandrolone decanoate $(11,25)$. Since the results of our study are in agreement with previous studies it seems reasonable to conclude that nandrolone decanoate during treatment periods up to 8 weeks, even in higher doses (11), does not exert effects on skinfold thicknesses and percentage fat in male strength athletes. Nevertheless, in clinical trials it has been shown that long term administration of nandrolone decanoate in therapeutic doses may lead to a decrease of total fat mass in postmenopausal or obese women and obese, older men $(18,19,28)$.

At the end of the eight weeks nandrolone decanoate administration period only the circumference of the neck was significantly increased. Although most circumferences showed increments after ND administration none of them was statistically significant. These observations were somewhat different to previous studies. Kuipers et al (1991) found gains in circumferences of neck and thorax during eight weeks nandrolone decanoate administration, whereas in students strength training with nandrolone decanoate administration did not induce any change in body dimensions (10). Furthermore, the results from AAS studies investigating circumferences are equivocal. Some researchers reported gains in circumferences of forearm, upper arm, thorax, thigh, lower leg during AAS use $(6,20,22,25,37,39))$, while others did not find any change $(2,10,14,27,38)$. However, the most prominent increases of circumferences were observed in non-blinded studies where the subjects self-administered high doses of different AAS (25). In the last decades a regimen with the concomitant use of several AAS has become 
popular. Nowadays the doses used by bodybuilders exceed the maximal therapeutical dose to a large extent $(2,25,40)$. It has been reported that changes of body composition in bodybuilders may last several months after drug withdrawal $(16,25)$ Nevertheless, Alen et al $(1984)$ reported that such high doses did not induce significant changes in circumferences of arms and legs in varsity strength athletes. Therefore, it still has to be established if such regimens provoke more effects since scientific data do not support this yet.

The discrepancies of the results in different studies may be due to differences in design, the population investigated, as well as to the drugs administered. For example, only in recent studies bodybuilders participated as volunteers. For these subjects body dimensions are the main objective of strength training and AAS use. In the earlier studies students and varsity strength athletes participated for whom improvement of body dimensions is not the primary goal. Furthermore, it is well established that the effects of AAS may be quite different depending on kind of drug, the dose administered, route of administration and duration (23). Recent research demonstrated clearly that pharmacokinetics and pharmacodynamics of nandrolone may be strongly influenced by the kind of nandrolone ester, injection site and injection volume (32).

In conclusion, the intramuscular administration of nandrolone decanoate (200 mg per week) during eight weeks induced a greater increase of body weight and bone-free lean body mass in experienced recreational bodybuilders than does strength training alone. The gains of the bone-free lean mass were mainly situated in the trunk and legs, but not in the arms. The changes in the trunk were detectable by measuring circumferences, while this was not the case for alterations in the legs. In addition regional changes of fat mass in the trunk that were found by DEXA could not be detected by skinfold measurements. Furthermore, the total fat mass, total percentage fat and total bone mineral mass remained unaffected by eight weeks nandrolone decanoate administration, whereas percentage fat of the legs decreased and remained lowered after drug cessation. The changes of the composition of regional body parts were elucidated less accurately by measurements of circumferences and skinfolds compared to DEXA. 


\section{REFERENCES}

1. Alen, $\mathbf{M}$, and K. Hakkinen. Androgenic steroid effects on serum hormones and on maxima! force development in strength athletes. J Sports Med Phys Fitness 27: 38-46, 1987.

2. Alen, M., K. Hakkinen, and P. V. Komi. Changes in neuromuscular performance and muscle fiber characteristics of elite power athletes self-administering androgenic and anabolic steroids. Acta Physiol Scand 122: 535-44, 1984.

3. Alen, M., M. Reinila, and R. Vihko. Response of serum hormones to androgen administration in power athletes. Med Sci Sports Exerc 17: 354-9, 1985.

4. Bhasin, S., T. W. Storer, S. N. Asbel, A. Kilbourne, R. Hays, H. I. Sinha, R. Shen, S. Arver, and G. Beall. Effects of testosterone replacement with a nongenital, transdermal system, Androderm, in human immunodeficiency virus-infected men with low testosterone levels. J Clin Endocrinol Metab 83: 3155-62, 1998.

5. Bhasin, S., T. W. Storer, N. Berman, K. E. Yarasheski, B. Clevenger, J. Phillips, W. P. Lee, T. J. Bunnell, and R. Casaburi. Testosterone replacement increases fat-free mass and muscle size in hypogonadal men. J Clin Endocrinol Metab 82: 407-13, 1997.

6. Bowers, R. W., and J. P. Reardon. Effects of methandrostenolone (Dianabol) on strength development and aerobic capacity. Med Sci Sports 4: 54 (abstract), 1972.

7. Bracco, D., D. Thiebaud, R. L. Chiolero, M. Landry, P. Burckhardt, and Y. Schutz. Segmental body composition assessed by bioelectrical impedance analysis and DEXA in humans. $J$ Appl Physiol 81: 2580-7, 1996.

8. Casner, S. J., R. G. Early, and B. R. Carlson. Anabolic steroid effects on body composition in normal young men. J Sports Med Phys Fitness 11: 98-103, 1971.

9. Crist, D. M., P. J. Stackpole, and G. T. Peake. Effects of androgenic-anabolic steroids on neuromuscular power and body composition. J Appl Physiol 54: 366-70, 1983.

10. Fahey, T. D., and C. H. Brown. The effects of an anabolic steroid on the strength, body composition, and endurance of college males when accompanied by a weight training program. Med Sci Sports 5: 272-6, 1973.

11. Friedl, K. E., J. R. Dettori, C. J. Hannan, T. H. Patience, and S. R. Plymate. Comparison of the effects of high dose testosterone and 19-nortestosterone to a replacement dose of testosterone on strength and body composition in normal men. J Steroid Biochem Mol Biol 40: 607-12, 1991.

12. Fuller, N. J., S. A. Jebb, M. A. Laskey, W. A. Coward, and M. Elia. Four-component model for the assesment of body composition in humans: comparison with alternative methods, and evaluation of the density and hydration of fat-free mass. Clinical Science 82: 687-693, 1992.

13. Fuller, N. J., M. A. Laskey, and M. Elia. Assessment of the composition of major body regions by dual-energy X-ray absorptiometry (DEXA), with special reference to limb muscle mass. Clin Physiol 12: 253-66, 1992.

14. Golding, L. A., J. E. Freydinger, and S. S. Fishel. Weight, size and strength - unchanged with steroids. Physician and Sportsmedicine 2: 39-43, 1974.

15. Grinspoon, S., C. Corcoran, H. Askari, D. Schoenfeld, L. Wolf, B. Burrows, M. Walsh, D. Hayden, K. Parlman, E. Anderson, N. Basgoz, and A. Klibanski. Effects of androgen administration in men with the AIDS wasting syndrome. A randomized, double-blind, placebo-controlled trial. Ann Intern Med 129: 18-26, 1998.

16. Hartgens, F., H. Kuipers, J. Wijnen, and H. A. Keizer. Body composition, cardiovascular risk factors and liver function in long term androgenic-anabolic steroids using bodybuilders three months after drug withdrawal. Int. J. Sports Med. 17: 429-433, 1996.

17. Hartgens, F., H. Kuipers, J. A. G. Wijnen, and S. M. M. Willems. Androgene-anabole steroïden in de sport; een literatuuroverzicht. Geneeskunde en Sport 25: 8-20, 1992. 
18. Hassager, C., J. Podenphant, B. J. Riis, J. S. Johansen, J. Jensen, and C. Christiansen. Changes in soft tissue body composition and plasma lipid metabolism during nandrolone decanoate therapy in postmenopausal osteoporotic women. Metabolism 38: 238-42, 1989.

19. Hassager, C., B. J. Riis, J. Podenphant, and C. Christiansen. Nandrolone decanoate treatment of post-menopausal osteoporosis for 2 years and effects of withdrawal. Maturitas 11: 305-17, 1989.

20. Hervey, G. R., A. V. Knibbs, L. Burkinshaw, D. B. Morgan, P. R. Jones, D. R. Chettle, and D. Vartsky. Effects of methandienone on the performance and body composition of men undergoing athletic training. Clin Sci 60: 457-61, 1981.

21. Johansen, K. L., K. Mulligan, and M. Schambelan. Anabolic effects of nandrolone decanoate in patients receiving dialysis: a randomized controlled trial. JAMA 281: 1275-81, 1999.

22. Johnson, L. C., G. Fisher, L. J. Silvester, and C. C. Hofheins. Anabolic steroid: effects on strength, body weight, oxygen uptake and spermatogenesis upon mature males. Med Sci Sports 4: 43-5, 1972.

23. Kochakian, C. D. Anabolic-androgenic steroids. Berlin: Springer Verlag, 1976.

24. Kohrt, W. M. Preliminary evidence that DEXA provides an accurate assessment of body composition. J Appl Physiol 84: 372-7, 1998.

25. Kuipers, H., J. A. G. Wijnen, F. Hartgens, and S. M. M. Willems. Influence of anabolic steroids on body composition, blood pressure, lipid profile and liver function in bodybuilders. Int J Sports Med 12: 413-418, 1991.

26. Lombardo, J. A. Anabolic-androgenic steroids. Nida Res Monogr 102: 60-73, 1990.

27. Loughton, S. J., and R. O. Ruhling. Human strength and endurance responses to anabolic steroid and training. J Sports Med Phys Fitness 17: 285-96, 1977.

28. Lovejoy, J. C., G. A. Bray, M. O. Bourgeois, R. Macchiavelli, J. C. Rood, C. Greeson, and C. Partington. Exogenous androgens influence body composition and regional body fat distribution in obese postmenopausal women - A clinical research center study. $J$ Clin Endocrinol Metab 81: 2198-2203, 1996.

29. Lovejoy, J. C., G. A. Bray, C. S. Greeson, M. Klemperer, J. Morris, C. Partington, and R. Tulley. Oral anabolic steroid treatment, but not parenteral androgen treatment, decreases abdominal fat in obese, older men. Int J Obes Relat Metab Disord 19: 614-24, 1995.

30. Marin, P. Testosterone and regional fat distribution. Obes Res 3: 609S-612S, 1995.

31. Mazess, R. B., H. S. Barden, J. P. Bisek, and J. Hanson. Dual-energy $x$-ray absorptiometry for total-body and regional bone-mineral and soft-tissue composition. Am J Clin Nutr 51: 1106-12, 1990.

32. Minto, C. F., C. Howe, S. Wishart, A. J. Conway, and D. J. Handelsman. Pharmacokinetics and pharmacodynamics of nandrolone esters in oil vehicle: effects of ester, injection site and injection volume. J Pharmacol Exp Ther 281: 93-102, 1997.

33. Modlesky, C. M., K. J. Cureton, R. D. Lewis, B. M. Prior, M. A. Sloniger, and D. A. Rowe. Density of the fat-free mass and estimates of body composition in male weight trainers. $J$ Appl Physiol 80: 2085-96, 1996.

34. Sattler, F. R., S. V. Jaque, E. T. Schroeder, C. Olson, M. P. Dube, C. Martinez, W. Briggs, R. Horton, and S. Azen. Effects of pharmacological doses of nandrolone decanoate and progressive resistance training in immunodeficient patients infected with human immunodeficiency virus. J Clin Endocrinol Metab 84: 1268-76, 1999.

35. Schols, A., P. B. Soeters, R. Mostert, R. J. Pluymers, and E. Wouters. Physiologic effects of nutritional support and anabolic steroids in patients with chronic obstructive pulmonary disease: A placebo-controlled randomized trial. Am. J. Respir. Crit. Care Med. 152: 1268-1274, 1995.

36. Strawford, A., T. Barbieri, R. Neese, L. M. Van, M. Christiansen, R. Hoh, G. Sathyan, R. Skowronski, J. King, and $M$. Hellerstein. Effects of nandrolone decanoate therapy in 
borderline hypogonadal men with HIV-associated weight loss.J Acquir Immune Defic Syndr Hum Retrovirol 20: 137-46, 1999.

37. Strømme, S. B., H. D. Meen, and A. Aakvaag. Effects of an androgenic-anabolic steroid on strength development and plasma testosterone levels in normal males. Med Sci Sports 6: 203-208, 1974.

38. Weiss, U., and H. Müller. Zür Frage der beeinflüssung des Krafttrainings durch anabole Hormone. Schweizerische Zeitschrift für Sportmedizin: 79-89, 1968.

39. Win-May, M., and M. Mya-Tu. The effect of anabolic steroids on physical fitness. I Sports Med Phys Fitness 15: 266-71, 1975.

40. Yesalis, C. E. Anabolic steroids in sport and exercise. Champaign: Human Kinetics, 2000. 


\title{
CHAPTER 5
}

\section{Androgenic-anabolic steroids and human deltoid muscle fibers: difference between polydrug regimens and single drug administration}

\author{
Fred Hartgens \\ Henny van Straaten \\ Swen Fideldij \\ Gerard Rietjens \\ Hans A. Keizer \\ Harm Kuipers
}

Netherlands Centre for Doping Affairs, Capelle aan den IJssel

Dept of Anatomy/Embryology, Maastricht University, Maastricht Dept of Movement Sciences, Maastricht University, Maastricht

Submitted for publication 


\section{CHAPTER 5}

\section{ABSTRACT}

Introduction: The objective of this investigation was to study the effects of androgenic-anabolic steroids (AAS) on deltoid muscle fiber characteristics in experienced, male strength athletes.

Methods: In a double blind study fifteen volunteers were administered nandrolone decanoate (ND) for eight weeks (200 mg per week, intramuscularly). In an additional study, 12 subjects self-administered various AAS in supratherapeutical dosages (AAS group), while 7 non-users served as controls. In all subjects, a percutaneous needle biopsy of the deltoid muscle was obtained at baseline and after 8 weeks. Muscle sections were pre-incubated at $\mathrm{pH} 4.4$, adenosine triphosphatase stained and morphometric analyzed. In each biopsy at least 150 fibers were classified for "gray level" and "lesser fiber diameter" to determine the mean fiber size, the size of type I and type II fibers, and the fiber type distribution.

Result: ND administration did not affect any parameter. In the AAS group mean muscle fiber size $(+12.6 \%)$, the size of type I $(+10.8 \%)$ and type II $(+14.6 \%)$ muscle fibers increased. Fiber type distribution remained unaltered.

Conclusions: Polydrug regimens of AAS in supratherapeutical dosages increase the size of deltoid muscle fibers (especially type II fibers) in experienced strength athletes, while ND in a therapeutical dose exerts no effect. 


\section{INTRODUCTION}

Strength training leads to hypertrophy of muscle tissue, mainly attributable to hypertrophy of the fast-twitch muscle fibers (23, 29-31). Muscle biopsy studies in experienced strength athletes demonstrated enlargements of muscle fibers of different muscles, i.e. the vastus lateralis, the gastrocnemius, the biceps brachii and deltoid muscles $(23,29-31)$. Since the muscle fibers did not seem to enlarge unlimited, these researchers hypothesized that after long term regular strength training the hypertrophic effects of individual fibers may reach a plateau. They further suggested that muscle hyperplasia may be responsible for the continuing growth after reaching such a plateau in fiber hypertrophy. Recently, data has been presented that supports the hypothesis that muscle hyperplasia indeed may occur in humans $(2,16,18,28)$.

Pronounced muscle hypertrophy and the underlying mechanism can be studied properly in strength athletes (e.g. weight lifters and bodybuilders). For many years the use of androgenic-anabolic steroids (AAS) among strength athletes is very popular due to the supposed effects on muscle strength, body composition and muscle mass (33). In the last decades the effects on strength and body composition have been well established and reviewed recently $(5,10)$. Most studies have drawn conclusions based on determination of body composition using the two-compartment model. However, such studies do not provide solid evidence for drawing conclusions at the muscle fiber level.

Data upon the effects of AAS on muscle fibers in strength athletes, however, is scarce and equivocal $(1,11,16,18,21,22)$. In cross-sectional studies muscle fiber size of AAS users has been reported to be larger than in non-users $(11,18)$. On the other hand, prospective studies provided more equivocal results. Alen et al (1984) found an increase of slow twitch muscle fiber size of the vastus lateralis muscle after 6 months administration of high doses AAS, although this study suffered from methodological weaknesses due to analysis of only a few number of muscle fibers in the subjects (1). Kuipers and coworkers also studied the effects of AAS on the vastus lateralis muscle, but did not find alterations of muscle fiber size in one study (22), whereas in another study in increase of mean vastus lateralis muscle fiber size was observed (21). These differences can mainly be attributed to methodological differences in muscle fiber size measurements. Alen et al (1984) and Kuipers et al (1993) determined muscle fiber cross-sectional areas $(1,21,22)$, whereas the lesser fiber diameter method according to Dubowitz (1985) was used in the other study $(1,21,22)$. The advantage of the latter method is that it avoids overestimating of fiber size due to oblique cut of the biopsy sections (6). Moreover, it is questionable whether the vastus lateralis muscle is the best choice for such investigations since the selective adaptation of upper body muscles to AAS has been described already long ago (20). Recently, this has been confirmed in strength athletes 
who showed predominant gains in muscle mass of the thorax, shoulder and upper arm $(11-13,22)$. Nevertheless, there is still uncertainty about the effects of AAS on muscle fibers, especially about the different effects of various AAS administration regimens and the possible predominance of some body parts over other body regions.

Based on the aforementioned observations we hypothesized that changes of muscle fibers would occur earlier and more pronounced in shoulder girdle muscles. Therefore, we decided to study the deltoid muscle. The purpose of this study was to investigate in a prospective design the effects of AAS on skeletal muscle fiber characteristics of the deltoid muscle in male strength athletes, with special reference to the dose-response relationship.

\section{METHODS}

\section{Subjects}

This study was part of a larger study exploring the effects of AAS on body composition and health in strength athletes. For the entire study project we recruited a large number of volunteers by flyers in regional gym clubs. The volunteers were informed about the studies in several meetings and by mailings. Approximately 90 strength athletes were willing to participate in one or more studies.

Before admission to the study the subjects had to meet all the criteria set by the investigators: male, strength training experience for a minimum of 3 years, at least 4 strength training work-outs per week or 8 hours strength training weekly, and age between 20 and 45 years. Exclusion criteria were as follows: hypertension, diabetes mellitus, liver disease or abnormal liver enzyme serum levels, hereditary hypercholesterolemia, elevated serum cholesterol (>6,5 $\mathrm{mmol} / \mathrm{l})$, infertility and smoking.

All athletes had to answer an extensive questionnaire with questions related to current and previous health status, training habits and history, dietary intake and the use of nutritional supplements, and the use of AAS. In individual interviews with a physician (F.H.) the questionnaires were gone over to obtain complete and correct data. In addition, a full medical examination for evaluation of the health status and to exclude any relevant disease conditions was performed by a physician. Only volunteers who appeared to be healthy and who met all criteria set by the investigators were admitted to the study.

The study was approved by the Medical Ethical Review Committee of the Maastricht University and the University Hospital Maastricht. Before entering the study every subject gave his written informed consent. 


\section{Study design}

To address the objectives set we conducted two studies that were assumed to be complementary. Study 1 was designed as a randomized, double blind, placebo controlled study and investigated the effects of 8 weeks administration of one single anabolic steroid in a high therapeutic dose. The anabolic steroid chosen for investigation was nandrolone decanoate (DecaDurabolin ${ }^{\circledR}$, Organon, Oss, The Netherlands), a very popular and commonly used substance by strength athletes. In this study fifteen volunteers participated, who were randomly assigned to the nandrolone decanoate $(n=8)$ or placebo group ( $n=7$ ), (ND-group and Plac-group, respectively). Once a week the strength athletes visited the laboratory for administration of the intramuscular injection containing either $200 \mathrm{mg} /$ week nandrolone decanoate or placebo for eight weeks. The injections were administered by one of the investigators.

In study 2 we used a non-blinded, prospective research design. We investigated the effects of self-administration of high doses AAS for 8 weeks on muscle fiber characteristics in 19 experienced strength athletes. The athletes purchased the AAS themselves on the black market, although some had received a prescription by a medical doctor. The self-administration of these substances was characterized by using several drugs simultaneously in weekly varying dosages that was based on their own insights and beliefs. This resulted, without any exception, in the administration of supratherapeutical doses of these substances. The researchers were in no way involved in obtaining AAS, composition of regimens and dosages, nor in the administration of the drugs. Twelve strength athletes who intended to start self-administration of AAS participated in this study (AAS group), whereas the control group (CO group) consisted of 7 non-using strength athletes. With the exception of one subject, all volunteers of the AAS group had large experience in self-administering doping substances, whereas in the controls only one subject had used one course of AAS previously. The AAS group had started the administration of AAS courses on average 4.2 years ago (range 0 - 14 years). The mean number of self-administered AAS courses were 6.9 (range $0-30$ courses). The characteristics of the subjects in both studies are presented in Tables 1 and 2.

\section{Muscle biopsy sampling procedure}

After local anesthesia of the skin and muscle fascia in all subjects a percutaneous needle biopsy from the posterior part of the right deltoid muscle was taken at baseline and after 8 weeks study period. In all volunteers the biopsy sample after 8 weeks was obtained at the same deltoid muscle part, but slightly proximal from the baseline sample.

The procedure was performed with the subjects in prone position on a examination couch with the right upper arm as relaxed as possible. During 
Table 1. Baseline physical and training characteristics of the strength athletes in study 1.

\begin{tabular}{lll}
\hline & $\begin{array}{l}\text { Nandrolone Decanoate } \\
(\mathrm{n}=8)\end{array}$ & $\begin{array}{l}\text { Placebo } \\
(\mathrm{n}=7)\end{array}$ \\
\hline Age (years) & $33 \pm 9$ & $31 \pm 8$ \\
Height $(\mathrm{cm})$ & $174 \pm 9$ & $177 \pm 5$ \\
Body mass $(\mathrm{kg})$ & $73.6 \pm 10.5$ & $83.8 \pm 9.0$ \\
Percentage fat $(\%)$ & $15.3 \pm 2.8$ & $17.6 \pm 2.4$ \\
Training experience (years) & $6.3 \pm 4.9$ & $6.8 \pm 2.9$ \\
Training (hours / week) & $7.8 \pm 1.9$ & $8.9 \pm 2.9$ \\
\hline
\end{tabular}

Table 2. Baseline physical, training and AAS characteristics of the strength athletes in study 2.

\begin{tabular}{lll}
\hline & $\begin{array}{l}\text { AAS } \\
(n=12)\end{array}$ & $\begin{array}{l}\text { Controls } \\
(\mathrm{n}=7)\end{array}$ \\
\hline Age (years) & $31 \pm 8$ & $32 \pm 6$ \\
Height $(\mathrm{cm})$ & $175 \pm 10$ & $178 \pm 3$ \\
Body mass $(\mathrm{kg})$ & $85.1 \pm 10.5$ & $86.9 \pm 8.4$ \\
Percentage fat $(\%)$ & $17.3 \pm 5.1$ & $17.7 \pm 4.3$ \\
Training experience (years) & $10.3 \pm 8.4$ & $8.1 \pm 4.3$ \\
Training (hours / week) & $8.5 \pm 2.4$ & $8.5 \pm 3.3$ \\
\hline
\end{tabular}

one procedure two muscle tissue specimens were taken using a Bergström needle with a diameter of 5 millimeter while applying suction to optimize sampling size $(3,7)$. Each muscle tissue sample was immediately mounted on a cork with Tissue Tek, quickly frozen in isopenthane and cooled to the melting point in liquid nitrogen $\left(-196^{\circ}\right.$ Celsius). Thereafter, the biopsy samples were stored at $-80^{\circ}$ Celsius until processing.

\section{Histological staining and morphometric analysis}

Using a cryostat microtome serial sections of approximately 10 micrometer were cut perpendicular to the fiber axis, at a temperature of $-30^{\circ}$ Celsius. The sections were mounted on glass slides and air dried. To optimize the distinction between type I and type II muscle fibers multiple sections from each biopsy sample were pre-incubated at various $\mathrm{pHs}$ of 4.2, 4.3, 4.4, 4.6 and 10.3 and thereafter adenosine triphosphatase (ATP-ase) stained (26). It turned out that pre-incubation at the $\mathrm{pH}$ of 4.4 provided the best distinction between type I and type II muscle fibers. Per strength athlete sections were morphometrically analyzed using a Leica DM RA video-microscope coupled to a Leica Quantimet Image Analysis System with Leica Q-Win software package (Leica Microsystems, Wetzlar, Germany). Each section was sampled into a 8-bit (256 gray levels) digital image after optimizing the gray level trajectory from o for black fibers to white (translucent) background. The fibers were detected automatically and the parameters "lesser fiber diameter" and "gray level" from at least 150 fibers per biopsy sample were stored. Per section a cumulative gray level histogram was drawn corresponding to type I and type II fibers. The percentage of each fiber type was determined. A 
few intermediate gray level classes could not be assigned to any of these types, and those were classified as "miscellaneous". The lesser fiber diameter of a fiber was determined by the longest short axis possible, the latter being perpendicular to the long axis (6). The lesser diameter was subsequently coupled to its fiber type.

\section{Monitoring training, nutrition, and compliance}

In all subjects training and nutritional habits were monitored by collecting dietary and training data in the week before the start of the study and in week 8 . The nutritional intake was determined by means of a three day diary. Analysis of the personal dietary diaries revealed that intake of macro and micro nutrients did not change throughout the study period. Training data were obtained by means of a one week log book. The training logs showed that weekly training work load did not change during the study period.

To monitor drug use in the participating strength athletes we collected urine samples in all subject before the start of the experiment, as well as after four and eight weeks study period. Eventually, about one third of all samples, at random chosen, was analyzed by the Netherlands institute for Drugs and Doping Research, Utrecht, The Netherlands. No baseline urine samples did contain any anabolic substance. During the study the subjects who received nandrolone decanoate (study 1) metabolites of this substance were found in the urine samples. In the strength athletes who self-administered AAS (study 2) analysis of the urine samples many metabolites of these substances were detected. In the urine samples of the placebo group (study 1) and the non-using controls (study 2) no metabolites of anabolic substances were found.

\section{Statistical analysis}

Data are presented as mean \pm s.d. Baseline data between groups were compared with the Mann-Whitney U-test. Intervention effects were analyzed using the Mann-Whitney U-test comparing the observed within-group changes. Statistical significance was accepted for P-values less than 0.05 .

\section{RESULTS}

\section{Study 1}

At baseline the physical and training characteristics of the subjects of the ND and placebo group were not significantly different with the exception of body mass that was lower in the ND group (table 1). The mean muscle fiber diameter, as well as the diameters of type I and type II muscle fibers of both 
Table 3. Effects of nandrolone decanoate on deltoid muscle fiber distribution and size in the double blind, placebo controlled study (study 1 ).

\begin{tabular}{llll}
\hline & & Baseline & 8 weeks \\
\hline Mean fiber diameter $(\mu \mathrm{m})$ & $\begin{array}{l}\text { Nandrolone } \\
\text { Placebo }\end{array}$ & $\begin{array}{l}70.8 \pm 13.1 \\
70.5 \pm 9.9\end{array}$ & $70.9 \pm 7.6$ \\
& & $74.9 \pm 11.6$ \\
Diameter type I $(\mu \mathrm{m})$ & $\begin{array}{l}\text { Nandrolone } \\
\text { Placebo }\end{array}$ & $62.6 \pm 9.6$ & $65.4 \pm 5.3$ \\
& $66.1 \pm 10.4$ & $68.6 \pm 9.1$ \\
Diameter type II $(\mu \mathrm{m})$ & $\begin{array}{l}\text { Nandrolone } \\
\text { Placebo }\end{array}$ & $80.9 \pm 18.1$ & $81.4 \pm 11.1$ \\
& & $77.8 \pm 13.4$ & $83.5 \pm 17.0$ \\
\% Fibers type I & Nandrolone & $55.0 \pm 10.9$ & $64.9 \pm 7.3$ \\
& Placebo & $61.1 \pm 12.7$ & $55.1 \pm 12.8$ \\
\% Fiber type II & Nandrolone & $44.1 \pm 11.1$ & $34.8 \pm 7.1$ \\
& Placebo & $37.6 \pm 12.8$ & $43.8 \pm 12.7$ \\
\% Miscellaneous & Nandrolone & $0.9 \pm 1.1$ & $1.3 \pm 1.8$ \\
& Placebo & $1.4 \pm 2.1$ & $1.2 \pm 1.9$ \\
\hline
\end{tabular}

groups were comparable at the start. The same was true for the fiber type distribution. After 8 weeks, no significant alterations of any muscle fiber parameter could be observed due to nandrolone decanoate and placebo administration (Table 3).

\section{Study 2}

The physical and training characteristics, as well as all muscle data of the self-administration group and the non-users were comparable at baseline (Table 2). In the control group eight weeks of strength training did not affect any muscle fiber parameter measured. On the other hand, in the AAS group significant intra-group enlargements of the muscle fiber size were observed during the eight weeks study period. The mean muscle fiber diameter increased $12.6 \%$ from $70.5 \pm 14.5$ to $79.4 \pm 12.1 \mu \mathrm{m}$ ( $P<0.03)$. The AAS induced enlargement of the diameters of type I and type II muscle fiber were $10.8 \%(\mathrm{P}<0.05)$ and $14.6 \%(\mathrm{P}<0.03)$, respectively. However, statistical analysis with the Mann-Whitney U-test for comparison of the differences observed in the two groups revealed that the alterations of mean fiber diameter $(\mathrm{P}<0.08)$, diameter type I fibers $(\mathrm{P}<0.10)$ and diameter type II fibers $(P<0.07)$ failed to reach the level of significance. The proportional distribution of the fiber types remained unaltered in both groups during the study period. (Table 4). 
Table 4. Effects of administration of multiple AAS on deltoid muscle fiber size and distribution (study 2).

\begin{tabular}{llll}
\hline & & Baseline & 8 weeks \\
\hline Mean fiber diameter $(\mu \mathrm{m})$ & AAS & $69.8 \pm 14.1$ & $77.6 \pm 13.3^{\#}$ \\
& Controls & $70.2 \pm 11.4$ & $70.7 \pm 5.7$ \\
Diameter type I $(\mu \mathrm{m})$ & AAS & $67.6 \pm 14.1$ & $74.9 \pm 11.1^{\#}$ \\
& Controls & $66.2 \pm 14.0$ & $65.4 \pm 7.2$ \\
Diameter type II $(\mu \mathrm{m})$ & AAS & $79.9 \pm 16.2$ & $91.6 \pm 15.9^{\#}$ \\
& Controls & $80.3 \pm 12.4$ & $80.6 \pm 5.9$ \\
\% Fibers type I & AAS & $72.9 \pm 8.0$ & $71.8 \pm 9.1$ \\
& Controls & $72.7 \pm 13.4$ & $67.1 \pm 7.3$ \\
\% Fiber type II & AAS & $26.3 \pm 7.9$ & $26.5 \pm 10.0$ \\
& Controls & $25.1 \pm 13.0$ & $31.4 \pm 7.0$ \\
\% Miscellaneous & AAS & $0.8 \pm 0.9$ & $1.5 \pm 1.8$ \\
& Controls & $2.2 \pm 4.5$ & $1.6 \pm 2.9$ \\
\hline
\end{tabular}

Legend: \# indicates $\mathrm{P}<0.05$

\section{DISCUSSION}

The most important observation of this study was that strength training combined with the administration of supratherapeutical doses of AAS in a polydrug regimen induced an enlargement of the deltoid muscle fibers in experienced strength athletes, whereas strength training plus the administration of a single anabolic steroid (i.e. nandrolone decanoate) in a therapeutical dose did not exert any effect. Moreover, the effects of the former regimen was more pronounced in the type II muscle fibers than in the type I fibers (enlargement of $14.6 \%$ versus $10.8 \%$, respectively). Therefore, these findings suggests that enlargement of deltoid muscle fibers may be attributed to the use of high doses of AAS and different substances simultaneously, although it remains to be established which factor is more important.

In the present study muscle fiber size measurements were performed using the lesser fiber diameter method (6). Compared to fiber area measurements this method has the advantage that overestimation of fiber size due to oblique cut fibers can be reduced largely (6). Therefore, the lesser fiber diameter method seems to be preferable although no proper comparisons of both methods have been performed yet.

The method of muscle fiber classification used in the present study was different from those used in previous studies $(1,16,21,22,24,25,31)$. In most studies classification of muscle fiber types was based on subjective methods by identifying differences in gray colors of the fibers by the investigator's eye. We adjusted a computer analysis of the gray colors of each individual fiber. This method is independent of the inability of the human eye to 
detect small differences in gray colors. Therefore, computer based analysis of the gray colors of the muscle fibers seems to be a more objective method, preconceived that the staining of the biopsy section was appropriate.

At baseline, in all groups studied a predominance of type I muscle fibers over type II fibers was observed. However, the type II fibers were approximately $15-30 \%$ larger than type I muscle fibers. The composition of the deltoid muscle in the present studies was in agreement with previous investigations, that indicated that this muscle is predominated by type I muscle fibers over type II fibers in athletes involved in strength disciplines (29-31). For example, Tesch and co-workers reported that the deltoid muscle of weight and power lifters as well as bodybuilders consisted of a preponderance of type I muscle fibers (54\% and $65 \%$, respectively), while in kayakers the predominance of type I fibers was even more pronounced (30). In strength athletes the size of the type II deltoid muscle fibers, however, is larger than of the type I fibers. This is in accordance with data of other muscle groups, including the vastus lateralis, gastrocnemius, trapezius, biceps brachii and triceps brachii muscle (24, 25, 29-31).

In the present study short-term self-administration of high doses AAS increased the size of the deltoid muscle fibers, with a more pronounced enlargement of type II fibers $(+14.6 \%)$ compared to type I fibers $(+10.8 \%)$. The deltoid muscle was not subject to AAS studies before, since previous investigations focused mainly on the thigh, the triceps brachii and the trapezius muscle $(1,4,8,11,16,19,21,22)$. The observations in these studies, however, were equivocal. In prospective studies the vastus lateralis muscle fibers of strength athletes have been shown to enlarge due to AAS when fiber area measurements were performed $(1,21)$. Conversely, measurements of the lesser fiber diameters of the vastus lateralis muscle did not reveal any changes under low and high dosages of AAS in strength athletes (22) nor in muscular dystrophia patients (9). Furthermore, in well designed studies enlargement of the triceps brachii area and thigh mass due to testosterone administration has been observed using magnetic resonance imaging (4) or ultrasonography (8). Unfortunately, the latter studies did not investigate changes at the muscle fiber level. Recently, two cross-sectional studies focused on cellular adaptation due to AAS abuse (11, 19). Both reported that the largest difference in muscle fiber size between AAS users and non-users could be observed in the type I muscle fibers, i.e. vastus lateralis muscle (11) and trapezius muscle (19), as a result of long-term AAS abuse. However, the present study nor previous studies ( 1 , 21,22 ) draw conclusions that could support the findings in the cross-sectional studies.

Although the present study was not designed to investigate the working mechanism underlying the observed changes, the available literature as well as the findings of the present study to address this issue. It has been 
well established that the administration of androgens increases protein synthesis and decreases protein breakdown $(9,27)$, although this was not reflected in increments of muscle mass on the cellular level (9). Van Marken Lichtenbelt et al. (2000) showed that the AAS induced changes in body dimensions and composition were due to an increase of muscle mass (32) and should not be attributed to an increase in fluid retention as proposed previously $(14,15)$. The intake of AAS in combination with strength training has been shown to induce an increase in muscle fiber size both by hypertrophy and the formation of new fibers $(16,19)$. Kadi and co-workers proposed that the fundamental process for muscle fiber growth seems to be the incorporation of the satellite cells into preexisting fibers to maintain a constant nuclear to cytoplasmatic ratio. Furthermore, satellite cells seem to play a key role that is enhanced by AAS administration $(16,19)$. Additionally, the role of androgen receptors is important. Androgen receptors are expressed in myonuclei of muscle fibers and in capillaries. Myonuclei that contain androgen receptors are more present in neck and shoulder muscles than in limb muscles. Administration of AAS induces an increase in androgen receptor containing myonuclei in the shoulder girdle muscles but not in the vastus lateralis $(16,17)$. This may, at least in part, explain the regional differences in expression of the effects of AAS on muscle fibers as well as on body dimensions as observed recently $(12,13,16,17,32)$.

In conclusion, in experienced strength athletes the size of deltoid muscle fibers increased due to the administration of various AAS simultaneously in supratherapeutical dosages, but not after the use of only one anabolic steroid (nandrolone decanoate) in a therapeutical dose. The effect on type II fiber size was more pronounced than on the size of type I fibers (enlargements of $+14.6 \%$ and $+10.8 \%$, respectively). Fiber type distribution remained unaffected after both AAS administration regimens. Further research should investigate whether the total dose used or the kind of substances administered would be more important for enlargement of muscle fibers.

\section{ACKNOWLEDGEMENTS}

We greatly acknowledge the technical assistance of Gerrit van Kranenburg (Dept of Movement Sciences, Maastricht University) for his help in processing the muscle biopsy samples and the ATP-ase staining procedure of the biopsy sections. 


\section{REFERENCES}

1. Alen, M., K. Hakkinen, and P. V. Komi. Changes in neuromuscular performance and muscle fiber characteristics of elite power athletes self-administering androgenic and anabolic steroids. Acta Physiol Scand 122: 535-44, 1984.

2. Appell, H.-J., S. Forsberg, and W. Hollmann. Satellite cell activation in human skeletal muscle after training: evidence for muscle fiber neoformation. Int J Sports Med 9: 297-299, 1988.

3. Bergstrom, J. Percutaneous needle biopsy of skeletal muscle in physiological and clinical research. Scand J Clin Lab Invest 35: 609-16, 1975.

4. Bhasin, S., T. W. Storer, N. Berman, C. Callegri, B. Clevenger, J. Phillips, T. J. Bunnell, R. Tricker, A. Shirazi, and R. Casaburi. The effects of supraphysiologic doses of testosterone on muscle size and strength in normal men. New Eng/ J Med 335: 1-7, 1996.

5. Celotti, F., and C. P. Negri. Anabolic steroids: a review of their effects on the muscles, of their possible mechanisms of action and of their use in athletics. I Steroid Biochem Mol Biol 43: 469-77, 1992.

6. Dubowitz, V. Muscle biopsy: a practical approach. Philadelphia: Bailliere Tindall, 1985.

7. Evans, W. J., S. D. Phinney, and V. R. Young. Suction applied to a muscle biopsy maximizes sample size. Med Sci Sports Exerc 14: 101-2, 1982.

8. Giorgi, A., R. P. Weatherby, and P. W. Murphy. Muscular strength, body composition and health responses to the use of testosterone enanthate: a double blind study. J Sci Med Sport 2: 341-55, 1999.

9. Griggs, R. C., W. Kingston, R. F. Jozefowicz, B. E. Herr, G. Forbes, and D. Halliday. Effect of testosterone on muscle mass and muscle protein synthesis. $J$ Appl Physiol 66: 498-503, 1989.

10. Hartgens, F., and H. Kuipers. Effects of androgenic-anabolic steroids in athletes; a review. 2001 (submitted for publication).

11. Hartgens, F., H. Kuipers, J. Wijnen, and H. A. Keizer. Body composition, cardiovascular risk factors and liver function in long term androgenic-anabolic steroids using bodybuilders three months after drug withdrawal. Int. J. Sports Med. 17: 429-433, 1996.

12. Hartgens, F., W. Van Marken Lichtenbelt, S. Ebbing, N. Vollaard, and H. Kuipers. Body composition and anthropometry in bodybuilders: regional changes due to nandrolone decanoate administration. Int J Sports Med, 2001 (in press).

13. Hartgens, F., W. Van Marken Lichtenbelt, S. Ebbing, N. Vollaard, G. Rietjens, and H. Kuipers. Androgenic-anabolic steroids induced changes of anthropometry and body composition in strength athletes. The Physician and Sportsmedicine 29: 49-66, 2001.

14. Hervey, G. R., I. Hutchinson, A. V. Knibbs, L. Burkinshaw, P. R. Jones, N. G. Norgan, and M. J. Levell. "Anabolic" effects of methandienone in men undergoing athletic training. Lancet 2: 699-702, 1976.

15. Hervey, G. R., A. V. Knibbs, L. Burkinshaw, D. B. Morgan, P. R. Jones, D. R. Chettle, and D. Vartsky. Effects of methandienone on the performance and body composition of men undergoing athletic training. Clin Sci 60: 457-61, 1981.

16. Kadi, F. Adaptation of human skeletal muscle to training and anabolic steroids. Acta Physiol Scand Suppl 646: 1-52, 2000.

17. Kadi, F., P. Bonnerud, A. Eriksson, and L. E. Thornell. The expression of androgen receptors in human neck and limb muscles: effects of training and self-administration of androgenic-anabolic steroids. Histochem Cell Biol 113: 25-9, 2000.

18. Kadi, F., A. Eriksson, S. Holmner, G. S. Butler-Browne, and L. E. Thornell. Cellular adaptation of the trapezius muscle in strength-trained athletes. Histochem Cell Biol 111: 189-95, 1999.

19. Kadi, F., A. Eriksson, S. Holmner, and L. E. Thornell. Effects of anabolic steroids on the muscle cells of strength-trained athletes. Med Sci Sports Exerc 31: 1528-34, 1999. 
20. Kenyon, A. T., K. Knowlton, I. Sandiford, F. C. Koch, and G. Lotwin. A comparative study of the metabolic effects of testosterone proprionate in normal men and women and in eunuchoidism. Endocrinology 26: 26-45, 1940.

21. Kuipers, H., B. F. Peeze, F. Hartgens, J. A. Wijnen, and H. A. Keizer. Muscle ultrastructure after strength training with placebo or anabolic steroid. Can J Appl Physiol 18: 189-96, 1993.

22. Kuipers, H., J. A. G. Wijnen, F. Hartgens, and S. M. M. Willems. Influence of anabolic steroids on body composition, blood pressure, lipid profile and liver function in bodybuilders. Int J Sports Med 12: 413-418, 1991.

23. MacDougall, J. D. Morphological changes in human skeletal muscle following strength training and immobilization. In: Human muscle power, edited by N. L. Jones, N. McCartney and A. J. McComas. Champaign, Illinois: Human Kinetic Publishers, Inc., 1986, p. 269-88.

24. MacDougall, J. D., D. G. Sale, S. E. Alway, and J. R. Sutton. Muscle fiber number in biceps brachii in bodybuilders and control subjects. J Appl Physiol 57: 1399-403, 1984.

25. MacDougall, J. D., D. G. Sale, G. C. Elder, and J. R. Sutton. Muscle ultrastructural characteristics of elite powerlifters and bodybuilders. Eur J Appl Physiol 48: 117-26, 1982.

26. Padykula, H., and E. Herman. Factors affecting the activity of adenosine triphosphatase and other phosphatases as measured by histochemical techniques. $J$ Histochem Cytochem 3: 161-70, 1955.

27. Sheffield-Moore, M., R. J. Urban, S. E. Wolf, J. Jiang, D. H. Catlin, D. N. Herndon, R. R. Wolfe, and A. A. Ferrando. Short-term oxandrolone administration stimulates net muscle protein synthesis in young men. J Clin Endocrinol Metab 84: 2705-11, 1999.

28. Sjostrom, M., J. Lexell, A. Eriksson, and C. C. Taylor. Evidence of fibre hyperplasia in human skeletal muscles from healthy young men? A left-right comparison of the fibre number in whole anterior tibialis muscles. Eur J App/ Physiol 62: 301-4, 1991.

29. Tesch, P. A. Skeletal muscle adaptations consequent to long-term heavy resistance exercise. Med Sci Sports Exerc 20: S132-4, 1988.

30. Tesch, P. A., and J. Karlsson. Muscle fiber types and size in trained and untrained muscles of elite athletes. J Appl Physiol 59: 1716-20, 1985.

31. Tesch, P. A., and L. Larsson. Muscle hypertrophy in bodybuilders. Eur J Appl Physiol 49: 301-6, 1982.

32. Van Marken Lichtenbelt, W., F. Hartgens, S. Ebbing, N. Vollaard, and H. Kuipers. Body builders' body composition: effect of androgenic-anabolic steroids. Submitted, 2000.

33. Yesalis, C. Anabolic steroids in sport and exercise (2nd ed.). Champaign IL: Human Kinetics, 2000. 


\title{
CHAPTER 6
}

\section{Prospective echocardiographic assessment of androgenic-anabolic steroids administration on cardiac structure and function in strength athletes}

\author{
Fred Hartgens \\ Emile C. Cheriex \\ Harm Kuipers
}

Netherlands Centre for Doping Affairs, Capelle aan den IJssel

Dept of Cardiology, University Hospital Maastricht

Dept of Movement Sciences, Maastricht University, Maastricht

Submitted for publication 


\section{ABSTRACT}

Introduction: In the last decades AAS abuse has been associated with the occurrence of serious cardiovascular disease in young athletes. Therefore, the purpose of this study was to investigate the effects of AAS on heart structure and function in experienced strength athletes, with special reference to the impact of the length of AAS abuse and the differences between the administration of a single anabolic steroid and polydrug regimens.

Methods: To meet the objectives set we designed two studies. In Study 1 the effects of AAS were assessed in 19 subjects (age $31 \pm 7$ years) who self-administered AAS for 8 or 14 weeks and in 16 non-using volunteers (age $33 \pm 5$ years) in a non-blinded design. The effects of administration of nandrolone decanoate ( $200 \mathrm{mg} / \mathrm{wk}$ i.m.) for eight weeks in 16 bodybuilders were subject of a randomised double blind, placebo controlled investigation (Study 2).

In all subjects $M$-mode and two-dimensional Doppler-echocardiography was performed at baseline and after 8 weeks AAS administration. In the athletes of study 1 who used AAS for 14 weeks a third echocardiogram was also made at the end of the AAS administration period. Echocardiographic determination of the aortic diameter (AD), left atrium diameter (LA), left ventricular end diastolic diameter (LVEDD), left ventricular end systolic diameter (LVESD), interventricular septum thickness (IVS), posterior wall end diastolic wall thickness (PWEDWT), posterior wall end systolic wall thickness (PWESWT), left ventricular mass (LVM), left ventricular mass index (LVMI), ejection fraction (EF), left ventricular end diastolic volume (EDV) and left ventricular end systolic volume (ESV) was performed. For assessment of the diastolic function measurements of $E$ and $A$ peak velocities and calculation of $E / A$ ratio were used. In addition, acceleration and deceleration times of the E-top (ATM and DT, respectively) were determined. For evaluation of factors associated with stroke volume the aortic velocity integral (AI), aorta peak flow (AV) and left ventricular ejection times (LVET) were determined.

Results: In study 1 eight weeks AAS self-administration did not result in changes of blood pressure or cardiac size and function. Additionally, duration of AAS self-administration did not have any impact on these parameters. Study 2 revealed that eight weeks administration of nandrolone decanoate did not induce significant alterations in blood pressure and heart morphology and function.

Conclusions: The administration of AAS does not lead to detectable echocardiographic alterations of heart morphology and systolic and diastolic function in experienced strength athletes. This is not influenced by the regimen used nor by the length of AAS administration. However, some reservations must be made since the detrimental effects of AAS on the heart are well described in animal studies using (ultra-)microscopic evaluation of heart cell structures. Since echocardiographic evaluation is not sensitive enough to detect alterations at the cellular level it may provide incorrect assessment of the actual cardiac condition in AAS users. 


\section{INTRODUCTION}

In the last decades it has been well established that regular physical activity protects against the occurrence of cardiovascular diseases $(26,31)$. Nowadays many people perform resistance training in gyms to improve their physical and mental health status or for esthetical purposes. Most people try to reach their goals with resistive training programs solely, but an increasing number uses performance enhancing substances for more and faster improvements $(1,45)$. Androgenic-anabolic steroids (AAS) have become very popular among strength athletes, especially because of their widespread availability on the black market $(17,45)$. The hazardous effects of these drugs on health status are of great concern since these athletes self-administer supratherapeutical doses and the quality of the substances purchased on the black market is not guaranteed $(13,17)$. Many detrimental side-effects of AAS including liver diseases $(15,18)$, dysfunction of the reproductive system $(2,3,34)$, and alterations of the mental state and behavior ( 5 , 30) have been reported in the literature. Recently, these substances have been associated with the occurrence of serious cardiovascular disease in healthy, young athletes $(11,12,14,16,19,22,25,38)$. Although these reports are of great concern, until now scientific data about a relationship between AAS administration and heart disease in humans is equivocal. In this light, several researchers have investigated the effects of AAS on blood pressure and heart morphology and function. However, these studies also provided inconclusive results. In some cross-sectional studies echocardiographic assessment of heart morphology and function revealed an increase of the posterior wall thickness, interventricular septum thickness and / or the left ventricular mass in steroid using strength athletes $(10,20,35,42$, 44), whereas other researchers were not able to detect any alteration at all $(9,27,36,41,46)$. Additionally, all longitudinal investigations, except one (35), could not demonstrate any changes of heart structure and function due to the administration of high doses of AAS in non-blinded studies $(9,27,37$, $46)$. On the other hand, on theoretical grounds $(21,33)$ and from animal studies it seems likely that AAS can affect myocardial structure and function considerably $(4,6,7,43)$. Summarizing the available research data, they do not support unequivocally whether AAS induce detrimental effects on the heart in humans. Therefore, the purpose of this study was to investigate the effects of AAS on heart structure and function in experienced strength athletes. Our main objectives were to study:

1) the effects of the administration of a single anabolic steroid and of polydrug regimens on heart morphology and function, and

2) the impact of duration of AAS self-administration on heart morphology and function. 
Table 1. Physical and training characteristics of the strength athletes.

\begin{tabular}{lll}
\hline Study 1 & $\begin{array}{l}\text { AAS } \\
(\mathrm{n}=17)\end{array}$ & $\begin{array}{l}\text { Controls } \\
(\mathrm{n}=15)\end{array}$ \\
\hline Age (years) & $32 \pm 7$ & $33 \pm 5$ \\
Height $(\mathrm{cm})$ & $176 \pm 9$ & $177 \pm 7$ \\
Body weight $(\mathrm{kg})$ & $84.9 \pm 10.2$ & $87.7 \pm 11.1$ \\
Percentage fat (\%) & $16.7 \pm 5.2$ & $19.5 \pm 3.7$ \\
Training load (hours/week) & $8.7 \pm 2.6$ & $8.3 \pm 2.4$ \\
Training experience (years) & $10.7 \pm 7.4$ & $8.8 \pm 3.8$ \\
\hline
\end{tabular}

\begin{tabular}{lll}
\hline Study 2 & $\begin{array}{l}\text { ND-group } \\
(\mathrm{n}=9)\end{array}$ & $\begin{array}{l}\text { PLAC-group } \\
(\mathrm{n}=7)\end{array}$ \\
\hline Age (years) & $33 \pm 9$ & $31 \pm 9$ \\
Height $(\mathrm{cm})$ & $175 \pm 10$ & $177 \pm 7$ \\
Body weight $(\mathrm{kg})$ & $76.0 \pm 12.1$ & $83.8 \pm 9.0$ \\
Percentage fat (\%) & $15.3 \pm 2.6$ & $17.6 \pm 2.4$ \\
Training load (hours/week) & $7.4 \pm 2.1$ & $9.1 \pm 2.0$ \\
Training experience (years) & $7.3 \pm 2.1$ & $6.4 \pm 2.8$ \\
\hline
\end{tabular}

\section{SUBJECTS AND METHODS}

Subjects. Since this study was part of a larger study exploring the effects of anabolic steroids on cardiovascular function and exercise performance in strength athletes we recruited a large number of volunteers by flyers in regional gym clubs. In several meetings the volunteers were extensively informed about the study objectives and approach. Approximately 90 strength athletes applied for participation in one or more of these studies. The subjects had to answer an extensive questionnaire with questions related to current and previous health status, training habits and history, dietary intake and use of nutritional supplements, and the use of AAS. In a personal interview with a medical doctor (F.H.) the completed questionnaires were discussed. Moreover, all subjects underwent a full medical examination for evaluation of their health status and to exclude any relevance disease conditions. Only volunteers who appeared to be healthy and who met all inclusion and exclusion criteria set by the investigators were admitted to the study. Inclusion criteria were: male, strength training experience for a minimum of 3 years, at least 4 strength training work outs per week or 8 hours strength training weekly, and age between 20 and 45 years. The following exclusion criteria were set: hypertension, diabetes mellitus, liver disease or abnormal liver enzyme serum levels, hereditary hypercholesterolaemia, elevated serum total cholesterol $(>6,5 \mathrm{mmol} / \mathrm{l})$, infertility and smoking.

The study was approved by the Medical Ethical Review Committee of the Maastricht University and the University Hospital Maastricht, and all subjects gave their written informed consent before participating. 
Table 2. Outline of the AAS used, dosages and route of administration in the subjects of study 1

\begin{tabular}{|c|c|c|c|c|}
\hline$\overline{N r . ~ I D ~}$ & $\begin{array}{l}\text { Duration } \\
\text { AAS use }\end{array}$ & $\begin{array}{l}\text { AAS used and } \\
\text { route of administration }\end{array}$ & Generic names & $\begin{array}{l}\text { Total amount } \\
\text { of drugs used }\end{array}$ \\
\hline 1. $B C 101$ & 16 weeks & $\begin{array}{l}\text { Stromba (i.m.) } \\
\text { Deca-Durabolin (i.m.) } \\
\text { Primobolan (p.o.) } \\
\text { Primobolan (i.m.) } \\
\text { Masteron (p.o.) } \\
\text { Proviron (p.o.) }\end{array}$ & $\begin{array}{l}\text { stanozolol } \\
\text { nandrolone decanoate } \\
\text { metenolone } \\
\text { metenolone } \\
\text { drostanolone } \\
\text { mesterolone }\end{array}$ & $\begin{array}{l}500 \mathrm{mg} \\
350 \mathrm{mg} \\
375 \mathrm{mg} \\
1400 \mathrm{mg} \\
14 \mathrm{mg} \\
350 \mathrm{mg}\end{array}$ \\
\hline 2. $5 \$ 102$ & 16 weeks & $\begin{array}{l}\text { Stromba (i.m.) } \\
\text { Deca-Durabolin (i.m.) } \\
\text { Primobolan (p.o.) } \\
\text { Primobolan (i.m.) } \\
\text { Masteron (p.o.) } \\
\text { Proviron (p.o.) }\end{array}$ & $\begin{array}{l}\text { stanozolol } \\
\text { nandrolone decanoate } \\
\text { metenolone } \\
\text { metenolone } \\
\text { drostanolone } \\
\text { mesterolone }\end{array}$ & $\begin{array}{l}500 \mathrm{mg} \\
350 \mathrm{mg} \\
375 \mathrm{mg} \\
1400 \mathrm{mg} \\
14 \mathrm{mg} \\
350 \mathrm{mg}\end{array}$ \\
\hline 3. MB108 & 8 weeks & $\begin{array}{l}\text { Deca-Durabolin (i.m.) } \\
\text { Parabolan (i.m) } \\
\text { Dianabol (p.o.) } \\
\text { Pregnyl (i.m.) }\end{array}$ & $\begin{array}{l}\text { nandrolone decanoate } \\
\text { trenbolone acetate } \\
\text { methandrostenolone } \\
\text { choriongonadotrophine }\end{array}$ & $\begin{array}{l}1600 \mathrm{mg} \\
228 \mathrm{mg} \\
940 \mathrm{mg} \\
9000 \mathrm{lU}\end{array}$ \\
\hline 4. JD111 & 12 weeks & $\begin{array}{l}\text { Testoviron (i.m.) } \\
\text { Strombaject (i.m.) } \\
\text { Decadurabolin (i.m.) }\end{array}$ & $\begin{array}{l}\text { testosterone enanthate } \\
\text { stanozolol } \\
\text { nandrolone decanoate }\end{array}$ & $\begin{array}{l}1250 \mathrm{mg} \\
700 \mathrm{mg} \\
100 \mathrm{mg}\end{array}$ \\
\hline 5. $E S 112$ & 16 weeks & $\begin{array}{l}\text { Strombaject (i.m.) } \\
\text { Stromba (p.o.) } \\
\text { Omnadren (i.m.) } \\
\text { Deca-Durabolin (i.m.) } \\
\text { Primobolan (i.m.) }\end{array}$ & $\begin{array}{l}\text { stanozolol } \\
\text { stanozolol } \\
\text { testosterone propionate } \\
\text { nandrolone decanoate } \\
\text { metenolone }\end{array}$ & $\begin{array}{l}750 \mathrm{mg} \\
450 \mathrm{mg} \\
375 \mathrm{mg} \\
875 \mathrm{mg} \\
300 \mathrm{mg}\end{array}$ \\
\hline 6. JN113 & 8 weeks & $\begin{array}{l}\text { Dianabol (p.o.) } \\
\text { Deca-Durabolin (i.m.) } \\
\text { Masteron (i.m.) }\end{array}$ & $\begin{array}{l}\text { methandrostenolone } \\
\text { nandrolone decanoate } \\
\text { drostanolone }\end{array}$ & $\begin{array}{l}960 \mathrm{mg} \\
300 \mathrm{mg} \\
300 \mathrm{mg}\end{array}$ \\
\hline 7. GS115 & 16 weeks & $\begin{array}{l}\text { Clenbuterol (p.o.) } \\
\text { Winstrol (p.o.) } \\
\text { Deca-Durabolin (i.m.) } \\
\text { Stromba (p.o.) } \\
\text { Stromba (i.m.) } \\
\text { Parabolan (i.m.) } \\
\text { Pregnyl (i.m.) } \\
\text { Undestor (i.m.) } \\
\text { Nolvadex (p.o.) }\end{array}$ & $\begin{array}{l}\text { clenbuterol } \\
\text { stanozolol } \\
\text { nandrolone decanoate } \\
\text { stanozolol } \\
\text { stanozolol } \\
\text { trenbolone acetate } \\
\text { choriongonadotrophine } \\
\text { testosterone undecanoate } \\
\text { tamoxiphene }\end{array}$ & $\begin{array}{l}\text { This subject used } \\
\text { these drugs from } \\
\text { the start in stacking } \\
\text { way, but did know } \\
\text { the doses. } \\
\text { He qualified the } \\
\text { dosages as high }\end{array}$ \\
\hline 8. FB121 & 8 weeks & $\begin{array}{l}\text { Deca-Durabolin (i.m.) } \\
\text { Strombaject (i.m.) } \\
\text { Pregnyl (i.m.) }\end{array}$ & $\begin{array}{l}\text { nandrolone decanoate } \\
\text { stanozolol } \\
\text { choriongonadotrophine }\end{array}$ & $\begin{array}{l}2000 \mathrm{mg} \\
750 \mathrm{mg} \\
13500 \mathrm{IU}\end{array}$ \\
\hline 9. RT122 & 16 weeks & $\begin{array}{l}\text { Stromba (p.o.) } \\
\text { Dianabol (p.o.) } \\
\text { Testosterone (i.m.) }\end{array}$ & $\begin{array}{l}\text { stanozolol } \\
\text { methandrostenolone } \\
\text { testosterone heptilate }\end{array}$ & $\begin{array}{l}1080 \mathrm{mg} \\
1240 \mathrm{mg} \\
3000 \mathrm{mg}\end{array}$ \\
\hline 10. GR124 & 8 weeks & $\begin{array}{l}\text { Dianabol (p.o.) } \\
\text { Proviron (p.o.) } \\
\text { Primobolan (i.m.) } \\
\text { Deca-Durabolin (i.m.) } \\
\text { Sustanon (i.m.) } \\
\text { Parabolan (i.m.) } \\
\text { Strombaject (i.m.) } \\
\text { Boldane (i.m.) } \\
\text { Stromba (p.o.) }\end{array}$ & $\begin{array}{l}\text { methandrostenolone } \\
\text { mesterolone } \\
\text { metenolone } \\
\text { nandrolone decanoate } \\
\text { testosterone (phenyl-) } \\
\text { propionate/ isohexanoate } \\
\text { trenbolone acetate } \\
\text { stanozolol } \\
\text { boldenone } \\
\text { stanozolol }\end{array}$ & $\begin{array}{l}560 \mathrm{mg} \\
1400 \mathrm{mg} \\
800 \mathrm{mg} \\
400 \mathrm{mg} \\
1750 \mathrm{mg} \\
602 \mathrm{mg} \\
250 \mathrm{mg} \\
300 \mathrm{mg} \\
420 \mathrm{mg}\end{array}$ \\
\hline
\end{tabular}


Table 2. (continued)

\begin{tabular}{|c|c|c|c|c|c|}
\hline$\overline{N r}$. & ID & $\begin{array}{l}\text { Duration } \\
\text { AAS use }\end{array}$ & $\begin{array}{l}\text { AAS used and } \\
\text { route of administration }\end{array}$ & Generic names & $\begin{array}{l}\text { Total amount } \\
\text { of drugs used }\end{array}$ \\
\hline 11. & $P W=25$ & 8 weeks & $\begin{array}{l}\text { Proviron (p.o.) } \\
\text { Primobolan (i.m.) }\end{array}$ & $\begin{array}{l}\text { mesterolone } \\
\text { metenolone }\end{array}$ & $\begin{array}{l}5600 \mathrm{mg} \\
1600 \mathrm{mg}\end{array}$ \\
\hline 12. & MD139 & 12 weeks & $\begin{array}{l}\text { Synasteron (p.o.) } \\
\text { Deca-Durabolin (i.m.) }\end{array}$ & $\begin{array}{l}\text { oxymetenolone } \\
\text { nandrolone decanoate }\end{array}$ & $\begin{array}{l}3500 \mathrm{mg} \\
1625 \mathrm{mg}\end{array}$ \\
\hline 13. & FL151 & 12 weeks & $\begin{array}{l}\text { Stromba (p.o.) } \\
\text { Stromba (i.m.) } \\
\text { Testoviron (i.m.) } \\
\text { Testex Leo (i.m.) } \\
\text { Pregnyl (i.m.) }\end{array}$ & $\begin{array}{l}\text { stanozolol } \\
\text { stanozolol } \\
\text { testosterone enanthate } \\
\text { testosterone cypionate } \\
\text { choriongonadotrophine }\end{array}$ & $\begin{array}{l}1036 \mathrm{mg} \\
850 \mathrm{mg} \\
3750 \mathrm{mg} \\
5000 \mathrm{mg} \\
4500 \mathrm{IU}\end{array}$ \\
\hline 14. & HK401 & 8 weeks & $\begin{array}{l}\text { Dianabol (p.o.) } \\
\text { Primobolan (p.o.) } \\
\text { Proviron (p.o.) }\end{array}$ & $\begin{array}{l}\text { methandrostenolone } \\
\text { metenolone } \\
\text { mesterolone }\end{array}$ & $\begin{array}{l}1115 \mathrm{mg} \\
1850 \mathrm{mg} \\
675 \mathrm{mg}\end{array}$ \\
\hline 15. & GT402 & 16 weeks & $\begin{array}{l}\text { Stromba (p.o.) } \\
\text { Anapolon (p.o.) }\end{array}$ & $\begin{array}{l}\text { stanozolol } \\
\text { oxymetholone }\end{array}$ & $\begin{array}{l}2170 \mathrm{mg} \\
1225 \mathrm{mg}\end{array}$ \\
\hline 16. & DV403 & 8 weeks & $\begin{array}{l}\text { Deca-Durabolin (i.m.) } \\
\text { Spiropent (p.o.) } \\
\text { Testoviron (i.m.) } \\
\text { Testex Leo (i.m.) } \\
\text { Masteron (i.m.) } \\
\text { Strombaject (i.m.) }\end{array}$ & $\begin{array}{l}\text { nandrolone decanoate } \\
\text { clenbuterol } \\
\text { testosterone enanthate } \\
\text { testosterone cypionate } \\
\text { drostanolone } \\
\text { stanozolol }\end{array}$ & $\begin{array}{l}4400 \mathrm{mg} \\
1.68 \mathrm{mg} \\
2500 \mathrm{mg} \\
1000 \mathrm{mg} \\
300 \mathrm{mg} \\
1200 \mathrm{mg}\end{array}$ \\
\hline 17. & EK404 & 12 weeks & $\begin{array}{l}\text { Strombaject (i.m.) } \\
\text { Testosterone (i.m.) } \\
\text { Spiropent (p.o.) } \\
\text { anadrol (p.o.) } \\
\text { pregnyl (i.m.) } \\
\text { nolvadex (p.o.) }\end{array}$ & $\begin{array}{l}\text { stanozolol } \\
\text { testosterone } \\
\text { clenbuterol } \\
\text { oxymetholone } \\
\text { choriongonadotrophine } \\
\text { tamoxiphene }\end{array}$ & $\begin{array}{l}1150 \mathrm{mg} \\
5500 \mathrm{mg} \\
1.00 \mathrm{mg} \\
1900 \mathrm{mg} \\
1500 \mathrm{IU} \\
440 \mathrm{mg}\end{array}$ \\
\hline
\end{tabular}

Study design. To meet the purpose of this investigation we designed two studies that were considered to be complementary.

Study 1. This study was conducted to investigate the effects of self-administration of high doses AAS on heart morphology and function as well as to explore the impact of duration of AAS use in 32 strength athletes. Seventeen strength athletes who intended to start self-administration of AAS, participated in this study (AAS group) and the control group (Controls) consisted of 15 non-using strength athletes. Physical and training characteristics of both groups are presented in Table 1.

Most participants $(n=26)$ performed resistive training mainly for esthetical purposes. Two strength athletes carried out strength training for esthetical reasons as well as part of their boxing training. The remaining four athletes were mainly involved in powerlifting training and competition.

The controls did not have any experience in AAS use. On the other hand, all participants of the AAS group had self-administered AAS before. They had started the administration of these substances on average 4.6 years before (range 1 to 14 years). These subjects used on average 2 cycles per year and the mean number of AAS cycles used was 6.7 (range 1 to 30 cycles). 
Before entering the study all volunteers were expected to be free of AAS use for at least three months. Information obtained from the subjects indicated that the mean AAS withdrawal period was 7.8 months (range 3 to 30 months). To exclude recent AAS use objectively, in all subjects (AAS group and Controls) urine samples were collected for drug analysis before entering the study.

The strength athletes purchased the drugs mainly on the black market although some had received a prescription from a medical doctor. AAS courses were composed on their own insights and beliefs. The investigators were not involved in providing AAS, no attempt was made to influence the choice of the AAS used nor did the researchers play any role in AAS administration. In table 2 an outline of the AAS used, route of administration and dose for each subject is given.

In all subjects echocardiographic measurements were performed before the start of the study and after eight weeks strength training with or without concomitant AAS self-administration (AAS group and Controls, respectively). In addition, since part of the AAS users had decided to self-administer AAS for 12 to 16 weeks in these strength athletes echocardiographic measurements were also performed at the end of the AAS course.

Study 2. This study was designed to investigate the effects of the administration of a single, very popular anabolic steroid, nandrolone decanoate (Deca-Durabolin ${ }^{\circledR}$, Organon BV, The Netherlands), on heart morphology and function in a randomized, double blind and placebo controlled design. Sixteen well-trained recreational bodybuilders volunteered for this study. They were randomly assigned to the nandrolone decanoate or placebo group (ND or PLAC, respectively). In both groups two subjects had previous experience with AAS administration, whereas the remainder had never used such substances before. Physical and training characteristics are presented in table 1.

Once a week the bodybuilders visited the laboratory for administration of the intramuscular injection containing either $200 \mathrm{mg} /$ week nandrolone decanoate or placebo for eight weeks. The injections were administered by one of the investigators (F.H.). The echocardiographic measurements were performed at baseline and after eight weeks study period.

Blood pressure measurements. After a resting period of 5 minutes in supine position, systolic and diastolic blood pressure were measured with a sphygmomanometer. In both studies, measurements were performed at baseline and after eight weeks.

Echocardiographic measurements. M-mode and two-dimensional Doppler-echocardiography using a Hewlett-Packard Sonos 2500 ultrasound system with standard imaging transducers was performed in all subjects. To avoid inter-observer variability, all echocardiographic measurements were made by the same experienced echocardiographer (E.C). Measured were aortic diameter (AD), left atrium diameter (LA), left ventricular end diastolic 
diameter (LVEDD), left ventricular end systolic diameter (LVESD), interventricular septum thickness (IVS), posterior wall end diastolic wall thickness (PWEDWT), posterior wall end systolic wall thickness (PWESWT), left ventricular mass (LVM), left ventricular mass index (LVMI), ejection fraction (EF), left ventricular end diastolic volume (EDV) and left ventricular end systolic volume (ESV).

Evaluation of diastolic function was performed by measuring $E$ and $A$ peak velocities and calculation of E/A ratio. In addition, acceleration and deceleration times of the E-top (ATM and DT, respectively) were measured. For evaluation of factors associated with stroke volume the aortic velocity integral (AI), aorta peak flow (AV) and left ventricular ejection times (LVET) were determined.

Monitoring training, nutrition and compliance. All participants were asked to maintain their regular training and nutritional habits. To monitor these habits the nutritional intake was determined by means of a three day diary and the training data were obtained by a one week log book. From all subjects of study 1 and 2 the dietary and training data were collected just before the start of the study and in week 8 . In the AAS users who self-administered AAS for 12 to 16 weeks (study 1) these data were also obtained in the last week of AAS use.

Throughout the study period in all subjects several urine samples were collected for drug analysis to objectively exclude recent drug use. The subjects of study 1 provided urine samples at baseline and after 8 weeks. In the athletes who self-administered AAS for 12 to 16 weeks another urine sample was collected at the end of drug administration period. The participants of study 2 provided urine samples at baseline and after 4 and 8 weeks study period. From the urine samples of both studies approximately one third was randomly selected for analysis by the Netherlands Institute for Drug and Doping Research (NIDDR), Utrecht (The Netherlands) to detect metabolites of anabolic agents.

Statistical analysis. All data are presented as mean and standard deviations (mean \pm s.d.). In both studies comparison of baseline data between groups were performed with the Mann-Whitney U-test. In the non-blinded investigation (study 1) the same test was applied for analysis of the intervention effects. We compared changes in the AAS group after eight weeks drug administration with the alterations in the Control group. The impact of duration of AAS self-administration was analyzed by comparing the changes at the end of the drug administration period between the short-term and long-term users. In the double blind study (study 2) the intervention effects were analyzed using ANCOVA since several echocardiographic data of ND and PLAC at baseline differed significantly. In all analyses the level of significance was set at $p<0.05$. 


\section{RESULTS}

Study 1. At baseline both groups were comparable with respect to the physical characteristics, training and nutritional data, as well as blood pressure and echocardiographic data. In the AAS group no significant alterations in blood pressure (Table 3) and the echocardiographic assessment of heart morphology and function could be observed after 8 weeks AAS administration (Table 4). Furthermore, analyzing the impact of duration of AAS self-administration did not reveal any difference between short-term and long-term use (Table 5).

Study 2. At baseline the physical characteristics, training and nutritional data, blood pressure and most echocardiographic measurements were comparable between groups. Echocardiographic determination of LVEDD, LVESD, LVM, EDV and ESV, however, were significantly different between both groups at the start. Eight weeks administration of nandrolone decanoate did not induce significant alterations in blood pressure (Table 3 ) and echocardiographic measurements of heart morphology nor in parameters reflecting systolic and diastolic cardiac function (Table 6).

Table 3. Systolic and diastolic blood pressure measurements at baseline and after 8 weeks in both studies.

\begin{tabular}{llll}
\hline & & Baseline & 8 weeks \\
\hline Study 1. & & & \\
Systolic blood pressure (mm Hg) & AAS & $131 \pm 12$ & $139 \pm 13$ \\
& Controls & $129 \pm 14$ & $134 \pm 8$ \\
& AAS & $83 \pm 6$ & $85 \pm 12$ \\
Diastolic blood pressure (mm Hg) & $\begin{array}{l}\text { Controls } \\
\text { Study 2. }\end{array}$ & & $81 \pm 9$ \\
Systolic blood pressure (mm Hg) & ND-group & $133 \pm 16$ & $128 \pm 16$ \\
& PLAC-group & $130 \pm 14$ & $123 \pm 5$ \\
& & & $83 \pm 13$ \\
Diastolic blood pressure (mm Hg) & ND-group & $83 \pm 13$ & $78 \pm 10$ \\
& PLAC-group & $84 \pm 6$ & \\
\hline
\end{tabular}


Table 4. Echocardiographic measurements at baseline and after 8 weeks in the non-blinded study (study 1).

\begin{tabular}{|c|c|c|c|}
\hline & & Baseline & 8 weeks \\
\hline$\overline{\mathrm{AD}(\mathrm{mm})}$ & $\begin{array}{l}\text { AAS } \\
\text { Controls }\end{array}$ & $\begin{array}{l}34.2 \pm 3.3 \\
33.9 \pm 3.5\end{array}$ & $\begin{array}{l}34.1 \pm 3.4 \\
33.9 \pm 3.3\end{array}$ \\
\hline $\mathrm{LA}(\mathrm{mm})$ & $\begin{array}{l}\text { AAS } \\
\text { Controls }\end{array}$ & $\begin{array}{l}41.2 \pm 3.6 \\
42.5 \pm 3.5\end{array}$ & $\begin{array}{l}41.7 \pm 3.7 \\
41.8 \pm 3.7\end{array}$ \\
\hline LV EDD $(\mathrm{mm})$ & $\begin{array}{l}\text { AAS } \\
\text { Controls }\end{array}$ & $\begin{array}{l}53.6 \pm 5.1 \\
53.5 \pm 4.3\end{array}$ & $\begin{array}{l}53.4 \pm 4.6 \\
53.2 \pm 3.9\end{array}$ \\
\hline $\operatorname{LVESD}(\mathrm{mm})$ & $\begin{array}{l}\text { AAS } \\
\text { Controls }\end{array}$ & $\begin{array}{l}35.0 \pm 4.4 \\
35.1 \pm 3.6\end{array}$ & $\begin{array}{l}35.1 \pm 3.9 \\
35.7 \pm 3.5\end{array}$ \\
\hline IVS (mm) & $\begin{array}{l}\text { AAS } \\
\text { Controls }\end{array}$ & $\begin{array}{l}8.6 \pm 0.9 \\
8.4 \pm 0.9\end{array}$ & $\begin{array}{l}8.8 \pm 1.1 \\
8.3 \pm 1.0\end{array}$ \\
\hline PWEDWT (mm) & $\begin{array}{l}\text { AAS } \\
\text { Controls }\end{array}$ & $\begin{array}{l}8.9 \pm 0.9 \\
8.5 \pm 0.8\end{array}$ & $\begin{array}{l}8.9 \pm 0.7 \\
8.6 \pm 0.8\end{array}$ \\
\hline PWESWT (mm) & $\begin{array}{l}\text { AAS } \\
\text { Controls }\end{array}$ & $\begin{array}{l}14.3 \pm 1.2 \\
14.3 \pm 1.3\end{array}$ & $\begin{array}{l}14.3 \pm 1.2 \\
13.9 \pm 1.3\end{array}$ \\
\hline$E F(\%)$ & $\begin{array}{l}\text { AAS } \\
\text { Controls }\end{array}$ & $\begin{array}{l}63.4 \pm 5.0 \\
63.1 \pm 4.2\end{array}$ & $\begin{array}{l}62.8 \pm 4.7 \\
60.9 \pm 4.9\end{array}$ \\
\hline LVM (gram) & $\begin{array}{l}\text { AAS } \\
\text { Controls }\end{array}$ & $\begin{array}{l}215.1 \pm 43.8 \\
207.3 \pm 46.1\end{array}$ & $\begin{array}{l}216.4 \pm 43.3 \\
206.0 \pm 44.6\end{array}$ \\
\hline LVMI $\left(\mathrm{gram} / \mathrm{m}^{2}\right)$ & $\begin{array}{l}\text { AAS } \\
\text { Controls }\end{array}$ & $\begin{array}{l}108.0 \pm 22.3 \\
100.9 \pm 20.1\end{array}$ & $\begin{array}{l}104.2 \pm 17.0 \\
100.5 \pm 20.6\end{array}$ \\
\hline $\operatorname{EDV}(\mathrm{ml})$ & $\begin{array}{l}\text { AAS } \\
\text { Controls }\end{array}$ & $\begin{array}{l}140.4 \pm 30.8 \\
139.8 \pm 25.3\end{array}$ & $\begin{array}{l}138.7 \pm 28.1 \\
138.4 \pm 24.0\end{array}$ \\
\hline $\operatorname{ESV}(\mathrm{ml})$ & $\begin{array}{l}\text { AAS } \\
\text { Controls }\end{array}$ & $\begin{array}{l}52.1 \pm 15.6 \\
51.8 \pm 12.5\end{array}$ & $\begin{array}{l}51.9 \pm 13.4 \\
54.1 \pm 13.0\end{array}$ \\
\hline AOINT $(\mathrm{cm})$ & $\begin{array}{l}\text { AAS } \\
\text { Controls }\end{array}$ & $\begin{array}{l}25.6 \pm 4.3 \\
27.7 \pm 5.0\end{array}$ & $\begin{array}{l}25.6 \pm 4.0 \\
27.4 \pm 5.8\end{array}$ \\
\hline $\mathrm{AV}(\mathrm{mm} / \mathrm{sec})$ & $\begin{array}{l}\text { AAS } \\
\text { Controls }\end{array}$ & $\begin{array}{l}138.8 \pm 24.0 \\
145.5 \pm 30.5\end{array}$ & $\begin{array}{l}147.2 \pm 33.7 \\
139.4 \pm 30.8\end{array}$ \\
\hline LVET (msec) & $\begin{array}{l}\text { AAS } \\
\text { Controls }\end{array}$ & $\begin{array}{l}285.0 \pm 24.2 \\
292.0 \pm 22.5\end{array}$ & $\begin{array}{l}278.8 \pm 28.3 \\
297.3 \pm 14.9\end{array}$ \\
\hline ATM (msec) & $\begin{array}{l}\text { AAS } \\
\text { Controls }\end{array}$ & $\begin{array}{l}96.0 \pm 21.0 \\
100.0 \pm 23.2\end{array}$ & $\begin{array}{l}100.0 \pm 20.9 \\
100.0 \pm 18.9\end{array}$ \\
\hline DT (msec) & $\begin{array}{l}\text { AAS } \\
\text { Controls }\end{array}$ & $\begin{array}{l}164.0 \pm 31.8 \\
174.1 \pm 28.1\end{array}$ & $\begin{array}{l}174.7 \pm 34.7 \\
162.0 \pm 38.4\end{array}$ \\
\hline E/A ratio & $\begin{array}{l}\text { AAS } \\
\text { Controls }\end{array}$ & $\begin{array}{l}1.51 \pm 0.44 \\
1.71 \pm 0.71\end{array}$ & $\begin{array}{l}1.41 \pm 0.41 \\
1.83 \pm 0.52\end{array}$ \\
\hline $\operatorname{RVD}(\mathrm{cm})$ & $\begin{array}{l}\text { AAS } \\
\text { Controls }\end{array}$ & $\begin{array}{l}3.6 \pm 0.4 \\
3.4 \pm 0.4\end{array}$ & $\begin{array}{l}3.6 \pm 0.4 \\
3.5 \pm 0.4\end{array}$ \\
\hline
\end{tabular}

Legend: Aortic diameter (AD), left atrium diameter (LA), left ventricular end diastolic diameter (LVEDD), left ventricular end systolic diameter (LVESD), interventricular septum thickness (IVS), posterior wall end diastolic wall thickness (PWEDWT), posterior wall end systolic wall thickness (PWESWT), left ventricular mass (LVM), left ventricular mass index (LVMI), ejection fraction (EF), left ventricular end diastolic volume (EDV), left ventricular end systolic volume (ESV), ratio between E-top velocity and A-top velocity (E/A ratio), acceleration times of the E-top (ATM), deceleration times of the E-top (DT), aortic integral (Al), aorta flow velocity (AV), left ventricular ejection times (LVET), right ventricular diameter (RVD). 
Table 5. Impact of duration of AAS self-administration on echocardiographic measurements: short-term $(n=10)$ versus long-term $(n=7)$ AAS administration.

\begin{tabular}{|c|c|c|c|}
\hline & & Baseline & end AAS course \\
\hline$\overline{A D}(\mathrm{~mm})$ & $\begin{array}{l}\text { Short-AAS } \\
\text { Long-AAS }\end{array}$ & $\begin{array}{l}34.4 \pm 3.7 \\
33.9 \pm 2.9\end{array}$ & $\begin{array}{l}34.7 \pm 4.1 \\
34.4 \pm 2.6\end{array}$ \\
\hline $\mathrm{LA}(\mathrm{mm})$ & $\begin{array}{l}\text { Short-AAS } \\
\text { Long-AAS }\end{array}$ & $\begin{array}{l}41.0 \pm 3.4 \\
41.5 \pm 4.0\end{array}$ & $\begin{array}{l}41.0 \pm 3.0 \\
41.6 \pm 4.6\end{array}$ \\
\hline $\operatorname{LVEDD}(\mathrm{mm})$ & $\begin{array}{l}\text { Short-AAS } \\
\text { Long-AAS }\end{array}$ & $\begin{array}{l}53.6 \pm 6.7 \\
53.6 \pm 3.0\end{array}$ & $\begin{array}{l}52.6 \pm 5.8 \\
54.1 \pm 3.1\end{array}$ \\
\hline LVESD $(\mathrm{mm})$ & $\begin{array}{l}\text { Short-AAS } \\
\text { Long-AAS }\end{array}$ & $\begin{array}{l}35.0 \pm 5.1 \\
35.0 \pm 3.9\end{array}$ & $\begin{array}{l}34.1 \pm 4.4 \\
35.6 \pm 3.3\end{array}$ \\
\hline IVS (mm) & $\begin{array}{l}\text { Short-AAS } \\
\text { Long-AAS }\end{array}$ & $\begin{array}{l}8.9 \pm 0.8 \\
8.4 \pm 0.9\end{array}$ & $\begin{array}{l}9.1 \pm 1.2 \\
8.5 \pm 0.8\end{array}$ \\
\hline PWEDWT $(\mathrm{mm})$ & $\begin{array}{l}\text { Short-AAS } \\
\text { Long-AAS }\end{array}$ & $\begin{array}{l}9.0 \pm 0.9 \\
8.8 \pm 0.9\end{array}$ & $\begin{array}{l}9.2 \pm 0.7 \\
8.9 \pm 0.6\end{array}$ \\
\hline PWESWT $(\mathrm{mm})$ & $\begin{array}{l}\text { Short-AAS } \\
\text { Long-AAS }\end{array}$ & $\begin{array}{l}14.8 \pm 1.2 \\
13.8 \pm 1.0\end{array}$ & $\begin{array}{l}14.6 \pm 1.3 \\
14.4 \pm 0.9\end{array}$ \\
\hline $\mathrm{EF}(\%)$ & $\begin{array}{l}\text { Short-AAS } \\
\text { Long-AAS }\end{array}$ & $\begin{array}{l}63.4 \pm 5.0 \\
63.4 \pm 5.4\end{array}$ & $\begin{array}{l}63.8 \pm 5.2 \\
62.6 \pm 4.1\end{array}$ \\
\hline LVM (gram) & $\begin{array}{l}\text { Short-AAS } \\
\text { Long-AAS }\end{array}$ & $\begin{array}{l}221.4 \pm 55.1 \\
207.9 \pm 28.3\end{array}$ & $\begin{array}{l}221.9 \pm 54.9 \\
214.9 \pm 25.6\end{array}$ \\
\hline LVMI (gram/m²) & $\begin{array}{l}\text { Short-AAS } \\
\text { Long-AAS }\end{array}$ & $\begin{array}{l}114.9 \pm 26.4 \\
100.2 \pm 14.5\end{array}$ & $\begin{array}{l}112.1 \pm 22.4 \\
101.3 \pm 11.0\end{array}$ \\
\hline$\overline{\operatorname{EDV}(\mathrm{ml})}$ & $\begin{array}{l}\text { Short-AAS } \\
\text { Long-AAS }\end{array}$ & $\begin{array}{l}141.3 \pm 40.1 \\
139.4 \pm 17.9\end{array}$ & $\begin{array}{l}134.7 \pm 35.2 \\
142.6 \pm 19.4\end{array}$ \\
\hline $\operatorname{ESV}(\mathrm{ml})$ & $\begin{array}{l}\text { Short-AAS } \\
\text { Long-AAS }\end{array}$ & $\begin{array}{l}52.3 \pm 17.6 \\
51.8 \pm 14.2\end{array}$ & $\begin{array}{l}48.8 \pm 14.6 \\
53.5 \pm 11.8\end{array}$ \\
\hline AOINT $(\mathrm{cm})$ & $\begin{array}{l}\text { Short-AAS } \\
\text { Long-AAS }\end{array}$ & $\begin{array}{l}26.6 \pm 5.7 \\
24.6 \pm 1.8\end{array}$ & $\begin{array}{l}26.2 \pm 5.4 \\
24.5 \pm 1.9\end{array}$ \\
\hline $\mathrm{AV}(\mathrm{mm} / \mathrm{sec})$ & $\begin{array}{l}\text { Short-AAS } \\
\text { Long-AAS }\end{array}$ & $\begin{array}{l}144.3 \pm 30.5 \\
132.5 \pm 12.9\end{array}$ & $\begin{array}{l}155.3 \pm 43.9 \\
131.5 \pm 12.2\end{array}$ \\
\hline LVET (msec) & $\begin{array}{l}\text { Short-AAS } \\
\text { Long-AAS }\end{array}$ & $\begin{array}{l}278.8 \pm 21.7 \\
291.3 \pm 26.4\end{array}$ & $\begin{array}{l}273.3 \pm 33.5 \\
286.3 \pm 22.6\end{array}$ \\
\hline ATM (msec) & $\begin{array}{l}\text { Short-AAS } \\
\text { Long-AAS }\end{array}$ & $\begin{array}{l}104.4 \pm 28.8 \\
95.0 \pm 15.1\end{array}$ & $\begin{array}{l}100.0 \pm 24.0 \\
102.5 \pm 13.9\end{array}$ \\
\hline DT (msec) & $\begin{array}{l}\text { Short-AAS } \\
\text { Long-AAS }\end{array}$ & $\begin{array}{l}168.9 \pm 29.8 \\
180.0 \pm 26.7\end{array}$ & $\begin{array}{l}180.0 \pm 33.5 \\
168.8 \pm 43.6\end{array}$ \\
\hline E/A ratio & $\begin{array}{l}\text { Short-AAS } \\
\text { Long-AAS }\end{array}$ & $\begin{array}{l}1.51 \pm 0.49 \\
1.51 \pm 0.40\end{array}$ & $\begin{array}{l}1.35 \pm 0.50 \\
1.56 \pm 0.35\end{array}$ \\
\hline $\operatorname{RVD}(\mathrm{cm})$ & $\begin{array}{l}\text { Short-AAS } \\
\text { Long-AAS }\end{array}$ & $\begin{array}{l}3.6 \pm 0.4 \\
3.6 \pm 0.3\end{array}$ & $\begin{array}{l}3.6 \pm 0.4 \\
3.7 \pm 0.3\end{array}$ \\
\hline
\end{tabular}

Legend: Aortic diameter (AD), left atrium diameter (LA), left ventricular end diastolic diameter (LVEDD), left ventricular end systolic diameter (LVESD), interventricular septum thickness (IVS), posterior wall end diastolic wall thickness (PWEDWT), posterior wall end systolic wall thickness (PWESWT), left ventricular mass (LVM), left ventricular mass index (LVMI), ejection fraction (EF), left ventricular end diastolic volume (EDV), left ventricular end systolic volume (ESV), ratio between E-top velocity and A-top velocity (E/A ratio), acceleration times of the E-top (ATM), deceleration times of the E-top (DT), aortic integral (AI), aorta flow velocity (AV), left ventricular ejection times (LVET), right ventricular diameter (RVD). 
Table 6. Echocardiographic measurements at baseline and after 8 weeks in the double blind, placebo controlled study (study 2).

\begin{tabular}{|c|c|c|c|}
\hline & & Baseline & 8 weeks \\
\hline$\overline{\mathrm{AD}(\mathrm{mm})}$ & $\begin{array}{l}\text { ND-group } \\
\text { PLAC-group }\end{array}$ & $\begin{array}{l}32.1 \pm 2.8 \\
33.9 \pm 2.1\end{array}$ & $\begin{array}{l}32.2 \pm 2.7 \\
33.3 \pm 2.4\end{array}$ \\
\hline $\operatorname{LA}(\mathrm{mm})^{\#}$ & $\begin{array}{l}\text { ND-group } \\
\text { PLAC-group }\end{array}$ & $\begin{array}{l}39.6 \pm 4.4 \\
43.7 \pm 2.1\end{array}$ & $\begin{array}{l}39.9 \pm 4.0 \\
42.9 \pm 3.4\end{array}$ \\
\hline $\operatorname{LVEDD}(\mathrm{mm})^{\# \#}$ & $\begin{array}{l}\text { ND-group } \\
\text { PLAC-group }\end{array}$ & $\begin{array}{l}49.8 \pm 3.2 \\
53.3 \pm 2.3\end{array}$ & $\begin{array}{l}50.0 \pm 2.0 \\
52.9 \pm 2.0\end{array}$ \\
\hline $\operatorname{LVESD}(\mathrm{mm})^{\# \#}$ & $\begin{array}{l}\text { ND-group } \\
\text { PLAC-group }\end{array}$ & $\begin{array}{l}32.4 \pm 2.4 \\
35.0 \pm 2.3\end{array}$ & $\begin{array}{l}32.9 \pm 3.3 \\
35.1 \pm 3.0\end{array}$ \\
\hline IVS (mm) & $\begin{array}{l}\text { ND-group } \\
\text { PLAC-group }\end{array}$ & $\begin{array}{l}8.0 \pm 0.9 \\
8.3 \pm 0.5\end{array}$ & $\begin{array}{l}7.9 \pm 0.8 \\
8.1 \pm 0.8\end{array}$ \\
\hline PWEDWT $(\mathrm{mm})$ & $\begin{array}{l}\text { ND-group } \\
\text { PLAC-group }\end{array}$ & $\begin{array}{l}8.4 \pm 0.7 \\
8.9 \pm 0.4\end{array}$ & $\begin{array}{l}8.3 \pm 0.7 \\
8.7 \pm 0.5\end{array}$ \\
\hline PWESWT (mm) & $\begin{array}{l}\text { ND-group } \\
\text { PLAC-group }\end{array}$ & $\begin{array}{l}14.0 \pm 1.3 \\
14.6 \pm 0.8\end{array}$ & $\begin{array}{l}13.8 \pm 0.8 \\
14.0 \pm 1.2\end{array}$ \\
\hline $\mathrm{EF}(\%)$ & $\begin{array}{l}\text { ND-group } \\
\text { PLAC-group }\end{array}$ & $\begin{array}{l}63.8 \pm 3.2 \\
62.7 \pm 3.8\end{array}$ & $\begin{array}{l}63.0 \pm 5.6 \\
61.6 \pm 5.8\end{array}$ \\
\hline LVM (gram) & $\begin{array}{l}\text { ND-group } \\
\text { PLAC-group }\end{array}$ & $\begin{array}{l}174.7 \pm 32.7 \\
205.7 \pm 17.0\end{array}$ & $\begin{array}{l}172.7 \pm 29.9 \\
198.3 \pm 14.2\end{array}$ \\
\hline LVMI (gram/m²) & $\begin{array}{l}\text { ND-group } \\
\text { PLAC-group }\end{array}$ & $\begin{array}{l}90.2 \pm 12.7 \\
101.9 \pm 8.4\end{array}$ & $\begin{array}{l}89.1 \pm 10.3 \\
98.9 \pm 9.5\end{array}$ \\
\hline $\operatorname{EDV}(\mathrm{ml})$ & $\begin{array}{l}\text { ND-group } \\
\text { PLAC-group }\end{array}$ & $\begin{array}{l}117.7 \pm 17.5 \\
137.3 \pm 13.6\end{array}$ & $\begin{array}{l}118.8 \pm 16.1 \\
134.7 \pm 12.0\end{array}$ \\
\hline $\operatorname{ESV}(\mathrm{ml}){ }^{\# \#}$ & $\begin{array}{l}\text { ND-group } \\
\text { PLAC-group }\end{array}$ & $\begin{array}{l}42.7 \pm 7.8 \\
51.0 \pm 8.7\end{array}$ & $\begin{array}{l}44.4 \pm 10.6 \\
51.7 \pm 10.7\end{array}$ \\
\hline AOINT $(\mathrm{cm})$ & $\begin{array}{l}\text { ND-group } \\
\text { PLAC-group }\end{array}$ & $\begin{array}{l}24.4 \pm 3.2 \\
26.2 \pm 3.5\end{array}$ & $\begin{array}{l}24.1 \pm 2.1 \\
25.3 \pm 1.9\end{array}$ \\
\hline $\mathrm{AV}(\mathrm{mm} / \mathrm{sec})$ & $\begin{array}{l}\text { ND-group } \\
\text { PLAC-group }\end{array}$ & $\begin{array}{l}136.9 \pm 20.6 \\
138.0 \pm 19.3\end{array}$ & $\begin{array}{l}128.9 \pm 10.7 \\
139.9 \pm 9.3\end{array}$ \\
\hline LVET (msec) & $\begin{array}{l}\text { ND-group } \\
\text { PLAC-group }\end{array}$ & $\begin{array}{l}275.6 \pm 24.0 \\
290.0 \pm 10.0\end{array}$ & $\begin{array}{l}277.8 \pm 13.9 \\
280.0 \pm 18.3\end{array}$ \\
\hline ATM (msec) & $\begin{array}{l}\text { ND-group } \\
\text { PLAC-group }\end{array}$ & $\begin{array}{l}84.4 \pm 12.4 \\
97.1 \pm 13.8\end{array}$ & $\begin{array}{l}100.0 \pm 17.3 \\
90.0 \pm 16.3\end{array}$ \\
\hline DT (msec) & $\begin{array}{l}\text { ND-group } \\
\text { PLAC-group }\end{array}$ & $\begin{array}{l}159.0 \pm 31.6 \\
158.6 \pm 27.9\end{array}$ & $\begin{array}{l}152.2 \pm 26.8 \\
158.6 \pm 13.5\end{array}$ \\
\hline E/A ratio & $\begin{array}{l}\text { ND-group } \\
\text { PLAC-group }\end{array}$ & $\begin{array}{l}1.57 \pm 0.52 \\
1.68 \pm 0.44\end{array}$ & $\begin{array}{l}1.69 \pm 0.48 \\
1.66 \pm 0.26\end{array}$ \\
\hline $\operatorname{RVD}(\mathrm{cm})$ & $\begin{array}{l}\text { ND-group } \\
\text { PLAC-group }\end{array}$ & $\begin{array}{l}3.2 \pm 0.3 \\
3.6 \pm 0.3\end{array}$ & $\begin{array}{l}3.5 \pm 0.5 \\
3.6 \pm 0.3\end{array}$ \\
\hline
\end{tabular}

Legend: Aortic diameter (AD), left atrium diameter (LA), left ventricular end diastolic diameter (LVEDD), left ventricular end systolic diameter (LVESD), interventricular septum thickness (IVS), posterior wall end diastolic wall thickness (PWEDWT), posterior wall end systolic wall thickness (PWESWT), left ventricular mass (LVM), left ventricular mass index (LVMI), ejection fraction (EF), left ventricular end diastolic volume (EDV), left ventricular end systolic volume (ESV), ratio between E-top velocity and A-top velocity (E/A ratio), acceleration times of the E-top (ATM), deceleration times of the E-top (DT), aortic integral (Al), aorta flow velocity (AV), left ventricular ejection times (LVET), right ventricular diameter (RVD).

\# means significant $(P<0.10)$ difference between both groups at the start \#\# means significant $(P<0.05)$ difference between both groups at the start 


\section{DISCUSSION}

Main observations. The main finding of the present investigation was that the administration of AAS did not affect blood pressure, heart structure and cardiac function of strength athletes as determined by echocardiography. Since both studies are complementary the absence of detectable alterations indicates that heart structure and systolic as well as diastolic function is not dependent on the regimen or dose of the AAS used nor on the duration of AAS administration.

Baseline echocardiographic measurements. In all subjects of both studies, the hearts showed enlargement of the left ventricle and left ventricle wall thickness, but all measurements were within the limits of physiologic adaptation as proposed by Pellicia and coworkers (28). In both studies, left ventricular mass ranged from 132 to 309 grams and the left posterior end-systolic wall thickness of the participating strength athletes was high, ranging from 12 to $17 \mathrm{~mm}$. In such cases it is mandatory to examine for a heart disease condition. However, in the absence of abnormal left ventricle filling, no decrement of the left ventricular cavity and a normal left ventricular hypertrophy pattern, which were appropriate in all our subjects, such cardiac enlargements can be attributed to vigorous and demanding training regimens rather than a heart disease condition (28). Finally, at baseline all subjects were considered to have normal echocardiographic examinations without any detrimental effect due to previous AAS use.

Effects of AAS administration. The present study showed that the administration of a high dose of nandrolone decanoate for 8 weeks did not affect cardiac structure and function as determined by echocardiography. The same applied for the use of high dosages of AAS polydrug regimens for 8 weeks as well as for such courses up to 16 weeks.

Several cross-sectional studies reported larger posterior wall thickness, interventricular septum thickness and / or the left ventricular mass in AAS using athletes compared to their non-using counterparts $(10,20,35,42,44)$. However, other investigators were unable to detect differences in cardiac dimensions between steroid users and non-users $(9,27,36,41,46)$. Only a few of these studies examined heart function, one reporting an impairment of diastolic function (42), while another did not (10). The discrepancies observed in the study outcome may be mainly attributable to confounding factors (especially, selection of subjects) rather than to steroid use. Our suggestion is enforced by the more consistent results of longitudinal studies. All longitudinal studies, except one (35), failed to demonstrate changes of heart structure and function due to the administration of high doses of AAS $(9,27,37,46)$. Only one study registered increments of the left ventricular end diastolic diameter (LVEDD), the thickness of the interventricular septum (IVS) and the left ventricular mass (LVM) during steroids use (35). However, it is noteworthy to mention that the subjects in 
that study trained more frequently (6.5 vs 5.0 sessions per week) and heavier (3.6 vs 2.7 heavy sessions per week) when on steroids compared to the period off steroids. Moreover, it is well known that detraining may induce a marked reduction of the training induced cardiac adaptations within a short time period (28). Therefore, to our opinion the findings by Sachtleben and coworkers remain debatable whether the cardiac alterations may be attributed to AAS administration rather than to the training alterations.

AAS and animal hearts. Although echocardiographic studies in human subjects may indicate that the side-effects of AAS on the heart structure seem to be limited, it has been well established in animal studies that these doping agents posses the potential to affect the heart. There is solid evidence available that the administration of testosterone or anabolic steroids leads to cardiomegaly in animals $(8,23,24,29,32)$. Such adaptations have been documented within a few weeks after starting AAS administration (23, 32), but might be reversible after cessation (29). Furthermore, steroids have been demonstrated to exert detrimental effects at the cellular level of animal hearts $(4,6,39,40)$. A direct hazardous effect on the mitochondria may lead to membranous defects and disturb the integrity of these cell substances $(6,7)$. Myofibrils may show disintegration or widened and twisted Z-bands or even complete dissolution of the sarcomeric units. Additionally, an increase of nonmyofibrillar filaments were found due to anabolic steroid administration $(6,7)$. When combined with exercise, AAS have been found to induce mild hypertrophy of the cardiac myocytes and impair the cardiac microvascular adaptation to physical conditioning (39, 40). Based on these findings, we hypothesize that alterations of the heart structure in human subjects due to AAS administration are very likely to occur, but that they can not be detected by current echocardiographic examination methods since such heart damage primarily seems to occur at the cellular level. Previously, Welder and Melchert (1995) provided already the theoretical base for our conclusion. Consequently, routine cardiological examinations may provide incorrect assessment of the cardiac condition in AAS using athletes leading to undeserved reassurance.

Conclusions. From this study we conclude that the administration of AAS does not lead to detectable echocardiographic alterations of heart morphology, systolic and diastolic function in experienced strength athletes. This applies for the administration of a high therapeutic dose of a single anabolic steroid (nandrolone decanoate) for eight weeks, as well as for AAS polydrug regimens in suprapharmacological doses during periods up to 16 weeks. However, since the detrimental effects of AAS on the heart are well described in animal studies using (ultra-)microscopic evaluation of heart cell structures, the results of the present study must be interpreted with reservations. Therefore, echocardiographic evaluation may provide incorrect assessment of the actual cardiac condition in AAS users since it is not sensitive enough to detect alterations at the cellular level. 


\section{REFERENCES}

1. Abraham, M., P. Cohen, R.-J. van Til, and M. A. L. de Winter. Licit and illicit drug use in the Netherlands, 1997. Amsterdam: Centrum voor Drugsonderzoek (CEDRO), 1999.

2. Alen, M., M. Reinila, and R. Vihko. Response of serum hormones to androgen administration in power athletes. Med Sci Sports Exerc 17: 354-9, 1985.

3. Alen, M., and J. Suominen. Effect of androgenic and anabolic steroids on spermatogenesis in power athletes. Int J Sports Med, 5(suppl.): 189-192, 1984.

4. Appell, H.-J., B. Heller-Umpfenbach, $M$. Feraudi, and H. Weicker. Ultrastructural and morphometric investigations on the effects of training and administratio of anabolic steroids on the myocardium of guinea pigs. Int J Sports Med 4: 268-274, 1983.

5. Bahrke, M. S., C. Yesalis, and J. E. Wright. Psychological and behavioural effects of endogenous testosterone and anabolic-androgenic steroids. An update. Sports Med 22: 367-90, 1996.

6. Behrendt, $\mathbf{H}$. Effect of anabolic steroids on rat heart muscle cells. I. Intermediate filaments. Cell Tissue Res 180: 303-15, 1977.

7. Behrendt, H., and H. Boffin. Myocardial cell lesions caused by an anabolic hormone. Cell Tissue Res 181: 423-6, 1977.

8. Brown, B. S., and A. H. Pilch. The effects of exercise and dianabol upon selected performances and physiological parameters in the male rat. Med Sci Sports 4: 159-65, 1972.

9. De Piccoli, B., F. Giada, A. Benettin, F. Sartori, and E. Piccolo. Anabolic steroid use in body builders: an echocardiographic study of left ventricle morphology and function. Int J Sports Med 12: 408-12, 1991.

10. Dickerman, R.D., F. Schaller, N. Y. Zachariah, and W. J. McConathy. Left ventricular size and function in elite bodybuilders using anabolic steroids. Clin J Sport Med 7: 90-3, 1997.

11. Ferenchick, G. S. Association of steroid abuse with cardiomyopathy in athletes [letter]. Am J Med 91, 1991.

12. Ferenchick, G. S., and S. Adelman. Myocardial infarction associated with anabolic steroid use in a previously healthy 37-year-old weight lifter. Am Heart J 124: 507-8, 1992.

13. Hartgens, F., H. Kuipers, J. Wijnen, and H. A. Keizer. Body composition, cardiovascular risk factors and liver function in long term androgenic-anabolic steroids using bodybuilders three months after drug withdrawal. Int. J. Sports Med. 17: 429-433, 1996.

14. Huie, $\mathbf{M}$. J. An acute myocardial infarction occurring in an anabolic steroid user (case study). Med Sci Sports Exerc 26: 408-13, 1994.

15. Ishak, K. G., and H. J. Zimmerman. Hepatotoxic effects of the anabolic/androgenic steroids. Semin Liver Dis 7: 230-236, 1987.

16. Kennedy, M. C., and C. Lawrence. Anabolic steroid abuse and cardiac death. Med J Aust 158: 346-8, 1993.

17. Koert, A., and R. Van Kleij. Handel in doping. Nieuwegein: Arko Uitgeverij, 1998.

18. Kopera, $\mathbf{H}$. Side effects of anabolic steroids and contraindications. Wien Med Wochenschr 143: 399-400, 1993.

19. Luke, J. L., A. Farb, R. Virmani, and R. H. Sample. Sudden cardiac death during exercise in a weight lifter using anabolic androgenic steroids: pathological and toxicological findings. $J$ Forensic Sci 35: 1441-7, 1990.

20. McKillop, G., I. C. Todd, and D. Ballantyne. Increased left ventricular mass in a bodybuilder using anabolic steroids. Br J Sports Med 20: 151-2, 1986.

21. Melchert, R. B., and A. A. Welder. Cardiovascular effects of androgenic-anabolic steroids. Med Sci. Sports Exerc 27: 1252-1262, 1995.

22. Mochizucki, R. M., and K. J. Richter. Cardiomyopathy and cerebrovascular accident associated with anabolic-androgenic steroid use. Physician Sportsmed 16: 109-114, 1988. 
23. Moore, L. G., I. F. McMurtry, and J.T. Reeves. Effects of sex hormones on cardiovascular and hematologic responses to chronic hypoxia in rats. Proc Soc Exp Biol Med 158: 658-62, 1978.

24. Morano, I., J. Gerstner, J. C. Ruegg, U. Ganten, D. Ganten, and H. P. Vosberg. Regulation of myosin heavy chain expression in the hearts of hypertensive rats by testosterone. Circ Res 66: 1585-90, 1990.

25. Nieminen, M. S., M. P. Ramo, M. Viitasalo, P. Heikkila, J. Karjalainen, Mantysaari, $\boldsymbol{M}$, and J. Heikkila. Serious cardiovascular side effects of large doses of anabolic steroids in weight lifters. Eur. Heart J. 17: 1576-1583, 1996.

26. Paffenbarger, R. S., Jr., A. L. Wing, and R. T. Hyde. Physical activity as an index of heart attack risk in college alumni. Am J Epidemiol 108: 161-75, 1978.

27. Palatini, P., F. Giada, G. Garavelli, F. Sinisi, L. Mario, M. Michieletto, and E. G. Baldo. Cardiovascular effects of anabolic steroids in weight-trained subjects. I Clin Pharmacol 36: 1132-40, 1996.

28. Pelliccia, A., and B. J. Maron. Outer limits of the athlete's heart, the effect of gender, and relevance to the differential diagnosis with primary cardiac diseases. Cardiol Clin 15: 381-96, 1997.

29. Pesola, M. K. Reversibility of the haemodynamic effects of anabolic steroids in rats. Eur J Appl Physio/ 58: 125-31, 1988.

30. Pope, H. G., Jr., E. M. Kouri, and J. I. Hudson. Effects of supraphysiologic doses of testosterone on mood and aggression in normal men: a randomized controlled trial. Arch Gen Psychiatry 57: 133-40; discussion 155-6, 2000.

31. Powell, K. E., P. D. Thompson, C. J. Caspersen, and J. S. Kendrick. Physical activity and the incidence of coronary heart disease. Annu Rev Public Health 8: 253-87, 1987.

32. Ramo, P., R. Kettunen, and L. Hirvonen. The effects of anabolic steroids and endurance training on systolic time intervals in the dog. Acta Physiol Scand 129: 543-8, 1987.

33. Rockhold, R. W. Cardiovascular toxicity of anabolic steroids. Annu Rev Pharmacol Toxicol 33: 497-520, 1993.

34. Ruokonen, A., M. Alen, N. Bolton, and R. Vihko. Response of serum testosterone and its precursor steroids, SHBG and CBC to anabolic steroid and testosterone self-administration in man. J Steroid Biochem 23: 33-8, 1985.

35. Sachtleben, T. R., K. E. Berg, B. A. Elias, J. P. Cheatham, G. L. Felix, and P. J. Hofschire. The effects of anabolic steroids on myocardial structure and cardiovascular fitness. Med Sci Sports Exerc 25: 1240-5, 1993.

36. Salke, R. C., T. W. Rowland, and E. J. Burke. Left ventricular size and function in body builders using anabolic steroids. Med Sci Sports Exerc 17: 701-4, 1985.

37. Spataro, A., G. Caselli, A. Pelliccia, A. Biffi, C. Iranquilli, F. Fernando, and G. Marcello. Anabolic steroids do not increase left ventricular mass index in well trained athletes (abstract). Med Sci Sports Exerc 24: S29, 1992.

38. Sullivan, M. L., C. M. Martinez, and E. J. Gallagher. Atrial fibrillation and anabolic steroids. J Emerg Med 17: 851-7, 1999.

39. Tagarakis, C. V., W. Bloch, G. Hartmann, W. Hollmann, and K. Addicks. Anabolic steroids impair the exercise-induced growth of the cardiac capiliary bed. Int J Sports Med 21: 412-8, 2000.

40. Tagarakis, C. V., W. Bloch, G. Hartmann, W. Hollmann, and K. Addicks. Testosterone-propionate impairs the response of the cardiac capillary bed to exercise. Med Sci Sports Exerc 32: 946-53, 2000.

41. Thompson, P. D., A. Sadaniantz, E. M. Cullinane, K. S. Bodziony, D. H. Catlin, B. G. Torek, and P. S. Douglas. Left ventricular function is not impaired in weight-lifters who use anabolic steroids. J Am Coll Cardiol 19: 278-82, 1992. 
42. Urhausen, A., R. Holpes, and $W$. Kindermann. One- and two-dimensional echocardiography in bodybuilders using anabolic steroids. Eur J Appl Physiol 58: 633-40, 1989.

43. Woodiwiss, A. J., B. Trifunovic, M. Philippides, and G. R. Norton. Effects of an androgenic steroid on exercise-induced cardiac remodeling in rats. J Appl Physiol 88: 409-15, 2000.

44. Yeater, R., C. Reed, I. Ullrich, A. Morise, and M. Borsch. Resistance trained athletes using or not using anabolic steroids compared to runners: Effects on cardiorespiratory variables, body composition, and plasma lipids. Br J Sports Med 30: 11-14, 1996.

45. Yesalis, C. Anabolic steroids in sport and exercise (2nd ed.). Champaign IL: Human Kinetics, 2000 .

46. Zuliani, U., B. Bernardini, A. Catapano, M. Campana, G. Cerioli, and M. Spattini. Effects of anabolic steroids, testosterone, and $\mathrm{HGH}$ on blood lipids and echocardiographic parameters in body builders. Int I Sports Med 10: 62-6, 1989. 
[120] 


\title{
CHAPTER 7
}

\section{Effects of androgenic-anabolic steroids on apolipoproteins and lipoprotein(a)}

\author{
Fred Hartgens \\ Gerard Rietjens \\ Hans A. Keizer \\ Harm Kuipers \\ Bruce H.R. Wolffenbuttel
}

Netherlands Centre for Doping Affairs, Capelle aan den IJssel

Dept of Endocrinology, Maastricht University and University Hospital Maastricht

Dept of Movement Sciences, Maastricht University, Maastricht

Submitted for publication 


\section{ABSTRACT}

Introduction: The use of high doses of androgenic-anabolic steroids (AAS) by young athletes has been associated with the premature occurrence of cardiovascular disease. The purpose of this study was to investigate the effects of AAS on serum lipoproteins and lipid levels and recovery of these parameters after drug cessation.

Methods: In a non-blinded study (Study 1) serum lipoproteins and lipids were assessed in 19 subjects (age $31 \pm 7$ years) who self-administered AAS for 8 or 14 weeks and in 16 non-using volunteers (age $33 \pm 5$ years). In another study (Study 2) we investigated in a randomised double blind, placebo controlled way the effects of administration of nandrolone decanoate (200 $\mathrm{mg} / \mathrm{wk}$ i.m.) for eight weeks on the same parameters in 16 bodybuilders. Determined were serum levels of total cholesterol (Tot-C), triglycerides (TRIGL), HDL-cholesterol (HDL-C), HDL2-cholesterol (HDL2-C), HDL3-cholesterol (HDL3-C), Apolipoprotein-A1 (Apo-A1), Apolipoprotein-B (Apo-B), Lipoprotein(a) [Lp(a)].

Results: In Study 1 serum HDL-C declined from $1.08 \pm 0.30$ to $0.43 \pm 0.22 \mathrm{mmol} / \mathrm{l}(\mathrm{p}<0.001)$, HDL2-C decreased from $0.21 \pm 0.18$ to $0.05 \pm 0.03 \mathrm{mmol} / \mathrm{l}$ and HDL $3-\mathrm{C}$ from $0.87 \pm 0.24$ to $0.40 \pm$ $0.20 \mathrm{mmol} / \mathrm{l}$. Serum levels ApoA1 decreased from $1.41 \pm 0.27$ to $0.71 \pm 0.34 \mathrm{~g} / \mathrm{l}$, while ApoB increased from $0.96 \pm 0.13$ to $1.32 \pm 0.28 \mathrm{~g} / /$ (both $p<0.001$ ). Also, $L p(a)$ declined, from of $189 \pm$ 315 to $32 \pm 63$ ( $p<0.001)$. Tot- $C$ and TRIGL did not change significantly. No changes occurred in the controls. Six weeks after AAS cessation serum levels of HDL-C, HDL2-C, ApoA1, Apo-B and Lp(a) were still not returned to baseline levels. Self-administration of AAS for 14 weeks was associated with slower recovery to pre-treatment lipid values than the administration for 8 weeks. In Study 2 fasting serum lipids and lipoproteins were assessed at baseline, after 4 and 8 weeks as well as six weeks after withdrawal. Both placebo and nandrolone had no effect on Tot-C, HDL-C, HDL2-C, HDL3-C, triglycerides, apoA1 and apoB levels. However, Lp(a) levels decreased significantly from $103 \pm$ to $65 \pm \mathrm{U} / \mathrm{l}$ in the nandrolone group, whereas under placebo a smaller reduction from $245 \pm$ to $201 \pm U / /$ could be observed.

Conclusions: The administration of several AAS simultaneously is accompanied with an increased atherogenic lipid profile, although Lp(a) levels may be influenced beneficially. The changes persists for more than six weeks after AAS withdrawal and normalization depends on duration of the AAS administration period. Short term administration of nandrolone decanoate does not affect serum lipids and lipoproteins, although it may selectively reduce $L p(a)$ levels. However, the impact on vascular prognosis needs to be established yet. 


\section{INTRODUCTION}

The use of androgenic-anabolic steroids (AAS) in young, healthy strength athletes has been associated with the occurrence of premature cardiovascular events $(6,13,15,16)$. These may in part be mediated by the adverse effects involving serum lipid parameters, which have been linked to these compounds. Previous studies have indicated that the use of anabolic steroids results in decreases of high-density lipoprotein cholesterol (HDL-C) and apolipoprotein A1, the major component of the HDL particle, and increases in low-density lipoprotein cholesterol $(L D L-C)(1,8,9,21,24)$. A growing number of strength athletes uses AAS to obtain a well-shaped body or to improve muscular strength. Most athletes take AAS for periods ranging from 8 to 12 weeks several times a year $(5,26,27)$. Self-administration of AAS may result in much higher doses than therapeutically recommended, with possibly more severe side effects, and more profound effects on serum lipids and lipoproteins. Especially the orally active 17-alpha alkyl steroids have been shown to exert severe effects on LDL-and HDL-cholesterol $(7,24)$.

Various studies have suggested that the level of lipoprotein(a) $[L p(a)]$ is an independent risk indicator for the development of vascular disease $(11,14$, 18). The fat composition of $L P(a)$ is comparable with that of LDL-cholesterol, but the most important difference is the presence of a specific apoprotein(a) $(20,25)$. This protein is attached to the apoB by a disulfide bridge. A close correlation has been reported between the serum level of $L p(a)$ and the accumulation of this particle in the vascular wall $(4,17)$. The serum level of $L p(a)$ seems to be genetically determined and, when elevated, can not be lowered by alterations in food intake or cholesterol lowering drugs $(10,19,23)$. Previous reports have suggested that, in contrast to their detrimental effects on lipids, anabolic steroids may favourably lower $\operatorname{Lp}(a)$ levels $(2,3,12)$.

To shed more light into the effects of AAS on lipoprotein and lipid metabolism the aim of the present studies was to investigate the effects of AAS on lipoproteins and lipids in healthy, young strength athletes. To obtain more insight in the relationship between dose of AAS and the response on plasma lipid parameters we performed two studies: a controlled, non-blinded investigation and a randomised, double blind placebo controlled study. The first investigated the effects of self-administration of high doses of AAS on these parameters. In the second study a frequently used single anabolic steroid, nandrolone decanoate, was subject for research upon the effects on lipoprotein risk factors and lipoprotein(a). In both studies we also assessed the recovery of the lipoprotein and lipid parameters after cessation of drug administration. 


\section{SUBJECTS AND METHODS}

This study was part of a larger study exploring the effects of anabolic steroids on cardiovascular function and exercise performance in strength athletes. Subjects were recruited by flyers in regional gym clubs. A total of 90 strength athletes was willing to participate in one or more of these studies after they were extensively informed about the studies in several meetings. All participants answered an extensive questionnaire with questions related to actual health status, history, training habits, and the use of AAS, and underwent full physical examination to exclude any relevance disease conditions. Inclusion criteria were: male, bodybuilding training experience of at least 3 years, at least 4 strength training work outs per week or 8 hours strength training weekly, and age between 20 and 45 years. The following exclusion criteria were set: hypertension, diabetes mellitus, liver disease or abnormal liver enzyme serum levels, hereditary hypercholesterolemia, elevated serum cholesterol $(>6,5 \mathrm{mmol} / \mathrm{l})$, infertility and smoking.

The study was approved by the Medical Ethical Review Committee of the Maastricht University and the University Hospital Maastricht, and all subjects gave their written informed consent before participating.

Study 1. In this study 35 male strength athletes participated. From this group 19 subjects employed self-administration of AAS for 8 or 14 weeks in addition to their usual strength training (AAS group). The results were compared with 16 subjects who trained without using AAS (CO group). Physical and training characteristics of both groups are provided in Table 1 . The controls had never used AAS before. On the other hand, all subjects of the AAS group (except one person) had previous experience in AAS self-administration. On average they had started AAS use 4.8 years before (range $1-14$ years). The mean number of cycles employed was 7.1 (range 1 - 30 cycles). At the start of the study the subjects were expected to be drug free for at least 3 months. Based on their own information the AAS users were drug free for $8.1 \pm 6.4$ months before the start of the study. To objectively exclude recent drug use, however, at the start of the study in all subjects urine was collected for drug analysis. In addition, urine samples were collected after 8 weeks study period in all subjects. Furthermore, in the AAS users at the end of drug administration period as well as six weeks after drug withdrawal urine collection was repeated. From the urine samples collected approximately one third was randomly selected for analysis by the Netherlands Institute for Drug and Doping Research (NIDDR), Utrecht (The Netherlands) to detect metabolites of anabolic agents.

The AAS self-administered by the participants included Stromba, either i.m. or p.o., Deca-Durabolin i.m., Primobolan either i.m. or p.o., Masteron p.o., Proviron p.o., Parabolan i.m., Dianabol p.o., and Testoviron i.m. The strength athletes purchased the AAS on the black market, although few subjects had received a prescription by a medical doctor. They composed their AAS 
courses based on their own insight and beliefs. The AAS users administered several steroids (oral and intramuscular) simultaneously. The total amount of AAS administered by each participant during the study exceeded the recommended therapeutical dose by 5 to 20 times. The investigators were not involved in purchasing and in the administration of these compounds nor did they recommend doses.

All subjects maintained their regular training and nutritional regimen, and both were monitored by diaries. Before the start of the study and in week 8 , all subjects recorded their training hours and nutritional habits with the aid of a three days nutritional diary. From this, the intake of protein, fat, saturated and unsaturated, carbohydrates, cholesterol, linolic acid, vitamins and trace elements was calculated, with the use of the computer program Becel (version NLO4a, Unilever, The Netherlands).

At baseline, and after 8 (and after 14) weeks of AAS use, depending on the duration of use, and 6 weeks after cessation, blood was drawn following a 10 hour fast, for the measurement of serum lipids and lipoproteins.

Study 2. This study was a randomised, double-blind and placebocontrolled clinical trial. Sixteen well-trained recreational body-builders volunteered to participate in the study. After an extensive baseline examination each subject received a weekly intramuscular injection of a high dose (200 mg) of nandrolone decanoate $(n=9)$ or placebo $(n=7)$ for eight weeks. Each injection was administered by one of the investigators (F.H.).

The period of AAS administration was 8 weeks. At baseline, after 4 and 8 weeks administration of placebo or nandrolone decanoate, and 6 weeks after cessation blood was drawn after a 10 hour fasting period for the measurement of serum lipids and lipoproteins.

Physical characteristics of the nandrolone decanoate group were $33 \pm 9$ years old, height $175 \pm 10 \mathrm{~cm}$ and body weight was $76.0 \pm 12.1 \mathrm{~kg}$. The characteristics of the placebo group were comparable (age $31 \pm 9$ years, height $177 \pm 5 \mathrm{~cm}$, body weight $83.8 \pm 9.0 \mathrm{~kg}$ ).

In all subjects training and nutritional habits were recorded by means of diaries. In accordance with study 1 we collected urine from all volunteers at baseline, after 4 and 8 weeks, and 6 weeks after drug withdrawal. At random one third of the samples was analysed for the detection of metabolites of anabolic substances.

Measurements. Serum total cholesterol (CHOD-PAP, Roche, Basel, Switzerland) and triglycerides (Triglycerid Rapid, Roche) were determined with enzymatic methods on a Cobas Bio analyser. HDL-cholesterol was measured enzymatically after precipitation of $L D L$ and VLDL with polyethylene glycol 6000. Apolipoproteins A1 and B were determined with an immunoturbidimetric assay (Roche, Basel, Switzerland) on a Cobas MIRA analyser. The within- and between-assay coefficients of variation were 1.9 and $6.9 \%$, respectively, for both determinations. Serum apolipoprotein(a) concentra- 
tion was measured by a solid phase two-site immunoradiometric assay using 2 monoclonal antibodies directed toward different epitopes of apo(a) (Pharmacia Diagnostics, Uppsala, Sweden). The within-assay coefficient of variation was $4 \%$ at a $\mathrm{LP}(\mathrm{a})$ concentration of $200 \mathrm{mg} / \mathrm{l}$, the between-assay variation was $7 \%$. One unit// of apo(a) is equal to $1 \mathrm{mg} / /$ of Lp(a).

Statistics. Data are expressed as mean \pm SD unless otherwise reported. Results were analysed on the StatView version 4.02 statistical software package (Abacus Concepts, Inc, USA). Group differences in baseline variables were compared by Mann-Whitney U-test. The same test was applied to compare changes of lipid variables between the treatment groups. Intra-group comparison of lipid variables after drug cessation with baseline data were performed with the Wilcoxon signed rank test, since data of non-using controls were only available during 8 weeks. P-values below 0.05 were considered statistically significant.

\section{RESULTS}

\section{Study 1}

The physical and training characteristics of the 35 participants of the self-administration study are presented in Table 1. At baseline the AAS and CO group were comparable with respect to age, height and weight, training experience and weekly training hours. Nutritional intake of AAS users and controls was comparable. No significant differences in lipid and lipoprotein parameters between the AAS and CO group were observed.

During the study all subjects maintained their regular training regimens. No change of the weekly training hours was observed in any subject. The same was true for nutritional intake. Although with the use of AAS no significant changes of total serum cholesterol were observed, a considerable increase of LDL-cholesterol was found, and a significant and severe drop in HDL-cholesterol levels. These changes were paralleled by a $35 \%$ increase of apo $B$ levels, and a $50 \%$ decrease of apo A1. Also a significant reduction of Lp(a) levels was observed (Table 2 ).

After stopping AAS administration the lipoprotein parameters only slowly returned to normal, although 6 weeks after AAS withdrawal they had not yet

Table 1. Baseline characteristics of the participants to the AAS self-administration study (Study 1)

\begin{tabular}{lll}
\hline & $\begin{array}{l}\text { AAS } \\
(n=19)\end{array}$ & $\begin{array}{l}\text { Controls } \\
(n=16)\end{array}$ \\
\hline Age (yrs) & $31 \pm 7$ & $33 \pm 5$ \\
Height $(\mathrm{cm})$ & $176 \pm 9$ & $177 \pm 7$ \\
Body Weight (kg) & $84.0 \pm 9.9$ & $89.1 \pm 11.4$ \\
Percentage fat (\%) & $17.0 \pm 5.7$ & $19.7 \pm 3.5$ \\
Training years & $10.0 \pm 7.3$ & $8.9 \pm 3.6$ \\
Training (hrs/wk) & $8.8 \pm 2.5$ & $8.2 \pm 2.3$ \\
\hline
\end{tabular}


Table 2. Sequence of changes in serum lipids and lipoproteins induced by 8 weeks AAS self-administration and recovery after drug cessation (Study 1)

\begin{tabular}{|c|c|c|c|c|}
\hline & & Baseline & after 8 weeks & $\begin{array}{l}6 \text { weeks } \\
\text { after drug cessation }\end{array}$ \\
\hline $\begin{array}{l}\text { Total cholesterol } \\
\text { (mmol/l) }\end{array}$ & $\begin{array}{l}\text { CO } \\
\text { AAS }\end{array}$ & $\begin{array}{l}5.02 \pm 0.90 \\
4.57 \pm 0.77\end{array}$ & $\begin{array}{l}4.76 \pm 0.71 \\
5.11 \pm 1.41\end{array}$ & $\begin{array}{l}\text { N.A. } \\
4.71 \pm 1.09\end{array}$ \\
\hline $\begin{array}{l}\text { Triglycerids } \\
(\mathrm{mmol} / \mathrm{l})\end{array}$ & $\begin{array}{l}\mathrm{CO} \\
\mathrm{AAS}\end{array}$ & $\begin{array}{l}1.79 \pm 1.41 \\
1.21 \pm 0.33\end{array}$ & $\begin{array}{l}1.70 \pm 1.27 \\
1.23 \pm 0.42\end{array}$ & $\begin{array}{l}\text { N.A. } \\
1.05 \pm 0.32\end{array}$ \\
\hline $\begin{array}{l}\text { HDL-Cholesterol } \\
\text { (mmol/l) }\end{array}$ & $\begin{array}{l}\mathrm{CO} \\
\mathrm{AAS}\end{array}$ & $\begin{array}{l}1.21 \pm 0.55 \\
1.08 \pm 0.30\end{array}$ & $\begin{array}{l}1.20 \pm 0.44 \\
0.43 \pm 0.22 \& \& \&\end{array}$ & $\begin{array}{l}\text { N.A. } \\
0.89 \pm 0.41 *\end{array}$ \\
\hline $\begin{array}{l}\mathrm{HDL}_{2} \text {-Cholesterol } \\
(\mathrm{mmol} / \mathrm{l})\end{array}$ & $\begin{array}{l}\mathrm{CO} \\
\mathrm{AAS}\end{array}$ & $\begin{array}{l}0.30 \pm 0.32 \\
0.21 \pm 0.18\end{array}$ & $\begin{array}{l}0.27 \pm 0.26 \\
0.05 \pm 0.03^{\&}\end{array}$ & $\begin{array}{l}\text { N.A. } \\
0.14 \pm 0.15^{* *}\end{array}$ \\
\hline $\begin{array}{l}\mathrm{HDL}_{3}-\mathrm{Cholesterol} \\
(\mathrm{mmol} / \mathrm{l})\end{array}$ & $\begin{array}{l}\text { CO } \\
\text { AAS }\end{array}$ & $\begin{array}{l}0.91 \pm 0.29 \\
0.87 \pm 0.24\end{array}$ & $\begin{array}{l}0.93 \pm 0.26 \\
0.40 \pm 0.20 \& \& \&\end{array}$ & $\begin{array}{l}\text { N.A. } \\
0.76 \pm 0.32\end{array}$ \\
\hline $\begin{array}{l}\text { Apo-A1 } \\
(g / l)\end{array}$ & $\begin{array}{l}\text { CO } \\
\text { AAS }\end{array}$ & $\begin{array}{l}1.54 \pm 0.39 \\
1.41 \pm 0.27\end{array}$ & $\begin{array}{l}1.48 \pm 0.20 \\
0.71 \pm 0.34\end{array} \& \& \&$ & $\begin{array}{l}\text { N.A. } \\
1.15 \pm 0.41^{* *}\end{array}$ \\
\hline $\begin{array}{l}\text { Apo-B } \\
(g / I)\end{array}$ & $\begin{array}{l}\text { CO } \\
\text { AAS }\end{array}$ & $\begin{array}{l}1.07 \pm 0.23 \\
0.96 \pm 0.13\end{array}$ & $\begin{array}{l}1.02 \pm 0.21 \\
1.32 \pm 0.28 \& \& \&\end{array}$ & $\begin{array}{l}\text { N.A. } \\
1.08 \pm 0.27^{*}\end{array}$ \\
\hline $\begin{array}{l}\text { Lipoprotein (a) } \\
\text { (units/l) }\end{array}$ & $\begin{array}{l}\text { CO } \\
\text { AAS }\end{array}$ & $\begin{array}{l}161 \pm 281 \\
189 \pm 315\end{array}$ & $\begin{array}{l}136 \pm 213 \\
32 \pm 63^{* *} \& \& \&\end{array}$ & $\begin{array}{l}\text { N.A. } \\
102 \pm 223^{* *}\end{array}$ \\
\hline
\end{tabular}

N.A. indicates data are not available.

Interaction (difference compared to change in CO group): $\&=p<0.05 ; \& \&=p<0.01 ; \& \& \&=p<0.001$. For comparison of data after drug cessation and baseline in the AAS group Wilcoxon signed rank test was used: ${ }^{*}=p<0.05 ;^{* *}=p<0.01$ (compared to baseline values)

returned to baseline levels. In those subjects who used AAS for 14 weeks, recovery after cessation was significantly slower than in subjects who followed an 8-week administration period. In particular $L p(a)$ levels remained decreased in the long-term users, whereas short-term AAS administration showed complete return to baseline values of $L p(a)$ six weeks after drug withdrawal (Table 3).

\section{Study 2}

Baseline serum levels of the lipoproteins and lipids of the 16 participants in the double-blind nandrolone study are presented in table 4 . There were no significant differences between the two groups at the start. Both placebo and nandrolone had no effect on total, HDL-, HDL2-, HDL3- and LDL-cholesterol, and triglycerides. Also, no significant changes of the apolipoproteins $A 1$ and $B$ were observed. L $p(a)$ levels in the bodybuilders who received nandrolone decreased significantly from 103 (range 8-227 U/l) to 65 (range 8-130 U/I), which equals a reduction of approximately $40 \%$. In the placebo treated subjects also a significant reduction of $L P(a)$ levels could be 
observed. Baseline value was $245 \mathrm{U} / \mathrm{l}$ (range 38-756 U/I) and after 8 weeks this parameter amounted $201 \mathrm{U} / \mathrm{I}$ (range 46-617 U/I), which means a decrement of $19 \%$. However, the alterations of $L p(a)$ were statistically not significant between both groups.

Table 3. Impact of duration of AAS self-administration on lipoprotein parameters and on recovery after cessation of use. Compared are the effects of AAS use for 8 weeks $(n=9)$ and administration of 14 weeks $(n=10)$.

\begin{tabular}{|c|c|c|c|c|}
\hline & $\begin{array}{l}\text { Duration of } \\
\text { AAS use }\end{array}$ & Baseline & End of AAS period & $\begin{array}{l}6 \text { weeks after } \\
\text { drug cessation }\end{array}$ \\
\hline $\begin{array}{l}\text { Total cholesterol } \\
(\mathrm{mmol} / \mathrm{l})\end{array}$ & $\begin{array}{l}8 \text { weeks } \\
14 \text { weeks }\end{array}$ & $\begin{array}{l}4.23 \pm 0.59 \\
4.88 \pm 0.81\end{array}$ & $\begin{array}{l}4.87 \pm 1.54 \\
5.26 \pm 1.48\end{array}$ & $\begin{array}{l}4.41 \pm 0.73 \\
4.98 \pm 1.31\end{array}$ \\
\hline $\begin{array}{l}\text { Triglycerides } \\
(\mathrm{mmol} / \mathrm{I})\end{array}$ & $\begin{array}{l}8 \text { weeks } \\
14 \text { weeks }\end{array}$ & $\begin{array}{l}1.22 \pm 0.37 \\
1.20 \pm 0.32\end{array}$ & $\begin{array}{l}1.34 \pm 0.38 \\
1.12 \pm 0.36\end{array}$ & $\begin{array}{l}1.11 \pm 0.39 \\
1.00 \pm 0.24\end{array}$ \\
\hline $\begin{array}{l}\text { HDL-Cholesterol } \\
(\mathrm{mmol} / \mathrm{l})\end{array}$ & $\begin{array}{l}8 \text { weeks } \\
14 \text { weeks }\end{array}$ & $\begin{array}{l}1.01 \pm 0.25 \\
1.14 \pm 0.35\end{array}$ & $\begin{array}{l}0.47 \pm 0.20^{* *} \\
0.63 \pm 0.30^{* *}\end{array}$ & $\begin{array}{l}0.89 \pm 0.32 \\
0.90 \pm 0.49^{*}\end{array}$ \\
\hline $\begin{array}{l}\mathrm{HDL}_{2}-\mathrm{Cholesterol} \\
(\mathrm{mmol} / \mathrm{l})\end{array}$ & $\begin{array}{l}8 \text { weeks } \\
14 \text { weeks }\end{array}$ & $\begin{array}{l}0.23 \pm 0.21 \\
0.19 \pm 0.15\end{array}$ & $\begin{array}{l}0.05 \pm 0.04^{*} \\
0.05 \pm 0.04^{*}\end{array}$ & $\begin{array}{l}0.14 \pm 0.13^{*} \\
0.14 \pm 0.18\end{array}$ \\
\hline $\begin{array}{l}\mathrm{HDL}_{3} \text {-Cholesterol } \\
(\mathrm{mmol} / \mathrm{l})\end{array}$ & $\begin{array}{l}8 \text { weeks } \\
14 \text { weeks }\end{array}$ & $\begin{array}{l}0.78 \pm 0.12 \\
0.96 \pm 0.29\end{array}$ & $\begin{array}{l}0.43 \pm 0.18^{* *} \\
0.57 \pm 0.30^{* *}\end{array}$ & $\begin{array}{l}0.74 \pm 0.24 \\
0.77 \pm 0.38\end{array}$ \\
\hline $\begin{array}{l}\text { Apo-AI } \\
(g / l)\end{array}$ & $\begin{array}{l}8 \text { weeks } \\
14 \text { weeks }\end{array}$ & $\begin{array}{l}1.39 \pm 0.22 \\
1.44 \pm 0.31\end{array}$ & $\begin{array}{l}0.82 \pm 0.29^{* *} \\
0.91 \pm 0.42^{* *}\end{array}$ & $\begin{array}{l}1.21 \pm 0.34 \\
1.10 \pm 0.47^{* *}\end{array}$ \\
\hline $\begin{array}{l}\text { Apo-B } \\
(\mathrm{g} / \mathrm{l})\end{array}$ & $\begin{array}{l}8 \text { weeks } \\
14 \text { weeks }\end{array}$ & $\begin{array}{l}0.90 \pm 0.10 \\
1.00 \pm 0.14\end{array}$ & $\begin{array}{l}1.22 \pm 0.23^{*} \\
1.32 \pm 0.34^{* *}\end{array}$ & $\begin{array}{l}0.99 \pm 0.09 \\
1.16 \pm 0.36\end{array}$ \\
\hline $\begin{array}{l}\text { Lipoprotein (a) } \\
\text { (units/l) }\end{array}$ & $\begin{array}{l}8 \text { weeks } \\
14 \text { weeks }\end{array}$ & $\begin{array}{l}68 \pm 51 \\
299 \pm 410\end{array}$ & $\begin{array}{l}21 \pm 26^{* *} \\
42 \pm 84^{* *}\end{array}$ & $\begin{array}{l}58 \pm 68 \\
142 \pm 303^{* *} \&\end{array}$ \\
\hline
\end{tabular}

Data are presented as mean \pm s.d.

Within group changes: ${ }^{*}=p<0.05 ;{ }^{* *}=p<0.01$ (compared to baseline values) Interaction: $\&=p<0.05$ (difference compared to change in CO group) 
Table 4. Sequence of serum levels of lipids and lipoproteins of the bodybuilders in the randomized, double blind, placebo controlled study (Study 2).

\begin{tabular}{|c|c|c|c|c|}
\hline & & $\begin{array}{l}\text { Baseline } \\
\text { (week o) }\end{array}$ & $\begin{array}{l}\text { End of AAS } \\
\text { administration } \\
\text { period } \\
\text { (week } 8 \text { ) }\end{array}$ & $\begin{array}{l}6 \text { weeks after } \\
\text { drug cessation } \\
\text { (week 14) }\end{array}$ \\
\hline \multirow[t]{2}{*}{ Apo-A1 (g/I) } & Nandrolone & $1.37 \pm 0.20$ & $1.36 \pm 0.29$ & $1.39 \pm 0.26$ \\
\hline & Placebo & $1.41 \pm 0.11$ & $1.50 \pm 0.25$ & $1.49 \pm 0.33$ \\
\hline \multirow[t]{2}{*}{ Apo-B (g/l) } & Nandrolone & $0.98 \pm 0.23$ & $1.08 \pm 0.18$ & $0.98 \pm 0.20$ \\
\hline & Placebo & $1.11 \pm 0.32$ & $1.13 \pm 0.36$ & $1.12 \pm 0.27$ \\
\hline \multirow[t]{2}{*}{ Total cholesterol (mmol/l) } & Nandrolone & $4.78 \pm 0.85$ & $5.06 \pm 0.57$ & $4.72 \pm 0.67$ \\
\hline & Placebo & $5.10 \pm 1.01$ & $5.26 \pm 1.37$ & $5.16 \pm 0.71$ \\
\hline \multirow[t]{2}{*}{ Triglycerids (mmol/l) } & Nandrolone & $1.14 \pm 0.37$ & $1.13 \pm 0.22$ & $1.37 \pm 0.59$ \\
\hline & Placebo & $1.29 \pm 0.38$ & $1.45 \pm 0.58$ & $1.30 \pm 0.60$ \\
\hline \multirow[t]{2}{*}{ HDL-Cholesterol ( $\mathrm{mmol} / \mathrm{l})$} & Nandrolone & $1.13 \pm 0.32$ & $1.06 \pm 0.36$ & $1.08 \pm 0.30$ \\
\hline & Placebo & $1.16 \pm 0.19$ & $1.22 \pm 0.41$ & $1.17 \pm 0.37$ \\
\hline \multirow[t]{2}{*}{$\mathrm{HDL}_{2}$-Cholesterol (mmol/1) } & Nandrolone & $0.09 \pm 0.06$ & $0.06 \pm 0.05$ & $0.07 \pm 0.04$ \\
\hline & Placebo & $0.10 \pm 0.05$ & $0.14 \pm 0.20$ & $0.13 \pm 0.08$ \\
\hline \multirow[t]{2}{*}{$\mathrm{HDL}_{3}$-Cholesterol (mmol/l) } & Nandrolone & $1.04 \pm 0.30$ & $1.00 \pm 0.32$ & $1.00 \pm 0.28$ \\
\hline & Placebo & $1.05 \pm 0.15$ & $1.07 \pm 0.28$ & $1.04 \pm 0.31$ \\
\hline \multirow[t]{2}{*}{ Lipoprotein(a) (Units/I) } & Nandrolone & $\begin{array}{l}103 \pm 68 \\
(8-227)\end{array}$ & $\begin{array}{l}65 \pm 44 * * \\
(8-130)\end{array}$ & $\begin{array}{l}89 \pm 66 \\
(12-185)\end{array}$ \\
\hline & Placebo & $\begin{array}{l}245 \pm 245 \\
(38-756)\end{array}$ & $\begin{array}{l}201 \pm 194 * * \\
(46-617)\end{array}$ & $\begin{array}{l}240 \pm 224 \\
(29-657)\end{array}$ \\
\hline
\end{tabular}

Data are presented as mean \pm s.d.; for $L p(a)$ also the ranges (between brackets) are presented. Within group changes: ${ }^{*}=p<0.05 ;{ }^{* *}=p<0.01$ (compared to baseline values). Interaction: $\&=p<0.05$ (difference compared to change in placebo group)

\section{DISCUSSION}

Previously, several studies have associated the use of androgenic-anabolic steroids and their subsequent adverse effects on serum lipid parameters to the development of premature cardiovascular events in healthy strength athletes $(6,15,16)$. In the present study we have demonstrated that the use of 'cocktails' of AAS increases serum apo B levels, and severely decreases serum HDL-cholesterol and apo A1 levels, while it lowers the serum concentration of the atherogenic $L p(a)$ particle. Unlike the other anabolic steroids such as the various 17-alpha alkyl steroids, which were used in the self-administration study, nandrolone decanoate, even in high doses, had no detrimental effects on lipid profile in body-builders. The 'classic' lipid parameters and apo A1 and B levels remained constant, whereas a remarkable reduction of $L p(a)$ levels could be observed due to nandrolone decanoate administration. In the placebo group also a decrease of serum $L p(a)$ was found, although this was approximately half of the reduction in the 
nandrolone treated subjects. However, the net effect of nandrolone decanoate over placebo on $\mathrm{Lp}(\mathrm{a})$ serum levels did not reach statistical significance. It is very likely that this lack of significance is due to the large differences between individual values of $L p(a)$ and the small number of participants in study 2.

It is known that $L p(a)$ is an independent risk indicator for the development of vascular disease $(11,14)$. The serum level of $L P(a)$ seems to be genetically determined and, when elevated, can not be lowered by alterations in food intake or cholesterol lowering drugs $(10,19)$. Until now only one study assessed the effects of self-administration of high doses AAS in body-builders (2). In a cross-sectional study the authors reported that more non-AAS users had elevated $L p(a)$ levels compared to AAS users (2).

In patients with atherosclerosis due to hyperlipidemia and elevated Lp(a) levels it is advocated to lower serum cholesterol as much as possible in order to prevent new events or to achieve regression of atherosclerosis. Some investigators even have tried to perform specific apheresis techniques to lower elevated $\mathrm{LP}(\mathrm{a})$ levels in such patients. Considering the absence of any effects of nandrolone on lipid parameters together with a substantial lowering of $L p(a)$ levels, it may be attractive to assess whether this drug may have long-term beneficial effect in these athletes. Various studies reported that nandrolone decanoate has the potential to lower serum levels of Lp(a) in several disease conditions $(3,12,22)$.

Another interesting finding of the present study was that serum levels of apo $A 1$ and $B$ were not influenced by the duration of AAS use. After 14 weeks of use, the serum levels of these parameters were not different from those after 8 weeks. It is known that lipid levels undergo their largest alterations during the first weeks of AAS administration (24). However, we observed that the suppressive effect of AAS on serum lipoprotein and lipids levels persisted during long-term administration. Six weeks after AAS withdrawal the serum levels of HDL-cholesterol, Apo-A1 and $L p(a)$ were not normalized in the long-term AAS users, whereas in the short-term users the lipids and lipoproteins, except HDL2-cholesterol, had returned to baseline levels already. This suggests that longer periods of drug use will cause prolonged deleterious alterations of lipid profile, despite a prolonged lowering of $L p(a)$ levels.

We conclude that long-term use of AAS is accompanied with an increased atherogenic lipid profile, which persists for more than 6 weeks after cessation of use. This may be associated with the occurrence of premature cardiovascular events in these athletes, despite a lowering effect on $L p(a)$ levels which per se may be beneficial. Nandrolone decanoate may selectively reduce $L p(a)$ levels, and therefore it may be used safely in disease conditions like osteoporosis and muscle wasting. Whether it can impact vascular prognosis of subjects with atherosclerosis, hyperlipidemia, and elevated levels of $L p(a)$ needs to be determined in prospective clinical trials. 


\section{REFERENCES}

1. Applebaum-Bowden, D., S. M. Haffner, and W. R. Hazzard. The dyslipoproteinemia of anabolic steroid therapy: increase in hepatic triglyceride lipase precedes the decrease in high density lipoprotein cholesterol. Metabolism 36: 949-952, 1987.

2. Cohen, L. I., C. G. Hartford, and G. G. Rogers. Lipoprotein (a) and cholesterol in body builders using anabolic androgenic steroids. Med Sci Sports Exerc 28: 176-179, 1996.

3. Crook, D., M. Sidhu, M. Seed, M. O'Donnell, and J. C. Stevenson. Lipoprotein Lp(a) levels are reduced by danazol, an anabolic steroid. Atherosclerosis 92: 41-7, 1992.

4. Cushing, G. L., J. W. Gaubatz, M. L. Nava, B. J. Burdick, T. M. Bocan, J. R. Guyton, D. Weilbaecher, M. E. DeBakey, G. M. Lawrie, and J. D. Morrisett. Quantitation and localization of apolipoproteins [a] and $B$ in coronary artery bypass vein grafts resected at re-operation. Arteriosclerosis 9: 593-603, 1989.

5. De Boer, A., S. F. van Haren, F. Hartgens, D. de Boer, and A. J. Porsius. Onderzoek naar het gebruik van prestatieverhogende middelen bij bodybuilders in Nederland. Nederlands Centrum voor Dopingvraagstukken, Universiteit Utrecht, 1996.

6. Ferenchick, G. S., and S. Adelman. Myocardial infarction associated with anabolic steroid use in a previously healthy 37-year-old weight lifter. Am Heart J 124: 507-8, 1992.

7. Friedl, K. E., C. J. Hannan, R. E. Jones, and S. R. Plymate. High-density lipoprotein cholesterol is not decreased if an aromatizable androgen is administered. Metabolism 39:: 69-74, 1990.

8. Glazer, G. Atherogenic effects of anabolic steroids on serum lipid levels; a literature review. Arch Intern Med 151: 1925-1933, 1991.

9. Haffner, S. M., R.S. Kushwaha, D.M. Foster, D. Applebaum-Bowden, W.R. Hazzard. Studies on the metabolic mechanism of reduced high density lipoproteins during anabolic steroid therapy. Metabolism 32: 413-420, 1983.

10. Kostner, G. M. Lipoprotein $L p(a)$ : impact on atherosclerosis and immunochemical quantification. Przegl Lek 46: 560-2, 1989.

11. Kostner, G. M., P. Avogaro, G. Cazzolato, E. Marth, G. Bittolo-Bon, and G. B. Qunici. Lipoprotein $\mathrm{Lp}(\mathrm{a})$ and the risk for myocardial infarction. Atherosclerosis 38: 51-61, 1981.

12. Lippi, G., G. Guidi, O. Ruzzenente, V. Braga, and S. Adami. Effects of nandrolone decanoate (Decadurabolin) on serum Lp(a), lipids and lipoproteins in women with postmenopausal osteoporosis. Scand J Clin Lab Invest 57: 507-11, 1997.

13. Luke, J. L., A. Farb, R. Virmani, and R. H. Sample. Sudden cardiac death during exercise in a weight lifter using anabolic androgenic steroids: pathological and toxicological findings. $J$ Forensic Sci 35: 1441-7, 1990.

14. M. Bewu, A., and P. N. Durrington. Lipoprotein (a): structure, properties and possible involvement in thrombogenesis and atherogenesis. Atherosclerosis 85: 1-14, 1990.

15. Mochizucki, R. M., and K. J. Richter. Cardiomyopathy and cerebrovascular accident associated with anabolic-androgenic steroid use. Physician Sportsmed 16: 109-114, 1988.

16. Nieminen, M. S., M. P. Ramo, M. Viitasalo, P. Heikkila, J. Karjalainen, Mantysaari, $M$, and J. Heikkila. Serious cardiovascular side effects of large doses of anabolic steroids in weight lifters. Eur. Heart J. 17: 1576-1583, 1996.

17. Rath, M., A. Niendorf, T. Reblin, M. Dietel, H. J. Krebber, and U. Beisiegel. Detection and quantification of lipoprotein(a) in the arterial wall of 107 coronary bypass patients. Arteriosclerosis 9: 579-92, 1989.

18. Rosengren, A., L. Wilhelmsen, E. Eriksson, B. Risberg, and H. Wedel. Lipoprotein (a) and coronary heart disease: a prospective case-control study in a general population sample of middle aged men. Br Med J 301: 1248-51, 1990.

19. Scanu, A. M. Lipoprotein(a): a genetically determined lipoprotein containing a glycoprotein of the plasminogen family. Semin Thromb Hemost 14: 266-70, 1988. 
20. Scanu, A. M. Lipoprotein(a). A potential bridge between the fields of atherosclerosis and thrombosis. Arch Pathol Lab Med 112: 1045-7, 1988.

21. Taggart, H. M., B. D. Applebaum, S. Haffner, G. R. Warnick, M. C. Cheung, J. J. Albers, C. d. Chestnut, and W. R. Hazzard. Reduction in high density lipoproteins by anabolic steroid (stanozolol) therapy for postmenopausal osteoporosis. Metabolism 31: 1147-52, 1982.

22. Teruel, J. L., M. A. Lasuncion, M. Rivera, A. Aguilera, H. Ortega, A. Tato, R. Marcen, and J. Ortuno. Nandrolone decanoate reduces serum lipoprotein(a) concentrations in hemodialysis patients. American Journal of Kidney Diseases. Apr 29: 569-575, 1997.

23. Thiery, J., V. W. Armstrong, J. Schleef, C. Creutzfeldt, W. Creutzfeldt, and D. Seidel. Serum lipoprotein $L p(a)$ concentrations are not influenced by an HMG CoA reductase inhibitor. Klin Wochenschr 66: 462-3, 1988.

24. Thompson, P. D., E. M. Cullinane, S. P. Sady, C. Chevenert, A. L. Saritelli, M. A. Sady, and P. N. Herbert. Contrasting effects of testosterone and stanozolol on serum lipoprotein leveis. JAMA 261: 1165-1168, 1989.

25. Utermann, G. The mysteries of lipoprotein(a). Science 246: 904-10, 1989.

26. Yesalis, C. E. Anabolic steroids in sport and exercise. Champaign: Human Kinetics, 1993.

27. Yesalis, C. E., C. K. Barsukiewicz, A. N. Kopstein, and M. S. Bahrke. Trends in anabolic-androgenic steroid use among adolescents. Arch Pediatr Adolesc Med 151: 1197-206, 1997. 


\title{
CHAPTER 8
}

\section{General discussion}

\author{
ETHICAL CONSIDERATIONS IN RESEARCHING THE \\ PATHOLOGICAL-PHYSIOLOGICAL EFFECTS OF DOPING \\ SUBSTANCES IN ATHLETES
}

It is well known that the administration of doping substances to enhance sports performance contravenes the rules of the sports federations, is unethical and will induce detrimental effects on health status $(9,15,24)$. However, these arguments do not discourage athletes, trainers, coaches and even medical doctors to stop such practices (13). If anything, the use of doping substances is pushed due to the purposed performance enhancing capacities. And since in elite competition the differences between first and, for example, sixth place, may be very small, the differences in prestige and financial benefits may be huge. This may stimulate athletes to enhance performance by all possible means, even if they are unethical and athletes put up with detrimental effects on health status.

On the other hand, there are many amateur and recreational athletes who administer doping substances too, and even adolescents are prone to such practices (28). In the last decades it has demonstrated that the magnitude of abuse of doping agents among these athletes is widespread and of a very large magnitude $(13,28)$. Therefore, we cannot deny the problems that accompany doping abuse.

We have to recognize that it is an illusion to rule out doping abuse completely. On the other hand, this does not imply that we do not have to do anything. From a medical point of view several efforts can contribute to the management of the doping issue. First, we have to provide accurate information about the performance enhancing effects as well as the side effects to athletes and their accompanying persons, including trainers and medical doctors. We need an open dialogue, since the effects of scare tactics have been demonstrated to fail prematurely. However, until now there is a huge lack of well documented research data about the effects of doping agents on exercise performance. Moreover, in this area many substances have never been investigated at all (25). Most information has been adopted from the field of sports and may, therefore, preserve anecdotal lore about these drugs. 
Another important point is that the lists of prohibited substances of sports federations have to be reconsidered (23). The presence of a substance on a doping list may, in itself, convey the impression that the substance indeed does enhance performance, even if this is not the case at all $(20,23)$.

Furthermore, we know that many athletes are used to administer doping agents in higher dosages than are recommended for therapeutical use ( 9 , $13,28)$. As stated before, there is lack of evidence that such dosages may actually enhance performance, but it is well known that the health risk will increase with the dose administered.

Since doping substances are general medications, one would suspect that medical doctors are able to provide information about these drugs. Unfortunately, the opposite is true. Recently it has been demonstrated that the knowledge of general practitioners about doping is very limited. In a survey the general practitioners admitted frankly that they felt incompetent to provide correct information to athletes $(7,10)$.

Several attempts have been undertaken to estimate the magnitude of doping use in recent years. In the Netherlands, a few researchers have investigated the total number of doping users. Based on the report by Vogels et al (1994) the number of doping users among athletes in fitness centers and gyms was estimated to be at least 35,000 (27). More recent research by Abraham et al (1999), however, calculated that over 100,000 people in the Dutch population had used doping substances at least once (1). In an anonymous survey, $3 \%$ of the elite Dutch athletes admitted to have used doping substances, while another $3 \%$ mentioned that they considered to start the administration of such agents in the (near) future (6).

Koert and Van Kleij (1998) recognized three major reasons of concern, after investigating the trading in doping substances. First, they found that doping abuse among people has been extended. Second, more people used more doping substances but in higher dosages, and often in combination with other drugs like XTC, cocaine and amphetamines. And finally, they reported an increase in the number of falsifications of the doping substances on the black market, where most agents are dealt, and these turned out to be of inferior quality. These conclusions are of great concern, especially from a medical point of view (19).

From our experience in the AAS project it turned out that athletes who experience the actual effects (performance enhancing as well as side effects) at their own body reconsider future administration of doping substances. This observation is supported by the findings in the "Lijf, Sport en Middelen"-project from the Netherlands Centre for Doping Affairs (unpublished data).

Overlooking the aforementioned facts, it is concluded that there is a large lack of information about the actual effects of doping substances on performance, muscle mass and health status, and the use of doping substances is increasing which is of major medical concern. Therefore, we advocate to continue investigating the effects of doping substance on performance as 
well as on health status. Such research has to be in accordance with general practices by athletes. This will provide evidence based information that can be used in the management of the doping problem. Until recently, much research was not in accordance with general practices of athletes and lead to inaccurate conclusions. For example, in 1977 the prominent American College of Sports Medicine (ACSM) concluded, based on well designed scientific studies in the seventies, that androgenic-anabolic steroids did not improve performance or muscle mass (5). However, the most important criticism on these studies was that they were not in agreement with sports practices. A few years later, the ACSM changed the position stand by stating that under special circumstances the use of androgenic-anabolic steroids may improve performance, muscle mass and strength in athletes (4).

Scientific research upon the pathological and physiological effects of doping substances may place investigators in a dilemma. On one hand, in sports it is a common practice to administer high dosages of doping agents, whereas ethical considerations do not allow to copy such practices in a research setting. On the other hand, there is a great lack of scientific data concerning the wanted and unwanted effects of banned substances. Another point that should be realized is that doping substances include pharmacological agents that are also administered in the treatment of diseases. Research on banned substances may have spin off for medical practice as far as indications, effects and side effects are concerned. Recombinant erythropoietin (rhEPO), for example, was initially only administered in kidney failure patients. The experiences with rhEPO obtained in athletes was extended to healthy subjects and new indications have been identified. Therefore, research in this area has to balance between practice and ethics. It is generally accepted that researching the effects of pharmacological substances requires good clinical practice with thorough protection of volunteers. Since administration of doping may mean the use of supratherapeutical dosages, in doping research this may be also applied but strict medical supervision is necessary. It is possible to examine athletes who self-administer doping substances, but from a scientific point of view it would be preferable to apply randomized, double blind study designs. However, the value of double blind designs may be limited because ethical considerations prevent the application of studies in accordance with athletes practices. Furthermore, in the case of the administration of supratherapeutical doses, premature unblinding of the design is likely to occur due to the experienced (side-)effects. Therefore, a combination of randomized, double blind studies and non-blinded studies may be appropriate in this research field. A method to overcome, at least in part, the aforementioned considerations in blinded trials, is the conduction of dose-response studies. This will bring forth well documented and valuable information. For the unblinded studies it would be preferable to standardize the self-administered substances as well as the dosages. In practice this will be barely impossible, but may be overcome by including large numbers of athletes. 


\section{EFFECTS OF AAS ON BODY COMPOSITION: A SYNTHESIS}

The studies presented in this thesis provided answers to the most important objectives of the AAS project and, thus, added novel scientific data upon the effects of AAS on body composition and anthropometry. This research clearly showed, in line with previous research, that the administration of AAS supplementary to a strength training program changes body composition significantly in experienced strength athletes. However, the observed alterations in relation to dose and substances used, and the impact of the length of AAS administration may be even of more importance.

Dose and substance administered. These studies showed that the extent of body changes depends on the AAS administration regimen and dosages used. Strength training accompanied by polydrug regimens with suprapharmacological dosages of AAS increased body weight and lean body mass more than the intramuscular administration of nandrolone decanoate in a therapeutic dose. Moreover, this was reflected in larger gains of limb and trunk circumferences.

The DEXA analyses revealed that the enlargement of the limbs in the self-administering users could be attributed to an increase of lean mass, while fat mass and bone mineral content remained constant.

The administration of a therapeutic dose of nandrolone decanoate for eight weeks did not affect limb circumferences, although DEXA analyses revealed regionally different responses. The increment in bone free lean mass of the legs was only slightly lower than in the self-administering athletes this was not reflected in changes of circumferences.

Fat mass remained in all studies unaffected, independent on the dose and drugs administered. Nandrolone decanoate as well as the high dose polydrug regimens did not lower fat mass. Although in animal studies the opposite was observed, our findings may indicate that AAS (whether in low or high dose) do not reduce fat mass in eugonadal lean young men.

Regional differences. While nandrolone decanoate increased only the circumference of the neck, high dose polydrug regimens induced enlargements of 7 circumferences. The legs and arm circumferences increased more pronounced than the circumference of the trunk.

On the other hand, DEXA measurements revealed that the bone free lean mass of the trunk increased more, in absolute terms, than the bone free mass of arms and legs. However, the relative gain of bone free mass was most prominent in the arms compared to legs and trunk (14\% versus $7 \%$ and $7 \%$, respectively).

The administration of a therapeutic dose of nandrolone decanoate for eight weeks did not affect limb circumferences, although DEXA analyses revealed increments of trunk and legs bone free lean mass, but not in the arms. Although the increment in bone free lean mass of the legs was only slightly 
lower than in the self-administering athletes this was not reflected in changes of circumferences.

Impact of duration of AAS administration. it turned out that the length of AAS administration on itself is not related to the extent of body changes. Short-term ( 8 weeks) and long-term (12-16 weeks) AAS self-administration had the same effects on body weight and lean body mass, whereas duration did not affect fat mass in any way. Moreover, the effects on circumferences of limbs and trunk were comparable. Finally, after drug withdrawal all body changes remained present largely for 6 weeks independent of the length of AAS used.

This observation does not support the claims of many strength athletes that longer courses of AAS may exert more pronounced effects on body composition. One has to take into account that many users periodically increase the dosages of AAS during one course and their claims may be based on increasing dosages rather than on the length of an AAS course. It is hypothesized, both by athletes and scientists, that the steroid-induced effects may reach a plateau after several weeks of AAS administration. To obtain additional effects one has to increase the dose of the AAS administered and / or switch to other anabolic substances.

Unfortunately, in our studies we were not able to investigate the effects of such regimens and did not make any attempt to influence the regimens chosen by the subjects. The athletes determined the AAS courses based on their own beliefs and insights and purchased the substances by themselves, mainly on the black market. The long-term users kept the dosages of the AAS at a rather constant level after the 8th week until the end of the course. Therefore, this did not allow us to study the effects of long term use of increasing dosages.

Which tissue is affected? Until now it has been thought that the steroid induced body changes could be attributed to an increase of body water, i.e. water retention and increased blood volume $(11,14)$, although the effects on muscle mass were still debatable $(3,16,17,21,22)$. Although our studies do not have the potential to solve this issue completely, they provide more insight in this topic. They show that high dose polydrug regimens increase deltoid muscle fiber size, whereas a therapeutic dose of nandrolone decanoate does not affect these muscle fibers. In previous research the size of the vastus lateralis muscle fibers remained unchanged after administration of a low dose nandrolone decanoate as well as after high dose polydrug regimens (22). This supports the theory that upper body muscles may show selective adaptation to AAS administration $(16,18)$. Therefore, we conclude that high dose polydrug regimens may increase the fiber size of upper body muscles more than of the lower body. And moreover, high dose polydrug regimens are more effective than the administration of a single anabolic substance in a therapeutic dose. 
Recently, in another study that is not presented in this thesis, we were able to determine the impact of water retention after AAS administration (26). It turned out that the high dosages used by the subjects in our studies induced a lean mass gain that showed a normal composition, without any indication for AAS induced water retention. Additionally, total bone mineral content as well as bone mineral density were unaffected by AAS administration (26). Holma (1977) concluded that a blood volume expansion of approximately $15 \%$ may be observed after AAS administration (14). However, this conclusion has not been confirmed in later research and is therefore debatable. With respect to blood changes by AAS use, it has been well established that anabolic substances may increase blood cell counts in young healthy men, especially of red blood cells and platelets $(2,8)$. Whether these alterations may lead to a redistribution of blood volume has not been determined yet.

Individual variations. Although not presented in this thesis, the individual variation in expression of effects due to AAS administration needs some attention. In gyms anecdotic lore exists that steroid induced body weight increments of $15 \mathrm{~kg}$ and more are likely to occur in some individual after one AAS course. Although we were not able to observe such large body changes in our studies, the interindividual differences were sometimes large. This was the case after nandrolone decanoate administration, as well as in the self-administering subjects who composed the identical AAS courses. A practical consequence of this observation is that nobody can determine what the most appropriate AAS course for an individual is. A common practice is that many athletes seek medical advice to obtain the AAS course that increases body weight and dimensions as much as possible but does not affect health status. Knowledge as to the individual response to AAS can only be obtained by thoroughly monitoring of several AAS courses. This approach is potentially also useful for physicians who guide strength athletes. However, physicians applying such an approach may come into collision with the medical code.

Conclusions. From these observations we conclude that steroid induced body changes may primarily be attributed to increments of muscle mass of the upper body rather than of the lower body. This may be explained by the larger number of androgen receptors in upper body muscles, since the acceleration of protein synthesis appears to be comparable in all body regions. The effects of high doses on muscle fiber size are more pronounced than those of low dosages. Recent research undermines the water retention theory as proposed by Hervey and coworkers $(11,12)$, while it remains unclear how blood volume changes due to AAS administration. 


\section{EFFECTS OF AAS ON THE CARDIOVASCULAR SYSTEM: A SYNTHESIS}

Dose and substance administered. The studies in this thesis demonstrate that the detrimental effects on serum lipids and lipoproteins are more pronounced after polydrug regimens compared to the use of nandrolone decanoate alone. Although AAS have been associated with an unfavorable lipoprotein profile, at least nandrolone decanoate seems to be an exception. From our and other studies it seems likely that this particular substance, at least in the investigated doses, does not exert unfavorable effects on serum values of lipids and lipoproteins. Contrary, nandrolone decanoate may beneficially affect serum lipoprotein(a) levels, although the clinical relevance has to be established yet.

Echocardiographic examination demonstrated that the cardiac structure and function remained unaffected by low and high dosages AAS. However, on a ultrastructural level the heart structure may be affected within several weeks after the start of AAS administration. Moreover, in animal studies heart function has been reported to decrease due to AAS administration. Although animal data may not be extrapolated to other species without great caution, these observations may indicate that echocardiographic examination may underestimate the actual heart damage since the technique applied can not detect ultrastructural alterations.

Impact of duration of AAS administration. The effects of short and long term AAS on serum lipids and lipoproteins were comparable. However, after drug cessation the time to full recovery of the disturbed lipids/lipoprotein profile was prolonged.

The length of AAS administration had no impact on echocardiographic indices of heart structure and function. These findings indicate that long term AAS use is associated with an increased risk for cardiovascular events compared to short term administration.

Conclusions. General used practices of polydrug administration of AAS will change serum lipoprotein profile unfavorably. This induces a temporary increased risk for the occurrence of cardiovascular disease since after drug cessation serum values will recover completely. Compared with short term administration, long term AAS use is associated with a prolonged period of increased risk, both by the length of the AAS course but also by the prolonged recovery period after withdrawal. Short and long term AAS administration does not induce echocardiographic alterations of cardiac structure and function. In AAS users, normal findings on echocardiographic examination does not exclude heart abnormalities since these substances may induce primarily ultrastructural changes of heart cells that cannot be detected by echocardiography. 


\section{FUTURE DIRECTIONS}

Since it is an illusion to think that the use of doping substances by athletes can be banned completely, efforts have to be made to keep the doping problem under control. Scientific research upon the performance enhancing effects as well as the untoward effects of doping agents may contribute substantially to this purpose. However, both ethical considerations and scientific standards have to be taken into account. Therefore, we advocate to perform double blind studies to investigate dose-response relationships of doping substances, and unblinded studies that provide information about doping use in the field of sports. The combination of randomized, double blinded and unblinded studies will provide valuable and practically-oriented information and both approaches will complement each other. To my conviction, based on experience in the previous years, practically-oriented research will have more impact on athletes than studies purely for the sake of science, both with respect to the effects on performance as well as on the untoward effects. 


\section{REFERENCES}

1. Abraham, M., P. Cohen, R.-J. van Til, and M. A. L. de Winter. Licit and illicit drug use in the Netherlands, 1997. Amsterdam: Centrum voor Drugsonderzoek (CEDRO), 1999.

2. Alen, M. Androgenic steroid effects on liver and red cells. Br J Sports Med 19: 15-20, 1985.

3. Alen, M., K. Hakkinen, and P. V. Komi. Changes in neuromuscular performance and muscle fiber characteristics of elite power athletes self-administering androgenic and anabolic steroids. Acta Physiol Scand 122: 535-44, 1984.

4. American College of Sports Medicine. Position stand on the use of anabolic-androgenic steroids in sports. Med Sci Sports Exerc 19: 534-9, 1987.

5. American College of Sports Medicine. Position statement on the use and abuse of anabolic-androgenic steroids in sports. Med Sci Sports 9, 1977.

6. De Groot, S., F. Hartgens, and M. F. Zweers. Enquete onder topsporters over doping, dopingcontroles en medicijngebruik in de sport. Rotterdam: Nederlands Centrum voor Dopingvraagstukken, 1999.

7. Greenway, P., and M. Greenway. General practitioner knowledge of prohibited substances in sport. Br J Sports Med 31: 129-31, 1997.

8. Hartgens, F., K. Hamulyak, C. Pernot, K. Depuydt, T. Gordijn, H. A. Keizer, and H. Kuipers. Effects of high doses androgenic-anabolic steroids on haematologic parameters in bodybuilders. 8th FIMS European Sports Medicine Congress, Granada (Spain), 1995, p. 80.

9. Hartgens, F., and H. Kuipers (eds). Verboden middelen in de sport. Houten: Bohn Stafleu Van Loghum, 2000.

10. Hartgens, F., G. Rietjens, S. Van Haren, T. Vogels, and E. Vrijman. Huisarts en doping. Een onderzoek naar de aard en omvang van consulten over doping bij huisartsen en naar de kennis en attitude van huisartsen over doping. Rotterdam: Nederlands Centrum voor Dopingvraagstukken en TNO- Preventie en Gezondheid, 1998.

11. Hervey, G. R., I. Hutchinson, A. V. Knibbs, L. Burkinshaw, P. R. Jones, N. G. Norgan, and M. J. Levell. "Anabolic" effects of methandienone in men undergoing athletic training. Lancet 2: 699-702, 1976.

12. Hervey, G. R., A. V. Knibbs, L. Burkinshaw, D. B. Morgan, P. R. Jones, D. R. Chettle, and D. Vartsky. Effects of methandienone on the performance and body composition of men undergoing athletic training. Clin Sci 60: 457-61, 1981.

13. Hoberman, J. M. Mortal engines. Philadelphia: The Free Press, 1992.

14. Holma, P. Effect of an anabolic steroid (metandienone) on central and peripheral blood flow in well-trained male athletes. Ann Clin Res 9: 215-21, 1977.

15. International Olympic Committee. Statistics 1997 of the IOC accredited laboratories. International Olympic Committee, Lausanne, 1998.

16. Kadi, F. Adaptation of human skeletal muscle to training and anabolic steroids. Acta Physiol Scand Suppl 646: 1-52, 2000.

17. Kadi, F., A. Eriksson, S. Holmner, and L. E. Thornell. Effects of anabolic steroids on the muscle cells of strength-trained athletes. Med Sci Sports Exerc 31: 1528-34, 1999.

18. Kenyon, A. T., K. Knowlton, I. Sandiford, F. C. Koch, and G. Lotwin. A comparative study of the metabolic effects of testosterone proprionate in normal men and women and in eunuchoidism. Endocrinology 26: 26-45, 1940.

19. Koert, A., and R. Van Kleij. Handel in doping. Nieuwegein: Arko Uitgeverij, 1998.

20. Koornneef, M., H. Kuipers, and F. Hartgens. Beheering van de dopingproblematiek. In: Verboden middelen in de sport, edited by F. Hartgens and H. Kuipers. Houten: Bohn Stafleu Van Loghum, 2000.

21. Kuipers, H., B. F. Peeze, F. Hartgens, J. A. Wijnen, and H. A. Keizer. Muscle ultrastructure after strength training with placebo or anabolic steroid. Can J Appl Physiol 18: 189-96, 1993. 
22. Kuipers, H., J. A. G. Wijnen, F. Hartgens, and S. M. M. Willems. Influence of anabolic steroids on body composition, blood pressure, lipid profile and liver function in bodybuilders. Int J Sports Med 12: 413-418, 1991.

23. Mottram, D. R. Banned drugs in sport - Does the International Olympic Committee (IOC) list need updating? Sports Medicine. Jan 27(1): 1-10, 1999.

24. Mottram, D. R. Drugs in sport. London: E\&FN SPON, 1996.

25. Reents, S. Sport and exercise pharmacology. Champaign, IL: Human Kinetics, 2000.

26. Van Marken Lichtenbelt, W., F. Hartgens, S. Ebbing, N. Vollaard, and H. Kuipers. Body builders' body composition: effect of androgenic-anabolic steroids. Submitted, 2000.

27. Vogels, T., E. Brugman, B. Coumans, M.J. Danz, R.A. Hirasing, E. van Kernebeek. Lijf, sport en middelen. Nederlands Instituut voor Praeventieve Gezondheidszorg TNO, Leiden, 1994.

28. Yesalis, C. Anabolic steroids in sport and exercise (2nd ed.). Champaign IL: Human Kinetics, 2000. 


\section{Summary}

Since many years the use of doping substances in sport is widespread. Many attempts have been made by national and international sports federations and governments to fight the abuse of doping substances in the organized sport, especially in elite sport. However, in the last decades it has been demonstrated that the abuse of doping agents by strength athletes in gyms and fitness centers exceeds the misuse in elite athletes by far. The substances most often used by these athletes are an-drogenic-anabolic steroids (AAS) because of the assumed muscle building properties. Abuse of these drugs is of great medical concern since they are mainly purchased on the black market, the large dos-ages used and the lack of medical supervision. Since the knowledge about the effects of AAS on body composition and health was still incomplete and controversial, we started a series of studies upon these drugs that are reflected in this thesis. The main goal of these investigations was to study the effects of AAS on body composition and cardiovascular system in strength athletes and, additionally, whether the effects were influenced by the doses of AAS administered and / or by the duration of misuse of these substances. To meet the objectives set the following questions were formulated:

- What are the effects of the administration of AAS on body composition and anthropometry in ex-perienced strength athletes?

- What are the effects of AAS on the cardiovascular system with special reference to cardiac size and function and to serum lipids and lipoproteins?

- Is there a relationship between the observed (side-)effects and the dose of AAS used?

- Is there a relationship between the observed (side-)effects and duration of AAS administration?

In Chapter 2 we review the current knowledge about the wanted and untoward effects of AAS abuse in athletes. This knowledge provided the base for the experiments in the latter chapters.

In Chapter 3 we describe a study investigating the short and long term effects of strength training with concomitant AAS self-administration on body dimensions and total and regional body composition in an unblinded study design. Most subjects purchased the AAS on the black market, although some had obtained a prescription by a medical doctor, and 
self-administered several drugs together in weekly varying doses based on their own beliefs and insight. AAS increased body weight by $4.4 \mathrm{~kg}$ and lean body mass by $4.5 \mathrm{~kg}$, and produced increases in several circumferences. Percentage body fat determined by measuring skinfolds decreased slightly in AAS users, although total fat mass remained unchanged. The observed changes persisted six weeks after AAS withdrawal, though for some meas-urements only partially. The effects of 8 weeks and 12-16 weeks AAS self-administration produced comparable effects. Dual Energy X-ray Absorptiometry (DEXA) demonstrated that AAS stimulate the bone free mass of all body parts, while no regional changes in fat mass could be observed.

In a randomized, placebo controlled, double blind study design we investigated the effects of nandro-lone decanoate (Deca-Durabolin ${ }^{\circledR}$, Organon BV, Oss, The Netherlands), a commonly used and very popular anabolic steroid among strength athletes, on total body composition and anthropometry, but alterations on a regional level were also subject of this study (Chapter 4). After randomization the subjects received weekly intramuscular injections of nandrolone decanoate ( $200 \mathrm{mg}$ weekly) or pla-cebo for eight weeks. DEXA measurements revealed that total body mass ( $+2.6 \mathrm{~kg}$ ) and bone-free lean mass $(+3.5 \mathrm{~kg}$ ) increased significantly during nandrolone decanoate administration. Six weeks after drug withdrawal the bone-free lean mass was still increased compared to baseline levels. The most pronounced increments of the bone-free mass were observed at the trunk (+2.09 kg) and legs (+1.08 $\mathrm{kg}$ ). Percentage fat of the legs decreased during the drug intervention period $(-1.9 \%)$ and remained lowered six weeks after drug withdrawal. No alteration in any variable of the arms was ob-served. Skinfolds did not change during the entire study period in both groups. After 8 weeks nandrolone decanoate administration only circumference of the neck was increased $(+0.9 \mathrm{~cm})$ significantly, although all other circumferences underwent non-significant gains.

Measurements of skinfolds were not able to detect changes of fat mass of body parts. On the other hand, DEXA revealed that total fat mass and total percentage fat remained unaffected by drug administration, while percentage fat of the legs decreased and remained lowered after drug cessation. These results indicate that changes of the composition of body parts induced by nandrolone decanoate are elucidated less accurately by circumferences or skinfolds rather than by DEXA.

Chapter $\mathbf{5}$ describes two studies investigating the effects of strength training in combination with AAS administration on muscle ultrastructural characteristics with special reference to the difference between single drug administration and polydrug regimens. Study 1 was a double blind, placebo controlled study that investigated the effects of eight weeks intramuscular administration of nandrolone decanoate. The subjects received weekly injections containing either $200 \mathrm{mg}$ nandrolone decanoate or placebo. In 
study 2 the effects of self-administration of high doses AAS for 8 weeks were studied. The athletes purchased the drugs on the black market, although some had obtained a prescription from a medical doctor. Self-administration of AAS was characterized by using several AAS simultaneously in weekly varying dosages based on their own beliefs and insight. The dosages administered by the subjects were, without any exception, supratherapeutical. In all participants a percutaneous muscle biopsy from the posterior part of the deltoid muscle was obtained at baseline and after eight weeks study period.

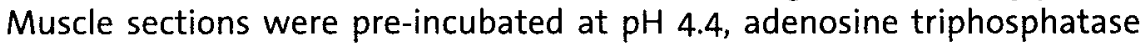
stained and morphometric analyzed. In each biopsy at least 150 fibers were classified for "gray level" and "lesser fiber diameter" to determine the mean fiber size, the size of type I and type II fibers, and the fiber type distribution. It turned out that eight weeks administration of nandrolone decanoate (200 mg weekly, intramuscularly) did not affect any muscle parameter. On the other hand, self-administration of AAS in high doses and polydrug regimens increased the mean muscle fiber size $(+12.6 \%)$, the size of type I $(+10.8 \%)$ and type II $(+14.6 \%)$ muscle fibers significantly. Fiber type distribution remained unaltered in both studies. From these studies we conclude that polydrug regimens of AAS in supratherapeutical dosages increase the size of deltoid muscle fibers (especially type II fibers) in experienced strength athletes, while administration of nandrolone decanoate in a therapeutical dose exerts no effect on deltoid muscle fibers.

The effects of AAS administration on the heart in experienced strength athletes are described in Chapter 6. Using the same study design as in chapter 5 we investigated cardiac structure and func-tion by means of echocardiography. This study revealed that eight weeks administration of AAS does not lead to detectable echocardiographic alterations of heart morphology, systolic and diastolic function in experienced strength athletes. This applies for the administration of a high therapeutic dose of a single anabolic steroid (nandrolone decanoate) for eight weeks, as well as for AAS polydrug regimens in suprapharmacological doses during periods up to 16 weeks. However, we emphasize to inter-pret these results with some reservations since the detrimental effects of AAS on the heart are well described in animal studies using (ultra-)microscopic evaluation of heart cell structures. From this study we can not exclude that AAS administration may induce ultrastructural alterations in humans and, therefore, echocardiographic evaluation may provide incorrect assessment of the actual cardiac condition in AAS users since it is not sensitive enough to detect alterations at the cellular level.

In Chapter 7 we describe the effects of AAS on cardiovascular risk factors, especially serum lipids and lipoproteins levels and recovery of these parameters after drug withdrawal. Determined were serum levels of Apo-A, Apo-B, Total cholesterol, Triglycerides, HDL-cholesterol, HDL2-cholesterol, HDL3-cholesterol, and lipoprotein(a). This study showed that the adminis- 
tration of several AAS simultaneously in suprapharmacological dosages is accompanied with an increased atherogenic lipid profile, although $\operatorname{Lp}(a)$ levels may be influenced beneficially. The changes persisted for more than six weeks after AAS withdrawal and normalization depended on duration of the AAS administration period. Eight weeks administration of nandrolone decanoate did not affect serum lipids and lipoproteins, although it may selectively reduce $L p(a)$ levels. However, the impact of our observations on vascular prognosis requires further investigation. 


\section{Samenvatting}

Sinds vele jaren is het gebruik van doping in de sport wijdverbreid. Nationale en internationale sportorganisaties en overheden hebben vele pogingen ondernomen om het gebruik van dopinggeduide middelen, met name in de topsport, te reduceren. Echter, de laatste decennia is gebleken dat misbruik van dergelijke middelen door bezoekers van sportscholen en fitnesscentra veel prominenter aanwezig is. Deze sporters gebruiken vooral androgeneanabole steroïden (AAS) vanwege de spieropbouwende eigenschappen. Dit is medisch gezien een groot probleem omdat de meeste producten op de zwarte markt verkregen worden, er enorm hoge doseringen gebruikt worden en er in de meeste gevallen geen medische begeleiding beschikbaar is. Omdat de kennis over de effecten van AAS op lichaamssamenstelling en gezondheid beperkt en controversieel is, hebben wij een aantal studies opgezet om deze effecten nader te bestuderen. Het belangrijkste doel van de studies die in dit proefschrift beschreven zijn, was om te onderzoeken welke effecten AAS op lichaamssamenstelling en het cardiovasculaire systeem van ervaren, goed getrainde krachtsporters uitoefenen. Tevens wilden wij nagaan of de effecten afhankelijk waren van de toegediende dosering van de AAS en/of de duur van het gebruik van dergelijke middelen. Hiertoe hebben wij de volgende onderzoeksvragen geformuleerd:

- Welke effecten heeft toediening van AAS op lichaamssamenstelling en anthropometrie van ervaren krachtsporters?

- Welke effecten oefenen AAS uit op het cardiovasculaire systeem, met speciale aandacht voor de hartgrootte en -functie als ook voor serumwaarden van lipiden en lipoproteinen

- Bestaat er een relatie tussen de (neven-)effecten en de toegediende dosering van AAS?

- Bestaat er een relatie tussen de waargenomen (neven-)effecten en de duur van AAS-toediening?

In Hoofdstuk 2 geven we een overzicht van de actuele kennis over de gewenste en ongewenste effecten van AAS toediening bij sporters. Dit hoofdstuk vormt de basis voor alle experimentele studies in de volgende hoofdstukken.

In Hoofdstuk 3 beschrijven we een studie, waarin we de korte en lange termijn effecten van krachttraining met en zonder AAS toediening op de totale en regionale lichaamssamenstelling hebben onderzocht. In een 
niet-geblindeerde studieopzet konden we waarnemen dat het gebruik van AAS tijdens een regulier krachttrainingprogramma een toename van het lichaamsgewicht $(+4.4 \mathrm{~kg})$ en vetvrije massa $(+4.5 \mathrm{~kg})$ tot gevolg had en tevens tot een toename van diverse omvangmaten leidde. Het vetpercentage, dat via huidplooimetingen bepaald werd, nam gering af, maar de vetmassa toonde geen enkele verandering tijdens AAS gebruik. Zes weken na het stoppen van AAS toediening waren alle veranderingen grotendeels behouden gebleven. Het gebruik van AAS gedurende 8 weken en 12-16 weken gaf identieke resultaten bij bepaling van de lichaamssamenstelling. Dual Energy X-ray Absorptiometry (DEXA) metingen toonden dat de vetvrije massa van drie lichaamsregio's (armen, benen en romp) door AAS gebruik toenam, terwijl geen veranderingen van de vetmassa in deze lichaamsregio's geconstateerd werd.

In een gerandomiseerde, dubbelblinde, placebogecontroleerde studie hebben we de effecten van nandrolon decanoaat (Deca-Durabolin ${ }^{\circledR}$, Organon, Oss, Nederland), een anabole steroid dat erg populair is bij krachtsporters, op lichaamssamenstelling (totaal en regionaal) en anthropometrische parameters onderzocht (Hoofdstuk 4). Na randomisatie kregen de deelnemende krachtsporters wekelijks een intramusculaire injectie met nandrolon decanoaat ( $200 \mathrm{mg}$ per week) of placebo toegediend gedurende een periode van 8 weken. Metingen van de lichaamssamenstelling met behulp van DEXA toonde dat door toediening van nandrolon decanoaat de totale lichaamsmassa van de krachtsporters met $2.6 \mathrm{~kg}$ toenam, terwijl de vetvrije massa $3.5 \mathrm{~kg}$ steeg. Zes weken nadat de toediening van nandrolon decanoaat was gestopt, bleek de vetvrije massa nog steeds verhoogd in vergelijking met de uitgangswaarde. Het grootste veranderingen van de vetvrije massa werden aan de romp $(+2.09 \mathrm{~kg})$ en benen $(+1.08 \mathrm{~kg})$ waargenomen. Het vetpercentage van de benen nam af $(-1.9 \%)$ tijdens nandrolon decanoaat toediening en dit bleef gehandhaafd tot zes weken na stoppen. Via de DEXA metingen kon geen enkele veranderingen van de parameters van de armen waargenomen worden. Ook de huidplooimetingen lieten geen veranderingen tijdens de gehele studieperiode zien. De nekomvang nam tijdens de nandrolon decanoaat toediening significant toe $(+0.9 \mathrm{~cm})$, terwijl de overige 10 omvangmaten geen significante veranderingen vertoonden. Veranderingen van de vetmassa van lichaamsdelen konden niet met huidplooimetingen worden gedetecteerd. Daarentegen bleek uit de DEXA metingen dat het vetpercentage van de benen afnam, terwijl de totale vetmassa en het lichaamsvetpercentage geen veranderingen ondergingen tijdens de 8 weken nandrolon decanoaat toediening. Deze resultaten geven een indicatie dat veranderingen in samenstelling van bepaalde lichaamsregio's ten gevolge van de toediening van nandrolon decanoaat beter met behulp van DEXA gedetecteerd kunnen worden in vergelijking met meting van omvangmaten en huidplooien. 
Hoofdstuk 5 beschrijft twee studies waarin de effecten van krachttraining met AAS op spierkenmerken onderzocht werden. Hierbij ging speciale aandacht uit naar een vergelijking van toediening van een enkel anabole steroïd (nandrolon decanoaat) met het gebruik van meerdere middelen gelijktijdig in hoge doseringen. In studie 1 werd hetzelfde onderzoeksdesign en protocol als in hoofdstuk 4 gehanteerd. In een gerandomiseerde, dubbelblind, placebogecontroleerd onderzoeksdesign kregen de krachtsporters wekelijks een intramusculaire injectie met nandrolon decanoaat ( $200 \mathrm{mg}$ per week) of placebo toegediend. In studie 2 werd een niet geblindeerd, maar wel gecontroleerd design gehanteerd. De krachtsporters dienden zichzelf meerdere AAS gelijktijdig in supratherapeutische doseringen toe. In beide studies werd bij de proefpersonen voor aanvang van de studie en na 8 weken studieperiode een percutaan spierbiopt uit het posterieure deel van de musculus deltoideus verkregen. De spierbiopten werden gepre-incubeerd bij $\mathrm{PH}=4.4$, gekleurd met adenosine trifosfaat en morfometrisch geanalyseerd. Van elk spierbiopt werden minimaal 150 spiervezels beoordeeld op spiervezeldistributie en de grootte van de vezels. Hieruit werd de gemiddelde spiervezelgrootte als ook de grootte van de type I en type 11 spiervezels bepaald. Na 8 weken toediening van nandrolon decanoaat ( $200 \mathrm{mg}$ per week, intramusculair) konden geen veranderingen zien in de spierparameters waargenomen worden. Daarentegen is gebleken dat het gelijktijdig gebruik van meerdere AAS in hoge doseringen een duidelijke toename van de spierparameters oplevert. De gemiddelde spiervezelgrootte $(+12.6 \%)$, de grootte van type I $(+10.8 \%)$ en type II ( $+14.6 \%)$ waren significant toegenomen na 8 weken AAS gebruik. De spiervezeldistributie bleek niet onderhevig aan veranderingen, onafhankelijk van de toegediende AAS. Uit deze studie kan men concluderen dat bij ervaren krachtsporters het gebruik van meerdere AAS gelijktijdig in supratherapeutische doseringen leidt tot een toename van de grootte van de spiervezels van de musculus deltoideus, met name van de type II vezels. Toediening van nandrolon decanoaat (200 mg per week, i.m.) gedurende 8 weken heeft geen effect op de spiervezelgrootte en -distributie van de musculus deltoideus.

De effecten van AAS op het hart worden in hoofdstuk 6 beschreven. Hierbij werd dezelfde studieopzet als in hoofdstuk 5 gehanteerd. De hartdimensies en hartfunctie werden middels echocardiografie onderzocht. Uit deze studie is gebleken dat 8 weken AAS toediening niet tot waarneembare veranderingen van de hartdimensies en de hartfunctie leidden, noch effect hadden op de systolische en diastolische bloeddruk. Dit gold zowel voor toediening van nandrolon decanoaat als ook voor het gelijktijdig gebruik van meerdere middelen in supratherapeutische doseringen gedurende 8 of 12-16 weken. Toch dienen deze bevindingen met enige terughoudendheid geïnterpreteerd te worden, aangezien in dierexperimenteel onderzoek duidelijk is aangetoond dat AAS ultrastructurele veranderingen van de hartspiercel kunnen induceren. Aan de hand van de resultaten uit onze 
studie kan derhalve niet uitgesloten worden dat AAS ook bij de mens tot ultrastructurele veranderingen van de hartspiercellen kan leiden die bij echocardiografisch onderzoek niet waargenomen kunnen worden.

Tot slot beschrijven we in hoofdstuk 7 de invloed van AAS op cardiovasculaire risicofactoren, in het bijzonder de serumconcentraties van lipiden en lipoproteinen alsmede het herstel hiervan na stoppen van AAS toediening. Hiertoe werden de serumwaarden van Apo-A1, Apo-B, totaal cholesterol triglyceriden, HDL2-cholesterol, HDL3-cholesterol en lipoproteine(a) bepaald. De studie toonde dat toediening van meerdere AAS in hoge doseringen gepaard gaat met een verhoogd atherogene vetstatus, hoewel de serumwaarden van het lipoproteine(a) juist gunstig beïnvloed werden. De tijdsperiode die AAS gebruikt werden had geen effect op de veranderingen van de serumwaarden. De veranderingen bleken 6 weken na stoppen van de AAS nog ten dele aanwezig. Het herstel van de serumwaarden bij sporters die 12-16 weken AAS genomen hadden, was duidelijk langzamer dan bij de sporters die gedurende 8 weken AAS genomen hadden. Daarentegen bleek de toediening van nandrolon decanoaat (200 mg per week, intramusculair, gedurende 8 weken), behoudens een selectieve reductie van lipoproteine(a) serumwaarde, geen effect op de serumwaarden van lipiden en lipoproteinen uit te oefenen. De impact van deze observaties op de prognose voor het krijgen van cardiovasculaire aandoeningen dient nog nader onderzocht te worden. 


\section{Nawoord}

Ik heb ze proberen te tellen, maar heb het moeten opgeven. Ze zijn niet te tellen, het zijn er honderden geweest. lk heb het over alle personen die op welke manier dan ook bijgedragen hebben aan de tot stand koming van dit proefschrift. Vanaf het begin in 1994 tot het eindproduct dat nu (anno 2001) voor u ligt. Er waren vele knappe koppen, heel deskundig allemaal: meedenkend, mee-ontwikkelend, meelezend, corrigerend, aanvullend, moeilijke vragen stellend. Er waren de studenten, nog niet zo deskundig, maar wel vol enthousiasme en bij weer en ontij meewerkend, ook nogal eens ingeschakeld bij het o zo belangrijke "domme" werk. Er waren de vele collega's (in Maastricht en Rotterdam, later in Capelle aan den IJssel) die op allerlei manieren meegeholpen hebben: in het lab, achter de PC, op het internet, via de e-mail, per telefoon, bij het kopieerapparaat; ook niet geheel onbelangrijk de discussies en adviezen in de koffiekamer en op de gang. Er waren de mensen van diverse "andere" capgroepen aan de Universiteit Maastricht en in het Academisch Ziekenhuis Maastricht die enthousiast het onderzoek ondersteunden en wegen baanden. Wie ik ook zeker niet mag vergeten zijn alle techneuten: computers, chemicaliën, bloedverwerking, bloedanalyses, plasjescontrole, dat had ik alleen nooit gered. Er waren de vele proefpersonen: wat hebben we van jullie gevraagd en ja hoor, ze draafden telkens op als we weer wat moois bedacht hadden. Er was het thuisfront: tja, wat moet ik daar tegen zeggen. Daarom voor iedereen vijf woorden die wel nog te tellen zijn:

Mensen, allemaal heel hartelijk bedankt! 


\section{Curriculum vitae}

Fred Hartgens was born on 22 October 1959 in Roermond. He completed secondary school (Gymnasium-B) at the Bischoppelijk College in Roermond in June 1978. He started the training for physiotherapist in Heerlen. After receiving his degree in 1983 he worked part-time in a center for physiotherapy in Maasbracht and Wessem until 1991, and followed from 1984 to 1988 the specialization training to orthopedic manual therapist. In 1983 he started also the medical training at Maastricht University. His interest in scientific research was turned to practice when Professor Harm Kuipers at Maastricht University offered him the opportunity to start an investigation upon the effects of androgenic-anabolic steroids in athletes. He decided to get this chance and worked on that project from 1987 to 1989. During that period a busy time was present because he had to combine the training for orthopedic manual therapist and the regular medicine training, together with his research job and his work as physiotherapist.

After receiving his MD degree in 1991 he was selected for the full time specialization training to sports physician that he completed in 1995. In 1993 he was asked by the Netherlands' Center for Doping Affairs (NeCeDo) to develop a scientific department. He accepted this opportunity and from January 1994 he worked (and still works) part-time as a research and science coordinator of NeCeDo. Because of the excellent relationship with the Department of Movement Sciences at Maastricht University its Head (Professor Harm Kuipers) was willing to host the scientific department of the NeCeDo. Most research work of NeCeDo is, therefore, performed at Maastricht University.

In 1996 Fred had the opportunity to start an outpatient clinic in sportsmedicine at the Department of Surgery (Traumatology division) at the University Hospital Maastricht. Since 2000 he works also in the Sport Medical Center Maastricht. For more than 8 years he is medical staff member of the professional soccer team Roda JC in Kerkrade. Since 1997 he is head of the medical department of the Dutch Triathlon Federation and Fred was a member of the medical staff of the Dutch Olympic team at the Olympic Games of Sydney in 2000. 


\section{List of publications}

\section{FULL PAPERS (IN ENGLISH)}

1. Hartgens F., E.C. Cheriex, H. Kuipers. Prospective echocardiographic assesment of androgenic-anabolic steroids administration on cardiac structure and function in strength athletes. Submitted.

2. Rietjens G.J.W.M., F. Hartgens, H. Kuipers, H.A. Keizer. Red blood cell profile of elite Olympic distance triathletes; a three year follow-up. Submitted.

3. Van Marken Lichtenbelt W.D., F. Hartgens, S. Ebbing, N. Vollaard, H. Kuipers. Bodybuilders' body composition: effect of nandrolone decanoate. Submitted.

4. Van Marken Lichtenbelt W.D., F. Hartgens, S. Ebbing, N. Vollaard, H. Kuipers. Validity of body composition methods in bodybuilders. Submitted.

5. Hartgens F., G. Rietjens, H.A. Keizer, H. Kuipers, Wolffenbuttel B.H.R. Effects of androgenic-anabolic steroids (AAS) on apolipoproteins and lipoprotein(a). Submitted.

6. Hartgens F., H. van Straaten, S. Fideldij, G. Rietjens, H.A. Keizer, H. Kuipers. Androgenic-anabolic steroids and human deltoid muscle fibres: difference between polydrug regimens and single drug administration. Submitted.

7. Hartgens F., H. Kuipers. Effects of androgenic-anabolic steroids in athletes; a review. Submitted.

8. Hartgens F., W.D. Van Marken Lichtenbelt, N. Vollaard, S. Ebbing, H. Kuipers. Body composition and anthropometry in bodybuilders: regional changes due to nandrolone decanoate use. Int J Sports Med 22(3): 235-241, 2001.

9. Hartgens F., W.D. van Marken Lichtenbelt, S. Ebbing, N. Vollaard, H. Kuipers. Androgenic-anabolic steroids induced alterations of bodycomposition in strength athletes. The Physician and Sportsmedicine 29(1): 49-66, 2001. 
10. Van Baak M.A., L.H.J. Mayer, R.E.S. Kempinski, F. Hartgens. Effect of salbutamol on muscle strength and endurance performance in non-asthmatic men. Med Sci Sports Exerc 32(7): 1300-1306, 2000.

11. Kortekaas E., F. Hartgens. Can precooling improve endurance performance in warm environments? Geneeskunde en Sport 32(3): 22-26, 1999.

12. Verstappen F.T.J., M. Twellaar, F. Hartgens, W. van Mechelen. Physical fitness and sports skills in relation to sports injuries. A four-year prospective investigation of sports injuries among physical education students. Int. J. Sports Med 19: 586-591, 1998.

13. Pernot C., F. Hartgens, H.A. Keizer, H. Kuipers, K. Hamulyak. Effects of self-administration of high doses androgenic-anabolic steroids on fibrinolytic activity in non elite bodybuilders. Fibrinolysis 10 (suppl 2): 53-54, 1996.

14. Hartgens F., H. Kuipers, J.A.G. Wijnen, H.A. Keizer. Body composition, cardiovascular risk factors and liver function in long term androgenic-anabolic steroids using bodybuilders three months after drug withdrawal. Int. J. Sports Med. 17(6): 429-433, 1996.

15. Kuipers H., F.M. Peeze Binkhorst, F. Hartgens, J.A.G. Wijnen, H.A. Keizer. Muscle ultrastructure after strength training with placebo or anabolic steroid. Can. J. Appl. Physiol. 18(2): 189-196, 1993.

16. Kuipers H., J.A.G. Wijnen, F. Hartgens, S.M.M. Willems. Influence of anabolic steroids on body composition, blood pressure, lipid profile, and liver functions in body-builders. Int. J. Sports Med. 12(4): 413-418, 1991.

\section{FULL PAPERS (IN DUTCH)}

1. Hartgens F.,W. Wijnen, R. Slegers, G.-J. Eggink, J. Verbruggen, J. Stapert De behandeling van fasciitis plantaris. In dit Verband $10(3)$ : 11-13, 2000.

2. Hartgens F., J. Verstuyft. Doping. Bijblijven 15(10): 17-26, 1999.

3. De Hon O., F. Hartgens, M.A. Van Baak, L.J.R.M. Buisman, G. Rietjens. De invloed van een eenmalige toediening van een supratherapeutische dosis salbutamol op de longfunctie en duurprestatie van niet-astmatische sporters. Geneeskunde en Sport 32(5): 9-15, 1999.

4. Hartgens F., G.-J. Eggink, W. Wijnen, J. Verbruggen, J. Stapert. De nachtspalk bij chronische fasciitis plantaris: een nieuwe therapie ook bij sporters? Geneeskunde en Sport 32(4): 5-9, 1999. 
5. Kuipers H., F. Hartgens. Gebruik van geneesmiddelen voor het verbeteren van sportprestaties. Nederlands Tijdschrift voor Geneeskunde 141:1965-1968, 1997.

6. Hartgens F. Misbruik van androgene-anabole steroiden in de sport. Patient Care 24(2): 14-24, 1997.

7. Hartgens F. Hoe lang duurt het voor verschijnselen van anabolengebruik bij een vrouw zijn verdwenen? Vademecum 15(4): 21 januari, 1997.

8. Hartgens F. Doping anno 1996. Geneesmiddelenbulletin 30(11): 125-132, 1996.

9. Hartgens F., H. Kuipers, J.A.G. Wijnen, H.A. Keizer. De effekten van intermitterend gebruik van androgene-anabole steroiden bij bodybuilders. Geneeskunde en Sport 28(2): 38-42, 1995.

10. Hartgens F., J.A.G. Wijnen, S.M.M. Willems, H. Kuipers. De effekten van androgene-anabole steroiden tijdens gebruik en na stoppen bij ervaren bodybuilders. Geneeskunde en Sport 25(2): 64-71, 1992.

11. Hartgens F., H. Kuipers, J.A.G. Wijnen, S.M.M. Willems. Androgene-anabole steroiden in de sport; een literatuuroverzicht. Geneeskunde en Sport 25(1): 8-20, 1992.

12. Willems S.M.M., H. Kuipers, J.A.G. Wijnen, F. Hartgens. Bodybuilding: een inventariserende studie naar training, voeding en spierversterkende middelen. Geneeskunde en Sport 24(2): 51-55, 1991.

13. Kuipers H., J.A.G. Wijnen, F. Hartgens, S.M.M. Willems. Welke informatie geeft aminozuurbepaling in het plasma bij gezonde sporters? Sportgericht 11: 113-116, 1989.

\section{ABSTRACTS}

1. De Hon O.M., F. Hartgens, M.A. van Baak, L.J.R.M. Buisman, G. Rietjens. Acute inhalation of salbutamol increases endurance performance in well-trained non-asthmatic athletes. Med Sci Sports Exerc 31(5): S402, 1999.

2. Hartgens, F. Doping. In: Van der Poel B.N.M. en R.F.A. Weber. Ontwikkelingen in de geneeskunde 1998 (congresboek), pp 6-9. Rotterdam, 1998.

3. Van Baak M.A., L.H.J. Mayer, R.E.S. Kempinski, F. Hartgens. Effect of salbutamol on muscle strength and endurance performance in non-asthmatic men. Med Sci Sports Exerc 30(5): S323, 1998. 
4. Rietjens G.J., F. Hartgens, V. Visser, M.A. van Baak, H. Kuipers. The effect of salbutamol on lung function and exercise performance in endurance athletes. Med Sci Sports Exerc 30(5): S323, 1998.

5. Hartgens F., G. Rietjens, E. Cheriex, K. Hamulyak, B. Wolffenbuttel, H.A. Keizer, H. Kuipers. Effects of an anabolic steroid on cardiovascular risk factors and the left ventricle in bodybuilders. Med Sci Sports Exerc 29(5): S292, 1997.

6. Stubenitsky K., W.D. van Marken Lichtenbelt, F. Hartgens. The four component model for estimating body composition in bodybuilders. Med Sci Sports Exerc 29(5): S215, 1997.

7. Van Marken Lichtenbelt W.D., K. Stubenitsky, F. Hartgens. Effect of androgenic-anabolic steroids on weight, body fat, and hydration of the fat free mass. Med Sci Sports Exerc 29(5): S294, 1997.

8. Wolffenbuttel B.H.R., F. Hartgens, G. Rietjens, H.A. Keizer, H. Kuipers. Effects of androgenic-anabolic steroids (AAS) on apolipoproteins and lipoprotein(a). Presented at the annual meeting of the International Atherosclerosis Society, Paris, 1997.

9. Wolffenbuttel B.H.R., F. Hartgens, G. Rietjens, H.A. Keizer, H. Kuipers. Nandrolone decanoate reduces lipoprotein(a) levels without effect on other lipid parameters. Presented at the annual meeting of the International Atherosclerosis Society, Paris, 1997.

10. Van Baak M.A., L. Mayer, R. Kempinski, F. Hartgens. The effect of salbutamol on muscle strength and endurance exercise performance in non-asthmatic men. Congress of the Dutch College of Clinical Pharmacology, Utrecht, The Netherlands, 1996.

11. Pernot C., F. Hartgens, H.A. Keizer, H. Kuipers, K. Hamulyak. Effects of self-administration of high doses androgenic-anabolic steroids on fibrinolytic activity in non elite bodybuilders. Fibrinolysis Congress, Leiden, The Netherlands, 1996.

12. Cheriex E., F. Hartgens, T. Gordijn, K. Depuydt, H.A. Keizer, H. Kuipers. Cardiac dimensions and function are not affected by eight weeks androgenic-anabolic steroid use. Med. Sci. Sports Exerc. 28(5, supplement): \$35, 1996.

13. Hartgens F., K. Depuydt, T. Gordijn, H.A. Keizer, H. Kuipers. Effect of eight weeks androgenic-anabolic steroids use on circumferences in non elite bodybuilders. Med. Sci. Sports Exerc. 28(5, supplement): \$36, 1996.

14. Hamulyak K., F. Hartgens, C. Pernot, H.A. Keizer, H. Kuipers. Eight weeks use of androgenic-anabolic steroids increases fibrinolytic activity in bodybuilders. Med. Sci. Sports Exerc. 28(5, supplement): S36, 1996. 
15. Bortel L.M. van, J.A. Wijnen, F. Hartgens, H. Kuipers, M.A. van Baak. Effect of carvedilol on endurance exercise performance. Eur. Heart J. 16(abstract supplement): 60, 1995.

16. Hartgens F., K. Hamulyak, C. Pernot, K. Depuydt, T. Gordijn, H.A. Keizer, $H$. Kuipers. The effects of high doses androgenic-anabolic steroids on haematologic parameters in bodybuilders. Abstract book FIMS-congress, page 80, october 1995, Granada, Spanje.

17. Bortel L. van, J. Wijnen, F. Hartgens, H. Struijker Boudier, M. van Baak. Do ß-blockers with vasodilating properties offer a better endurance exercise performance than classical B-blockers? Joint Meeting of the German and Dutch Pharmacological Societies, 4-7 october 1995, Maastricht, The Netherlands.

18. Bortel L.M. van, J.A. Wijnen, F. Hartgens, H. Kuipers, M. van Baak. Do $B$-blockers with vasodilating properties offer a better endurance exercise performance? Pharmacy World and Science 17(6, supplement): M7, 1995.

19. Hartgens F., H. Kuipers, J.A.G. Wijnen, S.M.M. Willems. Body composition of bodybuilders with and without previous use of anabolic steroids. Med. Sci. Sports Exerc. 23(4) suppl.: S58, 1991.

20. Wijnen J.A.G., F. Hartgens, H. Kuipers, S.M.M. Willems. Changes in body composition during anabolic steroid use and after abstination in experienced bodybuilders. Med. Sci. Sports Exerc. 23(4) suppl.: S58, 1991.

21. Hartgens F., H. Kuipers, J.A.G. Wijnen, S.M.M. Willems. Influence of nandrolone decanoate on body composition in experienced bodybuilders. Pflügers Archiv 414(4): S197, 1989.

22. Hartgens F., H. Kuipers, J.A.G. Wijnen, S.M.M. Willems. Influence of anabolic steroids on body composition in experienced bodybuilders. Med. Sci. Sports Exerc. 21(2) suppl.: S26, 1989.

\section{REPORTS}

1. De Hon, O.N., F. Hartgens. Denksport en doping. Rotterdam, Nederlands Centrum voor Dopingvraagstukken, 2000.

2. De Hon, O.N., F. Hartgens. Mind sports and doping. Rotterdam, Nederlands Centrum voor Dopingvraagstukken, 2000.

3. De Groot S., F. Hartgens, M.F. Zweers. Enquete onder topsporters over doping, dopingcontroles en medicijn-gebruik in de sport. Rotterdam/Arnhem, Nederlands Centrum voor Dopingvraagstukken I NOC*NSF, 1999. 
4. Hartgens F., G. Rietjens, S.F. van Haren, T. Vogels, E.N. Vrijman. Huisarts en doping. Rotterdam, Nederlands Centrum voor Dopingvraagstukken/ TNO-PG, 1998.

5. De Boer A., S.F. van Haren, F. Hartgens, D. de Boer, A.J. Porsius. Onderzoek naar het gebruik van prestatieverhogende middelen bij bodybuilders in Nederland. Rotterdam, Nederlands Centrum voor Dopingvraagstukken/ Universiteit van Utrecht, 1996.

\section{BOOKS}

1. Hartgens F., H. Kuipers (eds.). Verboden middelen in de sport. Houten, Bohn Stafleu Van Loghum, 2000.

\section{BOOK SECTIONS}

1. Van Wimersma Greidanus T.B., F. Stoele, F. Hartgens. Overzicht. In: Hartgens F., H. Kuipers (eds.). Verboden middelen in de sport. Houten, Bohn Stafleu Van Loghum, 2000, pp 3-11.

2. Hartgens F. Gedragsregels en richtlijnen voor artsen omtrent doping. In: Hartgens F., H. Kuipers (eds.). Verboden middelen in de sport. Houten, Bohn Stafleu Van Loghum, 2000, pp. 32-36.

3. Koornneef M., H. Kuipers, F. Hartgens. Beheersing van de dopingproblematiek. In: Hartgens F., H. Kuipers (eds.). Verboden middelen in de sport. Houten, Bohn Stafleu Van Loghum, 2000, pp. 86-92.

4. Hartgens F. Androgene-anabole steroiden. In: Hartgens F., H. Kuipers (eds.). Verboden middelen in de sport. Houten, Bohn Stafleu Van Loghum, 2000, pp. 143-174.

5. Benders J.A.I., A.A. ten Berge, M.B. van Doorn et al. De praktijk van de arts. In: Hartgens F., H. Kuipers (eds.). Verboden middelen in de sport. Houten, Bohn Stafleu Van Loghum, 2000, pp. 207-246.

6. Sitsen A., F. Hartgens. Geneesmiddelen en doping. In: Mosterd W.L. et al (red.). Het Sport-Medisch Formularium. Houten, Bohn Stafleu Van Loghum, 2000.

7. Hartgens F. Dopinggebruik en sport. In: Adriaansen A. et al (red.). Grote geneesmiddelen encyclopedie ( 5 e editie). Houten, Health Base, 1999. pp 32-34. 